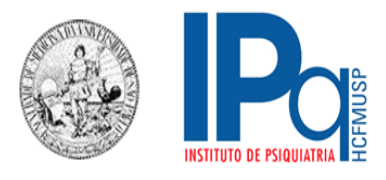

FACULDADE DE MEDICINA DA UNIVERSIDADE DE SÃO PAULO

\author{
MARIA CECILIA MENEGATTI CHEQUINI
}

\title{
A religiosidade e a espiritualidade na prática psiquiátrica
}

\author{
Tese apresentada à Faculdade de Medicina da \\ Universidade de São Paulo para a obtenção do \\ título de Doutor em Ciências \\ Programa de Psiquiatria \\ Orientador: Prof. Dr. Homero Pinto Vallada Filho
}

(Versão corrigida. Resolução CoPGr 6018/11, de 1 de novembro de 2011. A versão original está disponível na Biblioteca da FMUSP)

\section{São Paulo}




\title{
Maria Cecilia Menegatti Chequini
}

\section{A religiosidade e a espiritualidade na prática psiquiátrica}

\author{
Tese apresentada à Faculdade de Medicina da \\ Universidade de São Paulo para a obtenção do \\ título de Doutor em Ciências \\ Programa de Psiquiatria \\ Orientador: Prof. Dr. Homero Pinto Vallada Filho
}

(Versão corrigida. Resolução CoPGr 6018/11, de 1 de novembro de 2011. A versão original está disponível na Biblioteca da FMUSP)

\section{São Paulo}


Dados Internacionais de Catalogação na Publicação (CIP)

Preparada pela Biblioteca da

Faculdade de Medicina da Universidade de São Paulo

C)reprodução autorizada pelo autor

Menegatti-Chequini, Maria Cecilia

A religiosidade e a espiritualidade na prática

psiquiátrica / Maria Cecilia Menegatti-Chequini. --

São Paulo, 2020 .

Tese(doutorado)--Faculdade de Medicina da

Universidade de São Paulo.

Programa de Psiquiatria.

Orientador: Homero Pinto Vallada Filho.

Descritores: 1.Religião 2.Espiritualidade

3.Psiquiatria 4.Cuidados médicos 5.Saúde mental

6. Ética

$\mathrm{USP} / \mathrm{FM} / \mathrm{DBD}-159 / 20$

Responsável: Erinalva da Conceição Batista, CRB-8 6755 
A meus pais, Mario e Darcília, pela formação.

A meu marido pela compreensão, suporte e apoio incondicionais. 


\section{AGRADECIMENTOS}

Agradecimento especial

Ao Prof. Dr. Homero Pinto Vallada Filho, pelo privilégio de tê-lo como orientador, pela confiança, por toda dedicação e investimento.

Pela sensibilidade com que me conduziu nas mais diversas e improváveis situações.

Ainda, se não por tudo isso, minha imensa gratidão pela parceria, pela amizade e pelos sábios conselhos que me fizeram ver além. 
Ao Absoluto, Incognoscível, Extraordinário... que nos enche de espanto, paralisa, seduz, arrebata e inebria. A esse Poder inefável, que é fonte de vida, de sentido e de beleza, minha eterna gratidão e completa reverência.

Ao Prof. Dr. Mário Fernandes Pietro Peres, pela amizade, ajuda, incentivo e, sobretudo, pela generosidade de ter confiado a mim o projeto desta tese, por ele idealizado. Serei sempre grata.

À equipe do Programa de Saúde, Espiritualidade e Religiosidade (ProSER), do Instituto de Psiquiatria da Faculdade de Medicina da Universidade de São Paulo (IPqHC-FMUSP), em particular, ao Prof. Dr. Frederico Camelo Leão, pela recepção e ajuda dispensadas e a todos aqueles com quem convivi e tantas trocas realizamos, especialmente, Katya Stübing, Camila C. Braghetta e Marcus Zulian Teixeira.

Aos membros da banca de qualificação, composta pelos Professores Doutores Francisco Lotufo Neto, Marcelo Saad e Mario Rodrigues Louzã. Agradeço por todas as sugestões e orientações que tanto contribuíram para o aprimoramento desta tese. Uma especial menção ao Prof. Lotufo, por ter incentivado a execução do projeto e contribuído em sua construção.

Ao Prof. Dr. Alexander Moreira-Almeida, pelo interesse e encorajamento.

Ao Dr. Edison Shiguemi Hirata, que gentilmente nos forneceu a listagem dos funcionários do IPq-HC-FMUSP.

A todas as secretárias das unidades de atendimento do IPq-HC-FMUSP, notadamente, a Norma Aparecida da Silva, pelo auxílio na coleta de dados.

A todos os funcionários da secretaria do Programa de Pós-Graduação, especialmente, Eliza Fukushima e Isabel Ataide, pela atenção e orientações referentes às normas administrativas do programa.

A Katia Ichi, pela colaboração na coleta dos dados, generosidade e eficiência que sempre demonstrou diante de minhas necessidades. 
À Professora Cleusa Ferri e aos Professores Everton Maraldi e Alexandre Andrade Loch, pela prontidão e eficiência com que me ajudaram nas análises estatísticas. Ao Professor Felipe Corchs, pelas ideias e discussões na área de "machine learning".

Ao Prof. Dr. Wang Yuan Pang, pelas orientações e sugestões na metodologia e nas análises dos dados.

À querida Juliane P. de Bernardin Gonçalves, grande parceira, com quem dividi todas as alegrias e percalços desta trajetória.

A toda minha família, meus pais sempre presentes, meu marido, minhas irmãs, irmão e sobrinhos amados, pelo interesse e incentivo. Sempre ao Ettore, fonte inesgotável de inspiração.

À Associação Mantenedora João Evangelista de São Paulo; ao LIM-23 (HCFMUSP) e à CAPES, por meio do Programa de Pós-Gradução em Psiquiatria da FMUSP, pelo suporte financeiro fornecido.

Por fim, a todos os psiquiatras que gentilmente disponibilizaram seu tempo para responder ao questionário, permitindo que esta pesquisa se concretizasse. 
Vocatus atque non vocatus, Deus aderit *

\footnotetext{
* Inscrição latina, que significa: Invocado ou não, Deus está presente. Está gravada em pedra, acima da porta de entrada da casa de Carl Gustav Jung (hoje um museu), localizada em Küsnacht, perto de Zurique. Além disso, encontra-se na coletânea dos 'Adagia', de Erasmo (séc. XVI) [Collectanea Adagiorum]. Contudo, é um oráculo délfico (Jung CG. Cartas 1956-1961. 2003. Vol. III, p. 304).
} 
Esta tese está de acordo com as seguintes normas, em vigor no momento desta publicação:

Referências: adaptado de International Committee of Medical Journals Editors (Vancouver).

Universidade de São Paulo. Faculdade de Medicina. Divisão de Biblioteca e Documentação. Guia de apresentação de dissertações, teses e monografias. Elaborado por Anneliese Carneiro da Cunha, Maria Julia de A. L. Freddi, Maria F. Crestana, Marinalva de Souza Aragão, Suely Campos Cardoso, Valéria Vilhena. 3a ed. São Paulo: Divisão de Biblioteca e Documentação; 2011.

Abreviaturas dos títulos dos periódicos de acordo com List of Journals Indexed in Index Medicus. 


\section{SUMÁRIO}

\section{LISTA DE SIGLAS}

\section{LISTA DE TABELAS}

LISTA DE FIGURAS

\section{RESUMO}

\section{ABSTRACT}

\section{INTRODUÇÃO}

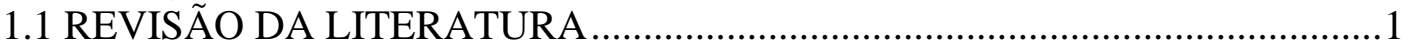

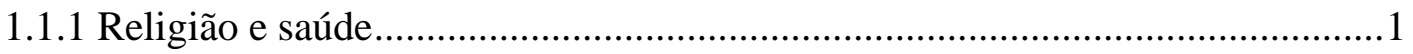

1.1.2 Abordagem empírica da religiosidade e da espiritualidade na saúde................3

1.1.2.1 Conceitos de religião, religiosidade e espiritualidade ...................................4

1.1.2.2 A religiosidade e a espiritualidade como fator de promoção à saúde .............6

1.1.2.3 A religiosidade e a espiritualidade como fator de risco à saúde.....................7

1.1.3 Associações de profissionais da saúde e a religiosidade/espiritualidade

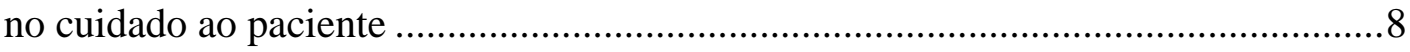

1.1.4 Evolução dos critérios diagnósticos em psiquiatria …...................................10

1.1.4.1 A psiquiatria centrada na pessoa .............................................................

1.1.5 A religiosidade e a espiritualidade na prática clínica ....................................14

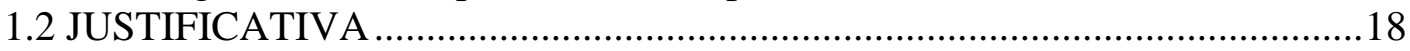

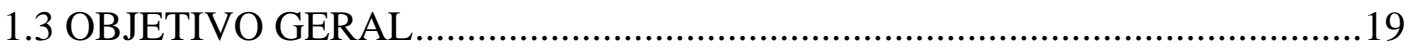

2 MÉTODOS COMUNS AOS TRÊS ESTUDOS....................................................20

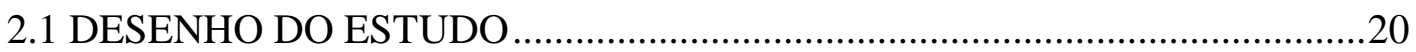

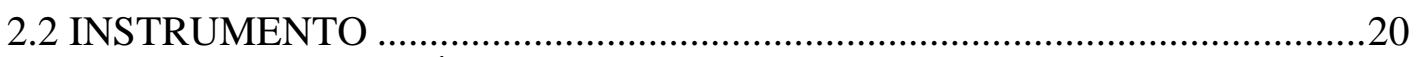

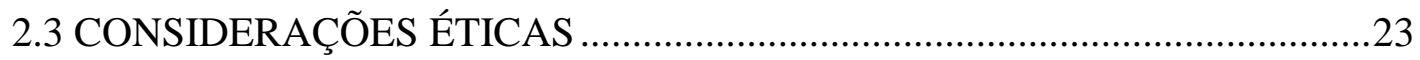

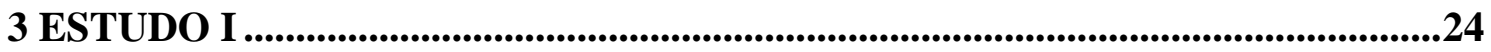

3.1 OBJETIVOS

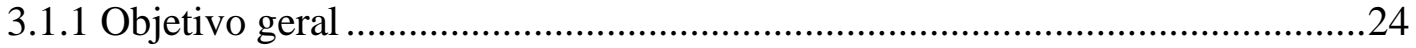

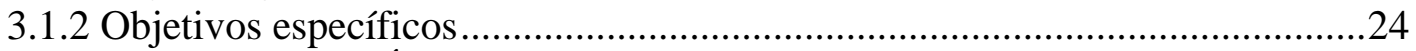

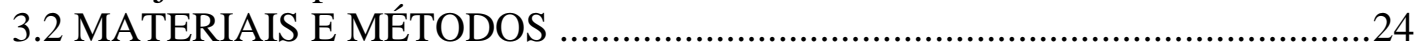

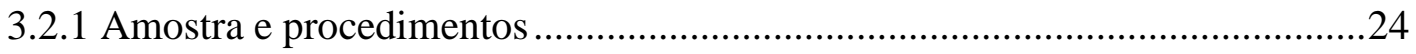

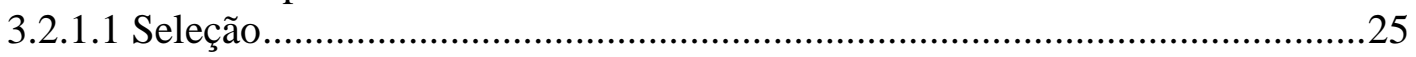

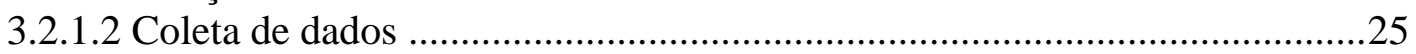

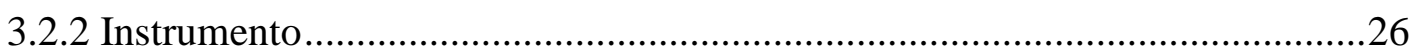

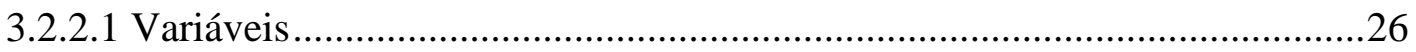

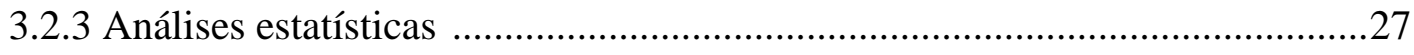

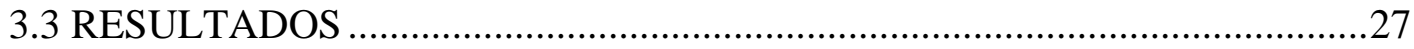

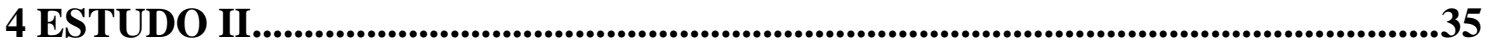

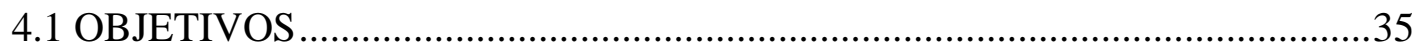




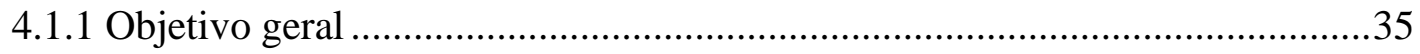

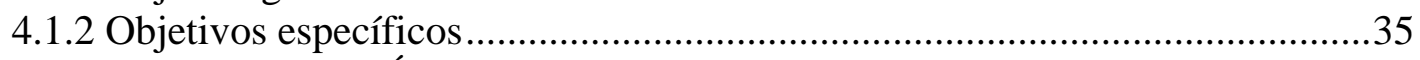

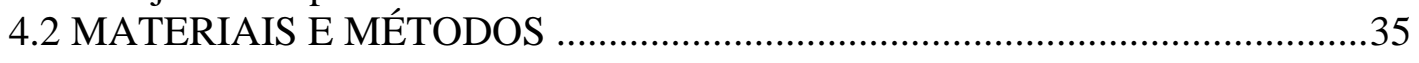

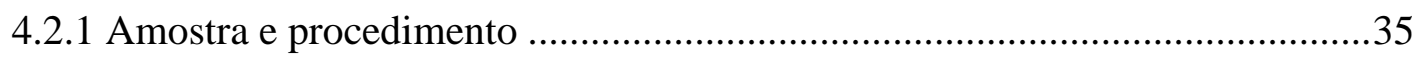

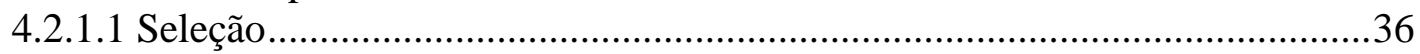

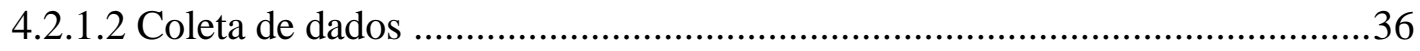

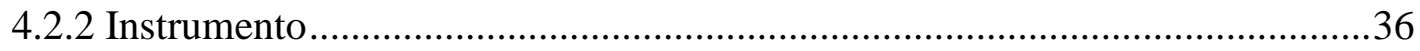

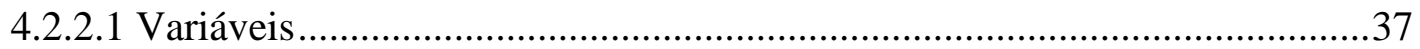

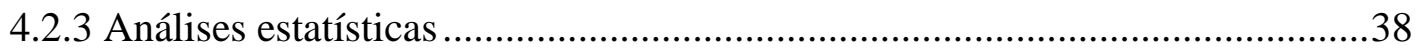

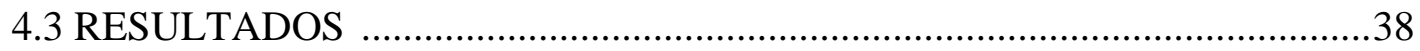

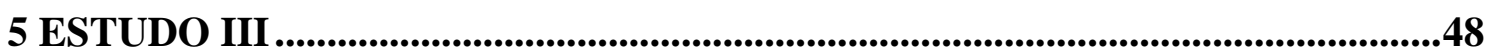

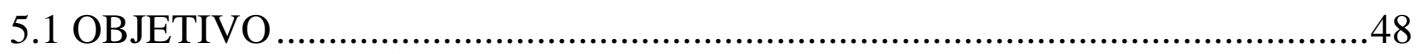

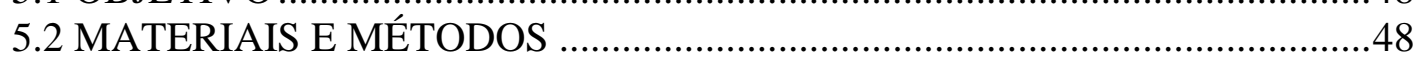

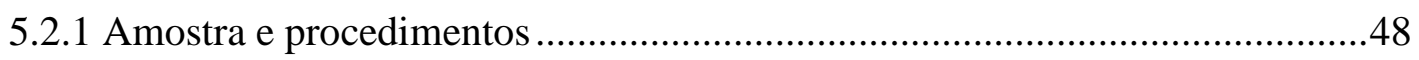

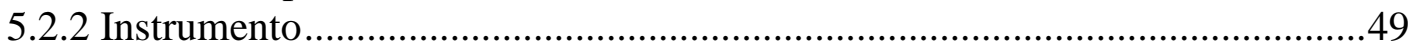

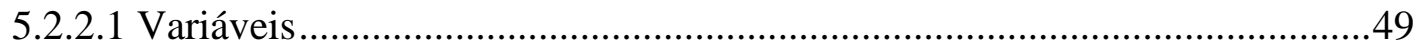

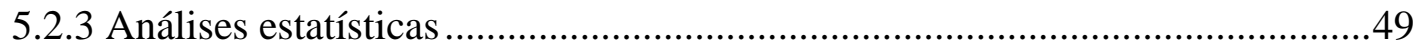

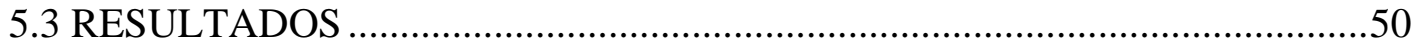

6 DISCUSSÃO GERAL DOS TRÊS ESTUDOS ...................................................56

6.1 COMPARAÇÃO DOS RESULTADOS: ESTUDOS 1 e 2 …..........................56

6.2 COMPARAÇÃO DOS RESULTADOS DOS ESTUDOS 1, 2 e 3 COM A

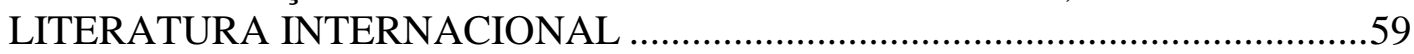

6.3 IMPLICAÇÕES E CONSIDERAÇÕES FUTURAS ....................................69

6.4 LIMITAÇÕ̃ES DOS ESTUDOS …........................................................... 71

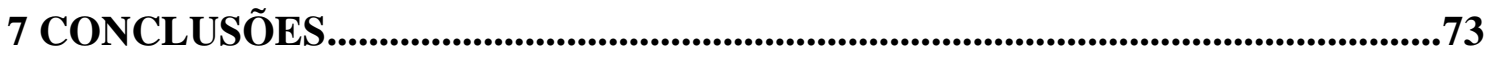

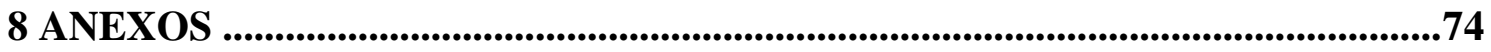

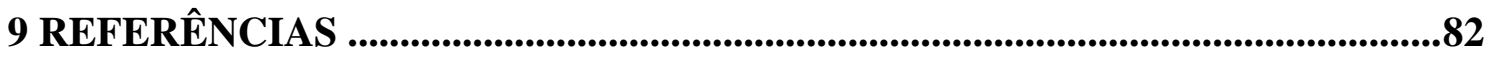

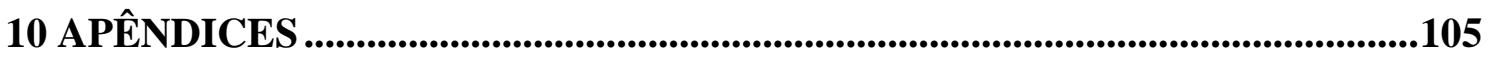


AA

$\mathrm{AACN}$

ABP

ACGME

ACP

ACPA

AIC

APA

ApA

APAF

APL

ARMH

ASIM

BIC

BPSS

CAAE

CAPPesq

CID-10

CNA

DSM

EPA

FMUSP

GAP
Alcoólicos Anônimos

American Association of Colleges of Nursing

Associação Brasileira de Psiquiatria

Accreditation Council for Graduate Medical Education

American College of Physicians

American Catholic Psychological Association

Akaike Information Criteria

American Psychiatric Association

American Psychological Association

American Psychiatric Association Foundation

Análise de Perfil Latente

Academy of Religion and Mental Health

American Society of Internal Medicine

Bayesian Information Criteria

Biopsychosocial-Spiritual Interview Method

Certificado de Apresentação de Aprovação Ética

Comissão de Ética para Análise de Projetos de Pesquisa

Classificação Internacional de Doenças

Canadian Nurses Association

Diagnostic and Statistical Manual of Mental Disorders

European Psychiatric Association

Faculdade de Medicina da Universidade de São Paulo

Group for the Advancement of Psychiatry 
IPq-HC-FMUSP Instituto de Psiquiatria do Hospital das Clínicas da Faculdade de Medicina da Universidade de São Paulo

JCAHO Joint Commission on Accreditation of Healthcare Organizations

LMR Lo-Mendell-Rubin

LRT Likelihood Ratio Test

LSD Least Significant Difference

OR Odds Ratio

ProSER Programa de Saúde, Espiritualidade e Religiosidade

$\mathbf{R} / \mathbf{E} \quad$ Religiosidade e Espiritualidade

RCBT Religiously integrated Cognitive-behavioral Therapy

RCP Royal College of Psychiatrists

RSIP Religious Spirituality Integrated Psychotherapy

SICPT Spirituality Integrated Cognitive Processing Therapy

SPSIG The Spirituality and Psychiatry Special Interest Group

SRPS Section on Religion, Spirituality and Psychiatry

TCC Terapia Cognitivo-comportamental

WPA World Psychiatric Association 
Pág.

Tabela 1. Características religiosas/espirituais dos psiquiatras da $\mathrm{ABP}$ e suas atitudes e comportamentos autorrelatados com relação à religiosidade e à espiritualidade na prática clínica $(n=484)$ 28

Tabela 2. Características sociodemográficas e profissionais dos psiquiatras da ABP distribuídas de acordo com ter ou não ter afiliação religiosa 29

Tabela 3. Atitudes dos psiquiatras da $\mathrm{ABP}$ relacionadas à religiosidade e à espiritualidade na prática clínica (análise estatística das respostas de um total de 484 participantes)

Tabela 4. Associações entre algumas características dos psiquiatras da ABP e a abordagem da religiosidade e da espiritualidade na prática clínica

Tabela 5. Características sociodemográficas e profissionais dos psiquiatras do IPq-HC-FMUSP relacionadas com a religiosidade e a espiritualidade......39

Tabela 6. Características religiosas e espirituais dos psiquiatras do IPq-HCFMUSP

Tabela 7. Atitudes dos psiquiatras do IPq-HC-FMUSP relacionadas à religiosidade e à espiritualidade na prática clínica

Tabela 8. Influência de crenças religiosas/espirituais e enfrentamento religioso/espiritual na prática clínica e no questionamento da fé por psiquiatras do IPq-HC-FMUSP (Correlações de Pearson) 
Tabela 9. Características sociodemográficas dos psiquiatras brasileiros $(\mathrm{n}=592) \ldots . .50$

Tabela 10. Análise de perfis latentes de respostas dos psiquiatras brasileiros ao questionário de religiosidade e espiritualidade na prática psiquiátrica ......51

Tabela 11. Análise de perfis latentes de respostas dos psiquiatras da ABP ao questionário de religiosidade e espiritualidade na prática psiquiátrica ......52

Tabela 12. Características, opiniões e comportamentos da amostra de acordo com os diferentes perfis religiosos/espirituais .55 
Pág.

Figura 1. Barreiras e dificuldades encontradas pelos psiquiatras da ABP na abordagem da religiosidade e da espiritualidade do paciente.

Figura 2. A Figura representa a frequência com que os psiquiatras da ABP perguntavam sobre a religiosidade e a espiritualidade na sua prática clínica, relacionada com o quanto eles se consideravam religiosos e espirituais

Figura 3. Barreiras / dificuldades dos psiquiatras do IPq-HC-FMUSP na abordagem da $\mathrm{R} / \mathrm{E}$ do paciente 46

Figura 4. Características religiosas e espirituais dos psiquiatras brasileiros de acordo com os diferentes perfis 53

Figura 5. Crenças religiosas/espirituais dos psiquiatras brasileiros de acordo com os diferentes perfis 


\section{RESUMO}

Menegatti-Chequini MC. A religiosidade e a espiritualidade na prática psiquiátrica [tese]. São Paulo: Faculdade de Medicina, Universidade de São Paulo; 2020.

Nas últimas décadas um corpo consistente de trabalhos vem apontando o envolvimento religioso/espiritual, geralmente, associado a indicadores positivos de saúde física e mental. No entanto, apenas recentemente os aspectos religiosos/espirituais vêm sendo considerados importantes na avaliação e no tratamento de pacientes. Além disso, alguns estudos têm relatado que as crenças religiosas/espirituais dos próprios médicos podem influenciar nas estratégias, decisões e no manejo clínico dos pacientes. Portanto, a presente tese buscou caracterizar o perfil religioso/espiritual de psiquiatras brasileiros e investigar sua influência nos cuidados de seus pacientes. Para tanto, foi realizada uma pesquisa do tipo observacional transversal, utilizando um questionário que avaliou as características da religiosidade/espiritualidade $(\mathrm{R} / \mathrm{E})$ do psiquiatra e sua prática clínica. Essa abordagem investigativa resultou em três estudos. O primeiro analisou 484 psiquiatras pertencentes à Associação Brasileira de Psiquiatria, que responderam à versão "on-line" do questionário. Destes, 71,4\% acreditavam em Deus, 67,4\% eram afiliados a uma instituição religiosa e, embora a maioria $(76,8 \%)$ considerasse importante a inclusão da $\mathrm{R} / \mathrm{E}$ na prática clínica, menos da metade $(45,5 \%)$ perguntava, frequentemente, sobre as crenças religiosas/espirituais de seus pacientes. Os psiquiatras que se declararam mais religiosos e/ou espirituais eram mais propensos a incluir a $\mathrm{R} / \mathrm{E}$ na assistência ao paciente. As dificuldades mais comuns relatadas na abordagem da R/E no contexto clínico foram: medo de extrapolar o papel de médico $(30,2 \%)$, falta de treino $(22,3 \%)$ e falta de tempo (16,3\%). O segundo estudo investigou 84 psiquiatras do Instituto de Psiquiatria do Hospital das Clínicas da Faculdade de Medicina da Universidade de São Paulo, um dos principais centros na formação de novos psiquiatras e de pesquisa em neurociências no Brasil. Os resultados foram semelhantes ao primeiro estudo, embora os percentuais tenham sido um pouco menores: 59,5\% declararam crença na existência de Deus e 57,7\% indicaram afiliação religiosa. Mais da metade $(64,2 \%)$ relatou que suas crenças religiosas influenciavam sua prática clínica e $50 \%$ discutiam frequentemente sobre a R/E com seus pacientes. As barreiras mais comuns na abordagem da R/E foram: falta de tempo $(27,4 \%)$, medo de exceder o papel do médico $(25 \%)$ e falta de treino $(19,1 \%)$. O terceiro estudo utilizou o método de análise de perfil latente na amostra envolvendo os psiquiatras participantes dos dois estudos anteriores $(n=592)$, com o objetivo de identificar subgrupos de perfis religiosos/espirituais entre os psiquiatras brasileiros. Os testes ANOVA e Qui-quadrado de Pearson foram empregados para identificar correlação entre opiniões e comportamentos na prática clínica. Foram identificados dois perfis ou categorias de profissionais de acordo com suas características religiosas/espirituais (valor de entropia> 0,96): o perfil denominado "menos religiosos" concentrou o maior número de psiquiatras do sexo masculino, com mais anos de experiência profissional, com maior percentagem de mestres e doutores e com tendência a não avaliar a R/E de seus pacientes; e o perfil "mais religiosos" reuniu os psiquiatras que mais consideravam a importância do papel da $\mathrm{R} / \mathrm{E}$ na saúde e, como esperado, eram aqueles que abordavam com mais frequência a temática da $\mathrm{R} / \mathrm{E}$ com 
seus pacientes. Concluindo, os resultados indicam que os valores religiosos/espirituais dos psiquiatras brasileiros estão associados a diferentes opiniões e comportamentos relacionados à abordagem da $\mathrm{R} / \mathrm{E}$ na prática clínica. Aqueles que são mais religiosos investigam mais a $\mathrm{R} / \mathrm{E}$ do paciente, e os menos religiosos tendem a ignorá-las. Os resultados também revelaram que a maioria dos psiquiatras acredita em Deus e considera importante a inclusão da R/E na assistência médica, mas apenas a metade deles aborda os aspectos religiosos/espirituais de seus pacientes, em parte, em razão da falta de preparo e treinamento específico.

Descritores: Religião; Espiritualidade; Psiquiatria; Cuidados médicos; Saúde mental; Ética. 
Menegatti-Chequini MC. Religiosity and spirituality in psychiatric practice [thesis]. São Paulo: "Faculdade de Medicina, Universidade de São Paulo"; 2020.

In recent decades, a substantive body of work has demonstrated that religious/spiritual involvement is generally associated with positive physical and mental health indicators. However, it is only quite recently that religious/spiritual aspects have been deemed important to the evaluation and treatment of patients. Moreover, a number of studies have reported that the religious/spiritual beliefs of the medical professionals involved may exert an influence on the strategies, decisions and clinical management of the patients. Therefore, the present work sought to characterize the religious/spiritual profiles of Brazilian psychiatrists and investigate the influence on patient care. To this end, a transversal observational study was conducted using a questionnaire that evaluated the religiosity/spirituality (R/S) characteristics of the psychiatrist and his/her clinical practice. This investigative approach resulted in three studies being carried out. The first analysed 484 psychiatrist members of the Brazilian Association of Psychiatry, who responded to the online version of the questionnaire. Of these, $71.4 \%$ believed in God, $67.4 \%$ possessed some affiliation with a religious institution and, although the majority $(76.8 \%$ ) considered the inclusion of $\mathrm{R} / \mathrm{S}$ to be important in clinical practice, less than half (45.5\%) regularly asked patients about their religious/spiritual beliefs. Psychiatrists who claimed to be more religious and/or spiritual were more inclined to include R/S in patient care. The most common difficulties reported in the approach to $\mathrm{R} / \mathrm{S}$ in a clinical context were: fear of overstepping their professional remit $(30.2 \%)$, lack of training $(22.3 \%)$ and lack of time $(16.3 \%)$. The second study examined 84 psychiatrists from the Institute of Psychiatry in the Faculty of Medicine Teaching Hospital at the University of São Paulo, one of the premier centres for the training of new psychiatrists and the study of neurosciences in Brazil. The results were similar to those of the first study, although the percentages were a little lower: $59.5 \%$ said they believed in the existence of God and $57.7 \%$ noted having religious affiliations. Over half $(64.2 \%)$ reported that their religious beliefs had an influence on their clinical practice and $50 \%$ had frequent discussions with their patients about R/S. The most common obstacles in the approach to R/S were: lack of time (27.4\%), fear of overstepping professional boundaries (25\%) and lack of training $(19.1 \%)$. The third study used the method of latent profile analysis on the sample, involving the psychiatrists who had taken part in the other two studies $(n=592)$, with the aim of identifying subgroups, among Brazilian psychiatrists, with religious/spiritual profiles. ANOVA and Pearson's chi-squared tests were employed to identify a correlation between opinions and conduct in clinical practice. Two profiles or categories of professional were identified according to their religious/spiritual characteristics (entropy value $>0.96$ ): the professionals described as "less religious" were predominantly male, had more extensive professional experience, a higher percentage of masters' degrees and doctorates and demonstrated a tendency to shy away from evaluating the R/S of their patients; the "more religious" profile brought together those psychiatrists who were most likely to consider the importance of the role of $\mathrm{R} / \mathrm{S}$ in health and, as 
expected, were those who would most frequently address the topic of R/S with their patients. In conclusion, the results show that the religious/spiritual values of Brazilian psychiatrists are associated with different opinions and behaviours related to the approach to $\mathrm{R} / \mathrm{S}$ in clinical practice. The more religious investigate the patient's R/S in greater depth, while the less religious tend to eschew it. The results also revealed that the majority of psychiatrists believe in God, and feel it is important to include R/S in medical care, though only half of them address the religious/spiritual aspects of their patients, in part due to the lack of preparation and specific training.

Descriptors: Religion; Spirituality; Psychiatry; Medical care; Mental health; Ethics. 


\section{INTRODUÇÃO}

\subsection{REVISÃO DA LITERATURA}

\subsubsection{Religião e saúde}

Desde os níveis mais arcaicos da civilização o ser humano relacionava a saúde ao sentido de sagrado, uma vez que atribuía poderes sobrenaturais a elementos da natureza que determinavam sua força, fertilidade, doença e morte. Toda a sua existência era de caráter sacramental ${ }^{1}$.

Em tempos pré-históricos não se distinguiam as doenças físicas das mentais e todos os males eram creditados a influências negativas de espíritos e outras manifestações místicas. Isso exigiu que os primeiros homens que se dedicaram à arte de curar fossem também líderes religiosos, capazes de estabelecer um modo de cura que incluísse o aspecto espiritual como meio de restabelecimento físico ${ }^{2}$.

Assim, ao longo de grande parte da história, a medicina esteve ligada às atividades religiosas, e os papéis dos líderes religiosos e dos médicos sobrepunham-se de modo frequente e, por vezes, de forma indiferenciada ${ }^{3}$. Como parte das atividades de assistência e caridade, os primeiros centros de tratamento, tanto na cultura ocidental como na cultura oriental foram decorrentes de serviços religiosos ${ }^{4}$.

Com a psiquiatria, parte da medicina, não foi diferente. Por muito tempo, houve um entrelaçamento das ideias sobre loucura e religião, medicina e teologia, bem como sobre os tratamentos e rituais nelas envolvidos ${ }^{5,6}$. Os primeiros hospitais psiquiátricos também foram organizados por monges e sacerdotes e as contribuições dos clérigos foram predominantes no século $\mathrm{XIX}^{7}$.

No Brasil, foram criadas as Santas Casas já no século $\mathrm{XVI}^{8}$, e a elas cabia, inclusive, o acolhimento dos doentes mentais. Ainda que em condições desfavoráveis, uma vez que a natureza de suas atividades era o atendimento de doenças físicas, tal acolhida não deixou de representar um novo tratamento para os "insanos" pobres ou desassistidos, que antes desfaleciam em decorrência dos maus tratos recebidos em ambientes inapropriados $^{9}$. O primeiro hospital psiquiátrico instalado no Brasil, em 1852 
no Rio de Janeiro, foi chamado "Hospício Pedro II" e funcionou inicialmente com um anexo do Hospital da Santa Casa de Misericórdia da Corte ${ }^{10}$.

No início do século XX, essa realidade sofre a influência de teorias como a de Sigmund Freud ${ }^{11,12}$ que, seguindo os ensinamentos do famoso neurologista francês Jean Charcot, passa a atribuir um caráter neurótico às experiências religiosas. Esse pressuposto orienta boa parte das correntes teóricas nas áreas da psiquiatria e da psicologia, que passam a entender as crenças e práticas religiosas, como patológicas ${ }^{13}$.

Além de Freud, outros teóricos contribuem para expandir ideias que associam a religiosidade ao pensamento irracional e à perturbação emocional. Por exemplo, em 1950, o psicólogo norte-americano Albert Ellis ${ }^{14}$, fundador da chamada Terapia Racional Emotiva, torna-se um dos propagadores das ideias antirreligiosas de Freud; entende que a devoção religiosa, por si só, é uma causa patológica, posição que sustentou com grande influência e aceitação, até sua morte, em $2007^{15,16}$.

Muito embora predomine na época, esse viés contrário à religião, é certo que alguns grupos de pesquisadores passam a defender a necessidade da integração dos aspectos religiosos/espirituais na atuação do médico. Assim, em 1954, é criada, na Filadélfia, a Academy of Religion and Mental Health (ARMH), tendo, dentre seus objetivos, "providenciar oportunidades educacionais para médicos, cientistas sociais, psiquiatras e outros para melhorar sua compreensão do papel da religião na manutenção, restauração ou aumento da saúde mental de indivíduos e grupos"17.

Posteriormente, em 1961, a mesma ARMH lança seu órgão de divulgação oficial, o Journal of Religion and Health, declarando em sua edição de lançamento que o periódico tem como objetivo fornecer um meio adicional de comunicação, por meio do qual membros do clero e representantes das ciências médicas e comportamentais possam expressar seus pensamentos e compartilhar seus conhecimentos, destinando-se a todos os interessados na indivisibilidade do bem-estar humano: físico, emocional e espiritual $^{18}$.

Não obstante esses esforços, a visão desfavorável da $\mathrm{R} / \mathrm{E}$ frente à psiquiatria ainda perdura, e com forte oposição. Os estudos que indicam o caráter benéfico da incorporação dos aspectos religiosos/espirituais para a saúde mental são tidos como desprovidos de suporte empírico, ao passo que outros, que caminham em sentido contrário, são comumente exaltados ${ }^{19}$. 
Provavelmente isso se deve, em grande parte, à própria característica dos profissionais da época. Em censo realizado pela American Psychiatric Association (APA), no ano de 1970, verifica-se que 59,6\% dos psiquiatras norte-americanos declaram-se ateus ou agnósticos e, daqueles que professam uma afiliação religiosa, cerca de $60 \%$ dizem que raramente ou nunca comparecem a cultos ou serviços religiosos ${ }^{20}$.

Embora essa percepção negativa das experiências religiosas não tivesse base em pesquisas científicas ou em estudos sistemáticos e tenha provindo apenas de observações clínicas, geralmente baseadas nas opiniões e crenças pessoais de seus autores $^{7}$, sua persistência influenciou o campo de estudo da interseção entre a ciência e a religião ${ }^{21}$ e acabou refletindo na formação dos profissionais de saúde mental.

Ainda no ano de 1980, o psiquiatra canadense Wendell W. Watters ${ }^{22}$ passa a ser uma das vozes mais contundentes à $\mathrm{R} / \mathrm{E}$, ao apontar uma influência negativa sobre a saúde mental. Segundo o autor, a religião é causa de sofrimento e incompatível com a saúde mental, além de representar um "anacronismo desumano". Até sua morte, em 2012, Watters considera a religião como um "perigo tóxico", uma forma de autoritarismo ${ }^{23}$.

Contudo, já no final do século XX e início do século XXI, surgem inúmeras evidências do impacto positivo das crenças religiosas/espirituais na saúde física e, sobretudo, na saúde mental ${ }^{2}$, de modo que um corpo consistente de estudos marca o início de uma nova era de atenção à R/E na psiquiatria.

\subsubsection{Abordagem empírica da religiosidade e da espiritualidade na saúde}

Nas últimas décadas, observa-se um aumento significativo de publicações envolvendo os temas R/E. Uma das mais importantes referências na área de R/E e saúde é o livro intitulado "Handbook of Religion and Health", publicado por Koenig et al. em $2001^{24}$, que apresenta a análise de 1.200 estudos sobre a relação entre a R/E e saúde realizados no período entre 1800 e 2000. Já sua segunda edição, lançada em $2012^{2}$, relaciona 2001 estudos quantitativos que também investigam o impacto da $\mathrm{R} / \mathrm{E}$ na saúde e que foram publicados em um período de apenas 10 anos (2000 e 2010). Portanto, podemos observar um aumento exponencial de publicações científicas ao 
longo dos anos, demonstrando o interesse da comunidade acadêmica para a temática R/E e saúde.

\subsubsection{Conceitos de religião, religiosidade e espiritualidade}

"Religião" e "espiritualidade" são conceitos complexos, multifacetados e multidimensionais, que não dispõem ainda de uma definição universalmente aceita por todos os pesquisadores. Essa falta de padronização, algumas vezes, gera polêmicas e divergências em torno de seus significados e pode, inclusive, dificultar as interpretações de investigações na área. Contudo, nos últimos anos, podemos observar progressivamente a formação de um certo entendimento em relação ao uso de alguns conceitos, já que ambos estão sendo utilizados em vários estudos contemporâneos para referirem-se à busca do sagrado ou do transcendente ${ }^{25}$.

Embora não exista um consenso universal, uma das referências mais usadas pelos pesquisadores é a de Koenig et al. $^{24}$. Eles entendem por religião um sistema organizado de crenças, símbolos e práticas para facilitar a aproximação do indivíduo com o sagrado ou transcendente (Deus, força superior ou verdade/realidade suprema). Já a espiritualidade é abordada pelos autores como a busca pessoal de respostas para questões relacionadas ao fim da vida, a seu significado e sobre as relações com o sagrado e o transcendente. No caso, ela pode ou não levar ao desenvolvimento de práticas religiosas e à formação de uma comunidade.

Além destas, existem outras definições ${ }^{26,27}$ propostas no meio acadêmico; são visões mais amplas sobre a espiritualidade, como a sugerida por Puchalski et al. ${ }^{28}$, que a entendem como um aspecto dinâmico e intrínseco do ser humano, que busca significado, propósito e transcendência, e que ocorre por meio das relações da pessoa consigo mesma, com a família, com a comunidade, com a sociedade e com o que lhe é significativo ou sagrado. Conforme este conceito, a espiritualidade pode expressar-se por meio de crenças e valores pessoais, além das tradições religiosas e suas práticas.

Ainda com o objetivo de auxiliar nas pesquisas, Koenig et al. ${ }^{24}$ sugerem uma divisão qualitativa para o termo religiosidade. Para os autores, trata-se do quanto um indivíduo acredita, segue e pratica uma religião. A religiosidade pode ser organizacional 
(participação em igrejas ou templos religiosos) ou não organizacional (envolve atividades religiosas particulares, como leitura de livros religiosos, oração, etc.).

Outros conceitos ainda muito utilizados na área referem-se à religiosidade intrínseca e extrínseca, propostos originalmente por Allport \& $\operatorname{Ross}^{29}$ : a primeira, diz respeito à expressão do pensamento religioso integrado à prática, ao cotidiano; refere-se ao fato do indivíduo fazer da religião o motivo principal de sua vida, conferindo-lhe sentido e significado. A religiosidade extrínseca, por sua vez, está relacionada aos ganhos externos provenientes da religião. Os valores extrínsecos são utilitários: o indivíduo com essa orientação entende a religião como meio para lhe fornecer, por exemplo, segurança, consolo, sociabilidade, distração, "status" e outros benefícios proporcionados pela religião instituída e suas práticas. Conforme os autores, uma forma breve de caracterizar as duas orientações seria dizer que o indivíduo "extrinsecamente motivado usa a sua religião, enquanto o intrinsecamente motivado vive a sua religião".

Pargament ${ }^{30}$, outro importante pesquisador na área, também contribui com a formulação do conceito de enfrentamento religioso, que definiu como o conjunto de estratégias religiosas e/ou espirituais utilizadas pelo indivíduo para manejar o estresse diário e/ou advindo de crises existenciais ou circunstanciais que ocorrem ao longo da vida. Segundo o autor, o enfrentamento pode ser positivo ou negativo. No primeiro caso, envolve estratégias consideradas benéficas aos praticantes, sendo elas: capacidade de perdão, busca de apoio espiritual, busca do amor e cuidado de Deus, etc.; já o enfrentamento negativo revela uma relação conflituosa com Deus, com a fé e com a comunidade religiosa; é prejudicial ao indivíduo e inclui sentimentos negativos, como: insatisfação e descontentamento com relação a Deus e a grupos religiosos/espirituais, culpa, punição, abandono e questionamentos quanto ao amor ou à existência de Deus ${ }^{31}$. No caso, o indivíduo vivencia um estado de tensão e conflito relacionado às suas questões religiosas/espirituais, que podem ocorrer nos níveis; intrapsíquico (interno), interpessoal (com outras pessoas) e divino (com Deus ou poder superior) ${ }^{32}$.

Várias dimensões específicas da religião, como atitudes religiosas, experiências religiosas, amor religioso e bem-estar religioso, dentre outras, têm sido conceituadas e avaliadas de forma independente umas das outras ${ }^{2}$. 
De toda forma, como alerta Verhagen ${ }^{33}$, quaisquer que sejam as divergências a respeito da definição e uso dos conceitos, isso não pode servir para deixar de considerar a R/E como parte fundamental da prática e da pesquisa psiquiátrica

\subsubsection{A religiosidade e a espiritualidade como fator de promoção à saúde}

A grande maioria dos estudos que investiga a relação entre R/E e saúde mostra que o envolvimento religioso e espiritual está associado à maior capacidade de enfrentamento e a indicadores positivos de saúde física e, principalmente, de saúde $\operatorname{mental}^{2,34}$.

Tais estudos demonstram que as crenças religiosas/espirituais possuem efeitos favoráveis nos desfechos de saúde, como melhor função imunológica ${ }^{35}$; menores taxas de morte por causas cardiovasculares ${ }^{36}$; melhoras nas doenças cardíacas ${ }^{37}$; maior sobrevida $^{38}$ e outros benefícios, como aqueles provenientes do impacto de comportamentos saudáveis no bem-estar geral; por exemplo, a diminuição de atividade sexual de risco, dietas, diminuição ou ausência do consumo de álcool e tabaco ${ }^{2,39,40}$.

Neste sentido, estudos epidemiológicos indicam que a $\mathrm{R} / \mathrm{E}$ está associada positivamente a taxas mais baixas de morte por câncer, decorrentes de um estilo de vida mais saudável propiciado pela prática religiosa/espiritual ${ }^{2}$. Estudo realizado com 253 pacientes do departamento de oncologia de um hospital universitário na Noruega demonstrou que altos índices de religiosidade estavam estatisticamente associados a menor risco de morte em decorrência da doença ${ }^{41}$. Da mesma forma, a frequência a serviços religiosos também mostrou associação com mortes por câncer. Em estudo realizado com 21.204 adultos norte-americanos, verificou-se que aqueles que nunca frequentavam um serviço religioso apresentavam maior risco de morte por câncer em relação aos que tinham, ao menos, uma frequência semanal ${ }^{42}$.

$\mathrm{Na}$ área de saúde mental, que concentra cerca de $80 \%$ dos trabalhos que investigam a $R / E$ e saúde ${ }^{43}$, uma série de estudos empíricos apresenta as crenças e práticas religiosas/espirituais associadas a desfechos positivos em saúde mental ${ }^{2,44}$. Esses estudos apontam a R/E associada a: menores índices e melhor recuperação nos casos de depressão $0^{45-47}$; menores taxas de suicídio ${ }^{48-50}$; menos abuso de substâncias ${ }^{51}$; maior estabilidade familiar e conjugal ${ }^{52}$; apoio e suporte social $^{53}$; maiores índices de 
propósito e significado de vida, esperança, otimismo, autoestima e outros benefícios relacionados à saúde mental ${ }^{2,44,54}$.

É importante pontuar que, com base em uma extensa revisão da literatura, Koenig at al. ${ }^{2}$ concluem que embora alguns estudos tenham descoberto que R/E está associada ao aumento da gravidade dos sintomas de ansiedade, outros estudos prospectivos, estudos experimentais e ensaios clínicos randomizados sugerem que a $R / E$ tende a reduzir a ansiedade. Além disso, os ensaios clínicos mostram que as terapias religiosas, de várias tradições religiosas, parecem ser mais eficazes para a melhora dos sintomas do transtorno de ansiedade que as terapias seculares tradicionais ${ }^{55}$.

Os estudos demonstram que os benefícios da R/E para a saúde mental não se restringem a pacientes com problemas mentais leves, mas estendem-se, inclusive, a pacientes com transtornos mentais graves ${ }^{56}, 57$. Por exemplo, um estudo suíço que analisa o conteúdo de entrevistas semiestruturadas sobre enfrentamento religioso, aplicadas em 115 pacientes ambulatoriais que atendem aos critérios diagnósticos do CID-10 para esquizofrenia ou outra psicose não-afetiva, aponta a religião como promovedora de: esperança, propósitos e significado de vida, integração social e adesão ao tratamento, além de proporcionar a diminuição dos sintomas psicóticos, riscos de tentativas de suicídio e abuso de substâncias ${ }^{58}$.

A religião é um dos primeiros recursos a que as pessoas e seus familiares recorrem quando defrontados com algum tipo de dificuldade, incluindo problemas graves com a saúde ${ }^{30}$. Uma pesquisa realizada com 406 pacientes diagnosticados com algum tipo de doença mental persistente, como: esquizofrenia paranoide; transtorno esquizoafetivo; transtorno depressivo maior; esquizofrenia indiferenciada; transtorno bipolar I e outras, indica que mais de $80 \%$ desses pacientes usam práticas ou atividades religiosas para lidar com a doença e, para $65 \%$ deles, a religião ajuda a reduzir a gravidade dos sintomas. Além disso, o estudo mostra que as atividades e crenças religiosas são mais atraentes aos pacientes que estão passando por sintomas mais graves, e que o aumento da atividade religiosa associa-se à redução destes sintomas ${ }^{59}$.

\subsubsection{A religiosidade e a espiritualidade como fator de risco à saúde}

Embora sejam a minoria dos relatos na literatura científica, alguns estudos vêm mostrando que nem todos os efeitos da R/E são positivos à saúde; ao contrário, podem, 
em algumas ocasiões, configurar-se como um fator prejudicial ou deletério ${ }^{60,61}$. Fato que corrobora a necessidade de atenção a esses temas por parte dos profissionais da saúde.

A R/E pode ser fonte de problemas sobretudo nos casos de enfrentamento religioso negativo em que as crenças religiosas/espirituais, utilizadas de maneira prejudicial, podem contribuir para o sofrimento do paciente, acentuando sentimentos de raiva, culpa e até mesmo desespero ${ }^{32}$.

O enfrentamento religioso/espiritual negativo está associado a pensamentos de punição como, por exemplo, "Deus me abandonou" ou "Deus está me castigando" e pode interferir de forma negativa na readaptação do paciente, alterando, inclusive, aspectos fisiológicos importantes no processo de sua recuperação ${ }^{62}$.

Um estudo americano sobre a relação entre conflitos religiosos/espirituais e vários tipos de sintomas psicopatológicos mostra o enfrentamento religioso negativo associado significativamente a várias formas de psicopatologia, incluindo: ansiedade; ansiedade fóbica; depressão; ideação paranoide; compulsão obsessiva e somatização. Aponta, ainda, que a relação entre enfrentamento religioso negativo, ansiedade e ansiedade fóbica é mais forte na fase inicial das doenças ${ }^{63}$. Ademais, existem evidências de conflitos religiosos atuando como preditores de futuros sintomas depressivos ${ }^{64}$ e de sua associação com sintomas de ansiedade generalizada e menores índices de satisfação com a vida e felicidade ${ }^{61}$.

Diante da possibilidade da R/E relacionar-se com desfechos negativos para a saúde em geral, é essencial que os profissionais de saúde sejam capazes de identificar a forma como o paciente utiliza sua R/E, se positiva ou negativamente ${ }^{65}$.

\subsubsection{Associações de profissionais da saúde e a religiosidade e a espiritualidade no cuidado ao paciente}

Com base nas inúmeras evidências do impacto da R/E na saúde e bem-estar dos pacientes, muitas organizações, de várias áreas da saúde, criam comitês específicos para cuidar dos assuntos relativos à inclusão da R/E na prática clínica e na formação do profissional. 
$\mathrm{Na}$ área da psicologia, a "American Psychological Association” (ApA) cria, em 1976, sua "Division 36", um grupo voltado à avaliação de assuntos referentes à R/E na atuação prática do psicólogo. Sua origem, contudo, remonta ao ano de 1946, com a criação da "American Catholic Psychological Association” (ACPA) e, já naquela época, expressava a preocupação com o tema ${ }^{66}$.

No campo da enfermagem, em 2007, a "American Association of Colleges of Nursing" (AACN) ${ }^{67}$ recomenda que os enfermeiros considerem as crenças e valores espirituais e religiosos dos indivíduos, famílias e comunidades na tomada de decisão, tratamento e cuidados destinados aos pacientes, mesma orientação adotada pela "Canadian Nurses Association" (CNA) ${ }^{68}$ em 2010.

Especificamente quanto às associações médicas, em 1998, o "American College of Physicians" (ACP), em consenso com a "American Society of Internal Medicine" (ASIM) incluem em suas diretrizes de ensino, que o médico seja capaz de extrair uma história espiritual dos pacientes e, para tanto, sugere quatro questões que podem ser usadas para a coleta da história religiosa/espiritual de pacientes doentes ou gravemente doentes. São elas: 1. “A fé (religião, espiritualidade) é importante para você?”; 2. "A fé tem sido importante para você em outras ocasiões de sua vida?"; 3. "Você tem alguém para falar de assuntos religiosos?" e 4. "Gostaria de conversar sobre assuntos religiosos ou espirituais com alguém?" 69.

Em 2001, a "Joint Commission"70, a maior entidade de certificação de excelência em serviços de saúde dos EUA, então chamada de "Joint Commission on Accreditation of Healthcare Organizations" (JCAHO), passa a exigir em seu protocolo de acreditação uma avaliação espiritual dos pacientes. Embora não determine nenhum modelo específico, a entidade sugere uma avaliação breve que deve explorar, no mínimo, três áreas: 1) a tradição de fé do paciente; 2) suas crenças mais significativas e 3 ) as práticas religiosas/espirituais importantes para o paciente.

$\mathrm{Na}$ área da psiquiatria, muitas organizações também passam a recomendar a inclusão da R/E na avaliação clínica e na formação dos psiquiatras. Podemos observar muitas iniciativas nas associações de classes, como, por exemplo, quando em 1990 a $\mathrm{APA}^{71}$ publica diretrizes para a abordagem da $\mathrm{R} / \mathrm{E}$ na prática clínica e ressalta sua utilidade como fundamental para o tratamento psiquiátrico, alertando os psiquiatras no sentido de cuidarem para não impor seus próprios sistemas de crenças aos pacientes, 
assim como para a necessidade de respeitar as crenças religiosas de seus assistidos na abordagem terapêutica. Mais recentemente, em 2016, por meio de sua entidade filantrópica e educacional, a "American Psychiatric Association Foundation" (APAF) elabora, em conjunto com a "Mental Health and Faith Community Partnership Steering Committee", uma entidade civil destinada a promover o diálogo entre os profissionais de saúde e líderes espirituais, o "Mental Health: A Guide for Faith Leaders"72, publicação dirigida aos clérigos e líderes espirituais, com objetivo de melhor capacitálos na compreensão das doenças mentais, nas formas de tratamento e sobre a importância do encaminhamento aos profissionais médicos.

Desde 1994, o "Accreditation Council for Graduate Medical Education" (ACGME), que estabelece padrões para os programas de educação médica nos Estados Unidos da América por meio de seu "Review Committee for Psychiatry" estipula que os residentes sejam capazes de demonstrar competência para lidar com os aspectos religiosos e espirituais dos pacientes ${ }^{73,74}$.

O "Royal College of Psychiatrists" (RCP) ${ }^{75}$, do Reino Unido funda em 1999 o comitê "The Spirituality and Psychiatry Special Interest Group" (SPSIG), dedicado a tratar dos assuntos relacionados à R/E. As recomendações atuais estabelecem critérios de conduta para a abordagem da $\mathrm{R} / \mathrm{E}$, no sentido de que seja rotineiramente investigada por se tratar, em muitos casos, de fator essencial à avaliação clínica do paciente. Dentre outras orientações, indica a importância de que o profissional esteja atento e disposto a reconhecer quando os cuidados adicionais de líderes e membros de comunidades religiosas sejam necessários. Adverte também quanto à necessidade da inclusão do tema $\mathrm{R} / \mathrm{E}$ na formação do profissional $^{76}$.

Com base no projeto elaborado pelos membros da SPSIG, a "Section on Religion, Spirituality and Psychiatry" (SRPS) da "World Psychiatric Association" $(\mathrm{WPA})^{77}$ declara, em 2010, sua posição com relação à "Religião e Psiquiatria". Reconhece a necessidade de integrar a $\mathrm{R} / \mathrm{E}$ na prática psiquiátrica e de saber distingui-la dos fenômenos patológicos. Nesse sentido, passa a incentivar a realização de estudos e pesquisas na área, a fim a capacitar os profissionais para uma abordagem mais integral do paciente, incluindo a R/E no contexto terapêutico. Em 2016, aprova sua "Position Statement on Spirituality and Religion in Psychiatry", em que reafirma a importância de 
se considerar a dimensão espiritual no ensino, pesquisa e prática clínica da psiquiatria $^{78}$.

Também a "European Psychiatric Association" (EPA) ${ }^{79}$, em 2011, reconhece que os aspectos religiosos/espirituais são importantes não só na prevenção de desordens mentais, como também na promoção da saúde mental. Conforme a EPA, a espiritualidade é um fator a ser considerado nos componentes da saúde, além dos aspectos físico, mental, emocional, social e ambiental, sendo necessário entendê-la como um recurso importante para ajudar as pessoas a lidarem com situações de estresse $^{80}$.

No Brasil, a Comissão de Estudos e Pesquisa em Espiritualidade e Saúde Mental $^{81}$ criada em fevereiro de 2014 para assessorar a Associação Brasileira de Psiquiatria (ABP) nos assuntos referentes à R/E e saúde mental, estabelece como objetivos a promoção e o incentivo de novos estudos na área de espiritualidade e saúde, além de propiciar a formação de cursos de educação continuada para médicos, a fim de habilitá-los na abordagem das questões religiosas/espirituais dos pacientes.

\subsubsection{Evolução dos critérios diagnósticos em psiquiatria}

Um importante marco na mudança do papel da R/E no trabalho dos profissionais de saúde mental pode ser observado nas subsequentes edições dos manuais de diagnóstico em psiquiatria, que deixam de associar a religião às perturbações mentais e passam a diferenciar as ideias e comportamentos religiosos/espirituais normais daqueles resultantes de transtornos mentais ${ }^{82,83}$.

O Manual de Estatística e Diagnóstico da Associação Psiquiátrica Americana ('Diagnostic and Statistical Manual of Mental Disorders' - DSM), em sua terceira edição (DSM-III, 1980), traz as experiências religiosas como exemplos de patologias. As doze menções à religião registradas em seu texto são de conotação negativa, sempre associando-as com doença ${ }^{82}$. Sete anos depois (1987), na publicação da edição revisada, o DSM-III-R, a abordagem dada ao tema continua com viés negativo; a religião é identificada com exemplos patológicos do tipo "pensamento ilógico", "incoerência" e "pobreza de conteúdo e fala" $"$. 
Entretanto, na edição revisada de 1994 (DSM-IV), a religião ganha uma nova abordagem, considerada como um grande avanço do ponto de vista cultural ${ }^{83}$. A adição de um novo código diagnóstico (V.62.89), intitulado 'Problema Religioso ou Espiritual' indica maior sensibilidade à R/E na psiquiatria, que passa a diferenciar as manifestações espirituais patológicas daquelas culturalmente aceitas e saudáveis ${ }^{85}{ }^{86}$. O objetivo é diminuir a ocorrência de iatrogenia, estabelecendo critérios para avaliação e diagnósticos mais precisos ${ }^{87}$. A partir da inclusão desse novo código diagnóstico, os aspectos religiosos e espirituais do paciente passam a fazer parte do foco da consulta e do tratamento psiquiátrico ${ }^{88}$.

A edição atual de 2013 (DSM-V) mantém a categoria referente aos problemas religiosos ou espirituais e suas aplicações podem ser encontradas na Seção II, em um capítulo que faz referência a algumas condições que podem ser foco da atenção clínica sem, contudo, caracterizá-las como transtornos mentais ${ }^{89}$.

\subsubsection{A psiquiatria centrada na pessoa}

O modelo biomédico tradicional atribui a todas as doenças, inclusive as mentais, um fundo ou uma causa estritamente biológica ${ }^{90}$. Embora vigente nas últimas décadas, o paradigma biomédico vem sendo severamente criticado pelo seu reducionismo biológico, que impede que todos os aspectos médicos relevantes da saúde e da doença sejam contemplados ${ }^{91,92}$.

O reconhecimento da necessidade de uma abordagem mais holística do paciente tem início com a proposta de George Engel ${ }^{93}$, que compreende o indivíduo dentro de um contexto mais amplo, incluindo os fatores sociais e psicológicos, além dos biológicos. Essa abordagem é conhecida como modelo biopsicossocial e propõe que as três dimensões sejam consideradas em todas as tarefas de assistência médica.

Embora o modelo biopsicossocial seja, de toda forma, um inegável avanço em vista do modelo biomédico, também sofre severas críticas, por não especificar exatamente o que seriam os aspectos biológicos, psicológicos e sociais e, assim, é considerado demasiadamente "eclético", a ponto de não fornecer ferramentas eficazes para um diagnóstico correto do paciente ${ }^{94,}{ }^{95}$. Ademais, negligencia os aspectos 
religiosos e espirituais, considerados indispensáveis para se ter uma visão integral do paciente e para promover uma medicina realmente centrada na pessoa ${ }^{96}$.

Nesse sentido, Sulmasy ${ }^{97}$ propõe uma abordagem ainda mais abrangente de assistência e pesquisa, que busca a máxima compreensão possível da totalidade do paciente. Partindo do pressuposto filosófico-antropológico de que o ser humano é uma pessoa intrinsecamente espiritual, entende o indivíduo como um "ser em relação" não apenas consigo mesmo em seus processos bioquímicos e entre as partes de seu corpo, mas também, em relação com os campos ecológico, físico, familiar, social, político e transcendente. $\mathrm{O}$ autor postula que os cuidados de saúde genuinamente holísticos referem-se a um sistema de assistência que atende ao montante de relacionamentos do paciente como um todo. Esta totalidade inclui não apenas seus aspectos biológicos, psicológicos e sociais, mas também os espirituais, que devem ser considerados por todos os profissionais de saúde. Para tanto, propõe a adoção do sistema biopsicossocialespiritual de atenção ao paciente e amplia a ideia original de Engel $^{93}$.

Da mesma forma, Hefti ${ }^{98,99}$ incorpora a seu modelo holístico os princípios da filosofia existencial do psiquiatra austríaco Viktor Frankl ${ }^{100}$, que tem como fundamento as ideias de "reumanização" da psiquiatria e da "conscientização do espiritual" e, assim, passa a considerar a necessidade da integração dos aspectos religiosos/espirituais no conceito introduzido por Engel, propondo a compreensão da R/E como uma dimensão distinta e independente, uma quarta dimensão, interagindo com os fatores biológicos, psicológicos e sociais do paciente, em um modelo que chama de "modelo biopsicossocial ampliado", em que a R/E pode atuar como fator causal, mediador ou moderador sobre a saúde mental, da mesma maneira que os fatores biológicos, psicológicos ou sociais.

Assim, dentro da perspectiva de atendimento integral do paciente, foram desenvolvidos alguns instrumentos que facilitam a investigação de seus aspectos religiosos/espirituais. Puchalski e Romer ${ }^{101}$, por exemplo, elaboraram o "FICA Spiritual History Tool". Conforme esta escala, o paciente deve ser questionado sobre suas crenças religiosas/espirituais e a importância delas para sua vida, bem como se faz parte de alguma comunidade religiosa ou tem práticas religiosas/espirituais e, por fim, se deseja que seu médico considere estes aspectos para seu tratamento. Da mesma maneira, para auxiliar os profissionais de saúde, Hodgson et al. ${ }^{102}$ desenvolveram o 
"Biopsychosocial-Spiritual (BPSS) Interview Method", questionário para entrevista inicial com o paciente com abordagem em quatro níveis: sintomas físicos, diagnóstico e tratamento médico do paciente (aspecto biomédico); os pensamentos, sentimentos e estado de saúde mental associados à doença/tratamento (aspecto psicológico); as fontes de apoio e relacionamento com os outros (aspecto socioambiental) e o sistema de crenças do paciente (aspecto espiritual).

Além de instrumentos que facilitam a anamnese religiosa/espiritual do paciente, foram desenvolvidas técnicas de intervenções religiosas-espirituais integradas na psicoterapia (RSIP), que vêm se mostrando bastante benéficas à saúde mental ${ }^{40}$, podendo inclusive ser mais eficazes que tratamentos convencionais para pacientes religiosos nos casos de transtorno depressivos casos de transtornos depressivos, ansiedade generalizada e esquizofrenia ${ }^{103}$. Resultados bastante satisfatórios vêm vendo encontrados sobretudo em intervenções que fazem uso de abordagens que incluem as crenças e práticas religiosas/espirituais dos pacientes nas técnicas de terapia cognitivocomportamental (TCC) padrão; como, por exemplo, a terapia comportamental cognitiva religiosa $(\mathrm{RCBT})^{104,} 105$ e a terapia de processamento cognitivo espiritualmente integrada $\left(\right.$ SICPT) ${ }^{106}$.

Nesse contexto, não poderíamos deixar de mencionar que uma das técnicas pioneiras na inclusão dos aspectos espirituais na abordagem da pessoa foi o programa Alcoólicos Anônimos (AA). Criado em 1935 ${ }^{107}$, nos Estados Unidos da América, o programa alcançou notoriedade mundial no tratamento do alcoolismo com seu programa conhecido como "Doze Passos" em que, embora afirme não se tratar de uma entidade religiosa, tem toda sua terapêutica baseada na proposição espiritual de "um poder superior", que tem como função guiar o recuperando durante seu tratamento ${ }^{108}$. Um processo que chegou a ser chamado de "recuperação espiritual"109.

Concluindo, a formulação bio-psico-socio-espiritual centrada no paciente é multidimensional e, como tal, requer um paradigma multidisciplinar, de modo que a equipe terapêutica seja composta por profissionais de várias áreas da saúde ${ }^{96}$. Na abordagem holística ou integral da pessoa, os capelães hospitalares devem fazer parte da equipe interdisciplinar, com a mesma importância dos outros profissionais da saúde ${ }^{98}$. No particular, a relevância do trabalho da capelania é reconhecida pela sua capacidade de promover formas benéficas de enfrentamento religioso, que ajudam na recuperação 
física e mental dos pacientes ${ }^{110}$, devendo ser considerada por todos os profissionais de saúde.

\subsubsection{A religiosidade e a espiritualidade na prática clínica}

Diante das propostas de abordagem integral do paciente, que incluem os aspectos religiosos/espirituais na avaliação e tratamento do indivíduo, surge o interesse voltado aos comportamentos e às atitudes dos profissionais, relacionados à $\mathrm{R} / \mathrm{E}$ na prática clínica. Vários pesquisadores, sobretudo nos Estados Unidos da América e Reino Unido passam, então, a examinar como esses profissionais lidam com a R/E de seus pacientes ${ }^{111,112}$.

Os resultados destas investigações demonstram que grande parte dos médicos, inclusive os psiquiatras, concorda com a importância e necessidade de incluir a R/E na prática clínica, mas também deixam claro que nem sempre esses profissionais abordam as questões religiosas/espirituais de seus pacientes ${ }^{111,113-117}$.

Uma pesquisa canadense mostra que, enquanto metade dos psiquiatras entrevistados afirma que, muitas vezes, ou sempre colhem história religiosa/espiritual na avaliação clínica, apenas $17 \%$ de seus pacientes confirmam que são abordados sobre o assunto ${ }^{116}$. Da mesma forma, um estudo qualitativo com psiquiatras atuantes no Reino Unido conclui que, embora os profissionais concordem com a necessidade de integração da R/E na prática clínica, eles nunca abordam seus pacientes a respeito do assunto, a não ser por iniciativa dos próprios pacientes ${ }^{118}$.

Esta discrepância entre a percepção do profissional sobre a importância de se incluir a R/E na assistência ao paciente, e o que ele efetivamente faz na prática, pode ser decorrente de muitas barreiras encontradas por esses profissionais na tentativa de abordar a R/E no encontro clínico ${ }^{119}$. Alguns levantamentos informam que as dificuldades mais relatadas por psiquiatras ao tratar da R/E do paciente referem-se à falta tempo e, principalmente, à falta de conhecimento e treino ${ }^{118,120,121}$.

Com relação ao perfil religioso/espiritual dos psiquiatras, a literatura indica que os psiquiatras são menos propensos a acreditar em Deus, a participar de serviços religiosos e a declarar algum tipo de afiliação religiosa, quando comparados com a 
população em geral $^{113}, 116,122$, com seus pacientes ${ }^{116}$, com médicos de outras especialidades $^{120,123}$ e com psicólogos e assistentes sociais ${ }^{122}$.

Para alguns autores, esse perfil menos religioso dos psiquiatras, comparado com a população em geral, pode levá-los a desconsiderar a importância da inclusão da R/E na prática médica e criar uma distância entre eles e os pacientes, já que estes sentem necessidade e esperam que seus psiquiatras abordem $\mathrm{o}$ assunto durante $\mathrm{o}$ tratamento $^{124,125}$.

Nesse sentido, pesquisa realizada em um hospital psiquiátrico indica que a maioria dos internos expressa desejo de receber assistência religiosa. Dos 213 pacientes analisados, $82,2 \%$ solicitaram assistência religiosa durante a internação ${ }^{126}$. Da mesma forma, D'Souza ${ }^{127}$ mostra que os pacientes psiquiátricos julgam a espiritualidade como importante em suas vidas, e gostariam que seus terapeutas considerassem suas necessidades espirituais na avaliação e tratamento da doença.

Curlin et al. ${ }^{120}$ demonstram que, embora os psiquiatras sejam menos religiosos quando comparados com médicos de outras especialidades, são os que declaram maiores facilidade e experiência em abordar a R/E de seus pacientes, além de serem aqueles que mais consideram adequada sua abordagem. Por outro lado, são também os que mais reconhecem os aspectos negativos da $\mathrm{R} / \mathrm{E}$, bem como os menos propensos a encaminhar os pacientes para serviços religiosos, quando comparados com outros membros da equipe ou médicos de outras especialidades ${ }^{121,128}$. Esta tendência de não recomendar serviços de ordem religiosa, já tinha sido observada em estudos que demonstram a pouca inclinação dos psiquiatras em encaminhar pacientes para serviços de capelania ${ }^{129,130}$.

Os estudos que examinam as atitudes e comportamentos dos médicos relacionados à $\mathrm{R} / \mathrm{E}$ na prática clínica demonstram que as diversas características religiosas/espirituais desses profissionais definem diferentes comportamentos clínicos relacionados à $\mathrm{R} / \mathrm{E}$, ou seja, mostram que as características religiosas e espirituais dos médicos podem influenciar na maneira como tratam os aspectos religiosos/espirituais de seus pacientes ${ }^{111,131}$.

O mesmo ocorre com os psiquiatras. As suas características religiosas/espirituais tendem a moldar seus comportamentos clínicos ${ }^{113}$, ${ }^{132}$. Um estudo realizado com psiquiatras da "Christian Psychiatry", movimento pertencente à "Christian Medical and 
Dental Society", dos Estados Unidos da América, organização de caráter confessional que congrega médicos e dentistas evangélicos, indica que as atitudes clínicas destes profissionais são diferenciadas em assuntos relacionados ao tratamento do alcoolismo, assim como para episódios de intenção suicida, luto e sociopatia. Nesses casos, a maioria desses psiquiatras reconhece a maior eficácia da bíblia e da oração em comparação à medicação ${ }^{133}$. A forma como esses profissionais encaram a doença, vista como um problema também de caráter espiritual, acaba influenciando não só o diagnóstico, como a própria terapêutica adotada ${ }^{134}$.

Nesse mesmo sentido, um estudo canadense realizado com 1.204 psiquiatras demonstra que suas crenças e práticas religiosas/espirituais, especialmente, a religiosidade intrínseca, são fortes preditores da investigação da R/E do paciente ${ }^{116}$.

Ainda, demonstrando a influência das crenças nas decisões médicas, um outro estudo envolvendo 312 médicos de cuidados primários e 487 psiquiatras mostra que os médicos religiosos são mais propensos a aconselhar os pacientes a participarem de atividades religiosas. Os autores sugerem que, nesses casos, a religião proporciona uma visão mais positiva de comunidades religiosas e de provedores de cuidados pastorais, como recursos para a saúde mental ${ }^{135}$.

As evidências da influência da $\mathrm{R} / \mathrm{E}$ na saúde e na prestação de cuidados ao paciente apontam para a necessidade da implementação de programas de treinamento, que capacitem os profissionais a lidarem de modo adequado com a R/E de seus pacientes na prática clínica ${ }^{65,136}$.

Esforços nesse sentido podemos observar mais intensamente nos Estados Unidos da América, onde 90\% das escolas médicas têm a R/E inserida em suas grades curriculares e grande parte dos cursos de formação em psiquiatria tem a R/E como disciplina regular ${ }^{137,138}$. No Reino Unido, 59\% das escolas médicas fornecem algum tipo de ensino sobre espiritualidade ${ }^{139}$. Já no Brasil, poucas faculdades de medicina têm cursos que tratam especificamente da R/E e saúde, e menos da metade fornecem algum tipo de ensino sobre o tema ${ }^{140}$.

Entretanto, o Brasil já dispõe de alguns estudos sobre o comportamento dos médicos em relação à $\mathrm{R} / \mathrm{E}$ no cuidado ao paciente. Uma destas pesquisas analisa as atitudes relativas à R/E na prática clínica e na formação profissional de estudantes de 12 escolas de medicina. Os achados demonstram que a maioria dos estudantes de medicina 
acredita que a espiritualidade tenha impacto na saúde dos pacientes $(71,2 \%)$, e que esse impacto é positivo $(68,2 \%)$. Mais da metade gostaria de abordar a R/E em sua prática clínica $(58 \%)$, embora quase metade $(48,7 \%)$ sinta-se despreparada para isso. A maioria também considera que a temática $\mathrm{R} / \mathrm{E}$ deve ser incluída no currículo médico $(62,6 \%)^{141}$. Análises posteriores mostram que as opiniões desses estudantes sobre questões controversas do ponto de vista ético, como controle de natalidade, uso de células tronco, aborto, eutanásia e clonagem parecem ser moldadas por suas crenças religiosas. Os estudantes menos religiosos são mais favoráveis a essas questões ${ }^{142}$.

Um outro estudo do gênero, que compara médicos brasileiros de várias especialidades com médicos indianos e indonésios, mostra os brasileiros como os mais propensos a acreditar que a $\mathrm{R} / \mathrm{E}$ influencia na saúde do paciente e, ao lado dos indonésios, são também os que mais consideram apropriado discutir a $\mathrm{R} / \mathrm{E}$ na prática clínica. Por outro lado, os indonésios mostram-se mais religiosos e mais propensos a abordar a R/E no cuidado ao paciente ${ }^{143}$.

No que diz respeito à saúde mental, embora na última década tenha ocorrido um aumento significativo de pesquisas realizadas no Brasil, abordando o tema $\mathrm{R} / \mathrm{E}^{144}$, não existem dados empíricos sobre as características religiosas/espirituais dos psiquiatras relacionadas à abordagem da $\mathrm{R} / \mathrm{E}$ na prática clínica.

\subsection{JUSTIFICATIVA}

O Brasil é um país marcadamente religioso. De acordo com o último Censo Demográfico, $92 \%$ dos brasileiros têm religião, e 64,6\% são católicos, 22,2\% evangélicos, $2 \%$ espíritas, $0,3 \%$ umbandistas e candomblecistas, 2,7\% de outras religiosidades e apenas $8 \%$ não têm religião ${ }^{145}$. Conforme as análises de uma amostra probabilística da população brasileira, $83 \%$ consideram a religião muito importante em suas vidas e $31 \%$ frequentam serviços religiosos, pelo menos, uma vez por semana ${ }^{146}$.

Observa-se, portanto, que a religião é parte relevante no dia a dia de boa parte das pessoas e, provavelmente, a religião deva também influenciar a atuação profisssional de muitos brasileiros.

Neste contexto, torna-se importante a investigação do perfil religioso/espiritual do psiquiatra brasileiro e de seu comportamento e conduta clínica relacionada à $R / E$ de 
seus pacientes. As questões que devem ser averiguadas são: "Quais seriam as características religiosas/espirituais dos psiquiatras brasileiros?”; "Essas características poderiam influenciar na forma como esses profissionais percebem e lidam com as questões religiosas/espirituais de seus pacientes?”. Ainda: “Quais seriam os fatores que facilitariam ou dificultariam a abordagem da R/E na prática clínica?”.

Desse modo, a presente tese pretende analisar a hipótese de que as diferentes condutas dos psiquiatras brasileiros, relacionadas à $\mathrm{R} / \mathrm{E}$ na prática clínica, possam refletir as diferenças de suas próprias características e crenças religiosas/espirituais.

Para tanto, esta tese procurou responder a estas questões por meio de três abordagens investigativas. Abaixo apresentamos, inicialmente, uma seção metodológica comum aos três estudos (Capítulo 2); na sequência, um capítulo para cada estudo com descrições específicas dos participantes, das análises estatísticas utilizadas e dos resultados de cada um dos estudos separadamente (Capítulos 3, 4 e 5). As discussões dos resultados dos três trabalhos são realizadas em um único capítulo (Capítulo 6), pois tratam do mesmo tema. Para finalizar, apresentamos as considerações e conclusões finais (Capítulo 7).

\subsection{OBJETIVO GERAL}

O objetivo geral deste estudo foi levantar as características religiosas/espirituais dos psiquiatras brasileiros e verificar se elas estavam associadas a suas opiniões e comportamentos referentes à $\mathrm{R} / \mathrm{E}$ na prática clínica. 


\section{MÉTODOS COMUNS AOS TRÊS ESTUDOS}

\subsection{DESENHO DO ESTUDO}

A abordagem investigativa utilizada nesta tese é de um estudo observacional, descritivo, do tipo transversal e de abordagem quantitativa. Entretanto, não se deteve em uma abordagem metodológica apenas quantificativa, objetiva e estática, uma vez que buscou alicerçar o debate da temática com referenciais teóricos atuais, de metodologia tanto quantitativa como qualitativa.

\subsection{INSTRUMENTO}

Os dados coletados neste estudo foram obtidos por meio de um questionário (Anexo 1) baseado no instrumento "Religion and Spirituality in Medicine: Physicians' Perpectives", elaborado por Curlin et al. ${ }^{147}$ para investigar as interpretações e observações de médicos de várias especialidades sobre a influência da R/E na saúde de seus pacientes, assim como suas atitudes e comportamentos relacionados à $\mathrm{R} / \mathrm{E}$ na prática clínica. Esse questionário vem sendo utilizado também por outros grupos de pesquisa em diferentes partes do mundo ${ }^{112,148,149}$.

$\mathrm{O}$ instrumento foi adaptado para os fins desta pesquisa. Foi traduzido para o português pela autora e pelo Prof. Mário Fernandes Pietro Peres, testado em um estudo piloto realizado em duas etapas: na primeira, o questionário foi aplicado em 30 profissionais de saúde de várias especialidades, membros e participantes do Programa de Saúde, Espiritualidade e Religiosidade (ProSER), do Instituto de Psiquiatria do Hospital das Clínicas da Faculdade de Medicina da Universidade de São Paulo (IPqHC-FMUSP) e, na segunda, em 20 residentes do programa de psiquiatria do IPq-HCFMUSP. Os participantes consideraram as questões claras e objetivas nas duas etapas e não houve necessidade de adaptação adicional depois da testagem.

O questionário continha 35 questões que consistiam em medidas de autorrelatos e que acessavam três principais áreas: 


\section{a) Características sociodemográficas e profissionais}

Foram levantados dados relativos a: idade, gênero, estado civil, região, grau de instrução (incluindo pós-graduação "stricto sensu”); subárea de atuação na psiquiatria (adulto, infantil, geriátrica, forense e outras) e tempo de experiência profissional.

\section{b) Características religiosas/espirituais dos participantes}

Os psiquiatras foram avaliados quanto às suas crenças em um Deus ou Poder Superior, vida após a morte e reencarnação. Para estas questões, havia três alternativas de respostas: "sim", "não" e "não sei". Estas crenças foram escolhidas pelos pesquisadores em função do forte sincretismo que caracteriza a religiosidade brasileira e da vasta influência de ideias cristãs e espiritualistas presentes no contexto sociocultural $^{145}$.

Ainda com relação às crenças espirituais/religiosas, os participantes também foram questionados quanto à afiliação religiosa. As respostas para esta questão foram distribuídas em cinco categorias: Católica; Espírita (que incluiu as alternativas Espírita Kardecista e Espíritas Afro-brasileiras, como Umbanda, Candomblé e Quimbanda); Protestante ou Evangélica; outras religiões (em que foram incluídas as religiões Judaica, Islâmica, Hinduísta, Budista, Mórmon e outras) e nenhuma (que incluiu a agnóstica e a ateísta). As alternativas de respostas para a afiliação religiosa foram apresentadas, de acordo com o contexto brasileiro, em que os católicos, evangélicos e espíritas constituem a maioria dos religiosos ${ }^{145}$.

O questionário também continha questões relacionadas à frequência a templos religiosos, frequências de práticas religiosas/espirituais, como orar, realizar leituras de cunho religioso/espiritual e práticas espirituais não religiosas, como meditação e ioga. Para todas estas questões, as alternativas de resposta foram: "nunca", "uma ou mais vezes ao ano", "uma ou mais vezes ao mês", "uma ou mais vezes na semana" e "diariamente".

As medidas referentes à $\mathrm{R} / \mathrm{E}$ foram obtidas por meio de duas questões que avaliaram em que grau o participante considerava-se espiritualizado ou religioso. As questões "O quanto você se considera uma pessoa religiosa" e "O quanto você se considera uma pessoa espiritual?", ofereciam quatro alternativas de respostas: "nada", "pouco", "moderadamente" e "muito". Não foram definidos os termos religião e 
espiritualidade, permitindo, assim, que os participantes utilizassem suas próprias interpretações sobre os conceitos. Entretanto, as duas questões acima possibilitaram que os psiquiatras diferenciassem entre sua religiosidade e sua espiritualidade.

O estilo de enfrentamento, ou seja, a forma como o indivíduo reage diante de uma adversidade, foi medido por meio de duas questões extraídas da escala $\mathrm{RCOPE}^{150}$ : uma, que avaliou o enfrentamento religioso: "Eu procuro em Deus força, apoio e orientação", e outra, que avaliou o enfrentamento individual ou não religioso: "Eu tento compreender a situação e decidir o que fazer sem a ajuda de Deus". As alternativas de respostas para estas questões foram: "frequentemente", "ocasionalmente", "raramente" e "nunca".

A religiosidade intrínseca foi medida por meio de alternativas que abrangeram desde a plena concordância até a plena discordância das afirmações: "Eu me esforço muito para viver minhas crenças religiosas/espirituais em todos os aspectos de minha vida. Toda minha maneira de viver é baseada em minhas crenças religiosas/espirituais". Curlin et al. ${ }^{147}$ extraíram estas questões da escala "Hoge's Intrinsic Religious Motivation Scale"151, que é largamente utilizada para esses fins.

c) Opiniões e comportamentos relacionados à $R / E$ e sua abordagem na prática clínica e na formação do profissional

Os psiquiatras foram questionados com relação às seguintes questões: se suas próprias crenças influenciavam sua prática clínica; se entendiam a medicina como um chamado/missão; se a experiência como médicos fazia com que questionassem as próprias crenças e se consideravam um desafio manterem-se fieis às próprias crenças no trabalho como médicos. Para todas estas questões, as alternativas de respostas foram: "muito", "moderadamente", "pouco" e "nada".

Os participantes também responderam se consideravam importante integrar a R/E na prática clínica, na formação do médico e na formação continuada do psiquiatra. As alternativas de respostas foram quatro: "muito", "razoavelmente", "pouco" e "nada importante".

O questionário também levantou as opiniões dos psiquiatras relacionadas à influência da R/E na saúde de seus pacientes: o quanto a R/E poderia afetar as decisões dos pacientes quanto ao tratamento indicado e se a R/E poderia afetar o bem-estar e a 
evolução clínica de seu paciente. As alternativas das respostas foram: "frequentemente", "ocasionalmente", "raramente" e "nunca".

Com relação à abordagem da $\mathrm{R} / \mathrm{E}$ na prática clínica, os participantes foram questionados quanto à frequência com que colhiam uma história religiosa/espiritual de seus pacientes e se consideravam que avaliar a $\mathrm{R} / \mathrm{E}$ do paciente seria algo que o médico deveria ou poderia fazer. As quatro respostas para estas questões também variaram entre: "frequentemente", “ocasionalmente", "raramente" e "nunca".

Para identificar as barreiras e dificuldades encontradas pelos participantes na abordagem dos temas $\mathrm{R} / \mathrm{E}$ na prática clínica, eles foram convidados a responder uma questão de múltipla escolha com as seguintes alternativas: 1) nenhuma; 2) medo de extrapolar o papel do médico; 3) falta de treino; 4) falta de tempo; 5) não se sentir confortável com o tema; 6) o aspecto religioso/espiritual não é relevante para o paciente; 7) medo de ofender o paciente; 8) receio que os colegas não aprovem; 9) não é papel do médico; 10) não saber o porquê ou as razões.

\subsection{Considerações éticas}

Este estudo foi aprovado pela Comissão de Ética para Análise de Projetos de Pesquisa (CAPPesq) do Hospital das Clínicas da Faculdade de Medicina de São Paulo, Parecer número CAAE: 12513113.7.0000.0068 (Anexo 2). Foram garantidos os direitos fundamentais dos participantes como: privacidade, recusa e desistência. Além de esclarecimentos quanto aos objetivos do estudo, os participantes receberam informações referentes ao caráter confidencial e voluntário de sua participação. Para que os psiquiatras pudessem ter acesso ao conteúdo do questionário, era necessário que assinalassem um item específico manifestando seu consentimento livre e esclarecido para a participação na pesquisa. 


\section{ESTUDO I}

\subsection{OBJETIVOS}

\subsubsection{Objetivo geral}

Verificar se as características religiosas/espirituais dos psiquiatras brasileiros estão relacionadas às suas atitudes e comportamentos referentes à abordagem da R/E na prática clínica.

\subsubsection{Objetivos específicos}

- Levantar o perfil religioso/espiritual dos psiquiatras brasileiros.

- Investigar se as características gerais dos psiquiatras (sociodemográficas, religiosas/espirituais e opiniões e comportamentos relacionados à $\mathrm{R} / \mathrm{E}$ na prática clínica), estão associadas a ter ou não uma afiliação religiosa e também com investigar ou não os aspectos religiosos de seus pacientes.

- Explorar quais são as barreiras e dificuldades encontradas pelos psiquiatras na abordagem da $\mathrm{R} / \mathrm{E}$ na prática clínica e verificar se elas se relacionam com suas características religiosas/espirituais e, também, com suas atitudes e comportamentos referentes à $\mathrm{R} / \mathrm{E}$ na prática médica.

\subsection{MATERIAL E MÉTODOS}

\subsubsection{Amostra e procedimentos}

A amostra foi composta por psiquiatras brasileiros de ambos os sexos, residentes em todo o território nacional e pertencentes à Associação Brasileira de Psiquiatria $(\mathrm{ABP})$. 


\subsubsection{Seleção}

A amostra foi selecionada, em um primeiro momento, por meio do indicador profissional da $\mathrm{ABP}^{152}$, edição 2012 (última disponível para consulta no momento do estudo), que relacionava 5.379 psiquiatras associados. Do total de profissionais listados no guia, 3.018 disponibilizaram também seus endereços eletrônicos ("e-mails"). Outros 102 correios eletrônicos foram obtidos por meio de listagem de "e-mails" ("mailings"), adquiridos em sítios (“sites”) especializados da internet.

\subsubsection{Coleta de dados}

A todos os "e-mails" selecionados, foram enviadas mensagens contendo esclarecimentos a respeito do estudo e o convite para que os profissionais participassem da pesquisa respondendo, via internet ("on-line"), a um breve questionário confidencial (Anexo 1). O questionário foi armazenado em nuvem - "cloud computing", no sítio eletrônico do provedor de serviços "Google Docs", para onde as respostas foram encaminhadas.

Para o envio dos "e-mails", foi utilizado o "software" SendBlaster"153, próprio para essa finalidade. Os "e-mails" foram divididos em lotes de cem a 300 endereços, variando de acordo com o fluxo de dados da internet (variação dos índices de recebimento, retorno/devolução e reencaminhamento automático) e demandavam cerca de cinco dias para serem encaminhados.

Os formulários de respostas eram contabilizados somente se procedentes da lista de profissionais previamente selecionados; caso contrário, eram descartados.

Para otimizar a taxa de retorno, as mensagens foram reencaminhadas 10 vezes, salientando a proximidade do término da coleta de dados e a importância da participação do psiquiatra.

À medida que as respostas eram recebidas e contabilizadas, os "e-mails" correspondentes eram excluídos da lista de endereços que seriam reencaminhados.

A coleta de dados foi realizada no período entre 12 de setembro de 2013 até 06 de fevereiro de 2014. 


\subsubsection{Instrumento}

O instrumento utilizado para a coleta de dados está descrito acima nas páginas $20-23$.

\subsubsection{Variáveis}

Neste estudo, as variáveis utilizadas foram:

a) Sociodemográficas e profissionais (pág. 21):

- Idade, gênero, estado civil, área de atuação na psiquiatria e tempo de experiência profissional.

b) Características religiosas/espirituais (págs. 21-22):

- Crença em Deus;

- Afiliação religiosa que, para análises posteriores, foi transformada em variável binária: com religião e sem religião;

- Religiosidade e espiritualidade.

c) Opiniões e comportamentos relacionados à abordagem da $R / E$ na prática clínica e na formação do profissional:

- Importância da integração da $\mathrm{R} / \mathrm{E}$ na prática clínica e a inclusão da $\mathrm{R} / \mathrm{E}$ na formação do médico; para algumas análises estas variáveis foram categorizadas em "sim", que incluiu as respostas "muito importante" e "razoavelmente importante"; e "não", que somou as alternativas "pouco importante" e "nada importante" (pág. 22);

- Frequência da abordagem da $\mathrm{R} / \mathrm{E}$ do paciente que, posteriormente, foi transformada em variável binária e agrupou as alternativas, de forma que o sim correspondeu à alternativa "frequentemente", e o "não" às respostas “ocasionalmente", "raramente” e "nunca” (pág. 23);

- Barreiras e dificuldades na abordagem dos temas R/E (pág. 23). 


\subsubsection{Análises estatísticas}

O "software" utilizado para a análise dos dados foi o Stata $12.1^{154}$.

Os dados das variáveis contínuas foram expressos em média e desvio padrão.

Foram utilizados modelos de regressão logística para se estimar a associação entre as características gerais dos psiquiatras e ter ou não afiliação religiosa e também com o abordar ou não o tema R/E na prática clínica.

Todos os modelos foram ajustados para idade, gênero e estado civil, sendo apresentados como razão de chances com intervalo de confiança de $95 \%$.

\subsection{RESULTADOS}

Dos 3.120 "e-mails" enviados, 1.779 acusaram recebimento e 1.341 retornaram por motivos diversos, tais como: caixa postal com capacidade excedida, endereço de "email" desatualizado e outras razões técnicas, como pedido de reencaminhamento em data diversa e identificação da mensagem como "spam".

Dos 1.779 psiquiatras que receberam o convite para participar do estudo, 492 responderam ao questionário, equivalendo a uma taxa de resposta de $28 \%$.

Dos 492 questionários respondidos, oito foram eliminados: cinco por não procederem da listagem de "e-mails" selecionados, um por ter sido enviado duas vezes e dois por estarem incompletos. Foram analisados 484 formulários de respostas.

a) Características sociodemográficas, religiosas/espirituais e profissionais dos psiquiatras brasileiros

Um total de 484 psiquiatras residentes em todo o território nacional participaram da pesquisa; destes, $326(67,4 \%)$ declararam afiliação religiosa e $345(71,4 \%)$ disseram que acreditavam em Deus (Tabela 1). Dos 158 que não tinham religião, 45 (28,5\%) afirmaram que acreditavam em Deus. A média de idade dos respondedores foi 48,9 anos $(\mathrm{DP}=11.8)$.

A maioria declarou-se casada ou em união estável e distribuiu-se igualmente entre os que tinham $(70,3 \%)$ ou não tinham $(70,1 \%)$ afiliação religiosa (Tabela 2). 
Tabela 1 Características religiosas/espirituais dos psiquiatras da ABP e suas atitudes e comportamentos autorrelatados com relação à religiosidade e à espiritualidade na prática clínica $(n=484)$

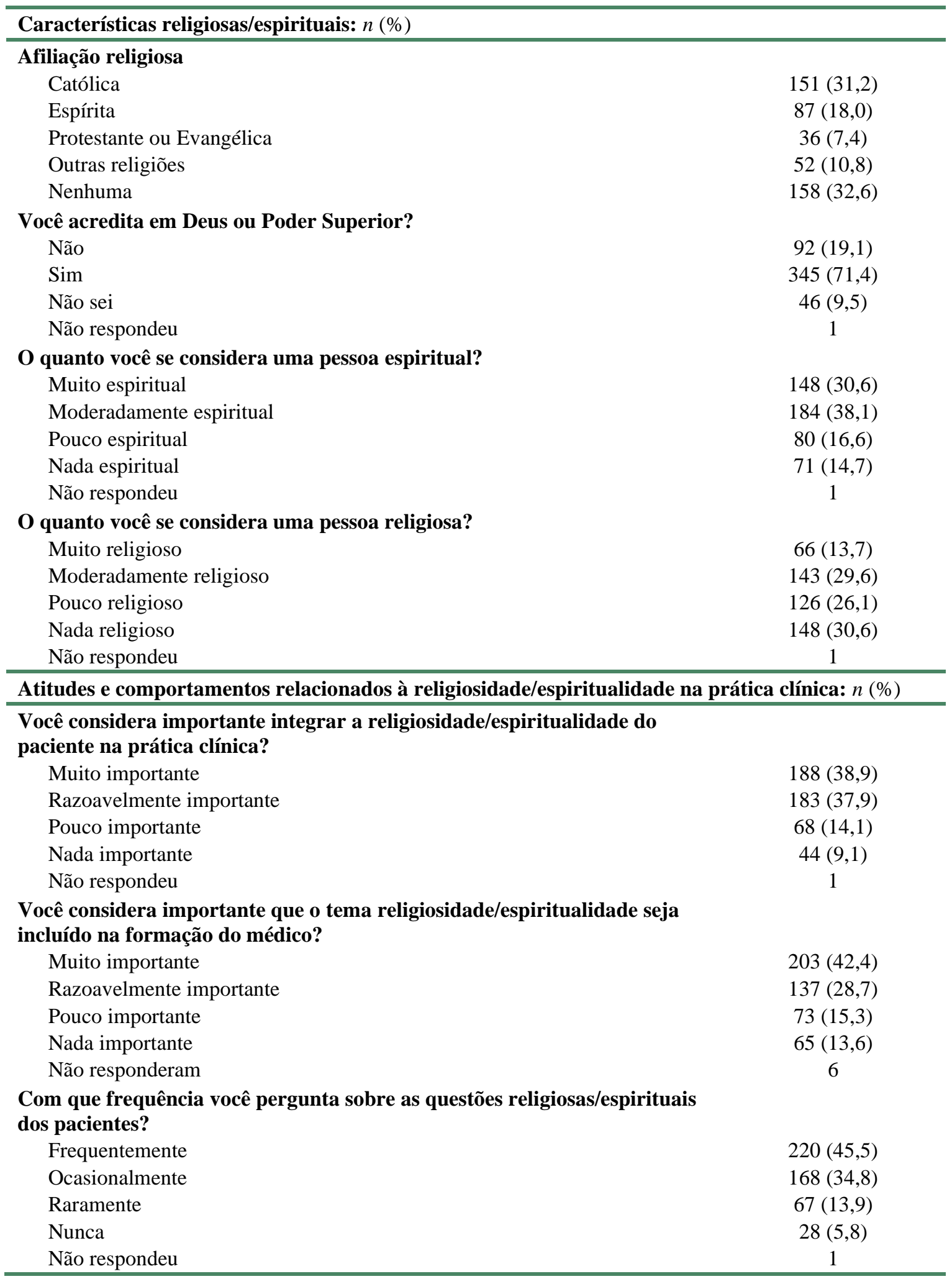


No que diz respeito à subespecialidade médica, a maior parte dos participantes $(89,7 \%)$ atuava no atendimento de adultos e não apresentou diferença quanto a possuir ou não afiliação religiosa; apenas aqueles que trabalhavam na área da psiquiatria forense mostraram-se mais propensos a declarar alguma religião ( $\mathrm{OR}=1,86,95 \%$ CI 1,02-3,39). Os psiquiatras tinham em média 21,3 (DP=11,7) anos de carreira, e quanto maior o tempo de atuação na psiquiatra maior era a tendência do psiquiatra em não declarar afiliação religiosa $(\mathrm{OR}=0,39,95 \%$ CI 0,18-0,83) (Tabela 2).

Tabela 2. Características sociodemográficas e profissionais dos psiquiatras da ABP distribuídas de acordo com ter ou não ter afiliação religiosa

\begin{tabular}{|c|c|c|c|c|}
\hline \multirow[b]{2}{*}{$\begin{array}{l}\text { Características } \\
\text { sociodemográficas e profissionais }\end{array}$} & \multicolumn{4}{|c|}{ Afiliação religiosa } \\
\hline & $\begin{array}{c}\text { Total } \\
n=484(\%)\end{array}$ & $\begin{array}{c}\text { Sem } \\
\text { afiliação } \\
n=158(\%)\end{array}$ & $\begin{array}{c}\text { Com } \\
\text { afiliação } \\
n=326(\%)\end{array}$ & $\begin{array}{l}\mathbf{A d j}, \mathbf{O R}^{a} \\
{[95 \% \mathrm{CI}]}\end{array}$ \\
\hline \multicolumn{5}{|l|}{ Idade em anos } \\
\hline $25-39$ & $143(29,5)$ & $50(31,7)$ & $93(28,5)$ & 1,00 \\
\hline $40-59$ & $236(48,8)$ & $76(48,1)$ & $160(49,1)$ & $1,10[0,71-1,73]$ \\
\hline $60+$ & $105(21,7)$ & $32(20,2)$ & $73(22,4)$ & $1,36[0,78-2,36]$ \\
\hline \multicolumn{5}{|l|}{ Gênero } \\
\hline Masculino & $284(58,7)$ & $105(66,5)$ & $179(54,9)$ & 1,00 \\
\hline Feminino & $200(41,3)$ & $53(33,5)$ & $147(45,1)$ & $1,65[1,09-2,50]^{*}$ \\
\hline \multicolumn{5}{|l|}{ Estado civil } \\
\hline Sem parceiro & $139(29,1)$ & $43(27,9)$ & $96(29,7)$ & 1,00 \\
\hline Com parceiro & $338(70,9)$ & $111(70,1)$ & $227(70,3)$ & $0,97[0,63-1,51]$ \\
\hline \multicolumn{5}{|l|}{ Subespecialidade na psiquiatria $^{b}$} \\
\hline Adulto & $434(89,7)$ & $139(88,0)$ & $295(90,5)$ & $1,46[0,78-2,76]^{c}$ \\
\hline Infantil & $101(20,9)$ & $33(20,9)$ & $68(20,9)$ & $0,95[0,58-1,53]^{c}$ \\
\hline Geriátrica & $107(22,1)$ & $36(22,8)$ & $71(21,8)$ & $0,99[0,62-1,58]^{c}$ \\
\hline Forense & $72(14,9)$ & $18(11,4)$ & $54(16,6)$ & $1,86[1,02-3,39]^{* c}$ \\
\hline \multicolumn{5}{|l|}{ Tempo (em anos) como } \\
\hline $0-10$ & $123(25,8)$ & $42(27,1)$ & $81(25,2)$ & $0,52[0,27-0,97]^{*}$ \\
\hline $11-19$ & $232(48,6)$ & $78(50,3)$ & $154(47,8)$ & $0,39[0,18-0,83]^{*}$ \\
\hline $20+$ & & & & \\
\hline
\end{tabular}

\footnotetext{
${ }^{a}$ Ajustadas por idade, gênero e estado civil.

${ }^{b}$ Questão de múltipla escolha: os dados de cada categoria representam o total da amostra.

${ }^{c}$ As categorias de respostas são "sim" ou "não" e a categoria de referência é "não".

$* p<0,05$.
} 
Os dados da Tabela 3 mostram que 76,8\% dos entrevistados consideraram "muito" ou "razoavelmente importante" integrar a R/E do paciente na prática clínica e 71,1\%, "muito" ou "razoavelmente importante" inserir os temas R/E na educação do médico. Em ambos os casos, esses participantes mostraram que tinham quatro vezes mais chances $(\mathrm{OR}=4,33,95 \%$ CI 2,75-6,81 e OR=4,14, 95\% CI 2,69-6,36) em declarar afiliação religiosa comparados àqueles que consideraram pouco ou nada importante integrar a R/E na prática clínica ou inseri-la na formação do médico.

Tabela 3. Atitudes dos psiquiatras da $\mathrm{ABP}$ relacionadas à religiosidade e à espiritualidade na prática clínica (análise estatística das respostas de um total de 484 participantes)

\begin{tabular}{|c|c|c|c|c|}
\hline \multirow[b]{2}{*}{$\begin{array}{l}\text { Atitudes relacionadas à } \\
\text { religiosidade/espiritualidade na } \\
\text { prática clínica }\end{array}$} & \multicolumn{4}{|c|}{ Afiliação religiosa } \\
\hline & $\begin{array}{c}\text { Total } \\
n=484 \\
(\%)\end{array}$ & $\begin{array}{l}\begin{array}{c}\text { Sem } \\
\text { afiliação } \\
n=158 \\
(\%)\end{array}\end{array}$ & $\begin{array}{c}\begin{array}{c}\text { Com } \\
\text { afiliação } \\
n=326 \\
(\%)\end{array}\end{array}$ & $\begin{array}{l}\text { Adj. OR } \\
\\
{[95 \% \mathrm{CI}]}\end{array}$ \\
\hline $\begin{array}{l}\text { Você considera importante } \\
\text { integrar a religiosidade/ } \\
\text { espiritualidade do paciente na } \\
\text { prática clínica? }\end{array}$ & $371(76,8)^{b}$ & $91(57,6)$ & $280(86,1)$ & $4,33[2,75-6,81]^{* c}$ \\
\hline \multicolumn{5}{|l|}{$\begin{array}{l}\text { Barreiras para abordar a } \\
\text { religiosidade e a espiritualidade } \\
\text { do paciente }\end{array}$} \\
\hline Nenhuma & $195(40,3)$ & $81(51,3)$ & $114(35,0)$ & $0,47[0,32-0,70]^{* c}$ \\
\hline $\begin{array}{l}\text { Medo de exceder o papel do } \\
\text { médico }\end{array}$ & $146(30,2)$ & $27(17,1)$ & $119(36,5)$ & $2,82[1,75-4,54]^{* c}$ \\
\hline Falta de treino & $108(22,3)$ & $25(15,8)$ & $83(25,5)$ & $1,91[1,15-3,17]^{* c}$ \\
\hline Falta de tempo & $79(16,3)$ & $21(13,3)$ & $58(17,8)$ & $1,46[0,84-2,53]^{c}$ \\
\hline $\begin{array}{l}\text { Você considera importante que } \\
\text { o tema } \\
\text { religiosidade/espiritualidade } \\
\text { seja incluído na formação do } \\
\text { médico? }\end{array}$ & $340(71,1)^{b}$ & $80(51,3)$ & $260(80,7)$ & $4,14[2,69-6,36]^{* c}$ \\
\hline
\end{tabular}

${ }^{a}$ Ajustadas por idade, gênero e estado civil.

${ }^{b}$ Inclui as categorias "muito importante" e "razoavelmente importante".

${ }^{c}$ As categorias de respostas são "sim" ou "não" e a categoria de referência é "não".

$* p<0,05$.

Quanto às barreiras em investigar a $\mathrm{R} / \mathrm{E}$ do paciente na prática clínica, encontramos que 40,3\% dos participantes afirmaram que não tinham nenhuma dificuldade e esses psiquiatras eram menos propensos em declarar afiliação religiosa 
$(\mathrm{OR}=0,47,95 \%$ CI $0,32-0,70)$. As dificuldades mais apontadas foram: medo de extrapolar o papel do médico $(30,2 \%)$ e falta de treino $(22,3 \%)$, e elas foram declaradas pelos psiquiatras que se mostraram mais tendentes a relatar afiliação religiosa $(\mathrm{OR}=2,82,95 \%$ CI 1,75-4,54 e OR=1,91, 95\% CI 1,15-3,17) (Tabela 3). Na sequência, as barreiras mais relatadas foram: falta de tempo, não se sentir confortável com o tema, não é papel do médico, os aspectos religiosos/espirituais não são relevantes ao paciente, medo de ofender o paciente, receio que os colegas não aprovem e não saber o porquê ou as razões, conforme apresentado na Figura 1.

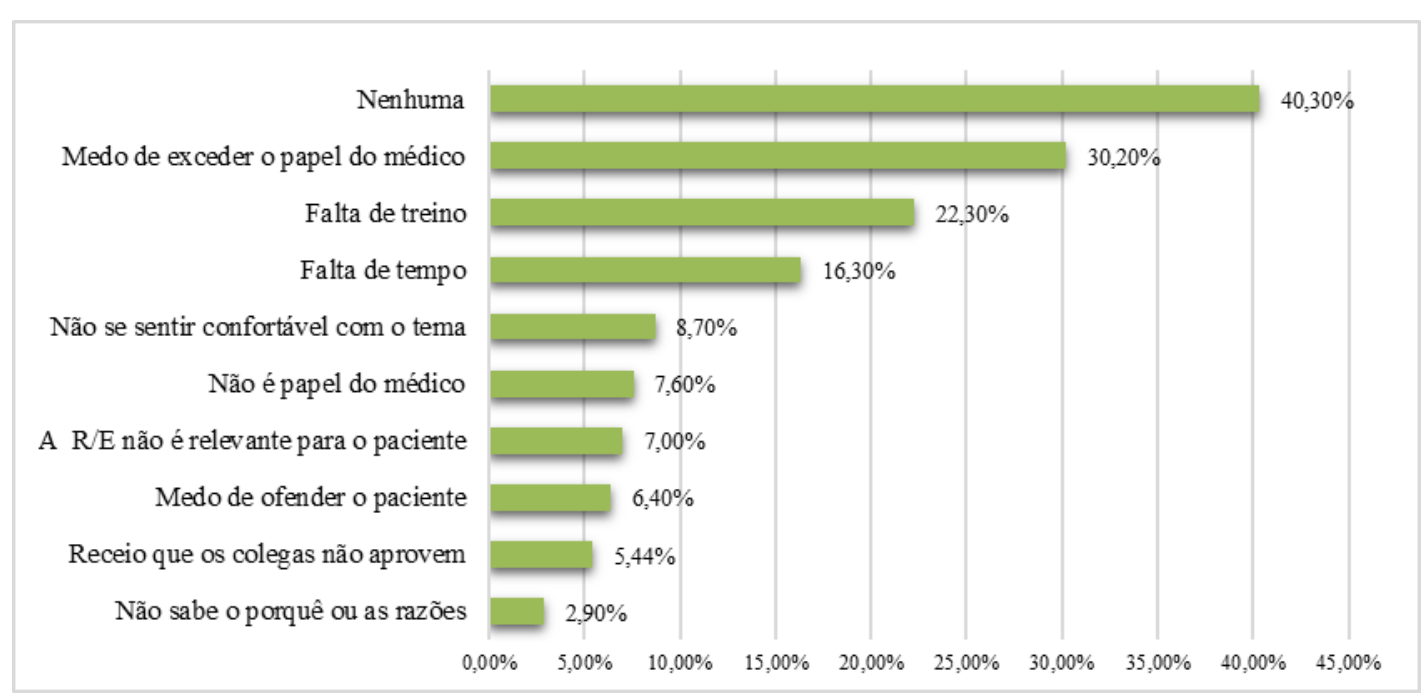

Figura 1. Barreiras e dificuldades encontradas pelos psiquiatras da $A B P$ na abordagem da religiosidade e da espiritualidade do paciente

b) Características religiosas/espirituais, atitudes e comportamentos dos psiquiatras relacionados à abordagem da $R / E$ na prática clínica

De um total de 484 psiquiatras entrevistados, 45,5\% disseram que perguntavam frequentemente sobre a religiosidade do paciente; o restante dividiu-se entre os que responderam "ocasionalmente" ou "raramente" $(48,7 \%)$, e "nunca" $(5,8 \%)$ (Tabela 1$)$.

As variáveis referentes às características sociodemográficas, assim como o tempo trabalhado na psiquiatria e a subespecialidade médica, não apresentaram associações com a abordagem da R/E na prática clínica.

No que diz respeito às medidas de R/E, encontramos que $68,7 \%$ dos entrevistados declararam-se "muito" ou "razoavelmente espirituais", mas, apenas 43,3\% 
consideraram-se "muito" ou "razoavelmente religiosos", quando responderam às questões que diferenciavam a religiosidade da espiritualidade. Um número ainda menor, $13,7 \%$ dos psiquiatras, disseram que se consideravam uma pessoa "muito religiosa" e, a grande maioria deles $(74,2 \%)$, disse que abordava "frequentemente" a R/E do paciente. Esses psiquiatras tinham quase cinco vezes mais chances $(\mathrm{OR}=4,58,95 \%$ CI $2,39-8,80)$ de colher uma história $\mathrm{R} / \mathrm{E}$ de seu paciente quando comparados àqueles que se consideravam nada religiosos. Os psiquiatras que se declararam "pouco espirituais" tinham menos tendência em abordar as questões religiosas/espirituais dos pacientes $(\mathrm{OR}=0,49,95 \%$ CI 0,24-0,97), quando comparados aos que se declararam "nada espirituais". Já os que se consideraram "muito espirituais" $(30,6 \%)$ eram os que tendiam a questionar mais a $\mathrm{R} / \mathrm{E}$ dos pacientes $(\mathrm{OR}=1,87,95 \%$ CI 1,05-3,35) (Tabelas $1,4 \mathrm{e}$ Figura 2).

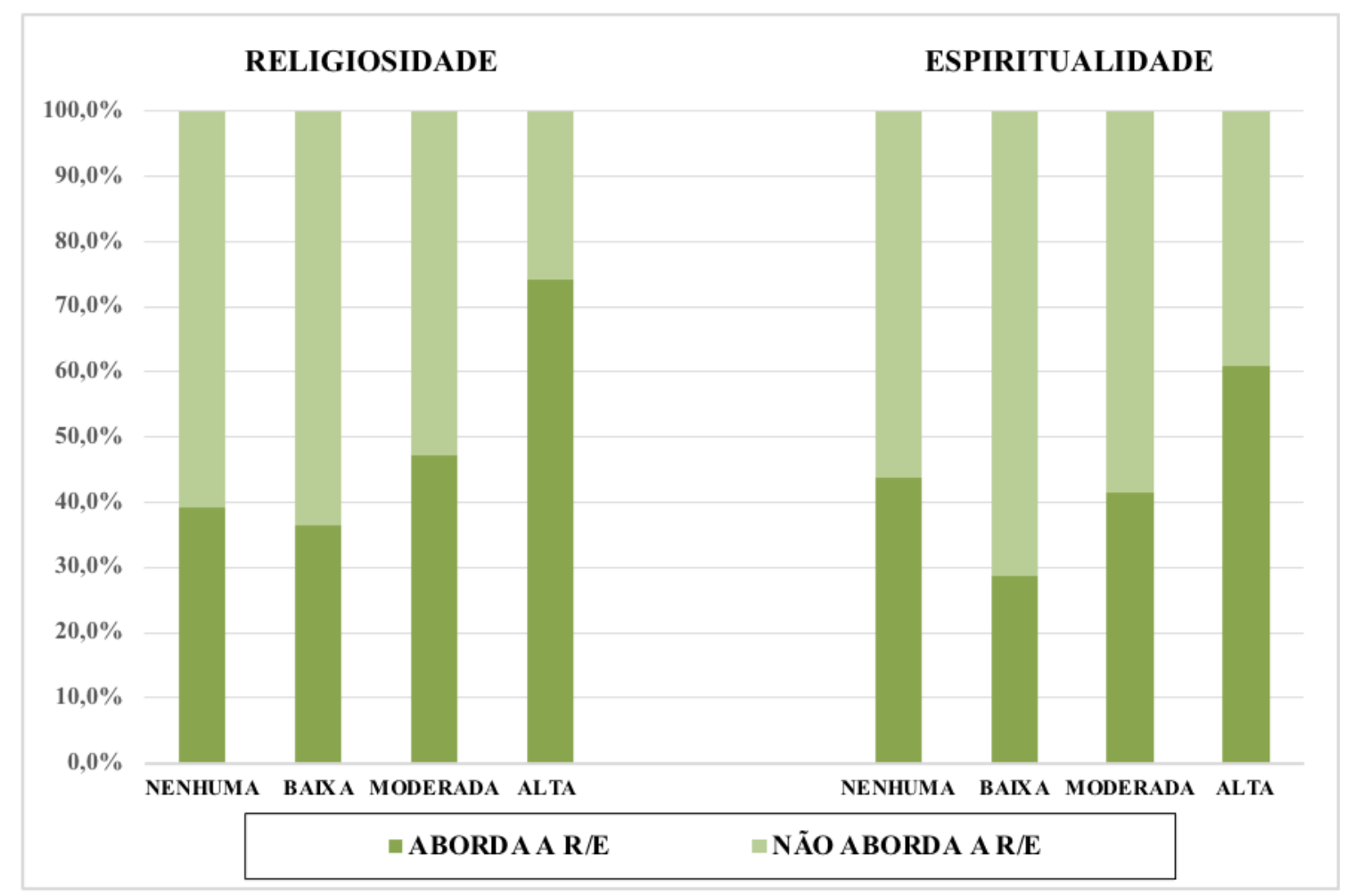

Figura 2. A Figura representa a frequência com que os psiquiatras da ABP perguntavam sobre a religiosidade/espiritualidade na sua prática clínica, relacionada com o quanto eles se consideravam religiosos e espirituais 
Os dados da Tabela 4 mostram que os psiquiatras que consideraram "muito" ou "razoavelmente importante" integrar a R/E na prática clínica $(\mathrm{OR}=2,17,95 \%$ IC 1,38$3,43)$ e na formação profissional ( $\mathrm{OR}=1,91,95 \%$ IC 1,26-2,90), assim como aqueles que relataram não ter nenhuma dificuldade na abordagem da $\mathrm{R} / \mathrm{E}$ no encontro clínico $(\mathrm{OR}=3,25,95 \%$ IC 2,21-4,77), tinham maior probabilidade (por volta de 2-3 vezes mais) em abordar a R/E de seus pacientes. Ao contrário daqueles que declararam receio em misturar o papel do médico, que demonstraram menor chance $(\mathrm{OR}=0,45,95 \%$ IC 0,30-0,67) de incluir a R/E na avaliação clínica de seus pacientes. 
Tabela 4. Associações entre algumas características dos psiquiatras da ABP e a abordagem da religiosidade e da espiritualidade na prática clínica

\begin{tabular}{|c|c|c|}
\hline & \multicolumn{2}{|c|}{$\begin{array}{l}\text { Abordar as questões espirituais e } \\
\text { religiosas dos pacientes }\end{array}$} \\
\hline & $\begin{array}{l}\text { Crude OR } \\
{[95 \% \mathrm{CI}]}\end{array}$ & $\begin{array}{l}\text { Adj. } \mathrm{OR}^{a} \\
{[95 \% \mathrm{CI}]}\end{array}$ \\
\hline \multicolumn{3}{|l|}{ Características religiosas/espirituais } \\
\hline \multicolumn{3}{|l|}{ O quanto você se considera uma pessoa religiosa? } \\
\hline Nada religiosa & 1,00 & 1,00 \\
\hline Pouco religiosa & $0,89[0,55-1,46]$ & $0,89[0,54-1,47]$ \\
\hline Moderadamente religiosa & $1,39[0,87-2,21]$ & $1,31[0,81-2,10]$ \\
\hline Muito religiosa & $4,47[2,35-8,51]^{*}$ & $4,58[2,39-8,80]^{*}$ \\
\hline \multicolumn{3}{|l|}{ O quanto você se considera uma pessoa espiritual? } \\
\hline Nada espiritual & 1,00 & 1,00 \\
\hline Pouco espiritual & $0,52[0,25-1,02]$ & $0,49[0,24-0,97]^{*}$ \\
\hline Moderadamente espiritual & $0,92[0,53-1,59]$ & $0,87[0,50-1,52]$ \\
\hline Muito espiritual & $2,00[1,13-3,55]^{*}$ & $1,87[1,05-3,35]^{*}$ \\
\hline Afiliação religiosa & $1,52[1,03-2,24]^{*}$ & $1,45[0,98-2,16]^{b}$ \\
\hline \multicolumn{3}{|c|}{ Atitudes relacionadas à religiosidade/espiritualidade na prática clínica } \\
\hline $\begin{array}{l}\text { Você considera importante integrar a religiosidade } \\
\text { e a espiritualidade do paciente na prática clínica? }\end{array}$ & $2,20[1,40-3,44]^{* c}$ & $2,17[1,38-3,43]^{* b}$ \\
\hline $\begin{array}{l}\text { Você considera importante que o tema } \\
\text { religiosidade/espiritualidade seja incluído na } \\
\text { formação do médico? }\end{array}$ & $1,86[1,24-2,81]^{* c}$ & $1,91[1,26-2,90]^{*} b$ \\
\hline \multicolumn{3}{|l|}{$\begin{array}{l}\text { Barreiras para abordar a religiosidade e a } \\
\text { espiritualidade do paciente. }\end{array}$} \\
\hline Nenhuma & $3,24[2,22-4,73]^{*}$ & $3,25[2,21-4,77] * b$ \\
\hline Medo de exceder o papel do médico & $0,45[0,30-0,68]^{*}$ & $0,45[0,30-0,67]^{*}$ \\
\hline Falta de treino & $0,94[0,61-1,45]$ & $0,96[0,62-1,49]^{b}$ \\
\hline Falta de tempo & $0,78[0,48-1,28]$ & $0,81[0,49-1,33]^{b}$ \\
\hline
\end{tabular}

${ }^{a}$ Ajustadas por idade, gênero e estado civil.

${ }^{b}$ As categorias de respostas são "sim" ou "não" e a categoria de referência é "não".

c Inclui as categorias "muito importante" e "razoavelmente importante".

${ }^{d}$ Questão de múltipla escolha: os dados de cada categoria representam o total da amostra.

$* p<0,05$. 


\subsection{OBJETIVOS}

\subsubsection{Objetivo geral}

Investigar se as características religiosas e espirituais dos psiquiatras que atuam em um dos principais centros de formação em psiquiatria do Brasil estão relacionadas com suas opiniões e comportamentos referentes à $\mathrm{R} / \mathrm{E}$ de seus pacientes na prática clínica.

\subsubsection{Objetivos específicos}

- Levantar as características religiosas/espirituais dos psiquiatras do IPq-HCFMUSP.

- Investigar se as características religiosas/espirituais desses psiquiatras influenciam na frequência com que abordam a R/E do paciente na prática clínica e se eles consideram que isso seja algo que o psiquiatra deva ou possa fazer.

- Verificar se a prática da medicina pode levar os psiquiatras entrevistados a questionarem suas próprias crenças religiosas/espirituais e a sentirem dificuldades em permanecer fiéis a elas.

- Analisar o impacto potencial do enfrentamento religioso/espiritual na prática clínica desses psiquiatras.

\subsection{MATERIAIS E MÉTODOS}

\subsubsection{Amostra e procedimentos}

A amostra foi composta por psiquiatras do corpo clínico do Instituto de Psiquiatria do Hospital das Clínicas da Faculdade de Medicina da Universidade de São 
Paulo. O IPq-HC-FMUSP é um dos principais centros de formação e treinamento de psiquiatras, assim como em atividades de pesquisas e inovação na área das neurociências. Seu programa de pós-graduação vem recebendo a nota máxima (sete) desde 2014 nas avalições criteriosas da Coordenação de Aperfeiçoamento de Pessoal de Nível Superior (CAPES).

\subsubsection{Seleção}

A seleção da amostra foi feita a partir de uma lista fornecida pelo departamento de recursos humanos do IPq-HC-FMUSP, que relacionava um total de 93 psiquiatras contratados e em atividade na instituição. Outros 28 psiquiatras, incluindo os docentes do Departamento de Psiquiatria da FMUSP (n=17) que tinham contrato de trabalho distinto dos médicos contratados pelo complexo do Hospital das Clínicas da FMUSP, e que não constavam da listagem, foram obtidos via internet. Ao final, selecionamos um total de 121 psiquiatras em exercício no IPq-HC-FMUSP.

\subsubsection{Coleta de dados}

Os psiquiatras foram abordados pessoalmente pela autora e convidados a participar da pesquisa. Além de receberem informações a respeito do estudo, foram instruídos a responder a um breve questionário, autoaplicável e confidencial, que foi entregue impresso a cada um dos profissionais. Os participantes não eram identificados nos formulários de resposta; para garantir o anonimato, os questionários foram recolhidos dentro de envelopes fornecidos previamente, depois armazenados conjuntamente.

A coleta de dados foi realizada em um período de seis meses, entre dezembro de 2013 e maio de 2014.

\subsubsection{Instrumento}

Neste estudo, o questionário utilizado foi descrito anteriormente nesta tese, nas páginas 20-23. 


\subsubsection{Variáveis}

As variáveis utilizadas neste estudo foram semelhantes àquelas descritas no estudo 1, sendo elas:

a) Sociodemográficas e profissionais (pag. 21):

- Idade, gênero, estado civil, grau de instrução (cursos de pós-graduação senso lato e senso estrito), área de atuação na psiquiatria e tempo de experiência profissional.

b) Características religiosas/espirituais (21-22):

- Crenças em: Deus ou Poder Superior, vida após a morte e reencarnação;

- Afiliação religiosa;

- Religiosidade, espiritualidade;

- Estilos de enfrentamentos religioso/espiritual.

c) Opiniões e comportamentos relacionados à $R / E$ e sua abordagem na prática clínica e na formação do profissional (22-23):

- Considerar que as próprias crenças influenciam na prática clínica; perceber a medicina como um chamado/missão;

- Acreditar que a prática médica leva o profissional a questionar suas próprias crenças;

- Julgar um desafio manter-se fiel às próprias crenças no trabalho como médico;

- Entender que avaliar a R/E do paciente é algo que o médico deve ou pode fazer;

- Frequência da abordagem da R/E do paciente; e

- Barreiras e as dificuldades encontradas na abordagem da R/E do paciente. 


\subsubsection{Análises estatísticas}

O "software" utilizado para a análise dos dados foi o SPSS (versão 17.0) ${ }^{155}$.

Análises descritivas foram utilizadas para mostrar as tendências de medidas centrais dos dados obtidos.

O teste exato de Fisher foi usado para estimar associações entre variáveis categóricas.

Os testes t e ANOVA foram empregados para avaliar as diferenças de médias entre os grupos.

Coeficientes de correlação momento-produto de Pearson foram obtidos para investigar as correlações entre variáveis.

A análise de regressão múltipla "stepwise" foi realizada para identificar quais das dificuldades enfrentadas pelos psiquiatras na abordagem da $\mathrm{R} / \mathrm{E}$ na prática clínica foram mais importantes na decisão de indagar (ou não indagar) sobre a R/E de seus pacientes.

Para todos os testes realizados, foi considerado o nível de significância estatística como sendo menor que $5 \%$ ou 0,05 .

\subsection{RESULTADOS}

Dos 121 psiquiatras selecionados para participar da pesquisa, 86 responderam ao questionário, equivalendo a uma taxa de resposta de $71 \%$. Dois formulários de respostas foram eliminados por estarem incompletos, restando, portanto, 84 questionários que foram analisados.

\section{a) Características sociodemográficas e profissionais}

Nos dados da Tabela 5, apresentamos um resumo das características sociodemográficas e profissionais dos psiquiatras associadas com as medidas de R/E. No que diz respeito à faixa etária e experiência profissional, a média de idade dos psiquiatras era 45,6 $\pm 9,8$ anos e o tempo médio trabalhado na psiquiatria foi $19,8 \pm 10,1$ anos. Com relação ao nível de instrução, 67,8\% dos participantes eram pós-graduados (mestres ou doutores), e a maior parte possuía o título de doutor. Observamos também 
que predominava o sexo masculino entre os entrevistados (relação de 3:2) e mais de dois terços eram casados ou estavam em uma relação estável. Sobre as áreas de atuação na psiquiatria, a grande maioria trabalhava no atendimento de adultos. Pode-se também observar na Tabela 5 que nenhuma das variáveis sociodemográficas apresentou associação estatisticamente significante $(\mathrm{p}<0,05)$ quando relacionadas com as medidas de R/E. Nota-se, ainda, que os participantes que trabalhavam com psiquiatria infantil apresentaram índices mais altos de espiritualidade.

Tabela 5. Características sociodemográficas e profissionais dos psiquiatras do IPqHC-FMUSP relacionadas com a religiosidade e a espiritualidade

\begin{tabular}{|c|c|c|c|c|c|c|c|}
\hline & & \multicolumn{2}{|c|}{ Religiosidade } & \multirow[b]{2}{*}{$P$} & \multicolumn{2}{|c|}{ Espiritualidade } & \multirow[b]{2}{*}{$P$} \\
\hline & & $\begin{array}{l}\text { Média } \\
\text { (DP) }\end{array}$ & $r$ & & $\begin{array}{l}\text { Média } \\
\text { (DP) }\end{array}$ & $r$ & \\
\hline $\begin{array}{l}\text { Idade em anos, } \\
\text { média (DP) }\end{array}$ & $45,6(9,8)$ & - & 0,03 & 0,744 & - & 0,07 & 0,455 \\
\hline Gênero & & & & 0,373 & & & 0,962 \\
\hline Feminino & $32(38,1)$ & $1,84(0,95)$ & & & $2,43(0,94)$ & & \\
\hline Masculino & $52(61,9)$ & $2,03(0,94)$ & & & $2,42(0,91)$ & & \\
\hline Estado civil & & & & 0,459 & & & 0,323 \\
\hline Sem parceiro & $24(28,6)$ & $2,08(0,88)$ & & & $2,58(0,88)$ & & \\
\hline Com parceiro & $60(71,4)$ & $1,91(0,97)$ & & & $2,36(0,93)$ & & \\
\hline Subespecialidades & & & & 0,247 & & & 0,508 \\
\hline Adulto & $70(83,3)$ & $1,88(0,90)$ & & & $2,37(0,93)$ & & \\
\hline Infantil & $18(21,4)$ & $2,33(0,97)$ & & & $2,77(0,73)$ & & \\
\hline Geriatria & $13(15,5)$ & $1,92(1,18)$ & & & $2,30(1,10)$ & & \\
\hline Forense & $11(13,1)$ & $2,45(1,28)$ & & & $2,54(0,68)$ & & \\
\hline Outros & $8(9,5)$ & $2,12(0,99)$ & & & $2,37(0,91)$ & & \\
\hline $\begin{array}{l}\text { Anos na psiquiatra, } \\
\text { média (DP) }\end{array}$ & $19,8(10,1)$ & - & $-0,02$ & 0,828 & - & $-0,09$ & 0,326 \\
\hline Nível de instrução & & & & 0,446 & & & 0,433 \\
\hline Residência & $12(14,3)$ & $1,75(1,05)$ & & & $2,16(1,11)$ & & \\
\hline Especialização & $15(17,9)$ & $1,66(0,89)$ & & & $2,20(0,86)$ & & \\
\hline Mestrado & $13(15,5)$ & $2,23(0,72)$ & & & $2,76(0,82)$ & & \\
\hline Doutorado & $32(38,1)$ & $2,00(0,98)$ & & & $2,50(0,91)$ & & \\
\hline Pós-doutorado & $12(14,3)$ & $2,16(1,02)$ & & & $2,41(0,90)$ & & \\
\hline
\end{tabular}

$r=$ coeficiente de correlação de Pearson

$\mathrm{DP}=$ desvio padrão 


\section{b) Crenças religiosas e espirituais dos psiquiatras}

Os participantes deste estudo declararam-se mais espirituais $(\mathrm{M}=2,43 ; \mathrm{DP}=0,92)$ que religiosos $(\mathrm{M}=1,96, \mathrm{DP}=0,95)$. Com relação ao quanto os psiquiatras consideraramse espirituais, 9,5\% responderam "muito espiritual", 44\% "moderadamente espiritual", $26,2 \%$ "pouco espiritual" e 20,2\% "nada espiritual". No que diz respeito ao quanto se consideravam religiosos, apenas 6\% assinalaram "muito religioso", 25\% “moderadamente religioso", 28,6\% "pouco religioso" e 40,5\% "nada religioso", ou seja, a maioria $(53,5 \%)$ se declarou "muito" ou "razoavelmente espiritual", mas apenas $31 \%$ mostraram-se "muito" ou "razoavelmente" religiosos.

Na Tabela 6 estão os resultados de algumas características religiosas e espirituais dos psiquiatras, incluindo as formas de enfrentamento religioso utilizadas por eles em situações de estresse. Os dados mostraram que quase dois terços da amostra $(57,7 \%)$ relataram algum tipo de afiliação religiosa, e a maioria era da religião católica, seguida da protestante ou evangélica, depois da espírita e a menor parte declarou outras religiões. Mais de um terço da amostra indicou a categoria "nenhuma", que incluiu os ateus e agnósticos.

Mais da metade dos psiquiatras declarou que acreditava em Deus, mais de um quarto mostrou-se indeciso e apenas 16,7\% disseram que não acreditavam. Quando questionados sobre a existência de vida após a morte, menos de um terço respondeu que sim; o restante disse que não acreditava ou não sabia. Menos de um quinto da amostra indicou crença em reencarnação, 80,9\% responderam que não acreditavam ou que não sabiam (Tabela 6). 
Tabela 6. Características religiosas/espirituais dos psiquiatras do IPq-HC-FMUSP

\begin{tabular}{lc}
\hline & $\boldsymbol{n}(\boldsymbol{\%})$ \\
\hline Afiliação religiosa & \\
Católica & $28(33,7)$ \\
Protestante ou Evangélica & $8(9,6)$ \\
Espírita & $5(6,0)$ \\
Outras religiões & $7(8,4)$ \\
Nenhuma & $35(42,8)$ \\
Não respondeu & 1 \\
Você acredita em Deus ou em um Poder Superior? & \\
Sim & $50(59,5)$ \\
Não & $20(23,8)$ \\
Não sei & $14(16,7)$ \\
Você acredita em vida após a morte? & \\
Sim & $24(28,6)$ \\
Não & $40(47,6)$ \\
Não sei & $20(23,8)$ \\
Você acredita em reencarnação? & \\
Sim & $16(19,0)$ \\
Não & $58(69,0)$ \\
Não sei & $10(11,9)$ \\
Eu tento compreender a situação e decidir o que fazer sem a ajuda de Deus. & \\
Frequentemente & $39(48,1)$ \\
Ocasionalmente & $22(27,2)$ \\
Raramente & $9(11,1)$ \\
Nunca & $11(13,6)$ \\
Não respondeu & 3 \\
Procuro em Deus força, apoio e orientação. & \\
Frequentemente & $18(21,9)$ \\
Ocasionalmente & $15(18,3)$ \\
Raramente & $16(19,5)$ \\
Nunca & $33(40,2)$ \\
Não respondeu & 2 \\
\hline & \\
\hline
\end{tabular}

No que diz respeito aos estilos de enfrentamento, 40,2\% dos psiquiatras declararam que procuravam Deus como fonte de força, suporte e guia "frequentemente" ou "ocasionalmente", enquanto 75,3\% disseram que decidiam o que fazer sem a ajuda de Deus "frequentemente" ou "ocasionalmente", ou seja, eles recorriam com maior frequência ao enfrentamento não religioso $(M=3,09 ; \quad D P=1,06)$ e menos ao enfrentamento religioso $(\mathrm{M}=2,21 ; \mathrm{DP}=1,19)$, conforme apresentado na Tabela 6. Como poderíamos esperar, o enfrentamento não religioso foi significativamente mais frequente 
entre os psiquiatras não-religiosos $(\mathrm{M}=3,34 ; \mathrm{DP}=1,16)$, quando comparados com os participantes religiosos $(M=2,89 ; \mathrm{DP}=0,96) ; t(78)=1,92 ; \mathrm{p}=0,049$.

c) Atitudes e comportamentos relacionados à abordagem da R/E na prática clínica

Os dados da Tabela 7 mostram algumas atitudes e comportamentos dos participantes relacionados à R/E em sua prática médica. Verificou-se que 64,6\% dos psiquiatras disseram que suas experiências como médicos fizeram questionar suas próprias crenças pelo menos um pouco e, menos da metade (40,2\%), considerou um desafio permanecer fiel à sua religião em seu trabalho como médico. Como pode ser visto nos dados da Tabela 8, questionar a fé mostrou uma correlação moderada com diferentes características religiosas/espirituais (crer em Deus, em vida após a morte, em reencarnação, considerar-se religioso ou espiritual e recorrer ao enfrentamento religioso), indicando que, quanto mais crentes os psiquiatras eram, mais a experiência como médico os levava a questionar suas crenças religiosas/espirituais. 
Tabela 7. Atitudes dos psiquiatras do IPq-HC-FMUSP relacionadas à religiosidade e à espiritualidade na prática clínica

\begin{tabular}{lc}
\hline & $\boldsymbol{n}(\boldsymbol{\%})$ \\
\hline $\begin{array}{l}\text { Minha experiência como médico fez com que eu questionasse as minhas } \\
\text { crenças religiosas/espirituais }\end{array}$ & \\
$\quad$ Muito & $9(11,0)$ \\
$\quad$ Moderadamente & $22(26,8)$ \\
Um pouco & $22(26,8)$ \\
$\quad$ Nada & $29(35,4)$ \\
$\quad$ Não respondeu & 2 \\
Eu considero um desafio permanecer fiel à minha religião em meu trabalho & \\
como médico & \\
$\quad$ Muito & $4(4,9)$ \\
$\quad$ Moderadamente & $8(9,7)$ \\
Um pouco & $21(25,6)$ \\
$\quad$ Nada & $49(59,7)$ \\
Não respondeu & 2 \\
Minhas crenças religiosas influenciam minha prática clínica & \\
Muito & $6(7,1)$ \\
Moderadamente & $31(36,9)$ \\
Um pouco & $17(20,2)$ \\
Nada & $30(35,7)$ \\
Com que frequência você pergunta sobre as questões religiosas/espirituais de & \\
seus pacientes? & \\
$\quad$ Frequentemente & \\
Ocasionalmente & $42(50,0)$ \\
Raramente & $27(32,1)$ \\
Nunca & $12(14,3)$ \\
Perguntar sobre a religiosidade/espiritualidade do paciente é algo que o & $3(3,6)$ \\
psiquiatra pode ou deve fazer? & \\
Sim & \\
$\quad$ Não & \\
Não sei & $74(88,1)$ \\
\hline & $7(8,3)$ \\
& $3(3,6)$ \\
\hline
\end{tabular}

Mais da metade da amostra (64,2\%) acreditava, pelo menos um pouco, que suas próprias crenças influenciavam em sua prática clínica (Tabela 7), e essa variável mostrou correlação forte ou moderada com: crença em Deus, vida após a morte, reencarnação, religiosidade, espiritualidade e enfrentamento religioso (Tabela 8). Considerar que as próprias crenças influenciavam na prática clínica diferiu entre os grupos que tinham e aqueles que não tinham afiliação religiosa $F(4,78)=10,42$, p<0,001. O teste post hoc indicou que todos os grupos religiosos pontuaram significativamente mais $(\mathrm{p}<0,05)$, quando comparados com o grupo composto pelos psiquiatras que não 
declararam afiliação religiosa, na questão que avaliou o quanto consideravam que as próprias crenças influenciavam na prática clínica.

A esse respeito, também encontramos que os psiquiatras que trabalhavam com crianças $t(82)=2,52, \mathrm{p}=0,013$, e aqueles que atendiam adultos $t(82)=2,03, \mathrm{p}=0,045$, foram significantemente inclinados a considerar que suas crenças influenciavam a prática clínica.

Do total de participantes, $88,1 \%$ consideraram que perguntar sobre a R/E do paciente era algo que o psiquiatra poderia ou deveria fazer. Metade da amostra respondeu que abordava "frequentemente" a R/E dos seus pacientes, enquanto 46,4\% abordavam apenas "ocasionalmente" ou "raramente" (Tabela 7).

Nenhuma das características sociodemográficas, assim como o tempo de atuação na psiquiatria, a subespecialidade na psiquiatria e crenças religiosas, estavam associados ao comportamento de abordar a $\mathrm{R} / \mathrm{E}$ do paciente. Entretanto, como apresentado na Tabela 8, a variável acreditar em reencarnação correlacionou-se positivamente com a frequência com que os psiquiatras perguntavam sobre a R/E do paciente. 
Tabela 8. Influência de crenças religiosas/espirituais e enfrentamento religioso/espiritual na prática clínica e no questionamento da fé por psiquiatras do IPq-HC-FMUSP (Correlações de Pearson)

\begin{tabular}{|c|c|c|c|c|c|c|c|}
\hline & $\begin{array}{l}\text { Crença } \\
\text { em Deus }\end{array}$ & $\begin{array}{l}\text { Crença em vida } \\
\text { após a morte }\end{array}$ & $\begin{array}{l}\text { Crença em } \\
\text { reencarnação }\end{array}$ & Espiritualidade & Religiosidade & $\begin{array}{l}\text { Enfrentamento } \\
\text { não religioso }\end{array}$ & $\begin{array}{l}\text { Enfrentamento } \\
\text { religioso }\end{array}$ \\
\hline \multicolumn{8}{|l|}{$\begin{array}{l}\text { Influência das crenças } \\
\text { religiosas na prática clínica }\end{array}$} \\
\hline $\begin{array}{l}\text { Minhas crenças religiosas } \\
\text { influenciam minha prática clínica }\end{array}$ & $\mathbf{0 , 5 3 3} * *$ & $0,457 * *$ & $0,234 *$ & $0,633 * *$ & $0,665^{* *}$ & $-0,263^{*}$ & $0,691 * *$ \\
\hline $\begin{array}{l}\text { Perguntar sobre a religiosidade e } \\
\text { a espiritualidade do paciente é } \\
\text { algo que o psiquiatra pode ou } \\
\text { deve fazer? }\end{array}$ & -0.148 & 0,051 & 0,175 & $-0,125$ & $-0,153$ & 0,013 & $-0,093$ \\
\hline $\begin{array}{l}\text { Com que frequência você } \\
\text { pergunta sobre as questões } \\
\text { religiosas/espirituais dos } \\
\text { pacientes? }\end{array}$ & $-0,077$ & 0,059 & $0,232 *$ & $-0,097$ & $-0,092$ & $-0,101$ & $-0,052$ \\
\hline \multicolumn{8}{|l|}{ Questionamento da fé } \\
\hline $\begin{array}{l}\text { Minha experiência como médico } \\
\text { fez com que eu questionasse as } \\
\text { minhas crenças } \\
\text { religiosas/espirituais }\end{array}$ & $\mathbf{0 , 3 5 5 * *}$ & $0,362 * *$ & $0,274 *$ & $0,236 *$ & $0,242 *$ & $-0,139$ & $\mathbf{0 , 3 3 7 *}$ \\
\hline $\begin{array}{l}\text { Eu considero um desafio } \\
\text { permanecer fiel à minha religião } \\
\text { em meu trabalho como médico }\end{array}$ & $0,271 *$ & 0,142 & 0,170 & 0,171 & 0,093 & 0,037 & 0,188 \\
\hline
\end{tabular}

\footnotetext{
$* \mathrm{p}<0.05, * * \mathrm{p}<0.00$
} 
No que diz respeito às barreiras e dificuldades encontradas pelos participantes ao abordar a R/E na prática clínica, encontramos que 44,1\% da amostra declararam que não tinham nenhuma dificuldade em abordar a R/E de seus pacientes, e estes estavam mais entre os homens que entre as mulheres (Teste exato de Fischer, p=0,041, adjusted residual=2,2), assim como tendiam a ser menos espirituais $(M=2,19 ; D P=0,97$; $t(82)=2,16 ; \mathrm{p}=0,034$ e menos religiosos $(\mathrm{M}=1,68 ; \mathrm{DP}=0,81 ; t(82)=2,55 ; \mathrm{p}=0,013)$.

Por outro lado, aqueles que apresentaram dificuldades e barreiras em avaliar a R/E do paciente na prática clínica declararam os motivos como sendo: falta de tempo, seguida do medo de extrapolar o papel do médico e da falta de treino. Na sequência vieram: o aspecto religioso/espiritual não é relevante para o paciente; medo de ofender o paciente; não se sentir confortável com o tema; não saber o porquê ou as razões; não é papel do médico e receio que os colegas não aprovem (Figura 3)

Mais homens que mulheres consideraram a falta de tempo como uma barreira relevante na investigação da R/E na prática clínica (Teste exato de Fischer, $p=0,023$; adjusted residual=2,4). Os psiquiatras que declararam medo de extrapolar o papel do médico como uma dificuldade pontuaram significativamente mais em religiosidade $(\mathrm{M}=2,52 ; \mathrm{DP}=1,03 ; t(82)=-3,30 ; \mathrm{p}=0,013)$ e espiritualidade $(\mathrm{M}=2,29 ; \mathrm{DP}=0,96 ;$ $t(50,43)=-3,06 ; \mathrm{p}=0,004)$.

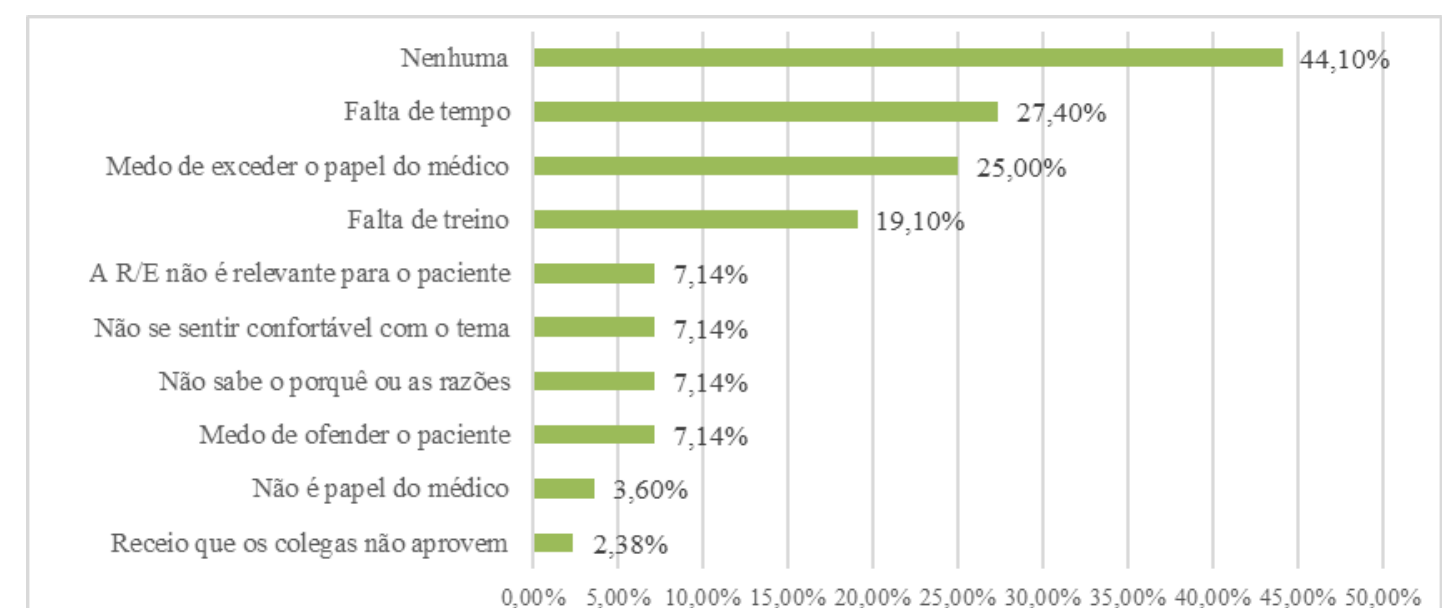

Figura 3. Barreiras / dificuldades dos psiquiatras do IPq-HC-FMUSP na abordagem da religiosidade e da espiritualidade do paciente 
A análise de regressão múltipla "stepwise" foi utilizada para identificar quais, das barreiras ou dificuldades na abordagem da $\mathrm{R} / \mathrm{E}$ na prática clínica, seriam os melhores preditores da frequência com que os psiquiatras perguntavam sobre a R/E do paciente (adjusted $\mathrm{R}^{2}=0,25 ; \mathrm{F}(3,80)=10,15 ; \mathrm{p}<0,001$ ). Os preditores mais significantes no final do modelo (em uma direção negativa) foram: "não é papel do médico" ( $\beta=$ $0,42 ; t=-4,34 ; \mathrm{p}<0,001)$, "não saber o porquê ou a razão" $(\beta=-0,30 ; t=-3,12 ; \mathrm{p}=0,002)$ e "falta de tempo" $(\beta=-0,25 ; t=-2,56 ; \mathrm{p}=0,012)$.

Com relação a considerar se o médico poderia ou deveria perguntar sobre a $\mathrm{R} / \mathrm{E}$ do paciente (adjusted $\mathrm{R}^{2}=0,16 ; \mathrm{F} 2,81=9,04 ; \mathrm{p}<0,001$ ) os melhores preditores foram: "não se sentir confortável com o tema" $(\beta=0,25 ; t=2,46 ; p=0,016)$ e (em uma direção negativa) "não é papel do médico" ( $\beta=-0,40 ; t=-3,88 ; \mathrm{p}<0,001)$. 


\subsection{OBJETIVO}

Identificar subgrupos de psiquiatras brasileiros, de acordo com as suas crenças religiosas/espirituais, e investigar se os perfis identificados possibilitam prever as suas atitudes e comportamentos relacionados à $\mathrm{R} / \mathrm{E}$ dos pacientes na prática clínica.

\subsection{MÉTODOS}

\subsubsection{Amostra e procedimentos}

O presente estudo seguiu os mesmos padrões dos dois estudos apresentados anteriormente, isto é, observação transversal e abordagem quantitativa.

O banco de dados deste terceiro estudo incluiu os dados obtidos nos dois estudos anteriores. No estudo 1 foram analisados 484 formulários de respostas (ver descrição mais detalhada nas págs. 24-34) de psiquiatras pertencentes à ABP e, a estes, acrescentamos as respostas de 35 psiquiatras que responderam ao questionário tardiamente e, por isso, não tinham sido incluídos no estudo 1. No estudo 2, avaliamos 84 psiquiatras do IPq-HCFMUSP (ver descrição mais detalhada nas págs. 35-47). No terceiro estudo, somamos os dois bancos e excluímos 11 formulários de respostas de psiquiatras que haviam respondido nas duas etapas da pesquisa. As respostas sobrepostas foram eliminadas do estudo 1 porque os "e-mails" utilizados pelos participantes para o encaminhamento das respostas ficavam registrados no sistema, permitindo sua identificação. No estudo 2, embora não fosse possível reconhecer os formulários de respostas dos psiquiatras, uma vez que eram entregues em envelopes sem identificação, o nome do participante era registrado no ato da entrega, possibilitando, dessa forma, identificá-los no do estudo 1. Restaram 592 formulários de resposta. 


\subsubsection{Instrumento}

\subsubsection{Variáveis}

Para a realização da análise dos dados, foram utilizadas todas as variáveis do questionário descrito nas páginas 20-23.

\subsubsection{Análises estatísticas}

Os dados contínuos e categóricos da amostra foram descritos. Para a análise de perfil latente (APL), o número total de participantes da amostra foi 592 psiquiatras brasileiros.

A APL é um método estatístico usado para identificar grupos ou classes homogêneos, por meio de dados multivariados, categoriais e contínuos. Ela é designada a averiguar se os dados podem ou não ser agrupados, de acordo com padrões de respostas similares. A APL é semelhante à análise de classes latentes; enquanto a primeira pode lidar com variáveis contínuas e categóricas, esta última lida apenas com variáveis dicotômicas. A análise é realizada ao tentar encaixar os dados em determinado número de categorias, observando quais parâmetros esta categorização gera. A melhor solução/categorização será escolhida de acordo com os parâmetros gerados. Os parâmetros utilizados para esta pesquisa foram: a) critério de informação de Akaike (“Akaike information criteria" - AIC), em que o menor valor indica melhor qualidade de informação oferecida pelas categorias geradas; b) critério de informação Bayesiano ajustado pelo tamanho da amostra ("sample-size adjusted Bayesian information criteria" - BIC), em que o menor valor indica melhor qualidade de informação oferecida pelas categorias geradas; c) entropia, uma medida de homogeneidade das classes geradas, indo entre 0 e 1 , onde 1 designa classes perfeitamente homogêneas; d) teste paramétrico "bootstrapped" de razão de verossimilhança ("Parametric bootstraped likelihood ratio test"), em que o p<0.05 indica que não há diferença entre classificar os dados em $n$ categorias ou em n-1 categorias); e) o teste Lo-Mendell-Rubin de razão de verossimilhança ajustado (LMR adjusted likelihood ratio test), em que o $\mathrm{p}<0.05$ indica que a solução atual é estatisticamente diferente da solução com n-1 classes, indicando que a atual deve ser escolhida em relação à solução com n-1 classes. 
Não há solução perfeita para a divisão de dados em perfis, assim, conforme Muthen \& Muthen ${ }^{156}$, a melhor solução deve ser apresentada levando-se em conta os parâmetros acima e o julgamento clínico.

As análises foram realizadas com o Mplus 8 para $\operatorname{OS}^{157}$.

\subsection{RESULTADOS}

Um total de 592 psiquiatras participaram deste estudo. Nesta amostra, a idade média foi 48 anos $(\mathrm{DP}=11,7), 60 \%$ dos psiquiatras eram do sexo masculino e mais de dois terços casados. Com relação à experiência profissional, os dados indicaram que o tempo médio trabalhado na psiquiatria foi 20,63 anos $(\mathrm{DP}=11,65)$; quanto ao nível educacional, a maior parte da amostra era pós-graduada e tinha o título de especialização. No que se refere à afiliação religiosa, 66,5\% dos psiquiatras declararam que tinham, pelo menos, uma religião, e a maioria era católica. Os dados da Tabela 9 apresentam um resumo dessas características sociodemográficas.

Tabela 9. Características sociodemográficas dos psiquiatras brasileiros $(n=592)$

\begin{tabular}{lc}
\hline & $n(\%)$ \\
\hline Idade (anos; média e desvio padrão) & $47,96(11,66)$ \\
Sexo (feminino) & $237(40,0)$ \\
Estado civil (casados) & $414(70,8 \%)$ \\
Nível Educacional & $153(26,1)$ \\
$\quad$ Residência & $204(34,8)$ \\
$\quad$ Especialização & $101(17,2)$ \\
$\quad$ Mestrado & $129(22,0)$ \\
$\quad$ Doutorado* & 5 \\
Não responderam & $20,63(11,65)$ \\
Tempo na psiquiatria (anos; média e desvio padrão) & \\
Afiliação religiosa & $186(31,5)$ \\
Católica & $40(6,8)$ \\
Protestante ou Evangélica & $104(17,6)$ \\
Espíritas & $63(10,6)$ \\
Outras religiões & $198(33,5)$ \\
Nenhuma & 1 \\
Não respondeu & 1 \\
\hline
\end{tabular}

*Inclui a categoria pós-doutorado 
No que diz respeito às opiniões e comportamentos dos participantes referentes à R/E na saúde e na prática clínica, os resultados mostraram que 44,6\% consideraram que a R/E interfere "frequentemente" na decisão do paciente sobre o tratamento indicado; o restante dos respondentes dividiu-se entre as respostas "ocasionalmente" (37,7\%), "raramente" (13,6\%) e "nunca" (4,1\%). Com relação a considerar que a R/E afeta o bem-estar do paciente, 64,8\% responderam "frequentemente", 29,6\% “ocasionalmente", $3,8 \%$ "raramente" e 1,8\% "nunca". Para a questão que avaliou se consideravam importante a inclusão da $\mathrm{R} / \mathrm{E}$ na formação médica, as respostas foram: 43,2\% declararam "muito importante", 28,9\% "razoavelmente", 14,9\% "pouco" e 12,9\% "nada importante". A inclusão da R/E na formação psiquiátrica foi considerada "muito importante" por 40,6\%, 30,1\% responderam "razoavelmente", 16,7\% "pouco" e 12,6\% "nada importante". Os dados também indicaram que 46,5\% dos psiquiatras abordavam "frequentemente" as questões religiosas e espirituais de seus pacientes, 33,8\% “ocasionalmente", 14,6\% "raramente" e apenas 5,1\% "nunca" abordavam a R/E em sua prática clínica.

Os dados da Tabela 10 apresentam a APL das respostas dos psiquiatras ao questionário. Os resultados indicaram que a melhor solução/categorização foi com duas classes de agrupamento, pois apresentou o melhor valor de entropia e foi o número de classes com valor Lo-Mendell-Rubin estatisticamente significante.

Tabela 10. Análise de perfis latentes de respostas dos psiquiatras brasileiros ao questionário de religiosidade e espiritualidade na prática psiquiátrica

\begin{tabular}{lcccccc}
\hline & AIC & BIC & Entropia & LRT & P & LMR $^{\mathbf{a}}$ \\
\hline 2 classes & 23291.237 & 23354.096 & $\mathbf{0 . 9 6 7}$ & -13756.570 & 0.0000 & $\mathbf{0 . 0 0 0 0}$ \\
3 classes & 22306.700 & 22393.735 & 0.927 & -11593.618 & 0.0000 & 0.4218 \\
$\mathbf{4}$ classes & 21858.771 & 21969.983 & 0.925 & -11081.349 & 0.0000 & 0.7613 \\
$\mathbf{5}$ classes & 21724.447 & 21859.835 & 0.933 & -10837.386 & 0.0000 & 0.7357 \\
\hline
\end{tabular}

${ }^{a}$ Lo-Mendell-Rubin

Os dados da Tabela 11 referem-se à análise do perfil latente da amostra representada somente pelos 508 participantes da ABP e demonstra que a inclusão dos psiquiatras do IPq-HC-FMUSP nas análises desse estudo não alterou os resultados; verificamos que a melhor escolha também seria com duas classes, com o maior valor 
para entropia e significância para o teste de Lo-Mendell-Rubin. Apenas três do total dos participantes mudaram de classe quando as análises foram realizadas com os dois grupos, indicando que essa inclusão significou apenas um aumento do número de participantes.

Tabela 11. Análise de perfis latentes de respostas dos psiquiatras da $A B P$ ao questionário de religiosidade e espiritualidade na prática psiquiátrica

\begin{tabular}{lcclcrc}
\hline & AIC & BIC & Entropia & LRT & P & LMR $^{\mathbf{a}}$ \\
\hline 2 classes & 20002.010 & 20056.941 & $\mathbf{0 . 9 6 8}$ & -11816.846 & 0.0000 & $\mathbf{0 . 0 0 0 0}$ \\
3 classes & 19114.807 & 19190.865 & 0.936 & -9949.005 & 0.0000 & 0.7634 \\
$\mathbf{4}$ classes & 18756.810 & 18853.995 & 0.922 & -9485.403 & 0.0000 & 0.7081 \\
$\mathbf{5}$ classes & 18647.516 & 18765.828 & 0.937 & -9286.405 & 0.0000 & 0.7223 \\
\hline
\end{tabular}

${ }^{\mathrm{a}}$ Lo-Mendell-Rubin

As Figuras 4 e 5 apresentam as características religiosas/espirituais e opiniões relacionadas à $\mathrm{R} / \mathrm{E}$ na prática clínica dos psiquiatras de acordo com os diferentes perfis.

O perfil 1 denominamos de "menos religiosos", pois comparando esses indivíduos com os psiquiatras do outro perfil, eles foram os que menos declararam visitas a templos religiosos/espirituais (médias 1,4 vs. 2,79), os que menos realizavam leituras religiosas/espirituais (médias 1,5 vs. 3,41), os que apresentaram menores frequências de oração/prece (médias 1,56 vs. 4,38) e menores frequências de práticas espirituais não religiosas, como meditação e ioga (1,74 vs. 2,74). Também tiveram menores médias em religiosidade intrínseca (1,49 vs. 3,25), espiritualidade (2,03 vs. $3,37)$, religiosidade (1,34 vs. 2,86) e enfrentamento religioso (1,41 vs. 3,43). Coerentemente, somente na questão que avaliou o enfrentamento não religioso as taxas foram maiores $(3,38$ vs. 2,38). Quanto às opiniões relacionadas à $\mathrm{R} / \mathrm{E}$ na prática clínica, foram os que menos consideraram que suas crenças religiosas/espirituais influenciavam em seu trabalho como médico (1,46 vs. 2,93), os que menos acreditavam que a medicina seria um chamado ou uma missão $(1,76$ vs. 3,10$)$ e, ainda, os que menos consideravam que a prática da medicina pudesse fazê-los questionar suas próprias crenças (1,95 vs. 2,53) (Figura 4). 


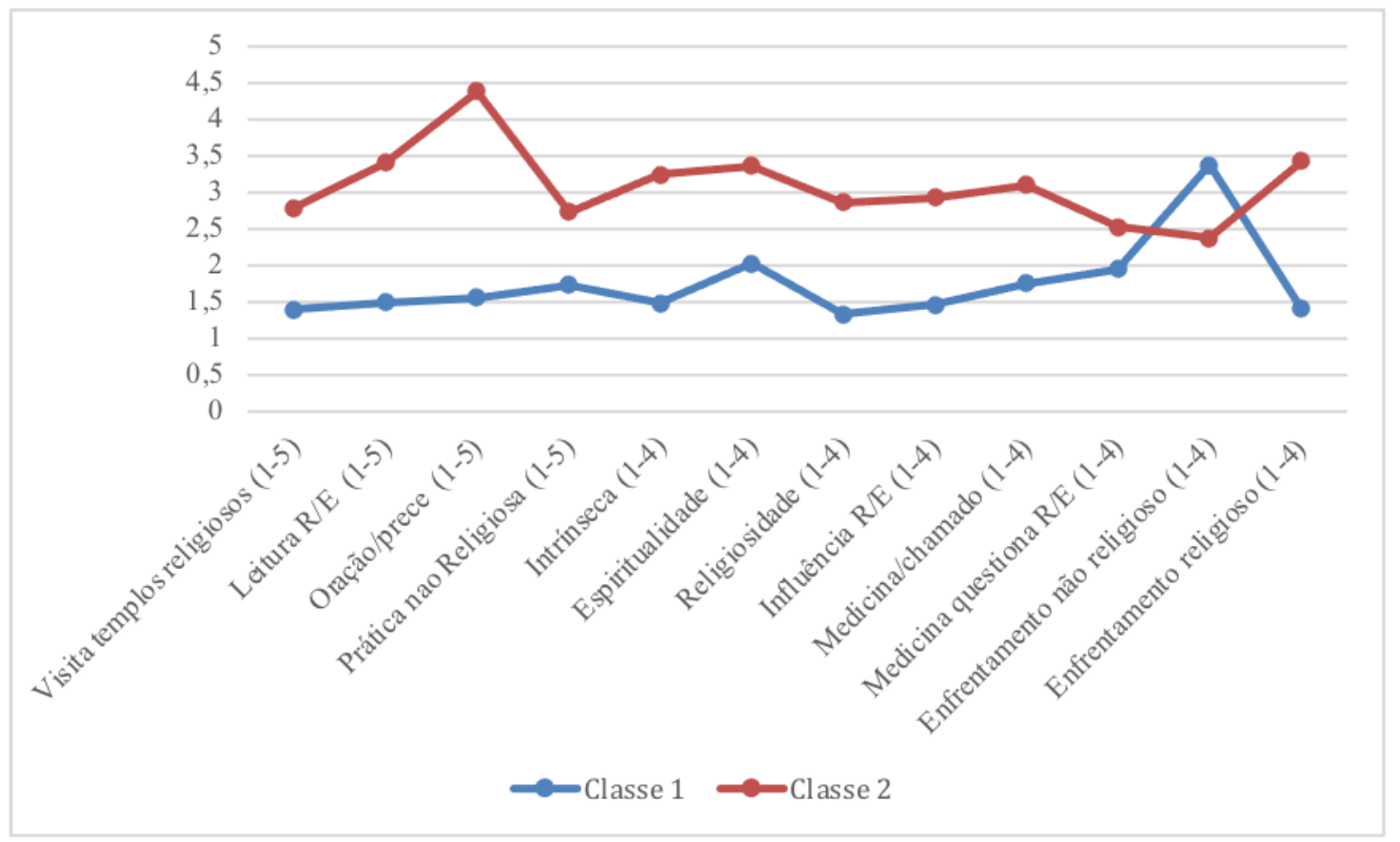

Figura 4. Características religiosas e espirituais dos psiquiatras brasileiros de acordo com os diferentes perfis

A Figura 5 apresenta as crenças religiosas/espirituais dos psiquiatras de acordo com os diferentes perfis. Observamos que o perfil 1 também agrupa os indivíduos com menores percentagens de crença em Deus $(40,2 \%$ vs. 99,4\%), vida após a morte $(13,5 \%$ vs. $87,9 \%)$, e reencarnação $(5,2 \%$ vs. $57,7 \%)$.

Como demonstrado nas Figuras 4 e 5, o perfil 2 reuniu os psiquiatras mais "crentes" e com características religiosas/espirituais mais presentes e, por isso, foi nomeado como "mais religiosos". 


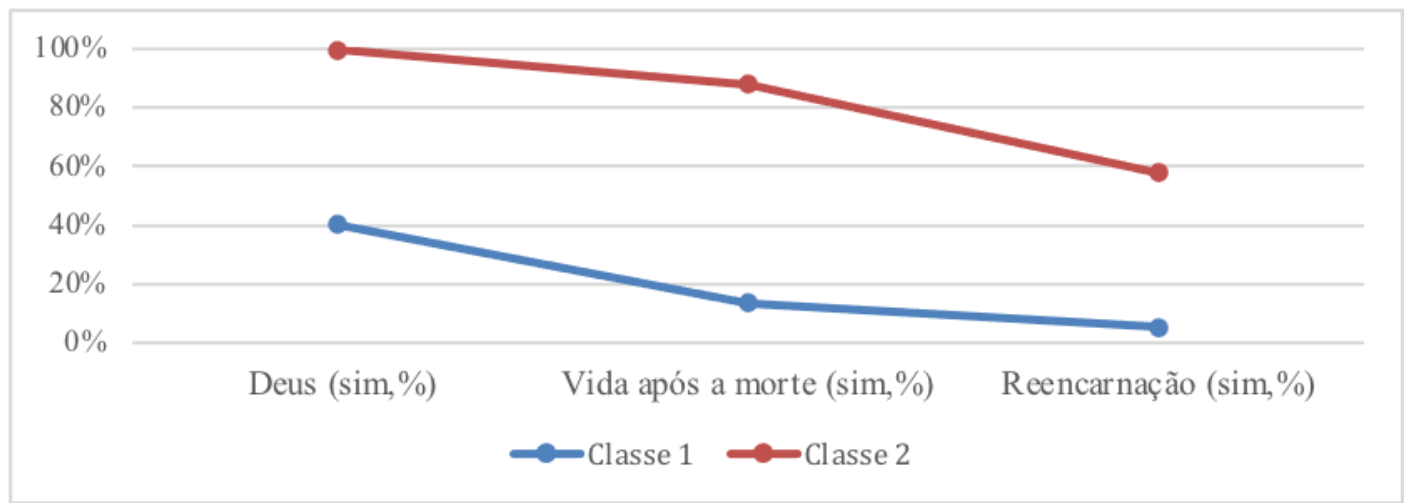

Figura 5. Crenças religiosas/espirituais dos psiquiatras de acordo com os diferentes perfis

Os dados da Tabela 12 descrevem a probabilidade condicional de cada item de resposta no respectivo perfil. O perfil 1 teve 245 (41,5\%) psiquiatras e a idade média de 48,54 anos, e o perfil 2 reuniu a maioria dos participantes $(n=347,59,6 \%)$ e idade média de 47,54 anos. Comparando os indivíduos dos dois perfis, observamos que os psiquiatras do perfil 1 tinham mais tempo na psiquiatria (a média em anos foi de 21,79 vs. 19,82$)$, foi o grupo que concentrou mais indivíduos do sexo masculino (66,5\% vs. $55,3 \%$ ) e reuniu os psiquiatras com maiores níveis educacionais: $28 \%$ tinham, no mínimo, o título de doutor, e alguns também eram pós-doutorados e livres-docentes, ao passo que no perfil 2 essa percentagem foi de apenas $17,7 \%$. 
Tabela 12. Características, opiniões e comportamentos da amostra de acordo com os diferentes perfis religiosos/espirituais

\begin{tabular}{|c|c|c|c|}
\hline & $\begin{array}{l}\text { Classe } 1 \\
(n=245)\end{array}$ & $\begin{array}{l}\text { Classe } 2 \\
(n=347)\end{array}$ & \multirow{2}{*}{$\mathbf{P}$} \\
\hline & $\begin{array}{l}\text { "Menos } \\
\text { religiosos" }\end{array}$ & $\begin{array}{l}\text { "Mais } \\
\text { religiosos" }\end{array}$ & \\
\hline \multicolumn{4}{|l|}{ Dados sociodemográficos e profissionais } \\
\hline Idade (anos; média, DP) & $48,54(11.95)$ & $47,54(11,46)$ & $0,313^{2}$ \\
\hline Sexo (feminino; \%, $n$ ) & $33,5 \%(82)$ & $44,7 \%(155)$ & $\mathbf{0 , 0 0 6}{ }^{1}$ \\
\hline Estado civil (casado; $\%, n$ ) & $73,4 \%(177)$ & $68,7 \%(237)$ & $0,473^{1}$ \\
\hline Nivel educacional (doutorado; $\%, n)^{3}$ & $28,0 \%(68)$ & $17,7 \%(61)$ & $0,001^{1}$ \\
\hline Tempo na psiquiatria (anos; média, DP) & $21,79(11.75)$ & $19,82(11,53)$ & $\mathbf{0 , 0 4 4 ^ { 2 }}$ \\
\hline \multicolumn{4}{|l|}{$\begin{array}{l}\text { Características religiosas/espirituais, opiniões e } \\
\text { comportamentos relacionados à religiosidade e à } \\
\text { espiritualidade na saúde e na prática Clínica }\end{array}$} \\
\hline Afiliação religiosa (nenhuma; \%, $n$ ) & $69,3 \%(169)$ & $8,4 \%(29)$ & $0,000^{1}$ \\
\hline Inclusão da R/E na formação médica (média,DP) & $2,47(1,14)$ & $3,37(0,81)$ & $0,000^{2}$ \\
\hline Inclusão da R/E na formação psiquiátrica (média,DP) & $2,39(1,09)$ & $3,36(0,80)$ & $0,000^{2}$ \\
\hline $\begin{array}{l}\text { Considera que a R/E afeta o tratamento do paciente } \\
\text { (média,DP) }\end{array}$ & $3,01(0,87)$ & $3,36(0,78)$ & $0,000^{2}$ \\
\hline $\begin{array}{l}\text { Considera que a } \mathbf{R} / \mathbf{E} \text { afeta a saúde do paciente } \\
\text { (média,DP) }\end{array}$ & $3,29(0,78)$ & $3,75(0,47)$ & $0,000^{2}$ \\
\hline Aborda a R/E do paciente (média,DP) & $3,06(0,97)$ & $3,33(0,78)$ & $0,000^{2}$ \\
\hline
\end{tabular}

A maioria $(69,3 \%)$ dos indivíduos do perfil 1 declarou que não tinha religião, ao contrário do perfil 2, em que 91,6\% dos psiquiatras indicaram uma afiliação religiosa. Com relação às opiniões referentes à R/E e saúde, os psiquiatras do perfil 1 foram os que menos consideraram que a $\mathrm{R} / \mathrm{E}$ influencia nas decisões dos pacientes sobre $\mathrm{o}$ tratamento indicado (média $=3,01$ vs. 3,36 ) e que a R/E pode afetar a saúde e o bemestar do paciente (média $=3,29$ vs. 3,75). Os indivíduos do perfil 1 também foram aqueles que menos consideraram importante a inclusão da $\mathrm{R} / \mathrm{E}$ na formação do médico (média $=2,47$ vs. 3,37) e na formação do psiquiatra (média $=2,39$ vs. 3,36). Com relação à abordagem da $\mathrm{R} / \mathrm{E}$ na prática clínica, encontramos que os psiquiatras do perfil 1 eram os que menos perguntavam sobre as questões religiosas/espirituais de seus pacientes (média $=3,06$ vs. 3,33) (Tabela 12). 


\section{DISCUSSÃO GERAL DOS TRÊS ESTUDOS}

Neste capítulo, serão discutidos os resultados referentes aos três estudos apresentados acima; inicialmente, as semelhanças e diferenças entre eles e, em seguida, a comparação desses achados com os trabalhos encontrados na literatura internacional.

\subsection{COMPARAÇÃO DOS RESULTADOS: ESTUDOS 1, 2 e 3}

Com o objetivo inicial de realizar um levantamento do perfil religioso/espiritual dos psiquiatras brasileiros, realizamos o estudo 1. Em seguida, no estudo 2 investigamos o perfil religioso/espiritual dos profissionais de um dos mais importantes centros na formação de psiquiatras e no desenvolvimento de pesquisas na área das neurociências. Finalmente, no estudo 3 agrupamos os psiquiatras dos estudos anteriores, com características semelhantes, em subgrupos específicos, com vistas a diferenciar os padrões de atitudes e comportamentos relacionados à $\mathrm{R} / \mathrm{E}$ na prática clínica.

Apesar das análises estatísticas realizadas nos dois primeiros estudos terem sido distintas, a comparação entre eles foi possível, uma vez que apresentaram informações suficientes para que pudéssemos confrontá-los e, assim, identificar suas semelhanças e dessemelhanças.

No que diz respeito aos dados sociodemográficos, as amostras da ABP (estudo 1) e do IPq-HC-FMUSP (estudo 2) apresentaram resultados bastante similares com relação à idade (a média foi 49 e 45 anos, respectivamente); estado civil (a maioria era casada ou em união estável); gênero (a maior parte era do sexo masculino); subespecialidade médica (a maioria trabalhava na psiquiatria de adultos) e quanto ao tempo de atuação na psiquiatria, a média foi em torno de 20 anos nas duas amostras. Apenas em relação ao grau de instrução, a amostra de psiquiatras do IPq-HC-FMUSP apresentou índices superiores: 67,9\% possuíam título de mestrado e doutorado; na amostra da ABP, essa percentagem foi apenas 36\%. Tal diferença é compreensível, já que o IPq-HC-FMUSP é uma instituição acadêmica e, portanto, com maior percentual de psiquiatras com treinamento em pesquisa (mestres e doutores). No que se refere às subespecialidades em psiquiatria, no estudo 1 encontramos maior percentagem de 
afiliação religiosa entre os psiquiatras forenses e, no estudo 2, aqueles que trabalhavam na psiquiatria infantil eram os que se declaravam mais espirituais. Quanto ao gênero, no estudo 1, as mulheres relataram mais afiliação religiosa e, no estudo 2, os homens tinham menos dificuldades em abordar R/E de seus pacientes.

Com relação às crenças religiosas/espirituais, os resultados dos estudos 1 e 2 demonstraram que a maioria dos psiquiatras declarou afiliação religiosa: 67,4\% na amostra da ABP e uma percentagem um pouco menor $(57,7 \%)$ na amostra do IPq-HCFMUSP.

A religião católica foi a mais citada nos dois grupos (ABP e IPq-HC-FMUSP), porém, no estudo 1, ela foi seguida da religião espírita e não da protestante ou evangélica, como indica o Censo Demográfico da população brasileira, o que já era esperado, uma vez que o próprio Censo mostra que, no Brasil, o espiritismo tem sido mais popular entre os profissionais liberais, sendo os evangélicos, geralmente, mais prevalentes nos níveis socioeconômicos médio-baixo e baixo ${ }^{145}$. Entretanto, no estudo 2, em que a amostra possivelmente tenha representado psiquiatras de nível socioeconômico superior em relação ao restante do país, conforme dados de distribuição de renda regional ${ }^{158}$, os resultados não foram os esperados quando comparados com os do IBGE, ou seja, a religião católica foi seguida da protestante ou evangélica e, depois, da espírita. Futuros estudos talvez possam ajudar a entender melhor o porquê dessas diferenças.

Embora a maioria da população brasileira seja católica, ela tem sido caracterizada por uma crescente diversidade de grupos religiosos, desde o início do século XX. O Censo Demográfico brasileiro mostra um aumento de seguidores nas religiões evangélicas e no espiritismo (um movimento religioso e filosófico iniciado na segunda metade do século XIX), à custa do catolicismo. No entanto, a religião católica ainda é, de longe, a maior do Brasil, representando 64,6\% do total de religiosos ${ }^{145}$.

Além de apresentar taxas maiores em afiliação religiosa, a amostra da ABP também apresentou percentagens maiores relacionadas à crença em Deus (71,4\% vs. $59,5 \%$ ). Interessantemente, nas duas amostras o percentual de crença em Deus foi maior que o percentual de afiliação religiosa $(\mathrm{ABP}=67,4 \%$ e IPq-HC-FMUSP $=57,7 \%$ para afiliação religiosa). 
Ainda com relação às crenças religiosas, os psiquiatras dos dois grupos pontuaram mais em espiritualidade que em religiosidade. Na amostra da ABP, 68,7\% consideravam-se muito ou moderadamente espirituais e apenas 43,3\% muito ou moderadamente religiosos. Estas percentagens foram menores na amostra do IPq-HCFMUSP (53,5\% para espiritualidade e $31 \%$ em religiosidade).

No estudo 1, identificamos que apenas $45,5 \%$ dos respondentes perguntavam com frequência sobre a $\mathrm{R} / \mathrm{E}$ de seus pacientes e aqueles que se declaravam mais religiosos e mais espirituais eram mais inclinados a abordar o assunto. No estudo 2, $50 \%$ dos psiquiatras incluíam a $\mathrm{R} / \mathrm{E}$ na prática clínica e a crença em reencarnação apresentou-se associada positivamente à abordagem da R/E.

Mais de um terço das amostras (40,3\% da ABP e 44,1\% do IPq-HC-FMUSP) declarou não encontrar barreiras em lidar com os aspectos religiosos/espirituais dos seus pacientes, mas a maioria dos participantes, em ambos os estudos, relatou algum tipo de dificuldade com a abordagem do tema. As barreiras mais citadas pelos psiquiatras da $\mathrm{ABP}$ e do IPq-HC-FMUSP foram as mesmas, diferiram apenas quanto à frequência. Foram elas: medo de exceder o papel do médico (30,2\% vs. 25,0\%), falta de treino $(22,3 \%$ vs. $19,1 \%)$ e falta de tempo $(16,3 \%$ vs. $27,4 \%)$.

$\mathrm{Na}$ amostra da $\mathrm{ABP}$, os psiquiatras que declararam não ter dificuldades para discutir a R/E dos pacientes eram os mais inclinados a não relatar afiliação religiosa e também aqueles que mais abordavam a R/E no atendimento clínico. Na amostra do IPqHC-FMUSP, os participantes que não tinham dificuldades em lidar com a R/E, eram mais homens que mulheres, sendo também os que se declaravam menos religiosos e menos espirituais. Os psiquiatras do estudo 1, que relataram medo de exceder o papel do médico, indicavam mais afiliação religiosa e perguntavam menos sobre a R/E do paciente; já os psiquiatras do IPq-HC-FMUSP, que apresentaram essa dificuldade, pontuaram mais em religiosidade e em espiritualidade.

De maneira geral, os dados acima demonstraram que as amostras dos estudos $1 \mathrm{e}$ 2 eram bem mais semelhantes que discrepantes quanto às variáveis de interesse. Logo, resolvemos realizar um terceiro estudo, com o propósito de identificar diferentes subgrupos de psiquiatras que apresentassem características semelhantes de crenças, comportamento e prática profissional. Uma vantagem adicional em utilizarmos, na 
análise do estudo 3, todos os participantes dos estudos 1 e 2, foi o aumento do poder estatístico da própria análise na identificação de subgrupos com perfis semelhantes.

Os resultados da análise de perfil latente (APL) indicaram que os 592 psiquiatras brasileiros participantes poderiam ser, preferencialmente, divididos em dois subgrupos, com características distintas de perfis religiosos/espirituais. O perfil "menos religiosos" foi o menor grupo $(n=245)$ e reuniu os psiquiatras com menores índices de crenças e frequência de práticas religiosas/espirituais; o maior número de participantes do sexo masculino (2:1); os psiquiatras com níveis educacionais mais elevados (maior percentagem de mestres e doutores); com mais tempo de atuação na psiquiatria e aqueles que abordavam menos a $\mathrm{R} / \mathrm{E}$ na prática clínica. O perfil "mais religiosos" $(n=347)$ agrupou os psiquiatras com características opostas ao perfil anterior, ou seja, eram mais crentes e atuantes na vida religiosa; eram os que mais consideravam a influência da R/E na saúde e tratamento médico; atribuíam mais importância à inclusão da $\mathrm{R} / \mathrm{E}$ na formação profissional e aqueles que mais abordavam a R/E de seus pacientes.

\subsection{COMPARAÇÃO DOS ESTUDOS 1, 2 e 3 COM A LITERATURA INTERNACIONAL}

Nossos achados demonstraram que a maioria dos psiquiatras brasileiros declarou uma afiliação religiosa, mas um número ainda maior de participantes relatou crença em Deus. No estudo 1, encontramos que $28,5 \%$ dos psiquiatras que não tinham religião, acreditavam em Deus e, no estudo 2, a percentagem daqueles que acreditavam em Deus era um pouco maior em relação aos que relatavam afiliação religiosa. Por outro lado, um estudo com psiquiatras americanos ${ }^{159}$ mostra que $82 \%$ declaram afiliação religiosa, mas apenas 65\% indicam crença em Deus. Resultados parecidos são relatados em um estudo com psiquiatras alemães ${ }^{132}$, em que $70,7 \%$ têm religião, mas só $56 \%$ acreditam em Deus. Similarmente, uma outra pesquisa aponta que $80 \%$ dos médicos dinamarqueses de várias especialidades declaram alguma afiliação religiosa, mas apenas $56 \%$ consideram-se uma pessoa de fé ${ }^{160}$.

Estes dados parecem indicar que nem sempre a percentagem de afiliação religiosa relatada por um grupo reflete o nível de suas crenças religiosas/espirituais, e que declarar uma afiliação religiosa pode, em alguns casos, apenas fazer parte de um protocolo de identificação, indicar somente uma herança cultural ou familiar, ou seja, 
que o fato de identificar-se com uma religião não significa, necessariamente, professá-la e, por outro lado, não declará-la pode não significar incredulidade.

Em consonância com as informações apresentadas acima e também em concordância com evidências anteriores ${ }^{159}, 161,162$, observamos que os psiquiatras das duas amostras consideravam-se mais espirituais que religiosos, o que nos remete ao fato de que, nos últimos séculos, o conceito de religião tem mudado e as grandes organizações religiosas, que antes eram fonte de sentido e significado aceitos coletivamente, vêm sendo aos poucos substituídas por uma religiosidade mais individualizada, privada, na qual as pessoas independem de uma instituição e, muitas vezes, adotam das várias vertentes religiosas somente aquilo que vai ao encontro de suas vontades ou necessidades. O conceito de espiritualidade vem sendo usado para referir-se a essa tendência atual da desinstitucionalização e destradicionalização da religiosidade $^{163}$, fenômenos que podem ser favorecidos pelo alto grau de pluralismo e sincretismo religioso, característicos da sociedade brasileira ${ }^{145,164}$.

Com relação ao gênero, nossos estudos revelaram as mulheres mais religiosas quando comparadas aos homens. No estudo 1, elas eram mais propensas a declarar afiliação religiosa e, no estudo 2 , encontramos que os psiquiatras que declararam menos dificuldades para abordar os aspectos religiosos/espirituais de seus pacientes pontuaram menos em R/E e eram na maioria homens, indicando a possibilidade das mulheres atribuírem maior importância à R/E. Além disso, no estudo 3, a análise de perfil latente apontou um número maior de mulheres entre os psiquiatras 'mais religiosos'. Estes resultados são similares aos encontrados na literatura, por exemplo, um estudo canadense relata que psiquiatras do sexo feminino apresentam taxas mais elevadas de crenças religiosas, práticas religiosas e religiosidade intrínseca que colegas do sexo masculino $^{116}$. Neeleman e King ${ }^{113}$, no Reino Unido, também demonstram que a taxa de psiquiatras mulheres que acreditam em Deus é maior que a apresentada pelos homens.

Em revisão narrativa da literatura, Miller \& $\operatorname{Hoffman}^{165}$ mostram que a maior religiosidade da mulher é observada ao longo de toda sua vida e manifesta-se por meio de maior propensão em declarar afiliação religiosa, maior comprometimento pessoal com a prática religiosa e com maior frequência a igrejas ou cultos.

Nesse mesmo sentido, uma pesquisa patrocinada pelo Pew Research Center ${ }^{166}$ em 192 países e territórios, com populações das religiões católica, muçulmana, judaica, 
hindu, budista e outras também indica diferenças de sexo no tocante à religiosidade. De um modo geral, em todo o mundo, as mulheres declaram mais afiliação religiosa, maior frequência a cultos (com exceção das religiões muçulmana e judaica) e maiores índices de oração ou prece diária. Além disso, dos países pesquisados que dispõem de dados a respeito da população de ateus, em apenas um deles (França) o universo de homens é um pouco menor que o das mulheres (49\% vs. 51\%). No Brasil, a mesma pesquisa revela a semelhança no percentual da religiosidade feminina com a maior parte dos países pesquisados. As mulheres, comparadas aos homens, indicam índices maiores de frequência a cultos, de prática de orações diárias e a atribuição de maior importância à religião ${ }^{166}$. Estes dados corroboram aqueles encontrados em uma amostra probabilística da população brasileira, apontando maior religiosidade entre as mulheres ${ }^{146}$.

Vários estudos empíricos vêm demonstrando essa maior religiosidade da mulher em relação ao homem e esta diferença tem despertado intenso interesse dos pesquisadores desde 1930 167, 168 . No entanto, embora várias teorias tentem explicar os motivos dessa diferenciação de abordagens de carácter sociológico ${ }^{169}$ e psicológico ${ }^{170}$, até aquelas que fundamentam a maior irreligiosidade do homem em bases fisiológicas ${ }^{171,}{ }^{172}$, ainda não existem estudos empíricos concludentes capazes de justificar qualquer posição a respeito. Até agora, o que se observa é um princípio de consenso sobre o caráter multifatorial de sua origem ${ }^{173}$.

Com relação às áreas de atuação na psiquiatria, o estudo da $\mathrm{ABP}$ revelou que os psiquiatras forenses tinham maior propensão a declarar afiliação religiosa. Talvez uma investigação mais aprofundada desses dados pudesse corroborar a teoria de Norko ${ }^{174}$, que discute a relação entre a prática da psiquiatria forense e a espiritualidade. $\mathrm{O}$ autor parte do pressuposto de que a prática da medicina é o exercício de uma vocação, que embute, necessariamente, uma concepção de espiritualidade, uma vez que implica atendimento de uma chamada à cura do semelhante. Ademais, com base em evidências de que essa percepção é fortemente pronunciada entre os psiquiatras ${ }^{175}$, o autor entende que, na psiquiatria forense, esta condição mostra-se especial, pois, além da atuação como profissional da saúde, que já pressupõe um ato vocacional, o psiquiatra forense atua também auxiliando na busca da verdade e da justiça que, segundo ele, somente podem ser alcançadas com uma postura de preocupação com o bem comum, o que não deixa de expressar um exercício ou prática espiritual. 
Ainda, no que diz respeito à subespecialidade, os psiquiatras do IPq-HC-FMUSP que atuavam na área infantil, apresentaram maiores níveis de espiritualidade e esses dados são próximos àqueles encontrados por Curlim et al. ${ }^{176}$, no qual os pediatras, comparados com médicos de outras especialidades, também configuram entre os mais religiosos.

A literatura é carente de estudos sobre R/E e subespecialidades psiquiátricas, o que torna o assunto interessante para futuras investigações.

O número de anos trabalhados na psiquiatria associado a níveis menores de afiliação religiosa foi um dos achados interessantes de nossa pequisa. $\mathrm{O}$ estudo 2 não apresentou nenhuma associação entre estas variáveis, talvez em razão do tamanho amostral e, portanto, um menor grau de robustez estatística, mas, no estudo 1 identificamos que os psiquiatras da $\mathrm{ABP}$, com mais tempo na profissão, eram mais inclinados a não declarar afiliação religiosa e, a esse respeito, encontramos dados similares relatados em um estudo canadense, indicando que à medida que os anos de prática profissional aumentam, a importância atribuída pelos psiquiatras à $R / E$ na psiquiatria diminui e, por outro lado, a tendência de associá-la a aspectos negativos aumenta ${ }^{116}$.

Esses dados, pouco explorados na literatura, trouxeram várias reflexões no sentido de que tais achados possam ser decorrentes da influência de teorias antirreligiosas e antiespirituais na formação de uma geração de psiquiatras, que iniciaram suas práticas em uma época em que essas ideias eram predominantes. Nesse caso, devemos estar atentos para analisá-los e compará-los, uma vez que possam estar refletindo um fenômeno geracional e, não necessariamente, um fenômeno relacionado ao tempo trabalhado na especialidade.

Afinal, como já registrado nesta pesquisa, a religião tinha uma conotação amplamente negativa dentro da psiquiatria, desde o final século $\mathrm{XIX}^{177,}{ }^{178}$, sendo identificada com a própria insanidade mental e responsável, inclusive, por grande parte das causas de abrigamento em asilos psiquiátricos, sob os mais diversos diagnósticos, como "excitação religiosa", "loucura religiosa" e "melancolia religiosa", dentre outros $^{179}$. Para Freud, a religião deveria "ser considerada seriamente como adversária" do progresso científico, já que a supunha incapaz de suportar um exame crítico por parte da ciência ${ }^{180}$. 
Ainda na década de 1970 do século passado, as manifestações ou experiências místicas continuavam sendo associadas quase que exclusivamente a comportamentos patológicos, do tipo psicótico, ou a um fenômeno de regressão, dissociação ou fuga, como foi anunciado em 1976 pelo "Committee on Psychiatry and Religion" do GAP "Group for the Advancement of Psychiatry"181, dos Estados Unidos da América.

Além disso, no início, as abordagens psiquiátricas eram partidárias; algumas teorias defendiam a predominância dos aspectos biológicos na etiologia das doenças mentais, enquanto outras apontavam o fator psicológico como sua causa determinante. Apenas recentemente surgiram modelos mais abrangentes, que integram vários elementos na compreensão da saúde mental ${ }^{182}$. Atualmente, a psiquiatria objetiva a abordagem integral da pessoa e considera a interação dos fatores biológicos, psicológicos, sociais e religiosos/espirituais, tanto na avaliação diagnóstica como na conduta terapêutica ${ }^{98}$.

Portanto, devemos atentar para o fato de que a psiquiatria vem se transformando consideravelmente nas últimas décadas, assim como sua relação com a religião. As abordagens teóricas que compreendiam a expressão religiosa como uma manifestação patológica predominaram por várias décadas no campo da psiquiatria e da psicologia, influenciando muitos profissionais da área e, embora continuem presentes ${ }^{159}$, esta influência tem se tornado cada vez menos relevante.

Além disso, o avanço das pesquisas, demonstrando um número cada vez maior de evidências dos efeitos benéficos da R/E para a saúde mental, tem mudado a forma de se interpretar as experiências religiosas/espirituais dos pacientes.

Entretanto, apesar das evidentes mudanças na abordagem da R/E na psiquiatria, a literatura ainda chama a atenção para a característica mais "secular" da maioria dos psiquiatras; e nossa pesquisa corrobora esses achados. Identificamos nos estudos 1 e 2 que, apesar da maior parte da amostra declarar crenças religiosas/espirituais, os psiquiatras brasileiros revelaram-se menos religiosos que seus pacientes, indicando a tendência geral da classe em grande parte do mundo ${ }^{113}, 115,116$. Psiquiatras vêm se mostrando também menos religiosos quando comparados com médicos de outras especialidades ${ }^{143}, 159,162$.

Provavelmente, estas características ainda estejam refletindo a "tensão histórica" entre a religião e psiquiatria ${ }^{120}$, mas vale registrarmos uma das ideias discutidas por 
Coyle $^{183}$, sobre as possíveis razões da existência desta lacuna entre a fé dos psiquiatras e da população em geral. Conforme o autor, enquanto a medicina é um sistema empírico de informações, que sustenta seu conhecimento sobre fatos e relações de causalidade, a religião é produto da fé. Isso pode ocasionar que pessoas menos religiosas ou sem religião já sejam, naturalmente, atraídas para a psiquiatria, como uma alternativa de busca por propósito e significado na vida ou como uma alternativa de paradigma para a compreensão do comportamento humano. A esse respeito, um estudo comprova que os alunos de medicina sem afiliação religiosa têm três vezes mais chances de escolherem a psiquiatria, segundo evidências colhidas em 11 países da América Latina ${ }^{184}$.

Por outro lado, podemos pensar que esse "viés antirreligioso", observado na psiquiatria, pode levar os responsáveis pela admissão de jovens profissionais em programas de pós-graduação ou residência médica a afastar pessoas propensas a crenças religiosas, acentuando ainda mais a prevalência de pessoas não-religiosas no campo da psiquiatria $^{185}$. Para Rosmarin ${ }^{186}$, essa tendência cria uma resistência ao abordar a R/E na prática e na pesquisa psiquiátrica o que, por sua vez, perpetua suposições em todo o campo, de que a R/E são aspectos tangenciais ao funcionamento humano e uma questão secundária no tratamento.

Nesse sentido, replicando os dados da literatura, nossos estudos demonstraram que as crenças religiosas/espirituais dos psiquiatras influenciavam nas suas atitudes relacionadas à $\mathrm{R} / \mathrm{E}$ na prática clínica ${ }^{149,175,187}$. No estudo 1 , aqueles que consideravam importante a inclusão da $\mathrm{R} / \mathrm{E}$ na prática clínica e na formação do médico tinham mais afiliação religiosa. No estudo 2, encontramos índices maiores de crença em Deus, vida após a morte, reencarnação e enfrentamento ("coping”) religioso/espiritual, relacionados positivamente às variáveis considerar que as próprias crenças influenciam na prática médica e considerar que a prática da medicina pode levar ao questionamento das próprias crenças, indicando a possibilidade da prática médica causar conflitos entre psiquiatras mais religiosos, capazes de fazê-los questionar a própria fé. Estes dados são equivalentes a estudos anteriores ${ }^{149,188}$.

Da mesma forma, as crenças religiosas/espirituais dos psiquiatras brasileiros influenciavam na abordagem da $\mathrm{R} / \mathrm{E}$ de seus pacientes. Em nossos dois estudos encontramos que, apesar de a maioria dos psiquiatras concordar que a R/E deve fazer parte do tratamento médico, apenas a metade deles perguntava com frequência sobre os 
aspectos religiosos/espirituais de seus pacientes. Embora a afiliação religiosa não tenha apresentado associação com incluir ou não a R/E no tratamento médico, encontramos nos dois estudos que as crenças religiosas/espirituais influenciavam a investigação clínica desses aspectos. Os participantes que se consideravam mais religiosos e/ou mais espirituais (estudo 1) e os que acreditavam em reencarnação (estudo 2), abordavam com mais frequência a R/E de seus pacientes. Estes achados são similares aos encontrados na literatura, que apontam as crenças religiosas como preditoras da abordagem da $\mathrm{R} / \mathrm{E}^{111}$, 116, 132, 160, 188-190. São vários os estudos que têm demonstrado a relação existente entre as crenças religiosas/espirituais dos médicos e suas propensões em abordar ou não a $R / E$ no atendimento clínico ${ }^{191,192}$. Geralmente, os médicos com maior autopercepção de R/E tendem a investigar mais a R/E do paciente ${ }^{116,191}$, e o mesmo ocorre com aqueles que declaram maior frequência em práticas religiosas públicas e privadas ${ }^{193,194}$, ao contrário dos profissionais que não se identificam com nenhuma religião e nem participam de encontros religiosos, que são pouco inclinados a entender a $\mathrm{R} / \mathrm{E}$ dos pacientes e/ou indicá-los para aconselhamento espiritual ${ }^{195}$.

Assim, nossos estudos demonstraram que os psiquiatras menos religiosos eram também aqueles que menos discutiam a R/E com seus pacientes, reafirmando o fenômeno da "lacuna religiosa" entre os médicos e pacientes, tão divulgado na literatura $^{196,197}$, no qual os médicos, por não atribuírem importância à R/E em suas vidas, entendem que o mesmo ocorre com seus pacientes, acabando por negligenciar esses aspectos, já constatados como importantes para a maioria deles ${ }^{125}$.

Além dos aspectos discutidos acima, há outro fator relevante que tem sido discutido na literatura, como motivo da discrepância entre considerar importante a avaliação clínica da R/E e realmente incorporá-la na prática médica ${ }^{118,198}$. Trata-se das barreiras e dificuldades encontradas por alguns profissionais na abordagem do tema $^{13,65}$.

A esse respeito, os resultados dos estudos 1 e 2 indicaram que, embora uma parte considerável dos psiquiatras brasileiros não tenha dificuldade em incluir uma avaliação religiosa/espiritual no atendimento clínico, a maioria indicou algum desconforto em tratar desses assuntos com seus pacientes. As barreiras mais declaradas foram: medo de extrapolar o papel do médico, falta de treino e falta de tempo. Estes 
achados são correspondentes aos apresentados por estudos realizados com psiquiatras dos Estados Unidos da América, Alemanha e Reino Unido ${ }^{118,120,132 .}$

Verificamos que, no estudo 1, os psiquiatras que declararam falta de treino como dificuldade na investigação da $\mathrm{R} / \mathrm{E}$ eram mais tendentes a ter alguma religião e, os que indicaram medo de extrapolar o papel do médico, além de relatarem mais afiliação religiosa eram também menos inclinados a abordar a R/E. Parece bem coerente que esses profissionais, temerosos de exceder seu papel, tenham sido menos propensos a incluir a R/E em sua prática. Talvez o fato de terem uma orientação religiosa, somado à possibilidade de não terem recebido treino adequado para tratar da R/E no contexto clínico, exijam de alguns psiquiatras ainda mais cautela para manter a neutralidade necessária na relação terapêutica, de forma que não haja interferência de conteúdos pessoais, no caso, suas próprias crenças religiosas/espirituais.

Estes dados são semelhantes àqueles encontrados por Curlin et al. ${ }^{111}$, ao investigarem as dificuldades na abordagem da R/E em uma amostra de médicos de várias especialidades. A análise univariada aponta que os participantes que relatam falta de treino/conhecimento e desconforto ao lidar com a R/E de seus pacientes são menos propensos a abordar o assunto no atendimento médico, mas, nesse caso, diferente de nossos resultados, eles são menos religiosos e menos espirituais. No entanto, após o ajuste das características religiosas, os médicos que relatam desconforto com o tema permanecem menos propensos a abordar a R/E.

No estudo 2, o grupo que relatou medo de extrapolar o papel do médico como dificuldade para abordar a $\mathrm{R} / \mathrm{E}$ na prática clínica obteve resultados significantemente maiores em religiosidade e em espiritualidade e, por outro lado, aqueles que eram menos religiosos e menos espirituais eram também menos propensos a encontrar dificuldades na abordagem da R/E, reafirmando nossa suposição acima.

De acordo com Korup et al. ${ }^{199}$, é impossível para o médico apresentar-se neutro em termos de valores pessoais, incluindo aqueles decorrentes da religiosidade ou do ateísmo nos cuidados ao paciente. A neutralidade médica, com total isenção de valores pessoais, é um "ideal irrealista" à luz das evidências existentes. Para os autores, o importante é a conscientização desses conteúdos e a percepção de quando estão em ação na prática clínica, a fim de evitar conflitos com os valores do paciente. 
Os resultados acima, referentes às dificuldades e barreiras encontradas na abordagem da R/E, devem ser investigados com mais detalhes em estudos posteriores.

A propósito, como já comentamos anteriormente, pudemos observar nos estudos 1 e 2 que as características religiosas/espirituais dos psiquiatras brasileiros parecem influenciar na forma como atuam na prática clínica. Estes achados, que confirmam a hipótese desta tese, também foram demonstrados no estudo 3, por meio da análise de perfil latente, que identificou padrões polarizados de atuação clínica dos psiquiatras brasileiros relacionados com suas crenças pessoais: os mais religiosos investigavam mais a R/E dos pacientes, e os menos religiosos tendiam a ignorá-las.

Os psiquiatras do perfil "mais religiosos" foram assim denominados por apresentarem maiores índices de religiosidade, espiritualidade, religiosidade intrínseca, enfrentamento religioso, crença em Deus, crença em vida após a morte e crença em reencarnação e, coerentemente, foram os que mais declararam práticas religiosas e espirituais, como frequência em serviços religiosos, oração e leitura religiosa/espiritual. Eram também os que mais consideravam que suas crenças influenciavam em sua prática clínica, e que esta prática interferia em suas crenças pessoais. Tais resultados são semelhantes aos encontrados em um estudo anterior, em que se discute sobre uma potencial influência bidirecional da R/E do médico na prática clínica e da prática clínica na religiosidade do médico ${ }^{188}$. Condizem também com os achados de uma metanálise de 10 estudos envolvendo médicos de sete países, que mostram uma correlação positiva bastante acentuada entre o grau de religiosidade do médico e a percepção da influência que essa religiosidade exerce em seu trabalho ${ }^{149}$.

Mais uma das características que definiu o perfil "mais religiosos" foi considerar a medicina como um chamado, e este dado é compatível aos encontrados em outros estudos, em que médicos em geral e psiquiatras com maior R/E são mais tendentes a conceber a prática da medicina como uma vocação ${ }^{175,187}$.

A maioria dos psiquiatras do perfil "menos religiosos" era do sexo masculino, indicando, como já foi discutido neste trabalho, que as psiquiatras mulheres atribuem maior importância à $\mathrm{R} / \mathrm{E}$ em suas vidas ${ }^{113,116}$. Além de agrupar um percentual maior de homens, o perfil "menos religiosos", não surpreendentemente também reuniu os psiquiatras com menos afiliação religiosa, e estes dados são semelhantes àqueles 
encontrados na população brasileira, em que o sexo masculino lidera o grupo dos sem religião, com uma proporção de $9,7 \%$ para os homens, contra $6,4 \%$ para mulheres ${ }^{145}$.

No que se refere ao impacto da R/E na saúde e tratamento dos pacientes, nossos resultados apontaram que os participantes "mais religiosos" eram os que mais acreditavam nessa interferência. Estes dados são parecidos com os encontrados na literatura, mostrando que os psiquiatras com índices maiores de religiosidade intrínseca tinham uma percepção maior da influência da R/E na saúde dos pacientes e, quanto mais religiosos, mais eles tendiam a considerar essa influência positiva ${ }^{132,194}$. Outros estudos com médicos de várias especialidades também indicam essa mesma tendência ${ }^{191,200 .}$

Nossas análises também revelaram que os psiquiatras do perfil "menos religiosos" consideravam pouco importante a inclusão da R/E na formação profissional, o que parece coerente para quem atribui pouca importância à influência da $R / E$ na saúde e é menos disposto a abordar a R/E do paciente, diferentemente do indicado pelo estudo de Rensburg et al. ${ }^{201}$, em que todos os psiquiatras acadêmicos concordam que a espiritualidade deveria ser incorporada na avaliação clínica e formação em psiquiatria.

Um dos resultados mais relevantes deste estudo diz respeito à educação. Os psiquiatras do perfil "menos religiosos" tinham os níveis educacionais mais altos: foi o grupo que reuniu o maior número de doutores, pós-doutores e livre-docentes. Esta relação negativa entre religião e educação já foi verificada em estudos anteriores ${ }^{202,203}$, mas não se tem um consenso sobre o tema, uma vez que existem estudos que contrariam essa ideia, apresentando uma associação positiva entre religião e educação ${ }^{204-206}$. Há, inclusive, evidências de que essa relação negativa vem diminuindo significativamente nos últimos $\operatorname{anos}^{207}$, indicando certa aceitação na plausibilidade da religião e ciência serem visões de mundo compatíveis e afins ${ }^{206,208 .}$.

Entretanto, nossos dados parecem corroborar a "velha tese" de que educação leva a um declínio da religião ${ }^{209}$, o que seria entendido como parte do processo de dessacralização ou secularização da sociedade, em que os fundamentos da religião foram substituídos pela crença na ciência, crenças seculares, em geral em oposição às crenças religiosas $^{210,211}$.

No entanto, mais uma vez deparamo-nos com a possibilidade de nossos dados estarem representando um fenômeno geracional, já que a obtenção de títulos 
acadêmicos demanda mais tempo na área e, portanto, maior exposição a teorias antirreligiosas que poderiam ter influenciado as crenças desses psiquiatras.

Nossas análises ainda revelaram que os psiquiatras mais instruídos eram também os que menos discutiam a $\mathrm{R} / \mathrm{E}$ com seus pacientes e, nesse sentido, apesar das evidências sobre a tendência dos menos religiosos desconsiderarem a R/E nos cuidados ao paciente, estes dados causam estranheza, pois indicam uma associação negativa entre educação e a abordagem da R/E na prática clínica.

É interessante notar que os psiquiatras com níveis educacionais mais altos, que supostamente teriam mais contato com as evidências científicas e que deveriam advogar em causa delas, norteiem seus comportamentos clínicos com base em pressupostos ultrapassados. Diante de inúmeros estudos indicando o impacto da R/E na saúde mental, seria de se esperar que esses profissionais, mais experientes, treinados e instruídos, abordassem tais temas sem preconceitos e independentemente de seus valores religiosos. Considerar a influência da R/E como negativa para o paciente já é motivo suficiente para incluí-la adequadamente no tratamento médico, e não para negligenciá$\mathrm{la}^{212}$. Verificar se a R/E desempenha algum papel na ocorrência da doença e, se essa influência é positiva ou negativa na recuperação do paciente, é fundamental para que não haja erros diagnósticos ${ }^{213}$.

É importante salientar que a psiquiatria não perde seu caráter científico por investigar a relação da $\mathrm{R} / \mathrm{E}$ e saúde, já que se trata de fenômenos que podem ser investigados cientificamente ${ }^{214}$. Portanto, a abordagem da R/E não pode mais ser relegada pelos profissionais de saúde, sob pena de ver negligenciados aspectos importantes da saúde do paciente ${ }^{215}$. Hoje, essa abordagem é considerada um postulado ético no exercício da psiquiatria ${ }^{216}$, indispensável no atendimento integral do paciente ${ }^{217}$.

\subsection{IMPLICAÇÕES E CONSIDERAÇÕES FUTURAS}

Os resultados de nossos estudos parecem corroborar que o treino possa ser uma ferramenta importante para ajudar os psiquiatras brasileiros a atenderem às novas diretrizes das associações psiquiátricas, referentes à abordagem da R/E nos cuidados 
médicos e, assim, oferecer um atendimento centrado no paciente que inclua sua dimensão religiosa/espiritual.

Os aspectos socioculturais das expressões religiosas vêm sendo cada vez mais reconhecidos na psiquiatria. Atualmente, entende-se que a inclusão do contexto sociocultural onde ocorrem as manifestações religiosas é fundamental na formulação de critérios diagnósticos que diferenciem as manifestações espirituais patológicas daquelas culturalmente aceitas e saudáveis, a fim de se evitar diagnósticos errôneos e/ou iatrogênia ${ }^{213,218}$. No entanto, a maioria dos profissionais de saúde mental não teve, até o momento, um treinamento adequado para lidar com os aspectos religiosos/espirituais de seus pacientes e, por isso, pode estar atuando além dos recursos oferecidos em seu treinamento profissional nas questões relacionadas à $\mathrm{R} / \mathrm{E}^{219}$. Foi o que observamos em nossos relatos; nem todos os psiquiatras brasileiros estão preparados para incluir os aspectos religiosos/espirituais na avaliação e tratamento do paciente. Ao contrário, a maioria relata a falta de treino como uma das maiores dificuldades na abordagem da R/E no atendimento clínico.

Nesse caso, a implementação de programas de capacitação na área seria muito importante para ajudar os profissionais a lidarem com a R/E com profissionalismo, bem como para aumentar a conscientização sobre os possíveis vieses na avaliação da R/E do paciente. Poderia também ajudar a diminuir o desconforto relatado por alguns psiquiatras ao abordar questões envolvendo a R/E. Alguns desafios, no entanto, podem ser mais difíceis de serem superados por dependerem de circunstâncias que não estão inteiramente sob o controle do psiquiatra como, por exemplo, a falta de tempo no atendimento médico. A esse respeito, talvez o treino pudesse, inclusive, esclarecer que embora o cuidado espiritual não deva ser considerado uma prerrogativa exclusiva dos capelães da área da saúde, incluí-los na equipe multidisciplinar ajudaria a evitar dificuldades como "falta de tempo" e "medo de extrapolar o papel do médico", apontadas pelos psiquiatras ao abordar a R/E de seus pacientes. Esta estratégia seria importante na prestação de cuidados integrais ao paciente.

De modo geral, faz-se imperativo estimular o desenvolvimento de competências por meio de treinamentos e proposições teóricas com vistas a capacitar os psiquiatras na aplicação da anamnese religiosa/espiritual, na realização de diagnóstico diferencial entre as expressões de R/E e psicopatológicas, na indicação de serviços do clero e no 
uso de técnicas de intervenções religiosas/espirituais baseadas em evidências 220, 221. Naturalmente, o incremento destas habilidades ajudaria os psiquiatras a refletirem sobre as próprias crenças, sendo elas religiosas ou não, uma vez que, inconscientes, podem se tornar um fator limitante na discussão do tema com seus pacientes ${ }^{190}$.

Nessa perspectiva, o treinamento seria um meio de informar os psiquiatras sobre a relevância da $\mathrm{R} / \mathrm{E}$ na prática clínica e, principalmente, sobre a importância da "boa prática psiquiátrica", que observa limites significativos na abordagem da R/E e afasta a possibilidade de qualquer tipo de proselitismo, seja por crenças religiosas, políticas ou $\operatorname{ateístas~}^{222}$. É fundamental que os psiquiatras considerem seus próprios valores religiosos e respeitem os limites éticos de sua atuação, na busca do atendimento integral do indivíduo.

Em conclusão, é importante pontuar que a grande diversidade étnica, cultural e o pluralismo religioso que caracterizam a população brasileira, acentuam a necessidade de conhecimentos específicos e programas capazes de aperfeiçoar os profissionais de saúde mental no atendimento de pacientes nos diversos cenários socioculturais. É também bastante oportuno reproduzir uma passagem da tese de livre-docência, de 1997, do Prof. Francisco Lotufo Neto ${ }^{223}$ :

A religião, uma variável que influencia a saúde mental, está sendo negligenciada pela psiquiatria nos seus estudos e programas de tratamento e prevenção. É necessário que o psiquiatra esteja familiarizado com a literatura sobre religião e conheça a religiosidade de sua clientela, para saber como utilizá-la clinicamente.

\subsection{LIMITAÇÕES DOS ESTUDOS}

Esta pesquisa apresentou algumas limitações metodológicas. Entre elas, talvez a mais importante tenha sido sua natureza transversal, que não permite inferências formais sobre causalidade. Além disso, as informações foram obtidas por meio do autorrelato dos psiquiatras, uma forma de medida mais vulnerável a vieses de respostas.

A generalização dos dados deve ser realizada com cuidado, uma vez que a taxa de resposta do estudo 1, que reuniu a maior parte dos psiquiatras investigados em nossos estudos, pode ser considerada relativamente baixa (28\%), apesar do tamanho total da amostra ( $\mathrm{n}=484$ de um total de 1779). No entanto, a taxa de resposta ficou no 
intervalo esperado para pesquisas que usam métodos de coleta de dados não-presenciais do tipo mensagens eletrônicas ("e-mail"). Estudos mostraram que os psiquiatras, muitas vezes, são resistentes em participar de pesquisas de opinião ${ }^{224} \mathrm{e}$, geralmente, apresentam baixas taxas de retorno nas pesquisas, inclusive no Brasil ${ }^{225}$. Além do mais, as taxas de resposta para pesquisas realizadas via internet são menores em relação a outros métodos, como entrevistas pessoais, via correio ou telefone ${ }^{226}$. No entanto, $28 \%$ dos psiquiatras contatados completaram a pesquisa, uma percentagem de participação superior a outros estudos que utilizaram metodologia semelhante 226,227 . A taxa de resposta em estudos envolvendo empresários ${ }^{228}$, psiquiatras $^{225}$ e oncologistas ${ }^{229}$, geralmente, não passa de 20\%. Exemplo recente é uma pesquisa realizada no Brasil, via internet, envolvendo o contato de 365 centros espíritas na cidade de São Paulo, na qual apenas $35(15 \%)$ destes aceitaram participar ${ }^{230}$.

Ainda com relação ao estudo 1, é possível que as pessoas que aceitaram participar do estudo tenham sido aquelas que, de alguma forma, eram mais envolvidas com o assunto, tanto a favor como contra, ou seja, as pessoas mais religiosas e aquelas não religiosas podem ter se sentido mais inclinadas a responder ao questionário. Inclusive, no trabalho de Curlin et al. ${ }^{111}$, é relatado que os médicos não religiosos podem ter sido um pouco mais propensos a participar da pesquisa.

Outra dificuldade potencial na interpretação dos resultados diz respeito à definição de conceitos complexos e multifacetados, como espiritualidade e religiosidade. Nesse trabalho, esses termos não foram definidos, permitindo que os participantes aplicassem suas próprias definições e conceitos. Por esse motivo, os resultados dessa pesquisa devem ser interpretados com cautela.

Outro aspecto limitante desse estudo diz respeito à gama de crenças religiosas e espirituais abordada no questionário, que poderia ser maior, incluindo, principalmente, as informações sobre o entendimento dos psiquiatras dos conceitos de R/E, uma vez que existe na população brasileira uma percentagem expressiva de indivíduos que dizem ter duas ou mais religiões. Um estudo recente envolvendo 1169 adultos mostra que 27,7\% dos entrevistados têm múltiplas afiliações religiosas ${ }^{164}$. 


\section{CONCLUSÕES}

Os resultados dos três estudos demonstraram que a maioria dos psiquiatras brasileiros relatou ter afiliação religiosa, crença em Deus e declarava-se mais espiritual que religiosa. Os psiquiatras consideravam importante integrar a $\mathrm{R} / \mathrm{E}$ na prática clínica, mas nem todos incluíam frequentemente uma avaliação religiosa/espiritual na rotina de seu trabalho. As dificuldades para abordar a R/E do paciente apontadas com maior frequência foram: medo de extrapolar o papel do médico, falta de treino e de tempo.

As características religiosas/espirituais dos psiquiatras mostraram-se associadas às suas opiniões e comportamentos relacionados à $\mathrm{R} / \mathrm{E}$ na prática clínica, indicando que os valores religiosos/espirituais dos psiquiatras podem afetar os tipos de cuidados que os seus pacientes recebem. Aqueles que eram mais religiosos, tendiam a abordar mais os aspectos religiosos/espirituais do paciente, além de atribuir maior importância à $R / E$ na avaliação, tratamento e recuperação do paciente; ao passo que os menos religiosos eram propensos a negligenciar a $\mathrm{R} / \mathrm{E}$ do paciente.

Informações e treinamento sobre o tema R/E poderiam ajudar os psiquiatras a superar as barreiras para tratar deste tópico e integrar adequadamente os aspectos religiosos/espirituais de seus pacientes no contexto terapêutico.

A maioria dos participantes era favorável ao estabelecimento de programas de treinamento, para melhorar as habilidades dos psiquiatras em relação à abordagem da R/E no atendimento ao paciente. Os entrevistados também apoiaram a ideia de criar um curso relacionado à R/E para estudantes de graduação em medicina. 
ANEXO 1. Questionário utilizado na pesquisa (detalhes sobre o desenvolvimento do questionário ver nas páginas 19-22) ${ }^{1}$

\section{QUESTIONÁRIO}

\section{A Espiritualidade e a Religiosidade na Prática Psiquiátrica}

EU CONCORDO EM PARTICIPAR DA PESQUISA

\section{SIM}

1. Idade

2. Endereço:

Cidade

Estado

3. Gênero

${ }^{1}$ Feminino

${ }^{2}$ Masculino

4. Estado civil

$\square{ }^{1}$ Casado / União estável

${ }^{2}$ Solteiro

${ }^{3}$ Divorciado

${ }^{4}$ Viúvo

5. Grau de instrução

$\square{ }^{1}$ Graduação

${ }^{2}$ Residência

${ }^{3}$ Especialização

${ }^{4}$ Mestrado

${ }^{5}$ Doutorado

${ }^{6}$ Pós-doutorado

\footnotetext{
1 Para o estudo 2 foi feita adaptação do questionário em cinco perguntas com vistas a melhorar a clareza e fluidez nas repostas.
} 
6. Há quantos anos você concluiu a residência?

7. Em quais áreas da psiquiatria você atua? (Subespecialidade) (Marque todas as opções aplicáveis)

Adulto

Infantil

Geriátrica

Forense

Outras (especifique)

8. Há quanto tempo você trabalha na psiquiatria?

9. Qual é a sua afiliação religiosa?

${ }^{1}$ Católica

${ }^{2}$ Protestante

${ }^{3}$ Evangélica

${ }^{4}$ Espírita Kardecista

${ }^{5}$ Espíritas Afro-brasileiras (Umbanda, Candomblé, Quimbanda etc.)

${ }^{6}$ Judaica

${ }^{8}$ Islâmica

${ }^{9}$ Budista

${ }^{11}$ Agnóstica

${ }^{12}$ Ateísta

${ }^{13}$ Nenhuma

${ }^{14}$ Outras (especifique)

10. Com que frequência você visita algum templo religioso?

${ }^{1}$ Nunca

${ }^{2}$ Uma ou mais vezes ao ano

${ }^{3}$ Uma ou mais vezes ao mês

${ }^{4}$ Uma ou mais vezes na semana

${ }^{5}$ Diariamente

11. Com que frequência você faz algum tipo de leitura religiosa/ espiritual?

${ }^{1}$ Nunca

${ }^{2}$ Uma ou mais vezes ao ano

${ }^{3}$ Uma ou mais vezes ao mês

${ }^{4}$ Uma ou mais vezes na semana

${ }^{5}$ Diariamente 
12. Com que frequência você faz alguma reza, prece ou oração?

$\square^{1}$ Nunca,

$\square^{2}$ Uma ou mais vezes ao ano

$\square{ }^{3}$ Uma ou mais vezes ao mês

${ }^{4}$ Uma ou mais vezes na semana

${ }^{5}$ Diariamente

13. Com que frequência você realiza alguma prática espiritual não religiosa (como meditar, ioga etc.)?

$\square^{1}$ Nunca

${ }^{2}$ Uma ou mais vezes ao ano

${ }^{3}$ Uma ou mais vezes ao mês

${ }^{4}$ Uma ou mais vezes na semana

${ }^{5}$ Diariamente

14. Você acredita em Deus ou Poder Superior?

$\square{ }^{0}$ Não

${ }^{1}$ Não sei

${ }^{2} \mathrm{Sim}$

15. Você acredita em vida após a morte?

$\square{ }^{0}$ Não

$\square^{1}$ Não sei

${ }^{2} \mathrm{Sim}$

16. Você acredita em reencarnação?

$\square{ }^{0}$ Não

${ }^{1}$ Não sei

${ }^{2} \mathrm{Sim}$

Sobre sua religiosidade intrínseca

A religiosidade intrínseca refere-se ao quanto uma pessoa tem na religião o motivo principal que guia e dá sentido à sua vida.

17. Eu me esforço muito para viver minhas crenças religiosas/espirituais em todos os aspectos da minha vida. Toda minha maneira de viver é baseada nas minhas crenças religiosas/ espirituais.

$\square{ }^{1}$ Discordo plenamente

${ }^{2}$ Discordo moderadamente

${ }^{3}$ Concordo moderadamente

${ }^{4}$ Concordo plenamente

18. O quanto você se considera uma pessoa espiritual?

${ }^{1}$ Nada espiritual

${ }^{2}$ Pouco espiritual

${ }^{3}$ Moderadamente espiritual

${ }^{4}$ Muito espiritual 
19. O quanto você se considera uma pessoa religiosa?

${ }^{1}$ Nada religiosa

$\square^{2}$ Pouco religiosa

${ }^{3}$ Moderadamente religiosa

${ }^{4}$ Muito religiosa

20. Minhas crenças religiosas/espirituais influenciam minha prática clínica.

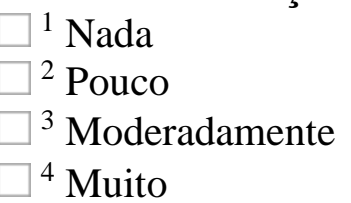

21. Para mim a medicina é um chamado

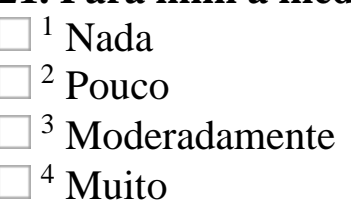

22. Minha experiência como médico fez com que eu questionasse as minhas crenças religiosas/espirituais.
$\square{ }^{1}$ Nada
$\square^{2}$ Pouco
${ }^{3}$ Moderadamente
${ }^{4}$ Muito

23. Considero um desafio permanecer fiel à minha religião em meu trabalho como médico.
$\square{ }^{1}$ Nada
]$^{2}$ Pouco
${ }^{3}$ Moderadamente
${ }^{4}$ Muito

\section{Enfrentamento religioso/espiritual}

Responda às questões abaixo com a alternativa que melhor expressa a forma como você enfrenta as situações de adversidade de sua vida.

24. Eu tento compreender a situação e decidir o que fazer sem a ajuda de Deus
${ }^{1}$ Nunca
${ }^{2}$ Raramente
${ }^{3}$ Ocasionalmente
${ }^{4}$ Frequentemente

25. Procuro em Deus força, apoio e orientação.
${ }^{1}$ Nunca
${ }^{2}$ Raramente
${ }^{3}$ Ocasionalmente
${ }^{4}$ Frequentemente 
26. Você considera importante integrar a religiosidade e a espiritualidade na prática clínica?

$\square{ }^{1}$ Nada importante

$\square^{2}$ Pouco importante

$\square^{3}$ Razoavelmente importante

${ }^{4}$ Muito importante

27. Você considera importante que o tema religiosidade/espiritualidade seja inserido na formação do médico?

$\square{ }^{1}$ Nada importante

${ }^{2}$ Pouco importante

${ }^{3}$ Razoavelmente importante

${ }^{4}$ Muito importante

28. Você considera importante que o tema religiosidade/espiritualidade seja inserido na educação continuada do psiquiatra?

$\square^{1}$ Nada importante

$\square^{2}$ Pouco importante

${ }^{3}$ Razoavelmente importante

${ }^{4}$ Muito importante

29. Na sua opinião, com que frequência as crenças religiosas/espirituais afetam o bem-estar e a evolução clínica do paciente?

$\square{ }^{1}$ Nunca

]$^{2}$ Raramente

${ }^{3}$ Ocasionalmente

${ }^{4}$ Frequentemente

30. Na sua opinião, com que frequência as crenças religiosas/espirituais afetam as decisões dos pacientes sobre o tratamento indicado?

$\square^{1}$ Nunca

${ }^{2}$ Raramente

${ }^{3}$ Ocasionalmente

${ }^{4}$ Frequentemente

31. Perguntar sobre a religiosidade/espiritualidade do paciente é algo que o psiquiatra pode ou deve fazer?

$\square^{1}$ Não

$\square^{2} \operatorname{Sim}$

${ }^{3}$ Não sei 
32. Com que frequência você pergunta sobre as questões religiosas/espirituais de seus pacientes?

$\square^{1}$ Nunca

$\square^{2}$ Raramente

${ }^{3}$ Ocasionalmente

${ }^{4}$ Frequentemente

33. Desafios ou barreiras para abordar a religiosidade/espiritualidade dos pacientes.

(Marque todas as opções aplicáveis)

Nenhuma

Falta de tempo

Falta de treino

Não é papel do médico

Medo de extrapolar o papel do médico

Os aspectos religiosos/espirituais não são relevantes para o paciente

Medo de ofender o paciente

Não se sentir confortável com o tema

Não saber o porquê ou as razões

Receio de que os colegas não aprovem

Se você quiser deixar algum comentário, opinião ou sugestão, use o espaço abaixo. Eles serão muito úteis para este estudo.

OBRIGADA PELA SUA PARTICIPAÇÃO! 


\section{ANEXO 2. Parecer do Comitê de Ética em Pesquisa}

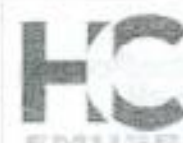

\section{USP - HOSPITAL DAS \\ CLINIICAS DA FACULDADE DE MEDICINA DA UNIVERSIDADE}

\section{PARECER CONSUBSTANCIADO DO CEP}

\section{DADOS DO PROJETO DE PESQUISA}

Titulo da Pesquisa: A RELIGIOSIDÁDE E A ESPIRITUALIDADE NA CLINICA PSIOUIÁTRICA Pesquisador: Homero Pinto Vallada Filne

Área Temática:

Versão: 3

CAAE: 12513113.7 .0000 .0068

Instituiçăo Proponente: HOSPITAL DAS CLINICAS DA FACULUADE DE MEDICINA DA U SP Patrocinador Principal: Financiamentc Proprio

\section{DADOS DA NOTIFICACÄO}

Tipo de Notificaçăo: Outros

Detalhe: Retifcaça Parecer Número 2,132.838 Pesquisadora Executante

Justificativa: Solicitc retificaçao do Parecer Número 2,132.838, Protocolo de Pesquisa CAMF

Data do Envlo: 04/07/2017

Situaçâo da Notificaçăo: Parecer Consubstanciado Emitido

DADOS DO PARECER

Nümero do Parecer: 2.155 .088

Apresentaçăo da Notificaçäo:

O pesquisador solicita correçăo no parecer $n^{\circ} 2.132 .830$ onde faltou constar que a cmenda tratava-se da alteraçäo de fina idade acadèmica para obtençāo de titulo de doutorado da pós-graduanda MARIA CECI_IA MENEGATTI CHEQUINI

Objetivo da Notificação:

Corrẹăc no parecer n².132.838

Avaliaça dos Riscos e Beneficios:

Nào se aplica

Comentários o Consideraçoos sobre a Notificaça:

Nenhum

Endersço: Rus Cvitio Firss de Carrocs. $2255^{\circ}$ antar

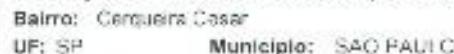

Teletone: (1):2661-7585 Fax: (11;2651-7585 E-mait cap9e59 admanc.fin.uso.br 


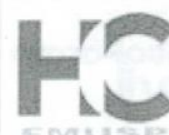

Continuaçăo do Parecer: 2.155 .088
USP - HOSPITAL DAS

CLIINICAS DA FACULDADE DE MEDICINA DA UNIVERSIDADE

Considerações sobre os Termos de apresentação obrigatória:

Nenhum

Conclusões ou Pendências e Lista de Inadequações:

Sem pendências, somente correção no parecer $n^{\circ} 2.132 .838$ relativo a emenda ao protocolo.

Considerações Finais a critério do CEP:

Este parecer foi elaborado baseado nos documentos abaixo relacionados:

\begin{tabular}{|l|l|c|l|c|}
\hline Tipo Documento & \multicolumn{1}{|c|}{ Arquivo } & Postagem & Autor & Situação \\
\hline Outros & Carta_04_de_julho_de_2017.pdf & $\begin{array}{c}\text { 04/07/2017 } \\
12: 23: 10\end{array}$ & $\begin{array}{l}\text { Homero Pinto } \\
\text { Vallada Filho }\end{array}$ & Aceito \\
\hline
\end{tabular}

Situação do Parecer:

Aprovado

Necessita Apreciação da CONEP:

Não

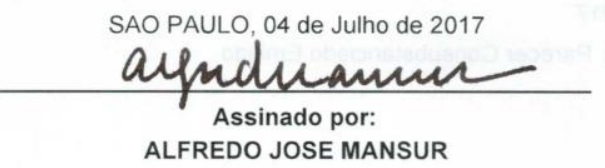

(Coordenador)

Endereço: Rua Ovidio Pires de Campos, $2255^{\circ}$ andar

Bairro: Cerqueira Cesar CEP: $05.403-010$

UF: SP Municipio: SAO PAULO

Telefone: (11)2661-7585 Fax: (11)2661-7585 E-mail: cappesq.adm@hc.fm.usp.br 


\section{REFERÊNCIAS}

1 Eliade M. História das crenças e das ideias religiosas. Da idade da pedra aos mistérios de Elêusis. Tradução de Roberto Carlos de Lacerda. Rio de Janeiro: Jorge Zahar Ed.; 2010. Vol. I, p. 13. 3v.

2 Koenig HG, King D, Carson V. Handbook of religion and health. $2^{\text {nd }}$ ed. New York: Oxford University Press; 2012.

3 Thielman SB. Reflections on the role of religion in the history of psychiatry. In: Koenig HG, Rosmarin D, editors. Handbook of Religion and Mental Health. San Diego (CA): Academic Press; 1998. p. 03-20.

4 Koenig HG. Religion and medicine I: historical background and reasons for separation. Int J Psychiatry Med. 2000; 30(4): 385-99.

$5 \quad$ Loschen E. Psychiatry and religion: a variable history. J Relig Health. 1974; 13(2): 137-42.

6 Thielman SB. Spirituality and the care of madness: historical considerations. In: Huguelet $\mathrm{P}$, Koenig $\mathrm{HG}$, editors. Religion and spirituality in psychiatry. Cambridge, UK: Cambridge University Press; 2009. p. 06-18.

7 Koenig HG. Religião, espiritualidade e psiquiatria: uma nova era na atenção à saúde mental. Rev Psiquiatr Clin. 2007; 34: 5-7.

8 Figueiredo G. As origens da assistência psiquiátrica no Brasil: o papel das Santas Casas. Rev Bras Psiquiatr. 2000; 22(3):133.

9 Moreira J. Notícia sobre a evolução da assistência a alienados no Brasil. Rev Latinoam Psicopatol Fundam. 1905; 14(4):728-69.

10 Oda A, Dalgalarrondo P. O início da assistência aos alienados no Brasil ou a importância e necessidade de estudar a história da psiquiatria. Rev Latinoam Psicopatol Fundam. 2004; 7(1):128-41. 
11 Freud S. O futuro de uma ilusão. Tradução de José Octávio de Aguiar Abreu. Rio de Janeiro: Imago; 1975 (Edição Standard Brasileira das Obras Psicológicas Completas de Sigmund Freud; vol. XXI).

12 Freud S. Moisés e o monoteísmo: três ensaios. Tradução de José Octávio de Aguiar Abreu. Rio de Janeiro: Imago; 1975 (Edição Standard Brasileira das Obras Psicológicas Completas de Sigmund Freud; vol. XXIII).

13 Neeleman J, Persaud R. Why do psychiatrists neglect religion. Br J Med Psychol. 1995; 68:169-78.

14 Ellis A. A case against religion: a psychoanalist's view. In: Ard BN, editor. Counseling and psychoterapy: classics on theories and issues. Palo Alto, CA: Science and Behavior Books; 1966. p. 270-82.

15 Halaz G. In conversation with Albert Ellis. Australas Psychiatry. 2004; 12(4):325-33.

16 Farley F. Albert Ellis (1913-2007). Am Psychol. 2009; 64(3):215-6.

17 Appel KE. Academy of religion and mental health: past and future. J Relig Health.1965; 4(3): 207-16.

18 Academy of Religion and Mental Health (ARMH). Editorial. J Relig Health. 1961; 1(1):9.

19 Sanua VD. Religion, mental health, and personality: A review of empirical studies. Amer J Psychiat. 1969; 125: 1203-13.

20 Franzblau AN, D’Agostino A, Draper E, Egan MH, Grosch WN, Honig EM, Rizzuto A. Psychiatrist's viewpoints on religion and their services to religious institutions and the ministry - Task Force Report 10 - American Psychiatric Association [internet]. 1975 [acessed 03 jan 2016]. Available from: www.psychiatry.org/File\%20Library/Psychiatrists/Directories/Library-andArchive/task-force-reports/tfr1975 Religion.pdf.

21 Ellis A. Psychotherapy and atheistic values: a response to A. E. Bergins's "Psychotherapy and religious values". J Consult Clin Psychol. 1980; 48(5): 635-9. 
22 Watters WW. Christianity and mental health. Humanist.1987; 47(6):5-11.

23 Michalsky W. God's psychiatrist? A biografical goodbye to Dr. Wendell Watters. Humanist Perspectives. 2013; 183:23-7.

24 Koenig HG, McCullough M, Larson D. Handbook of Religion and Health. New York: Oxford University Press; 2001.

25 Zinnbauer BJ, Pargament KI. Religiouness and spirituality. In: Paloutzian RF, Park CL, editors. Handbook of the Psychology of religion and spirituality. New York: The Guilford Press; 2005. p. 21-42.

26 Anandarajah G, Hight E. Spirituality and medical practice: using the HOPE questions as a practical tool for spiritual assessment. Am Fam Physician. 2001; 63(1): 81-8.

27 Puchalski CM, Ferrel B, Virani R, Otis-Green S, Baird P, Chochinov H, Handzo G, Nelson-Becker H, Prince-Paul M, Pugliese K, Sulmasy D. Improving the quality of spiritual care as a dimension of palliative care: the report of the consensus conference. J Palliat Med. 2009; 12(10): 885-904.

28 Puchalski CM, Vitillo R, Hull SK, Reller N. Improving the spiritual dimension of the whole person care: reaching national and international consensus. J Palliat Med. 2014; 17(6): 642-56.

29 Allport GW, Ross JM. Personal religious orientation and prejudice. J Pers Soc Psychol.1967; 5(4):432-43.

30 Pargament KI. The psychology of religion and coping. Theory, research, practice. New York: The Guilford Press; 1997.

31 Pargament KI, Ano GG, Wachholtz AB. The religious dimension of coping: advances in theory, research, and practice. In: Paloutzian RF, Park CL, editors. Handbook of the psychology of religion and spirituality. New York: The Guilford Press; 2005. p. 479-95.

32 Pargament KI, Lomax J. Understanding and addressing religion among people with mental illness. World Psychiatry. 2013; 12(1): 26-32. 
33 Verhagen $\mathrm{P}$. The case for more effective relationships between psychiatry, religion and spirituality. Curr Opin Psychiatry. 2010; 23(6):550-5.

34 Moreira-Almeida A, Lotufo Neto F, Koenig HG. Religiousness and mental health: a review. Rev Bras Psiquatr. 2006; 28(3):242-50.

35 Ai AL, Pargament KI, Appel HB, Kronfol Z. Depression following open-heart surgery: a path model involving interleukin-6, spiritual struggle, and hope under preoperative distress. J Clin Psychol. 2010: 66(10):1057-75.

36 Koenig HG. Medicine, Religion and Health. Where Science and Spirituality Meet. West Conshohocken, PA: Templeton Press; 2008. p. 96-112.

37 Gillum RF, Ingram DD. Frequency of attendance at religious services, hypertension, and blood pressure: the third national health and nutrition examination survey. Psychosom Med. 2006; 68(3): 382-5.

38 Chida Y, Steptoe A, Powell LH. Religiosity/spiritualitity and mortality. A systematic quantitative review. Psychoter Psychosom. 2009; 78(2): 81-90.

39 Garrusi B, Nakhaee N. Religion and smoking: a review of recent literature. Int J Psychiatr Med. 2012; 43(3):279-92.

40 Gonçalves JP, Lucchetti G, Menezes PR, Vallada H. Religious and spiritual intervention in mental health care: a systematic review and meta-analysis of randomized controlled clinical trials. Psychol Med. 2015; 45(14):2937-49.

41 Ringdal G, Gotestam K, Kaasa S, Kvinnslaud S, Ringdal K. Prognostic factors and survival in a heterogeneous sample of cancer patients. Br J Cancer. 1995; 73:1594-9.

42 Hummer RA, Rogers RG, Nam CB, Ellison CG. Religious involvement and US adult mortality. Demography. 1999; 36(2):273-85.

43 Koenig HG. Religion, spirituality, and health: The research and clinical implications [internet]. 2012 [cited 02 may 2015]. Available from: http://www.hindawi.com/journals/ISRN/2012278730.

44 Koenig HG. Religion, spirituality, and health: a review and update. Adv Mind Body Med. 2015; 29(3):19-26. 
45 Miller L, Bansal R, Wickramaratne P, Hao X, Tenke CE, Weissman, MM, Peterson, BS. Neuroanatomical correlates of religiosity and spirituality. A study in adults at high and low familial risk for depression. JAMA Psychiatry. 2014; 71(2):128-35.

46 Croezen S, Avendano M, Burdorf A, van Lenthe F. Social participation and depression in old age: a fixed-effects analysis in 10 European countries. Am J Epidemiol. 2015; 182(2):168-76.

47 Li S, Okereke O, Chang S, Kawachi I, Tyler J, VanderWeele TJ. Religious service attendance and lower depression among women: a prospective cohort study. Ann Behav Med. 2016; 50(6): 876-84.

48 Rasic DT, Belik SL, Elias B, Katz LY, Enns M, Sareen J. Spirituality, religion, and suicidal behavior in a nationally representative sample. J Affect Disord. 2009; 114(1):32-40.

49 VanderWeele TJ, Li S, Tsai A, Kawachi I. Association between religious service attendance and lower suicide rates among US women. JAMA Psychiatry. 2016; 73(8):845-51.

50 Kravolec K, Kunrath S, Fartacek C, Pichler E, Ploderi M. The gender-specific associations between religion/spirituality and suicide risk in a sample of austrian psychiatric inpatients. Suicide Life Threat Behav [internet]. 2017 [cited 02 jun 2018]. DOI:10.1111/sltb.12349.

51 Geppert C, Bogenschutz MP, Miller WR. Development of a bibliography on religion, spirituality and addictions. Drug Alcohol Rev. 2009; 26(4):389-95.

52 Spilman S, Neepl T, Donnellan MB, Schofield T, Conger R. Incorporating religiosity into a developmental model of positive family functioning across generations. Dev Psychol. 2013; 49(4):762-74.

53 Strawbridge W, Shema S, Cohen R, Kaplan G. Religious attendance increases survival by improving and maintaining good health behaviors, mental health, and social relationships. Ann Behav Med. 2001; 23(1): 68-74.

54 Bonelli R, Koenig HG. Mental disorders, religion and spirituality 1990 to 2010: a systematic evidence-based review. J Relig Health. 2013; 52(2):657-73. 
55 Koenig HG. Religion, spirituality, and anxiety disorders. In: Huguelet P, Koenig HG, eds. Religion and spirituality in psychiatry. Cambridge (UK): Cambridge University Press; 2009. p. 128-44.

56 Neeleman J, Lewis G. Religious identity and comfort beliefs in three groups of psychiatric patients and a group of medical controls. Int J Soc Psychiatry. 1994; 40(2):124-34.

57 Yangarber-Hicks N. Religious coping styles and recovery from serious mental illness. J Psychol Theol. 2004; 32:305-17.

58 Mohr S, Brandt P-Y, Borras L, Gillieron C, Huguelet P. Toward an integration of spirituality and religiousness into the psychosocial dimension of schizophrenia. Am J Psychiatry. 2006; 163(11):1952-9.

59 Tepper L, Rogers SA, Coleman EM, Malony HN. The prevalence of religious coping among patients with persistent mental illness. Psychiatr Serv. 2001; 52(5):660-5.

60 Pargament KI, Koenig HG, Tarakeshwar N, Hahn J. Religious struggle as a predictor of mortality among medically ill elderly patients: a 2-year longitudinal study. Arch Intern Med. 2001; 161(15):1881-5.

61 Abu-Raya H, Pargament KL, Krause N, Ironson G. Robust links between religious/spiritual struggles, psychological distress, and well-being in a national sample of american adults. Am J Orthopsychiatry. 2015; 85(6):565-75.

62 Trevino K, Pargament KI, Cotton S, Leonard AC, Hahn J, Caprini-Faigin CA, Tsevat J. Religious coping and physiological, psychological, social and spiritual outcomes in patients with HIV/AIDS: cross-sectional and longitudinal findings. AIDS Behav. 2010; 14(2):379-89.

63 McConnell K, Pargament KI, Ellison C, Flanelly KJ. Examining the links between spiritual struggles and symptoms of psychopathology in a national sample. J Clin Psychol. 2006; 62(12):1469-84.

64 Pirutinsky S, Rosmarin D, Pargament KI, Midlarsky E. Does negative religious coping accompany, precede, or follow depression among orthodox jews? J Affect Disord. 2011; 132(3):401-5. 
65 Moreira-Almeida A, Koenig HG, Lucchetti G. Clinical implications of spirituality on mental health: review of evidence and practical guidelines. Rev Bras Psiquiatr. 2014; 36(2):176-82.

66 Reuder ME. A history of Divison 36 (Psychology of Religion). In: Dewsbury DA, editor. Unification through division: histories of the divisions of the American Psychological Association. Washington DC: American Psychological Association; 1999. p. 91-108.

67 American Association of Colleges of Nursing (AACN). White Paper on the Education and Role of the Clinical Nurse Leader [internet]. 2007 [cited 23 apr 2018]. Available from: http://cnlassociation.org/wpcontent/pdf/ClinicalNurseLeader.pdf.

68 Canadian Nursing Association (CNA). Position Statement - Spirituality, Health and Nursing Practice [internet]. 2010 [cited 23 apr 2016). Available from: https://www.cna-alic.ca/ /media/page-content/pdfen/ps111_spirituality_2010_e.pdf?la=em.

69 Lo B, Quill T, Tulsky J. Discussing palliative care with patients. ACP-ASIM endof-life care consensus painel. Ann Intern Med. 1999; 130(9):744-9.

70 Joint Commission on Accreditation of Healthcare Organization (JCAHO). Medical Record - Spiritual Assessment [internet]. 2001 [cited 05 jul 2016). Available from: www.jcaho.org/standart/pharmfaq_mpfrm.html.

71 American Psychiatric Association (APA). Committee on religion and psychiatry. Guidelines regarding possible conflict between psychiatrists' religious commitments and psychiatric practice. Am J Psychiatry. 1990; 147(4):542.

72 American Psychiatric Association Foundation (APAF). Mental Health: A Guide for Faith Leaders. Arlington, VA: American Psychiatric Association Foundation; 2016.

73 Accreditation Council for Graduate Medical Education (ACGME). Program requirements for graduate medical education in Psychiatry [internet]. 1994 [cited 23 apr 2016]. Available from: www.acgme.org/Portals/0/PFassets/ProgramRequirements/400_psychiatry_201707-01.pdf. 
74 Bowman ES. Teaching religious and spiritual issues. In: Huguelet P, Koenig HG, eds. Religion and spirituality in psychatry. Cambridge, UK: Cambridge University Press; 2009. p. 332-53.

75 Royal College of Psychiatrists London (RCP). The Spirituality and Psychiatry Special Interest Group [internet]. 1999 [cited 02 may 2015]. Available from: www.rcpsych.ac.uk/college/specialinterestgroups/spirituality.aspx.

76 Royal College of Psychiatrists London (RCP). Recomendations for psychiatrists on spirituality and religion. Position Statement 2011 [internet]. 2013 [cited 02 may 2015]. Available from: www.rcpshy.ac.uk/pdf/PSO3_2013.pdf

77 Verhagen P, Cook C. Proposal for a world psychiatric association consensus or position statement on spirituality and religion in psychiatry. In: Verhagen PJ, van Praag HM, López-Ibor Jr J, Cox JL, Moussaoui D, editors. Religion and psychiatry: beyond boundaries. Oxford (UK): John Wiley \& Sons; 2010. p. 61532.

78 Moreira-Almeida A, Sharma A, Rensburg B, Verhagen P, Cook C. WPA Position statement on spirituality and religion in psychiatry. World Psychiatry. 2016; 15(1):87-8.

79 Campion J, Bhui K, Bhugra D. European Psychiatric Association (EPA) guidance on prevention of mental disorders. Eur Psychiatry. 2012; 27:68-80.

80 Kalra G, Christodoulou G, Jenkins R, Tsipas V, Christodoulou N, Lecic-Tosevski D, Mezzich J, Bhugra D. Mental health promotion: guidance and strategies. Eur Psychiatry. 2012; 27: 81-6.

81 Cordeiro Q. Creation of the section on spirituality and mental health at the brazilian psychiatric association. Psyche and spirit. 2014; 1(Feb 2014):2-3.

82 Lukoff D, Lu F, Turner R. Toward a more culturally sensitive DSM-IV. Psychoreligious and psychospiritual problems. J Nerv Ment Dis. 1992; 180(11):673-82.

83 Turner RP, Lukoff D, Barnhouse RT, Lu FG. Religious or spiritual problem. A culturally sensitive diagnostic category in the DSM-IV. J Nerv Ment Dis. 1995; 183(7):435-44. 
84 Larson DB, Thielman SB, Greenwold MA, Lyons JS Post SG, Sherrill KA, Wood KA, Larson SS. Religious content in the DSM-III-R glossary of technical terms. Am J Psychiatry. 1993; 150(12): 1884-5.

85 Lukoff D, Lu FG, Yang CP. DSM-IV religious and spiritual problems. In: Peteet JR, Lu FG, Narrow WE, editors. Religious and spiritual issues in psychiatric diagnosis: a research agenda for a DSM-V. Arlington, VA: American Psychiatric Association; 2011. p. 171-98.

86 Koenig HG. Religion and future psychiatric nosology and treatment. In: Boehnlein JK, editor. Psychiatry and Religion: the convergence of mind and spirit. Washington, DC: American Psychiatric Press; 2000. p.169-86.

87 Lukoff D, Lu F, Turner R. From spiritual emergency to spiritual problem: the transpersonal roots of the new DSM-IV category. J Humanist Psychol. 1998; 38(2): 21-50.

88 Lukoff D, Lu F, Turner R. Cultural considerations in the assessment and treatment of religious and spiritual problems. Psychiatr Clin North Am. 1995; 18(3):467-85.

89 American Psychiatric Association (APA). Manual Diagnóstico e Estatístico de Transtornos Mentais DSM-5. Tradução de Maria Inês Corrêa Nascimento. Porto Alegre: Artmed; 2014.

90 de Marco M. A evolução da medicina. In: de Marco M, ed. A face humana da medicina. Do modelo biomédico ao modelo biopsicossocial. São Paulo: Casa do Psicólogo; 2003. p.23-40.

91 Borrel-Carrió F, Suchman A, Epstein R. The biopsychosocial model 25 years later: principles, practice, and scientific inquiry. Ann Fam Med. 2004; 6(2): 57682.

92 Deacon B, McKay D. The biomedical model of psychological problems: a call for critical dialogue. Behav Ther. 2015; 38(7):231-5.

93 Engel G. The need for a new medical model: a challenge for biomedicine. Science. 1977; 196(4286):129-36. 
94 Craddock N, Antebi D, Attenburrow M, Bailey A, Carson A, Cowen, P, Eagles J, Ebmeier K, Farmer A, Ferrie N, Geddes J, Godwin G, Harrison P, Hawton K, Hunter S, Jacoby R, Jones I, Kedwell P, Ker M, Mackin P, McGuffin P, Macintyre D, McConville P, Mountain D, O'Donovan MC, Owen MJ, Oyebode F, Philliphs M, Price J, Shah P, Smith DJ, Walters J, Woodruff P, Young A, Zammit S. Wake-up call for british psychiatry. Br J Psychiatry. 2008; 193(1):6-9.

95 Ghaemi S. The rise and fall of the biopsychossocial model. Br J Psychiatry. 2009; 195(1):3-4.

96 Cox J, Verhagen PJ. Spirituality, religion and psychopathology: towards an integrative psychiatry. Int J Pers Cent Med. 2011; 1(1):146-8.

97 Sulmasy D. A Biopsychosocial-spiritual model for the care of patients at the end of life. Gerontologist. 2002; 42(3):24-33.

98 Hefti R. Integrating spiritual issues into therapy. In: Huguelet P, Koenig HG, eds. Religion and spirituality in psychiatry. Cambridge (UK): Cambridge University Press; 2009. p.244-67.

99 Hefti R. The extended biopsychosocial model: a whole-person-approach to psychosomatic medicine and psychiatry. Psyche \& Geloof. 2013; 24(2):119-29.

100 Frankl V. Psicoterapia e sentido da vida. Tradução de Alípio Maia de Castro. $4^{\text {a. }}$ ed. São Paulo: Quadrante; 2003.

101 Puchalski CM, Romer A. Taking a spiritual history allows clinicians to understand patients more fully. J Palliat Care Med. 2000; 3(1):129-37.

102 Hodgson J, Lamson A, Reese L. The biopsychosocial-spiritual interview model. In: Linville D, Hertlein K, editors. The therapist's notebook for family health care: homework, handouts, and activities for individuals, couples, and families coping with illness, loss, and disability. New York: The Haworth Press; 2007. p.312.

103 Lim C, Sim K, Renjan V, Sam HF, Quah SL. Adapted cognitive-behavioral therapy for religious individuals with mental disorder: a systematic review. Asian J Psychiatr. 2014; 9:3-12. 
104 Berk LS, Bellinger DL, Koenig HG, Daher N, Pearce MJ, Robins CJ, Nelson B, Shaw SF, Cohen HJ, King MB. Effects of religious vs. conventional cognitivebehavioral therapy on inflammatory markers and stress hormones in major depression and chronic medical illness: a randomized clinical trial. Open $J$ Psychiatr. 2015; 5(3):238-59.

105 Koenig HG, Boucher NA, O'Garo KN, Pearce M. Religiously-integrated cognitive behavioral therapy for major depression in chronic medical illness: review of results from a randomized clinical trial. Health and Social Care Chaplaincy. 2016; 4(2):237-53.

106 Wade NR. Integrating cognitive processing therapy and spirituality for the treatment of post-traumatic stress disorder in the military. Social Work and Christianity. 2016; 43(3):59-72.

107 Trice H, Staudenmeier Jr. W. A sociocultural history of Alcoholics Anonymous. In: Galanter M., editor. Recent Developments in Alcoholism. Boston: Springer; 1989. p. 11-35.

108 Alcoholics Anonymous. Twelve steps [internet]. 1953 [cited 27 jul 2016]. Available: from: https://www.aa.org/assets/en_US/en_tt_contents.pdf.

109 Galanter M. Spirituality and recovery in 12-steps programs: an empirical model. $J$ Subst Abuse Treat. 2007; 33(3):265-72.

110 Cummings JP, Pargament KI. Medicine for the spirit: religious coping in individuals with medical conditions. Religions. 2010; 1(1):28-53.

111 Curlin FA, Chin M, Sellergren S, Roach C, Lantos J. The association of physicians' religious characteristics with their attitudes and self-reported behaviors regarding religion and spirituality in the clinical encounter. Med Care. 2006; 44(5): 446-53.

112 Hvidt NC, Korup AK, Curlin FA, Baumann K, Frick E, Sondergaard J, Nielsen JB, Christensen RD, Lawrence R, Lucchetti G, Ramakrishnan P, Karimah A, Schulze A, Wermuth I, Schouten E, Hefti R, Lee E, AlYousefi NA, van Randwijk CB, Kuseyri C, Mukwayakala T, Wey M, Eglin M, Opshal T, Büssing A. The NERSH international collaboration on values, spirituality and religion in medicine: development of questionnaire, description of data pool, and overview of pool publications. Religions (Basel). 2016; 7(107). 
113 Neeleman J, King M. Psychiatrists religious attitudes in relation to their clinicalpractice - a survey of 231 psychiatrists. Acta Psychiatr Scand. 1993; 88(6): 420-4.

114 Shafranske E. Religious involvement and professional practices of psychiatrists and other mental health professionals. Psychiatr Ann. 2000; 30:525-32.

115 Payman V. Do psychogeriatricians 'neglect' religion? An antipodean survey. Int Psychogeriatr. 2000; 12(2):135-44.

116 Baetz M, Griffin R, Bowen R, Marcoux G. Spirituality and psychiatry in Canada: psychiatric practice compared with patient expectations. Can J Psychiatry. 2004; 49(4):265-71.

117 Lawrence RM, Head J, Christodoulou G, Andonovska B, Karamat S, Duggal A, Hillam J, Eagger S. Clinician's attitudes to spirituality in old age psychiatry. Int Psychogeriatr. 2007; 19(5):962-73.

118 Durà-Vilà G, Hagger M, Dein S, Gerard L. Ethnicity, religion and clinical practice: a qualitative study of beliefs and attitudes of psychiatrists in the United Kingdom. Ment Health Relig Cult. 2011; 14(01):53-64.

119 Koenig HG. Religion, spirituality, and medicine: Research, findings and implications for clinical practice. South Med J. 2004; 97(12):1194-200.

120 Curlin FA, Lawrence R, Odell S, Chin MH, Lantos J, Koenig HG, Meador KG. Religion, spirituality, and medicine: psychiatrists' and other physicians' differing observations, interpretations, and clinical approaches. Am J Psychiatry. 2007; 164(12):1825-31.

121 Lee E, Zahn A, Baumann K. Religiosity/spirituality and mental health: psychiatric staff's attitudes and behaviors. Open J Soc Sci. 2014; 2:7-13.

122 Bergin A, Jensen J. Religiosity of psychotherapists: a national survey. Psychotherapy.1990; 27(1):03-7.

123 Lawrence RE, Rasinski K, Yoon J, Curlin FA. Psychiatrists' and primary care physicians' beliefs about overtreatment of depression and anxiety. J Nerv Ment Dis. 2015; 203(2):120-5. 
124 Huguelet P, Mohr S, Borras L, Gillieron C, Brandt P. Spirituality and religious practices among outpatients with schizophrenia and their clinicians. Psychiatr Serv. 2006; 57(3):366-72.

125 Best M, Butow P, Olver I. Do patients want doctors to talk about spirituality? A systematic literature review. Patient Educ Couns. 2015; 98(11):1320-8.

126 Lucchetti G, Braguetta CC, Vallada C, Vallada H. Exploring the acceptance of religious assistance among patients of a psychiatric hospital. Int J Soc Psychiatry. 2013; 59(4):311-7.

127 D'Souza R. Do patients expect psychiatrists to be interested in spiritual issues? Australas Psychiatry. 2002; 10(1):44-7.

128 Lawrence RE, Rasinski KA, Yoon JD, Curlin FA. Primary care physicians' and psychiatrists' willingness to refer to religious mental health providers. Int J Soc Psychiatry. 2013; 60(7):627-36.

129 Koenig HG. Religious perspectives of doctors, nurses, patients, and families: some interesting differences. J Pastoral Care. 1991; 45(3):254-67.

130 Franzen AB. Physicians in the USA attendance, beliefs and patient interactions. $J$ Relig Health. 2015; 54(5): 18886-1900.

131 Curlin FA, Nwodim B, Vance MA, Chin MH, Lantos JD. To die, to sleep: US physicians' religious and other objections to physician-assisted suicide, terminal sedation, and withdrawal of life support. Am J Hosp Palliat Care. 2008; 25(2): $112-20$.

132 Lee E, Baumann K. German psychiatrists' observation and interpretation of religiosity/spirituality. Evid Based Complement Alternat Med. 2013; 2013:1-8.

133 Galanter M, Larson D, Rubenstone E. Christian psychiatry: the impact of evangelical belief on clinical practice. Am J Psychiatry. 1991; 148(1):90-5.

134 Gaines AD. The once and the twice-born: self and practice among psychiatrists and christian psychiatrists. In: Hahn RA, Gaines AD, editors. Physicians of Western Medicine. Dordrecht, Holland: D. Reidel Publishing Company; 1985. p. 223-46. 
135 Lawrence RE, Rasinski KA, Yoon JD, Curlin FA. Religion and anxiety treatments in primary care patients. Anxiety Stress Coping. 2013; 26(5):526-38.

136 Puchalski CM, Blatt B, Butler A. Spirituality and health: the development of a field. Acad Med. 2014; 89(1):10-6.

137 Puchalski CM, Larson DB, Lu FG. Spirituality in psychiatry residency training programs. Int Rev Psychiatry. 2001; 13(2):131-8.

138 Koenig HG, Hooten EG, Lindsay-Calkins E, Meador KG. Spirituality in medical school curricula: findings from a national survey. Int J Psychiatry Med. 2010; 40(4): 391-8.

139 Neely D, Minford EJ. Current status of teaching on spirituality in UK medical schools. Med Educ. 2008; 42(2):176-82.

140 Lucchetti G, Lucchetti ALG, Mendes Espinha DC, de Oliveira LR, Leite JR, Koenig HG. Spirituality and health in the curricula of medical schools in Brazil [internet]. BMC Med Educ [cited 23 mar 2017]. Available from: http://bmcmededuc.biomedcentral.com/articles/10.1186/1472-6920-12-78.

141 Lucchetti G, de Oliveira L, Koenig HG, Leite J, Lucchetti A. Medical students, spirituality and religiosity-results from the multicenter study SBRAME. BMC Med Educ. 2013; 13:162-69.

142 Lucchetti G, Oliveira LR, Leite JR, Lucchetti ALG. Medical students and controversial ethical issues: results from multicenter study SBRAME. BMC Med Ethics. 2014; 15: 85.

143 Lucchetti G, Ramakrishnan P, Karimah A, Oliveira RO, Dias A, Rane A, Shukla A, Lakshimi S, Ansari BK, Ramaswamy RS, Reddy RA, Tribulato A, Agarwal AK, Bhat J, Satyaprasad N, Ahmad M, Rao PH, Murthy P, Kuntaman K, Koenig HG, Lucchetti A. Spirituality, religiosity, and health: a comparison of physicians' attitudes in Brazil, India, and Indonesia. Int J Behav Med. 2015; 23(63): 63-70.

144 Damiano RF, Costa LA, Viana MT, Moreira-Almeida A, Lucchetti ALG, Lucchetti G. Brazilian scientific articles on "spirituality, religion and health". Arch Clin Psychiatry. 2016; 43(1):11-6. 
145 Brasil. Instituto Brasileiro de Geografia e Estatística (IBGE). Censo Demográfico 2010 - Características gerais da população, religião e pessoas com deficiência [internet]. 2010 [acessado 25 mai 2016]. Disponível em: https://biblioteca.ibge.gov.br/index.php/bibliotecacatalogo?view=detalhes \&id=794.

146 Moreira-Almeida A, Pinsky I, Zaleski M, Laranjeira R. Religious involvement and sociodemographic factors: a Brazilian national survey. Rev Psiquiatr Clin. 2010; 37(1):12-5.

147 Curlin FA, Lawrence R, Chin M, Lantos J. Religion, conscience, and controversial clinical practices. N Engl J Med. 2007; 356(6): 593-600.

148 Korup AK, Christensen R, Nielsen CT, Sondergaard J, AlYousefi NA, Lucchetti G, Baumann K, Lee E, Karimah A, Ramakrishnan P, Frick E, Büssing A, Schouten E, Hvidt NC. The international Nersh data pool - a methodological description of a data pool of religious and spiritual values of health professionals from six continents. Religions (Basel) [internet]. 2017 [cited $20 \mathrm{dez}$ 2017]. Available from: https://www.mdpi.com/2077-1444/8/2/24.

149 Korup AK, Sondergaard J, Lucchetti G, Ramakrishnan P, Bauman K, Lee E, Frick E, Büssing A, Alyousefi NA, Karimah A, Schouten E, Wermuth I, Hvidt NC. Religious values of pshysicians affect their clinical practice. A meta-analysis of individual participant data from 7 countries. Medicine (Baltimore) [internet]. 2019 [cited 26 jun 2020]. Available from: https://pubmed.ncbi.nlm.nih.gov/31568003/.

150 Pargament KI, Koenig HG, Perez L. The many methods of religious coping: development and initial validation of the RCOPE. J Clin Psychol. 2000; 56(4):519-43.

151 Hoge DR. A validated intrinsic religious orientation and prejudice. J Sci Study Relig. 1972; 11(4): 369-76.

152 Associação Brasileira de Psiquiatria (ABP). Indicador Profissional ABP 2009 2012. Rio de Janeiro: ABP Editora; 2010.

153 Nuraxis C. SendBlaster Pro Edition [computer program]. Version 3.1.6. New York; 2013. 
154 Statacorp. Stata Statistical Software [computer program]. Version12.1. College Station, TX; 2011.

155 Statistical Package for Social Science SPSS I [computer program]. Version 17.0 System. Chicago, IL; 2008.

156 Muthén BO, Muthén LK. Integrating person-centered and variable-centered analyses. Growth mixture modeling with latent trajectory classes. Alcohol Clin Exp Res. 2000; 24(882-91).

157 Muthén LK, Muthén BO. Mplus Statistical Analysis with Latent Variables [computer program]. Version 8. Los Angeles (CA): 2017.

158 Brasil. Instituto Brasileiro de Geografia e Estatística (IBGE). Censo Demográfico 2010 - Domicílios particulares permanentes, por classes de rendimentos nominalmensal domiciliar 'per capita', segundo as Grandes Regiões e as Unidades da Federação [internet]. 2010 [acessado 31 jul 2020]. Disponível em: https://censo2010.ibge.gov.br/sinopse/index.php?dados=P21\&uf=00.

159 Curlin FA, Odell S, Lawrence R, Chin MH, Lantos J, Meador KG, Koenig HG. The relationship between psychiatry and religion among US physicians. Psychiatr Serv. 2007; 58(9):1193-8.

160 Randwijk CB, Opsahl T, Hvidt EA, Korup AK, Bjerrum L, Thomsen KF, Hvidt NC. Characteristics of religious and spiritual beliefs of danish physicians: and likelihood of addressing religious and spiritual issues with patients. J Relig Health. 2019; 58(1):333-42.

161 Kattan W, Talwar V. Psychiatry residents' attitudes toward spirituality in psychiatry. Acad Psychiatry. 2013; 37(5): 360-62.

162 Robinson K, Cheng M, Hansen P, Gray R. Religious and spiritual beliefs of physicians. J Relig Health. 2017; 56:205-25.

163 Pargament KI. The psychology of religion and spirituality? Yes and no. Int $J$ Psychol Relig. 1999; 9(1):3-16.

164 Peres MFP, Swerts D, de Oliveira AB, Leão FC, Lucchetti ALG, Vallada H, Maraldi EO, Toniol R, Lucchetti G. Mental health and quality of life among 
adults with single, multiple, and no religious affiliations. $J$ Ner Ment Dis. 2020; 208(4):288-93.

165 Miller AS, Hoffman JP. Risk and religion: an explanation of gender differences in religiosity. J Sci Study Relig. 1995; 34(1):63-75.

166 Pew Research Center. The gender gap in religion around the world. Women are generally more religious than men, particulary among christians [internet]. 2016 [cited 20 may 2018]. Available from: http:Ilassets.pewresearch.org/wpcontent/uploads/sites/11/2016/03/Religion-and-Gender-Full-Report.pdf.

167 Gallup Jr GH. Why are women more religious? [internet]. 2002 [cited 21 may 2018]. Available from: https://news.gallup.com/poll/7432/why-women-morereligious.aspx.

168 Beit-Hallahmi B. Psychological perspectives on religion and religiosity. New York: Routledge; 2015. p. 89-108.

169 Francis LJ, Penny G. Gender differences in religion. In: Saroglou V, editor. Religion, personality, and social behavior. New York: Psychology Press; 2014. p. 313-37.

170 Francis LJ. The psychology of gender differences in religion: a review of empirical research. Religion. 1997; 27:81-96.

171 Stark R. Physiology and faith: addressing the 'universal' gender difference in religious commitment. J Sci Study Relig. 2002; 41(3): 495-507.

172 Miller AS, Stark R. Gender and religiousness: can socialization explanations be saved? AJS. 2002; 107(6):1399-423.

173 Sullins DP. Gender and religion: deconstructing universality, constructing complexity. AJS. 2006; 112(3):838-80.

174 Norko MA. What is truth? The spiritual quest of forensic psychiatry. J Am Acad Psychiatry Law. 2018; 46:10-22. 
175 Yoon J, Shin J, Nian A, Curlin FA. Religion, sense of calling, and the practice of medicine: findings from a national survey of primary care physicians and psychiatrists. South Med J. 2015; 108(3):189-95.

176 Curlin FA, Lantos J, Roach C, Sellergren S, Chin M. Religious Characteristics of U.S. Physcians. J Gen Intern Med. 2005; 20:629-34.

177 Savage GH. Religious insanity and religions revivals: effects of the "moody and sankey services". The Lancet. 1875; 106(2713):303-4

178 Fisher TW. Insanity and the revival. Bost Med Surg J. 1877; 97:59-62.

179 Geppert C. Religious insanity. A diagnosis at the intersection of 19th century american religion and psychiatry. J Nerv Ment Dis. 2019; 207(9):785-91.

180 Freud S. A questão de uma Weltanschauung. Tradução de Jayme Salomão. Rio de Janeiro: Imago; 1976 (Edição Standard Brasileira das Obras Psicológicas Completas de Sigmund Freud; vol. XXII).

181 Group for the Advancement of Psychiatry (GAP). Committee on psychiatry and religion. Mysticism: spiritual quest or psychic disorder?. New York: BrunnerRoutledge; 1976.

182 Loch AA. Estereótipos e crenças relacionados à esquizofrenia: um levantamento comparativo entre profissionais de saúde mental e a população geral do Brasil [tese]. São Paulo: Faculdade de Medicina, Universidade de São Paulo; 2013.

183 Coyle BR. Twelve myths of religion and psychiatry: lessons for training psychiatrists in spirituality sensitive treatments. Ment Health Relig Cult. 2001; 4(2):149-74.

184 Caizaya-Gallegos C, Mayta-Tristán P, Montenegro-Idrogo JJ, Avila-Figueroa J, Benitez-Ortega I, Cabrera-Enriquez J, Calixto O, Cardozo-López JP, GrandezUrbina JA, Moreno-Loaiza O, Rodriguez MA, Sepúlveda-Morales R, SierraAvendaño JA, Carreño F, Vásquez-Garcia GR, Vasquez-Sullca RR, Yescas G. Religious affiliation and the intention to choose psychiatry as a specialty among physicians in training from 11 Latin American countries. Transcult Psychiatry. 2019; 56(6):1237-54. 
185 Gartner J. Antirreligious prejudice in admission to doctoral programs in clinical psychology. Prof Psychol Res Pr. 1986; 17(5):473-5.

186 Rosmarin DH, Pirutinsky S, Pargament KI. A brief measure of core religious beliefs for use in psychiatry settings. Int J Psychiatry Med. 2011; 41(3):253-61.

187 Curlin FA, Dugdale Lantos J, Chin MH. Do religious physicians disproportionately care for the underserved?. Ann Fam Med. 2007; 5(4):353-60.

188 Ramakrishnan P, Karimah A, Kuntaman K, Shukla A, Ansari BKM, Rao PH, Ahmed M, Tribulato A, Agarwal K, Koenig HG, Murthy P. Religious/spiritual characteristics of indian and indonesian physicians and their acceptance of spirituality in health care: a cross-cultural comparison. J Relig Health. 2015; 54(2): 649-63.

189 Al-Yousefi NA. Observations of muslim physicians regarding the influence of religion on health and their clinical approach. J Relig Health. 2012; 51(2):269-80.

190 Hvidt EA, Sondergaard J, Hansen DG, Gulbrandsen P, Ammentorp J, Timmerman C, Hvidt NC. "We are the barriers": Danish general practitioners' interpretation of why the existential and spiritual dimensions are neglected in patient care. Commun Med. 2017; 14(2):108-20.

191 Best M, Butow P, Olver I. Doctors discussing religion and spirituality: A systematic literature review. Palliat Med. 2016; 30(4):327-37.

192 Franzen AB. Influence of physicians' beliefs on propensity to include religion/spirituality in patient interactions. J Relig Health. 2018; 57(4):1581-97.

193 Voltmer E, Büssing A, Koenig HG, Al Zaben F. Religiosity/spirituality of german doctors in private practice and likelihood of addressing R/S issues with patients. $J$ Relig Health. 2014; 53(6):1741-52.

194 Lee E, Baumann K. How korean psychiatric staff deal with religious and spiritual issues of patients: what is professional? [internet]. Religions. 2019 [cited $22 \mathrm{sept}$ 2019]. Available from:https://www.mdpi.com/2077-1444/10/10/544. 
195 Welgemoed M, Staden C. Does religious identification of South African psychiatrists matter in their approach to religious matters in clinical practice?. $S$ Afr J Psychiatr. 2014; 20(4):140-5.

196 Crosby JW, Bossley N. The religiosity gap: preferences for seeking help from religious advisors. Ment Health Relig Cult. 2012; 15(2):141-59.

197 Milner K, Crawford P, Edgley A, Hare-Duke L, Slade M. The experiences of spirituality among adults with mental health difficulties: a qualitative systematic review [internet]. Epidemiol Psychiatr Sci. 2019 [cited 19 aug 2019]. Available from: https://pubmed.ncbi.nlm.nih.gov/31046852/.

198 Camp ME. Religion and spirituality in psychiatric practice. Curr Opin Psychiatry. 2011; 24(6):507-13.

199 Korup AK, Sondergaard J, Christensen R, Nielsen CT, Lucchetti G, Ramakrishnan P, Baumann K, Lee E, Frick E, Büssing A, Alyousefi NA, Karimah A, Schouten E, Schulze A, Wermuth I, Hvidt NC. Religious values in clinical practice are here to stay. J Relig Health. 2020; 59:188-94.

200 Curlin FA, Sellergren S, Lantos J, Chin M. Physicians' observations and interpretations of the influence of religion and spirituality on health. Arch Intern Med. 2007; 167(7):649-54.

201 van Rensburg JABR, Poggenpoel M, Myburgh CPH, Szabo CP. Experience and views of academic psychiatrists on the role of spirituality in South African specialist psychiatry. Rev Psiquiatr Clin. 2012; 39(4):122-9.

202 Deaton AS. Aging, religion, and health. In: Wise DA, editor. Explorations in the economics of aging. Chicago: University of Chicago Press; 2011. p. 237-62.

203 Hungerman DM. The effect of education on religion: Evidence from compulsory schooling laws. J Econ Behav Organ. 2014; 104:52-63.

204 Lee JJ. Religion and college attendance: change among students. Rev High Ed. 2002; 25(4):369-84.

205 Uecker JE, Regnerus MD, Vaaler ML. Losing my religion: The social forces of religious decline in early adulthood. Soc Forces. 2007; 85(4):1667-92. 
206 Curcio CSS, Moreira-Almeida A. Who does believe in life after death? brazilian data from clinical and non-clinical samples. J Relig Health. 2019; 58:1217-34.

207 Schwadel P. Birth cohort changes in the association between college education and religious non-affiliation. Soc Forces. 2014; 93(2):719-46.

208 Baker DP. The great antagonism that never was: unexpected affinities between religion and education in post-secular society. Theory Soc. 2019; 48:39-65.

209 Baker JO, Smith BG. The Nones: social characteristics of the religiously unaffiliated. Soc Forces. 2009; 87(3):1251-63.

210 Chaves M. Secularization as declining religious authority. Soc Forces. 1994; 72(3):749-74.

211 Glaeser EL, Sacerdote BI. Education and religion. J Hum Cap. 2008; 2(2): 188215.

212 Huguelet P, Koenig HG. Conclusion: summary of what clinicians need to know. In: Religion and Spirituality in Psychiatry. Cambridge, UK: Cambridge University Press; 2009. p. 354-68.

213 Moreira-Almeida A, Cardena E. Differential diagnosis between non-pathological psychotic and spiritual experiences and mental disorders: a contribution from Latin American studies to the ICD-11. Rev Bras Psiquiatr. 2011; 33(01):21-36.

214 Pajevic I. Secular and postsecular psychiatry. Psychiatr Danub. 2012; 24(3):26266.

215 Cloninger CR. The science of well-being: an integrated approach to mental health and its disorders. World Psychiatry. 2006; 5(2):71-6.

216 Peteet JR. Spirituality and mental health: implications for ethics, medicine, and public health. Ethics Med Public Health. 2019; 9:75-9.

217 Saad M, Daher Jr. J, Medeiros R. Spirituality, religiousness and physical health: scientific evidence. In: Lucchetti G, Peres MFP, Damiano R, editors. Spirituality, 
religiouness and health: from research to clinical practice. Switzerland: Springer; 2019. p. 87-100.

218 Maraldi EO, Krippner S, Barros M, Cunha A. A dissociation from a cross-cultural perspective: implications of studies in Brazil. J Nerv Ment Dis. 2017; 205(7): 55867.

219 Moreira-Almeida A, Lotufo-Neto F. Methodological guidelines to investigate altered states of consciousness anomalous experiences [internet]. Int Rev Psychiatry. 2017 [cited 17 feb 2017]. Available from: https://pubmed.ncbi.nlm.nih.gov/28587556/.

220 Oliveira e Oliveira F, Pinto A. Psiquiatria e espiritualidade: em busca da formulação bio-psico-socio-espiritual do caso. HU Revista. 2018; 44(4):447-54.

221 Koenig HG, Peteet J, VanderWeele T. Religion and psychiatry: clinical implications [internet]. BJPsych Adv. 2020 [cited 27 feb 2020]. Available from: https://www.cambridge.org/core/journals/bjpsych-advances/article/religion-andpsychiatry-clinical-applications/A2C375C834E80F5E253F42D79EE4F39F.

222 Cook CCH. Religion and spirituality in clinical practice. BJPsych Advances. 2015; 21(1):42-50.

223 Lotufo Neto, F. Psiquiatria e religião: a prevalência de transtornos mentais em ministros religiosos [tese livre-docência]. São Paulo: Faculdade de Medicina, Universidade de São Paulo; 1997. p. 257

224 Cunningham CT, Quan H, Hemelgan B, Noseworth T, Beck CA, Dixon E, Samuel S, Ghali WA, Sykes LL, Jetté N. Exploring physician specialist response rates to web-based surveys. BMC Med Res Methodol. 2015; 15:32.

225 Banzato C, Pereira M, Santos Jr. A, Silva F, Loureiro Jr. J, Barros B. What do brazilian psychiatrists want from diagnostic classifications?. J Bras Psiquiatr. 2007; 56(2):88-93.

226 Nulty D. The adequacy of response rates to online and paper surveys: what can be done? Assessment \& Evalution in Higher Education. 2008; 33(3): 301-14. 
227 Duarte G, Osis M, Faúndes A, De Sousa M. Aborto e Legislação: opinião de magistrados e promotores de justiça brasileiros. Rev Saúde Pública. 2010; 44(3):406-20.

228 Harzing A. Response rates in international mail surveys: results of a 22 countries study. International Business Review. 1997; 6(6): 641-65.

229 Samano E, Ribeiro L, Camos A, Lewin F, Goldenstein PT, Costa LJM, Del Giglio A. Use of complementary and alternative medicine by brazilian oncologists. Eur J Cancer Care. 2005; 14(2): 143-8.

230 Lucchetti AL, Lucchetti G, Leão FC, Peres MFP, Vallada H. Mental and phsysical health and spiritual healing: an evaluation of complementary religious therapies provided by spiritist centers in the city of São Paulo, Brazil. Cult Med Psychiatry. 2016; 40:404-21. 


\section{APÊNDICES}

\section{APÊNDICE 1. Cópia dos trabalhos publicados e relacionados com a presente tese}

a) Menegatti-Chequini M. C., Gonçalves J. P. B., Leão F. C., Peres M.F.P., Vallada H. A preliminary survey on the religious profile of brazilian psychiatrists and their approach to patients' religiosity in clínical practice. BJPsych Open. 2016; 2:346-52.

\begin{tabular}{|c|c|}
\hline $\begin{array}{l}\text { BuPsych } \\
\text { (a) } 0 \text { (은 }\end{array}$ & $\begin{array}{l}\text { BJPsych Open (2016) } \\
\text { 2, 346-352. doi: } 10.1192 / \text { bjpo.bp. } 116.002816\end{array}$ \\
\hline
\end{tabular}

A preliminary survey on the religious profile of Brazilian psychiatrists and their approach to patients' religiosity in clinical practice

Maria Cecilia Menegatti-Chequini, Juliane P.B. Gonçalves, Frederico C. Leão, Mario F.P. Peres* and Homero Vallada*

\section{Background}

Although there is evidence of a relationship between religion spirituality and mental health, it remains unclear how Brazilian psychiatrists deal with the religion/spirituality of their patients.

Aims

To explore whether Brazilian psychiatrists enquire about religion/spirituality in their practice and whether their own beliefs influence their work.

\section{Method}

Four hundred and eighty-four Brazilian psychiatrists completed a cross-sectional survey on religion/spirituality and clinical

Results

Most psychiatrists had a religious affiliation (67.4\%) but more about patients' religion/spirituality. The most common reasons

Over the past few decades, numerous studies have reported that religion and spirituality are generally associated with better coping skills and positive health indicators, particularly with respect to mental health. ${ }^{1,2}$ Religion/spirituality has been associated, for example, with lower rates of suicide, depression, anxiety, and substance misuse, better recovery in cases of depression and greater overall well-being. ${ }^{1-4}$

Based on these growing number of studies supporting the relevance of religion/spirituality, medical organisations, among them the World Psychiatric Association (WPA), the Royal College of Psychiatrists (RCPsych), the American Psychiatric Association (APA) and more recently the Associação Brasileira de Psiquiatria (Brazilian Association of Psychiatry - ABP), have created specific committees to handle matters related to the inclusion of religion/ spirituality in clinical practice, as well as in medical training and spirituality inis colocis the conting in recenty published its, Position Stateme Religion in Psychintry" which acknowledges the importance of considering the spiritual dimension in psychiatric training

In response to the increased importance of religion/spirituality in clinical practice, further research has been carried out, with the purpose of investigating the religious and spiritual profiles of psychiatrists and their attitudes towards including religion/spirituality into the management and care of their patients. ${ }^{9-14}$ What was interesting to observe from those studies was that the majority of psychiatrists agree on the importance and the need to integrate religious/spiritual aspects in clinical practice. ${ }^{9,10,14}$ These authors share last authorship and have contributed equally to
this work. for not assessing patients' religion/spirituality were 'being for not assessing patients' religion/spirituality were 'being
afraid of exceeding the role of a doctor' $(30.2 \%)$ and 'lack of training' (22.3\%).

Conclusions

Very religious/spiritual psychiatrists were the most likely to ask about their patients' religion/spirituality. Training in how to deal with a patient's religiosity might help psychiatrists to develop better patient rapport and may contribute to the patient's quicker recovery.

Declaration of interest

None

Copyright and usage

The Royal College of Psychiatrists 2016. This is an open access article distributed under the terms of the creative Commons Non-Commercial, No Derivatives (CC BY-NC-ND)
license.

Owing to the lack of information about how Brazilian psychiatrists deal with religion/spirituality, the present work attempts to asess their current view on religion/spirituality, both with regard to their own religious and spiritual profle as well we regard to their own religious and spiritual profile as well as clinicas pactice, and wher these areas. A part from being the first systematic evaluntion in these areas. Apart from being the frst systematic evaluation into religion/spirituality in psychiatric practice to be carried out in

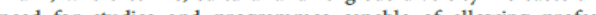
need for studies and programmes capable of allowing professionals to better care for patients in such a diverse sociocultural health education, management and prevention in psychiatry.

\section{Method}

Design of the study, sampling and procedures

This was a cross-sectional study of 3120 psychiatrists belonging to the $\mathrm{ABP}$ who were emailed information on the study and invited to participate by completing a confidential online questionnaire.

In order to optimise the return rate, the emails were re-sent, emphasising the limited period for data collection and the importance of their participation. The emails were sent between 12 September 2013 and 6 February 2014, and up to 10 times to the psychiatrists who did not respond.

Measurements

The survey presented in this study was based on the questionnaire Religion and Spirituality in Medicine: Doctors' Perspectives developed by Curlin et al, ${ }^{15}$ which evaluates doctors' religious/ spiritual characteristics and their influence, if any, on clinical practice and their patients' health. The survey was adapted and 
translated into Portuguese by one of the authors (M.F.P.P.) and revised by another (M.C.M.-C.). It consists of self-reported questions to assess the following three main areas.

\section{Sociodemographic and professional features}

The data included age, gender, marital status, location, degree level, specialty within psychiatry and length of professional experience.

\section{The participants' religious and spiritual features}

The psychiatrists were questioned about their beliefs in God or a superior power and about religious affiliation. The response categories were Catholic, Spiritist, Protestant or Evangelical, other religion (includes Jewish, Hindu, Muslim, Buddhist, Mormon and others) and none (includes agnostic, atheist and none), which were later coded as a binary variable (with or without religious affliation).

Two questions measured to what extent the participants considered themselves to be spiritual or religious. The questions, 'to what extent do you consider yourself to be a spiritual person?' and 'to what extent do you consider yourself to be a religious person?' had four possible responses: not at all, slightly, moderately, very religious and/or spiritual. We did not define the terms religion and spirituality, we allowed the respondents to apply their own definitions. However, the participants were asked questions to distinguish between their religion and their spirituality.

Opinions and behaviours related to religion/spirituality and the approach to religion/spirituality in clinical practice and in medical training

Regarding their opinions related to the role of religion/spirituality in clinical practice, the psychiatrists were asked whether they considered it important to integrate their patients' religious and spiritual aspects into clinical practice. The question had four possible responses: not, a little, reasonably and very important. The categories 'reasonably important' and 'very important' were grouped to identify those who considered it important to integrate religion/spirituality into clinical practice.

Concerning the approach to religion/spirituality in clinical practice, the participants were asked how often they enquired about their patients' religious/spiritual issues. The four possible responses were never, rarely, occasionally and frequently. A binary variable was created to identify those who did this frequently (yes $=$ frequently and no $=$ occasionally + rarely + never $)$.

Regarding medical training, the participants were asked whether they thought the inclusion of religion/spirituality themes in medical training was important. They could also choose from four responses: not, a little, reasonably and very important. The response to the question was categorised as 'yes' if the responses were very + reasonably important and 'no' if the responses were a little + not important.

To identify the barriers encountered by the participants in addressing religious/spiritual issues with their patients, they were prompted to respond to a multiple choice question with the following alternatives: (a) none, (b) fear of exceeding the role of a doctor, (c) lack of training, (d) lack of time, (e) not being comfortable with the issue, (f) the religious/spiritual aspect is not relevant for the patient, $(\mathrm{g}$ ) fear of offending the patient, (h) fear that peers may not approve, (i) it is not the doctor's job, and (j) do not know why.

\section{Statistical analysis}

Evaluated outcomes

The analysis of data was done with Stata 12.1 software. For the continuous variables, the data were expressed as median (s.d.). Models of logistic regression were used to estimate the association between the psychiatrists' general characteristics and having or not having a religious affiliation and their approach to religion/ spirituality in clinical practice. All the patterns were adjusted by age, gender, and marital status and are presented as odds ratios with a $95 \%$ confidence interval.

Ethical issues

The current project was approved by the Research Ethics Committee of the University of São Paulo Medical School. In addition to a detailed explanation of the study objectives, the participants received information regarding the confidential and voluntary nature of their participation in the research. Before completing the questionnaire, the participants had to agree and confirm electronically their free and informed decision to participate in the survey.

\section{Results}

In total 3120 emails were sent, of which 1779 were acknowledged and 1341 bounced back because of a variety of reasons (outdated email addresses, rejection by IPs and other technical reasons, such as full inboxes and identification as spam). From those 1779 email addresses, 492 completed the questionnaire (28\%). Of these 492 questionnaires received back, eight were excluded (five senders did not match the list of emails sent, one for having been returned twice and another two because the questionnaire was not fully completed). The final number of completed questionnaires was 484 .

Sociodemographic, professional and religious characteristics of Brazilian psychiatrists

A total of 484 psychiatrists completed the questionnaire, with an average age of 48.9 years (s.d.=11.8), of which $326(67.4 \%)$ declared a religious affiliation and $345(71.4 \%)$ said that they believed in God. Of the 158 without a religious affiliation, 45 (28.5\%) said they believed in God (see Table 1).

The majority $(70.9 \%)$ were married or in a stable relationship, both in the group who had a religious affiliation (70.3\%) and in the group who did not have a religious affiliation (70.1\%). Most (89.7\%) were adult psychiatrists, also evenly distributed in those who had and those who did not have a religious affiliation. Only those working in forensic psychiatry were more likely to have a religious affiliation (OR=1.86, 95\% CI 1.02-3.39) (Table 2).

On average, the participating psychiatrists had worked 21.3 (s.d.=11.7) years in clinical work. Those who had worked longer were less likely to have a religious affiliation $(\mathrm{OR}=0.39,95 \% \mathrm{CI}$ 0.18-0.83) (Table 2).

Of all the psychiatrists who responded, $76.8 \%$ considered it very or reasonably important to integrate patients' religion/ spirituality into clinical practice, and $71.1 \%$ considered it very or reasonably important to include religion/spirituality in medical training. In both cases, these participants were four times more likely $(\mathrm{OR}=4.33,95 \%$ CI $2.75-6.81$ and $\mathrm{OR}=4.14,95 \%$ CI $2.69-$ 6.36) to have a religious affiliation than those who considered it a little or not important to integrate religiosity in clinical practice or include it in medical training (Table 3).

Regarding the barriers to addressing the patients' religious/ spiritual aspects in clinical practice, the most cited difficulties 


\begin{tabular}{|c|c|}
\hline \multicolumn{2}{|c|}{ Religious/spiritual characteristics: $n$ (\%) } \\
\hline \multicolumn{2}{|c|}{ Religious affiliation } \\
\hline Catholic & $151(31.2)$ \\
\hline Spiritist & $87(18.0)$ \\
\hline Protestant or evangelical & $36(7.4)$ \\
\hline Other religion & $52(10.8)$ \\
\hline None & $158(32.6)$ \\
\hline \multicolumn{2}{|c|}{ Do you believe in God or a superior power? } \\
\hline No & $92(19.1)$ \\
\hline Yes & $345(71.4)$ \\
\hline Undecided & $46(9.5)$ \\
\hline $\mathrm{mv}$ & 1 \\
\hline \multicolumn{2}{|c|}{ To what extent do you consider yourself a spiritual person? } \\
\hline very spiritual & $148(30.6)$ \\
\hline Moderately spiritual & $184(38.1)$ \\
\hline Slightly spiritual & $80(16.6)$ \\
\hline Not spiritual at all & $71(14.7)$ \\
\hline $\mathrm{mv}$ & 1 \\
\hline \multicolumn{2}{|c|}{ To what extent do you consider yourself a religious person? } \\
\hline Very religious & $66(13.7)$ \\
\hline Moderately religious & $143(29.6)$ \\
\hline Slightly religious & $126(26.1)$ \\
\hline Not religious at all & $148(30.6)$ \\
\hline $\mathrm{mn}$ & 1 \\
\hline \multicolumn{2}{|c|}{$\begin{array}{l}\text { Attitudes and behaviours regarding religion/spirituality in clinical practice: } \\
n(\%)\end{array}$} \\
\hline \multicolumn{2}{|c|}{$\begin{array}{l}\text { Do you consider it important to integrate patients' religion/spirituality in } \\
\text { clinical practice? }\end{array}$} \\
\hline Very important & $188(38.9)$ \\
\hline Reasonably important & $183(37.9)$ \\
\hline A little important & $68(14.1)$ \\
\hline Not important & $44(9.1)$ \\
\hline $\mathrm{mv}$ & 1 \\
\hline \multicolumn{2}{|c|}{$\begin{array}{l}\text { Do you consider it important that the issues of religion/spirituality are } \\
\text { included in medical training? }\end{array}$} \\
\hline Very important & $203(42.4)$ \\
\hline Reasonably important & $137(28.7)$ \\
\hline A little important & $73(15.3)$ \\
\hline Not important & $65(13.6)$ \\
\hline $\mathrm{mv}$ & 6 \\
\hline \multicolumn{2}{|c|}{ How often do you enquire about patients' religious/spinitual issues? } \\
\hline Frequently & $220(45.5)$ \\
\hline Occasionally & $168(34.8)$ \\
\hline Rarely & $67(13.9)$ \\
\hline Never & $28(5.8)$ \\
\hline $\mathrm{mv}$ & 1 \\
\hline mv, missing values. & \\
\hline
\end{tabular}

were the fear of exceeding the role of the doctor (30.2\%), lack of training (22.3\%) and lack of time (16.3\%) (Table 3). The next most reported difficulties were not being comfortable with the issue $(8.7 \%)$, it is not the doctor's job $(7.6 \%)$, the religious/spiritual aspects are not relevant for the patient $(7.0 \%)$, fear of offending the patient $(6.4 \%)$, fear that peers may not approve $(5.4 \%)$ and do not know why $(2.9 \%)$. We also found that $40.3 \%$ of the total sample reported not having any barriers.

Those psychiatrists who reported having no barriers were less likely to have a religious affiliation $(\mathrm{OR}=0.47,95 \% \mathrm{CI} 0.32-0.70)$, whereas those participants who reported some barriers were more likely to have a religious affiliation $(\mathrm{OR}=2.82,95 \%$ CI $1.75-4.54)$ (Table 3).
Religious/spinitual characteristics, attitudes and behaviours of psychiatrists and their religion/ spirituality approach in clinical practice

Almost half $(45.5 \%)$ of the psychiatrists surveyed said they frequently enquired about their patients' religious/spiritual issues (Table 1). The participants' sociodemographic background, the number of years of experience and psychiatric sub-specialisation were not associated with enquiring about the patients' religion/ spirituality.

Only $43.3 \%$ of the respondents considered themselves to be very or moderately religious, whereas $68.7 \%$ considered themselves to be very or moderately spiritual, when answering the questions that distinguished religion and spirituality. An even smaller number, $13.7 \%$ of the psychiatrists, considered themselves to be very religious, and the great majority of these $(74.2 \%)$ were almost five times more likely $(\mathrm{OR}=4.58,95 \% \mathrm{Cl}$ $2.39-8.80$ ) to ask their patients about their religious/spiritual issues than those who saw themselves as not religious at all. The psychiatrists who declared themselves to be slightly spiritual were less likely ( $\mathrm{OR}=0.49,95 \% \mathrm{CI} 0.24-0.97)$ to enquire about patients' religious/spiritual issues, when compared to psychiatrists who were not at all spiritual. On the contrary, those who were very spiritual $(30.6 \%)$ tended to ask patients more often about their religion/spirituality ( $\mathrm{OR}=1.87,95 \% \mathrm{CI} 1.05-3.35)$ (Tables 1, 4 and Fig. 1).

The psychiatrists who considered it very or reasonably important to integrate religion/spirituality into clinical practice $(\mathrm{OR}=2.17$, 95\% CI 1.38-3.43) and medical training $(\mathrm{OR}=1.91$, $95 \%$ IC $1.26-2.90$ ), as well as those who reported not having any barriers to address religion/spirituality in clinical practice $(\mathrm{OR}=3.25,95 \% \mathrm{CI} 2.21-4.77)$, were more likely to enquire about their patients' religious/spiritual issues, whereas those who reported that they feared exceeding the doctor's role were less likely $(\mathrm{OR}=0.45,95 \% \mathrm{CI} 0.30-0.67)$ to enquire about their patients' religious/spiritual issues (Table 4).

\section{Discussion}

The results demonstrated that the great majority of Brazilian psychiatrists who replied to the survey considered it important to integrate religion/spirituality into clinical practice and into medical training. Half of them declared they frequently asked their patients about their religious and spiritual beliefs. The results also showed that there was no association between having a religious affiliation and enquiring about religion/spirituality in the clinical practice. However, psychiatrists who considered themselves to be very religious and/or spiritual were the most likely to enquire into their patients' religion/spirituality in clinical practice.

Regarding religious and spiritual characteristics, $67.4 \%$ of Brazilian psychiatrists who responded to our survey had a religious affiliation, in comparison with $92 \%$ of the Brazilian population. ${ }^{16}$ They also tended to have less religious affiliation when compared with psychiatrists in the United States $(82 \%),{ }^{17}$ Germany $(70.7 \%)^{11}$ and South Africa $\left.(84 \%)\right)^{12}$

However, Brazilian psychiatrists showed a greater percentage of belief in God $(71.4 \%)$, when compared with American $(65 \%),{ }^{17}$ German $(56 \%),{ }^{11}$ Canadian $(54 \%)^{10}$ and British $(23 \%)$ psychiatrists. ${ }^{9}$ In addition, as in the studies of Canadian ${ }^{10}$ and American psychiatrists, ${ }^{17}$ more participants in this study considered themselves to be spiritual than religious.

Perhaps there is a tendency for the surveyed psychiatrists to have a spiritual involvement that goes beyond social conventions, that is, it is possible that the beliefs of Brazilian psychiatrists tend to be more individualistic, independent or different from those 


\begin{tabular}{|c|c|c|c|c|}
\hline \multirow[b]{2}{*}{ Sociodemographic and professional characteristics } & \multicolumn{4}{|c|}{ Religjous affiliation } \\
\hline & Total $n=484(\%)$ & Without $n=158(\%)$ & With $n=326(\%)$ & Adj. $O R^{a}(95 \%$ CD) \\
\hline \multicolumn{5}{|l|}{ Age in years } \\
\hline $25-39$ & $143(29.5)$ & $50(31.7)$ & $93(28.5)$ & 1.00 \\
\hline $40-59$ & $236(48.8)$ & $76(48.1)$ & $160(49.1)$ & $1.10(0.71-1.73)$ \\
\hline $60+$ & $105(21.7)$ & $32(20.2)$ & $73(22.4)$ & $1.36(0.78-2.36)$ \\
\hline \multicolumn{5}{|l|}{ Gender } \\
\hline Male & $284(58.7)$ & $105(66.5)$ & $179(54.9)$ & 1.00 \\
\hline Female & $200(41.3)$ & $53(33.5)$ & $147(45.1)$ & $1.65(1.09-2.50)^{*}$ \\
\hline \multicolumn{5}{|l|}{ Marital status } \\
\hline Without partner & $139(29.1)$ & $43(27.9)$ & $96(29.7)$ & 1.00 \\
\hline With partner & $338(70.9)$ & $111(70.1)$ & $227(70.3)$ & $0.97(0.63-1.51)$ \\
\hline \multicolumn{5}{|l|}{ Subspeciality in psychiatry ${ }^{b}$} \\
\hline Adult & $434(89.7)$ & $139(88.0)$ & $295(90.5)$ & $1.46(0.78-2.76)^{c}$ \\
\hline Child & $101(20.9)$ & $33(20.9)$ & $68(20.9)$ & $0.95(0.58-1.53)^{c}$ \\
\hline Old age & $107(22.1)$ & $36(22.8)$ & $71(21.8)$ & $0.99(0.62-1.58)^{c}$ \\
\hline Forensic & $72(14.9)$ & $18(11.4)$ & $54(16.6)$ & $1.86(1.02-3.39)^{*}$ \\
\hline \multicolumn{5}{|l|}{ Time (in years) as a psychiatrist } \\
\hline $0-10$ & $122(25.6)$ & $35(22.6)$ & $87(27.0)$ & 1.00 \\
\hline $11-20$ & $123(25.8)$ & $42(27.1)$ & $81(25.2)$ & $0.52(0.27-0.97)^{*}$ \\
\hline $20+$ & $232(48.6)$ & $78(50.3)$ & $154(47.8)$ & $0.39(0.18-0.83)^{*}$ \\
\hline 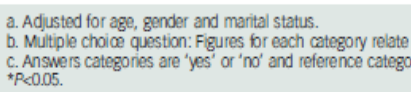 & & & & \\
\hline
\end{tabular}

connected with formal or institutional religions. Perhaps, since they belong to a society characterised by religious syncretism, it may be more difficult for them to relate to a specific religion, but they still reflect the high degree of religiosity of the Brazilian population. These levels are even more relevant when compared with the UK figures, in which a quarter of the population ${ }^{18}$ and $73 \%$ of psychiatrists have no religion. ${ }^{9}$

Although the majority of the Brazilian population is Catholic, it has been characterised by an increasing diversity of religious groups since the early 20 th century. The Brazilian census shows an increase in Evangelical religions and Spiritism (a religious and philosophical movement initiated in the second half of the 19th century), at the expense of Catholicism. However, the Catholic religion is still by far the largest in Brazil, and in our sample, Catholics comprise, as expected, the largest group, with Spiritists second, followed by Evangelicals. Spiritism has been popular amongst liberal professionals in Brazil but the Evangelicals are usually more prevalent in the middle-low and low socioeconomic levels. ${ }^{16}$

The results also indicated that women were more likely to declare a religious affiliation. There are studies in other countries which present similar observations. For example, a Canadian study ${ }^{10}$ reported that female psychiatrists had higher rates of religious beliefs, religious practices and intrinsic religiosity than male colleagues. Neeleman \& King in the UK also found that the rate of female psychiatrists who believed in God was higher. Despite the good empirical evidence to support these observations, there is a lack of empirical studies and a satisfactory theoretical basis to explain these differences. ${ }^{19}$

Among the medical specialties, psychiatry has been described as the least religious. ${ }^{13,20}$ An interesting observation in this survey was that those working in forensic psychiatry were the most likely to declare a religious affiliation. To our knowledge, there are no studies addressing the relationship between subspecialties in

Table 3 Attitudes regarding religion/spirituality in clinical practice of Brazilian psychiatrists (statistical analysis of the respondents from a total number of 484 participants)

\begin{tabular}{|c|c|c|c|c|}
\hline \multirow[b]{2}{*}{ Attitudes regarding religor/spirituality in clinical practice } & \multicolumn{4}{|c|}{ Religious affliation } \\
\hline & Total $n=484(\%)$ & Without $n=158(\%)$ & With $n=326(\%)$ & Ad]. $O R^{a}(95 \% \mathrm{Cl})$ \\
\hline $\begin{array}{l}\text { Do you consider it important to integrate patient's } \\
\text { religion/spirituality in clinical practice? }\end{array}$ & $371(76.8)^{\mathrm{b}}$ & $91(57.6)$ & $280(86.1)$ & $4.33(2.75-6.81)^{*}$ \\
\hline \multicolumn{5}{|l|}{ Barriers to address religion/spirituality with patient: ${ }^{c}$} \\
\hline None & $195(40.3)$ & $81(51.3)$ & $114(35.0)$ & $0.47(0.32-0.70)^{\times 4}$ \\
\hline Fear of exceeding the role of the doctor & $146(30.2)$ & $27(17.1)$ & $119(36.5)$ & $2.82(1.75-4.54)^{* d}$ \\
\hline Lack of training & $108(22.3)$ & $25(15.8)$ & $83(25.5)$ & $1.91(1.15-3.17)^{4}$ \\
\hline Lack of time & $79(16.3)$ & $21(13.3)$ & $58(17.8)$ & $1.46(0.84-2.53)^{d}$ \\
\hline $\begin{array}{l}\text { Do you consider it important that the issues of } \\
\text { religion/spirituality are included in medical training? }\end{array}$ & $340(71.1)^{b}$ & $80(51.3)$ & $260(80.7)$ & $4.14(2.69-6.36)^{* 4}$ \\
\hline $\begin{array}{l}\text { a. Adjusted for age, gender and marital status. } \\
\text { b. Inciudes responses 'very important' and 'reasonably important'. } \\
\text { c. Multiple choice question: Figures for each category relate to totat } \\
\text { d. Answers categones are yes' or 'no' and reference category is 'n } \\
\text { ¿P<0.05. }\end{array}$ & & & & \\
\hline
\end{tabular}




\begin{tabular}{|c|c|c|}
\hline & \multicolumn{2}{|c|}{ Enquire about patients' religious/spiritual issues } \\
\hline & Crude OR $(95 \% \mathrm{Cl})$ & Adj. $O R^{9}(95 \% \mathrm{Cl})$ \\
\hline \multicolumn{3}{|l|}{ Religious/spiritual characteristics } \\
\hline \multicolumn{3}{|l|}{ To what extent do you consider yourself a religious person? } \\
\hline Not religious at all & 1.00 & 1.00 \\
\hline Slightly religious & $0.89(0.55-1.46)$ & $0.89(0.54-1.47)$ \\
\hline Moderately religous & $1.39(0.87-2.21)$ & $1.31(0.81-2.10)$ \\
\hline Very religgous & $4.47(2.35-8.51)^{*}$ & $4.58(2.39-8.80)^{*}$ \\
\hline \multicolumn{3}{|l|}{ To what extent do you consider yourself a spiritual person? } \\
\hline Not spiritual at all & 1.00 & 1.00 \\
\hline Slightly spiritual & $0.52(0.25-1.02)$ & $0.49(0.24-0.97)^{*}$ \\
\hline Moderately spiritual & $0.92(0.53-1.59)$ & $0.87(0.50-1.52)$ \\
\hline Very spiritual & $2.00(1.13-3.55)^{*}$ & $1.87(1.05-3.35)^{*}$ \\
\hline Religious affliliation & $1.52(1.03-2.24)^{*}$ & $1.45(0.98-2.16)^{\mathrm{D}}$ \\
\hline \multicolumn{3}{|l|}{ Attitudes regarding religion/spirituality in clinical practice } \\
\hline Do you consider it important to integrate patients' religion/spirituality in clinical practice? & $2.20(1.40-3.44) \times c$ & $2.17(1.38-3.43)^{* \mathrm{~b}}$ \\
\hline $\begin{array}{l}\text { Do you consider it important that the issues of religion/spirituality are included in medical training? } \\
\text { Barriers to address religion/spirituality with patient: }\end{array}$ & $1.86(1.24-2.81)^{* c}$ & $1.91(1.26-2.90)^{* \mathrm{~b}}$ \\
\hline None & $3.24(2.22-4.73)^{*}$ & $3.25(2.21-4.77)^{* b}$ \\
\hline Fear of exceeding the role of the doctor & $0.45(0.30-0.68)^{*}$ & $0.45(0.30-0.67)^{* D}$ \\
\hline Lack of training & $0.94(0.61-1.45)$ & $0.96(0.62-1.49)^{\mathrm{b}}$ \\
\hline Lack of time & $0.78(0.48-128)$ & $0.81(0.49-1.33)^{\circ}$ \\
\hline $\begin{array}{l}\text { a. Adjusted for age, gender and marital status. } \\
\text { b. Answers categones are 'yes' or 'no' and reference category is 'no' } \\
\text { c. Includes the responses 'very important' and 'reessonabily important'. } \\
\text { d. Multiple choice question:. Figures for each category relate to total sample. } \\
{ }^{*} P \notin 0.05 \text {. }\end{array}$ & & \\
\hline
\end{tabular}

psychiatry and religion/spirituality, making it an interesting subject for further investigation.

We also found that not only the subspecialty but also the number of years working in psychiatry could be associated with having or not having a religious affiliation, with those with more time in the profession less likely to have any religious affiliation. A similar observation is presented in a Canadian study about psychiatrists ${ }^{10}$ which shows that as the years of professional practice increased, the importance attributed by psychiatrist to religion/spirituality in psychiatry decreased.

Of course, the field of psychiatry has changed considerably over the past decades, as has the relationship between psychiatry and religion, so the comparison of different studies should be

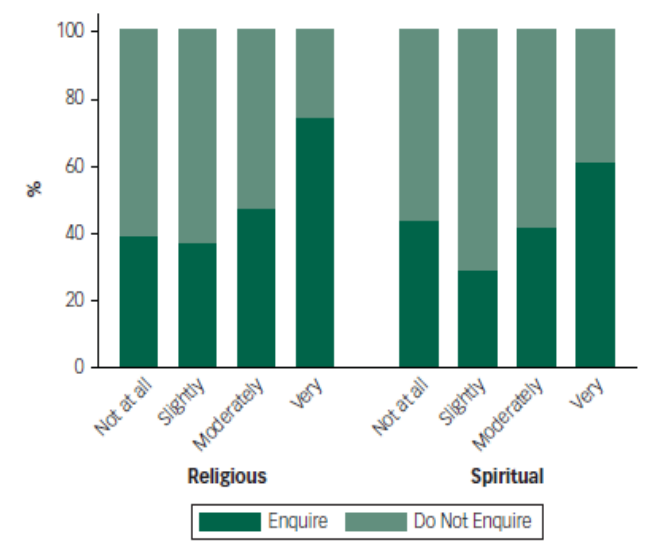

Fig. 1 The figure represents how much psychiatrists enquire about religion/spirituality in their clinical practice, according to how much the psychiatrists consider themselves religious and spiritual. made with caution, since these results may reflect a generational phenomenon, rather than be a function of time in the specialty.

For instance, it is worth remembering that psychiatry was strongly influenced by Freudian views that referred to religious ideas as being illusions, a product of neurosis and close to being 'psychiatric delusions'. ${ }^{21}$ This meant that some theoretical ideas understood religious expression to be pathological and for a long time influenced professionals in the area. ${ }^{22}$

In addition, some authors have emphasised the importance of discussing religion/spirituality in the therapeutic context and distinguished between their positive and negative aspects. ${ }^{23,24}$ They show that the ability to differentiate the pathological from the non-pathological contents of some manifestations of religiosity/ spirituality sometimes depends on specific training. ${ }^{25}$ Psychiatrists need not only to be able to make this distinction but also to be able to identify symptoms that are a result of the psychopathology rather than precede it or deal with even more complex cases which can present a combination of both manifestations. ${ }^{26}$

As in other studies, ${ }^{9,13,14}$ where there is a wide agreement among psychiatrists about the need for the integration of religion/ spirituality in clinical treatment, the vast majority of psychiatrists in this study considered it to be very or reasonably important to integrate their patients' religion/spirituality into their practice. Unsurprisingly, believing in the importance of the integration of religion/spirituality into clinical practice and medical training were also associated with greater rates of religious affiliation.

Some studies show that although psychiatrists consider it important to integrate religion/spirituality in the therapeutic context, in practice this does not often happen, ${ }^{9,10}$ unless the patients themselves took the initiative. ${ }^{27}$ In our study, $45.5 \%$ of the participants stated they often discussed religion/spirituality with their patients, a much lower figure than that reported in the study by Curlin $e t a l,{ }^{13}$ where a higher proportion (87\%) of American psychiatrists reported always asking about their patients' religion/ spirituality. 
Although a high proportion of psychiatrists declared that they do not have any barriers in addressing their patients' religion/ spirituality, the most commonly mentioned barriers were similar to those of previous studies: ${ }^{13,27}$ the fear of exceeding the role of a doctor, lack of training and lack of time.

The psychiatrists who declared that they did not have any barriers in addressing religion/spirituality in clinical practice were the most likely to enquire about these issues with their patients and less tending to have religious affiliation, whereas those who indicated having barriers such as the fear of exceeding the doctor's role and lack of training were the most likely to declare a religious affiliation, and, unsurprisingly, less likely to inquire about patients' religion/spirituality.

The Brazilian psychiatrists, as in studies with South African ${ }^{12}$ and British psychiatrists, ${ }^{9}$ showed that having a religious affiliation itself was not associated with psychiatrists asking about their patients' religion/spirituality. However, considering oneself very spiritual, and especially very religious, is associated with this. These findings are similar to an American study ${ }^{28}$ performed with general practitioners, which showed the more they identified themselves as spiritual and religious, the more likely they were to enquire about their patients' religious/spiritual issues. Although the psychiatrists in our study who declared themselves to be very religious were relatively few (17\%), they were almost five times more likely to enquire into their patients' religious and spiritual issues, when compared with those who declared themselves to be not religious at all.

\section{Limitations}

This study has some methodological limitations. Among them, perhaps the most important, is its cross-sectional nature, with information being collected through the self-reports of psychiatrists. In addition, a generalisation of the data has to be carried out carefully since the response rate could be considered as relatively low (28\%), despite the overall sample size ( $n=484$ from a total of 1779). However, the reply rate is in the expected range for research that uses electronic methods of data collection (email). Studies show that psychiatrists are often reluctant to participate in opinion polls ${ }^{29}$ and generally present a low return to surveys, including in Brazil. ${ }^{30}$ Moreover, the response rates for surveys performed via the Internet are lower in relation to those conducted by face-to-face, mail or telephone methods. ${ }^{31}$ However, $28 \%$ of those contacted completed the survey, a participation percentage higher than in other studies using a similar methodology. ${ }^{31,32}$ The rate of response for studies involving business people, psychiatrists ${ }^{30}$ and oncologists ${ }^{34}$ is not usually more than $20 \%$. In a more recent example in Brazil of a survey through the Internet, involving 365 spiritist centres in the city of São Paulo, ${ }^{35}$ only $15 \%$ agreed to participate.

Another possible limitation of the sample is that it may have selected individuals who are more passionate about the issue both for and against, so that those who are more religious and those who are not religious may have felt more inclined to respond to the questionnaire. Curlin $e t a 2^{28}$ suggested that non-religious doctors might have been more inclined to participate in the research.

Finally, a potential difficulty when interpreting the results concerns the definition of complex and multifaceted concepts such as spirituality and religiosity. In the present work, the terms religion and spirituality were not defined, allowing the respondents to apply their own definitions, and therefore, the survey results should be interpreted with caution. In addition, since there is no universal definition accepted by researchers, this lack of consensus also causes difficulty and requires caution when comparing the results between studies.

\section{Final remarks}

This is the first systematic Brazilian survey asking psychiatrists about religion/spirituality in their practice, and whether their own beliefs influence their clinical work. Two-thirds of the participants of this survey had a religious affiliation, and almost half enquired frequently about their patients' religion/spirituality. Most of the participants are in favour of establishing training programmes to improve the skills of psychiatrists in respect of their approach towards patients' religion/spirituality. Respondents also support the idea of creating a course related to religion/spirituality for undergraduate medical students. A larger survey involving a greater number of psychiatrist participants and using a more detailed questionnaire would be necessary to confirm and clarify the preliminary results of this study.

Furthermore, new studies to evaluate and understand the role of psychiatrists who include or do not include an assessment of their patients' religion/spirituality into their clinical practice as well as into their treatment plans and prevention strategies will be needed. In summary, this is a new area of investigation that could contribute significantly to a better clinical outcome for psychiatric patients.

Maria Cecilia Menegattichequini, MSC, Department and institute of PSychiatry, University of S50 Paulo Medical School, S580 Paulo, Brazil (LIM23); Juliane P.B. Gonçalves, MSC, Department and institute of Psychiatry, University of $\mathrm{S}^{\circ} \mathrm{P}$ Pay

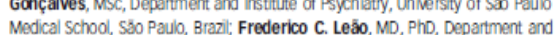
Medical school, S3o Paulo, Brazl; Frederico C. Leáo, MD, PhD, Department and Institute of Psychiatry, University of SSO Paulo Medical School, S30 Paulo, Brazil; Mario F. P. Peres, MD, PhD, Department of Neurology, Albert Einstein Hospitt, Psychiatry, University of 550 Paulo Medical School, S\$0 Paulo, Brazil (LM23).

Correspondence: Maria Cecilia Menegatti-Chequini, Department \& institute of Psychiatry, University of S\$o Paulo Medical School, Rua Dr. Ovidio Pires de Campos 785, Zip Code 05403-010, 550 Paulo, Brazl (UMQ3). Email: monchequiniogmail.com

First received 10 Feb 2016, final revision 10 Jul 2016, accepted 20 Sep 2016

\section{Funding}

This study wes partially funded by the Associaç50 Mantenedora 1050 Evangelista, 550 Paulo, Brazil.

\section{Acknowledgements}

We thank Rancisco Lotufo Neto and Alexander Moreira Almeida for their support and encouragement, Mrcia scarufea and Camila Martins for their statistical assistance, all the psychiatrists who took the time to complete the survey, and the Brazilin Association of Psychiatry.

\section{References}

1 Koenig HG, McCullough ME, Larson DB. Handbook of Religion and Health. Oxford University Press, 2001

2 Koenig HG, King D, Carson VB. Handbook of Religion and Health (2nd edn). Oxford University Press, 2012.

3 Koenig HG. Research on religion, spirituality, and mental health: a review. Can J Psychiatry 2009; 54: 283-91.

4 Bonelli R, Koenig HG. Mental disorders, religion and spirituality 1990 to 2010: a systematic evidence-based review. J Relig Health 2013; 52: 657-73.

5 American Psychiatric Association (APA), Committee on Religion and Psychiatry. Guidelines regarding possible conflict between psychiatrists' religious commitments and psychiatric practice. Am J Psychiatry 1990; 147: 542

6 Royal College of Psychiatrists. Saintuality and Psychiatry Special interest Group. RCP, 1999 (ittp'/Nww..cpsych ac. uk/oollege/specialirterestgroups/spirituality.aspx).

7 Cordeiro Q. Creation of the section on spirituality and mental health at the Brazilian Psychiatric Association. Psyche Spirt 2014; 1: 2-3.

8 Moreira-Almeida A, Sharma A, Rensburg B, Verhagen P, Cook C. WPA position statement on spirituality and religion in psychiatry. World Psychiatry 2016; 15: $87-8$. 
9 Neeleman I. King M. Psychiatrists religious attitudes in relation to their clinicalpractice - a survey of 231 psychiatrists. Acta Psychiatr Scand 1993; 88: 420-4.

10 Baetz M, Griffin R, Bowen R, Marcoux G. Spirituality and psychiatry in Canada: psychiatric practice compared with patient expectations. Can I Psychiatry 2004 49: $265-71$.

11 Lee E, Baumann K. German psychiatrists' observation and interpretation of religiosity/spirituality. Evid Based Complement Atternat Med 2013; 2013: 280168 (Epub).

12 Welgemoed M, Staden C. Does religious identification of South African psychia trists matter in their approach to religious matters in clinical practice? S Aft Psychiatr 2014; 20: 140-5.

13 Curlin F, Lawrence R, Odell S, Chin M, Lantos J, Koenig HG, et al. Religion, spirituality, and medicine: Psychiatrists' and other physicians' differing observ

tions, irterpretations, and clinical approaches. Am J Psychiatry 2007; 164: 1825-31.

14 Lawrence R, Head J, Christodoulou G, Andonowska B, Karamat S, Duggal A, et al 19: $962-73$.

15 Curlin F, Lawrence R, Chin M, Lantos J. Religion, conscience, and controversial clinical practioes. N Engl I Med 2007; 356: 593-600.

16 Instituto Brasileiro de Geografia e Estatística (IBGE. Censo Demográfico 2010

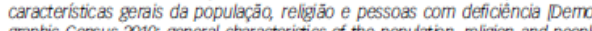
graphic Census 2010. general characteristics of the population, religion and pecp detalhessid $=794$ )

17 Curlin F, Odell S, Lawrence R, Chin M, Lantos J, Meador K, et al. The relationship between psychiatry and religion among US physicians. PSychiatt Serv 2007; 58 : 1193-8.

18 Office of National Statistics UK. Religion in England and Wales 2011 (ittps/ uww.ons gov. uk/peoplepopulationandiommunity/(culturalidentity/religion/articles/
religioninenglandandwales2011/2012-12-11\#measuring religion).

19 Francis $\sqcup$. The psychology of gender differenoes in religion: a review of empirica research. Religion 1997; 27: 81-96.

20 Robinson $\mathrm{K}$, Cheng M, Hansen P, Gray R. Religious and Spiritual Beliefs of Physicians (http'//link.springer.com/article/10.1007/10943016-0233-8)

21 Freud S. The future of an illusion, civilization and its discontents. Reprinted (19531974). In The Standard Edition of the Complete Psychological Works of Sigmund Freud (trans \& ed I Strachey): vol. 21, p. 31. Hogarth Press.

22 Neeleman J, Persaud R. Why do psychiatrists neglect religion. Br J Med Psychol 1995; 68: 169-78.

23 Koenig HG. Religion and mertal health: what should psychiatrists do? Psychiatr Bull 2008; 32: 201-3.
24 Moreira-Almeida A, Koenig HG, Lucchetti G. Clinical implications of spinituality to mental health: review of evidence and practical guidelines. Rev Bras Psiquiatt 2014; 36: 176-82.

25 Moreira-Almeida A, Cardena E. Differential diagnosis between non-pathologica psychotic and spiritual experiences and mental disorders: a contribution from Latin American studies to the ICD-11. Rev Bras Psiquiatr 2011; 33: 21-36.

26 Pintinsky S, Rosmarin D, Pargament K, Midlarsky E. Does negative religious coping accompany, precede, or follow depression among orthodox Jews? I Affect Disord 2011; 132: 401-5.

27 Durà-Vilà G, Hagger M, Dein S, Gerard L. Ethnicity, religion and clinical practice: a qualitative study of beliefs and attitudes of psychiatrists in the United Kingdom. Mert Health Relig Cult 2011; 14: 53-64.

28 Curlin F, Chin M, Sellergren S, Roach C, Lantos J. The association of ptysicians' religious characteristucs with their attutudes and self-eported benaviors regard

29 Cunningham CT, Quan H, Hemmelgam B, Noseworthy T, Beck CA, Dixon E, et al. Exploring physician specialist response rates to web-based surveys. BMC Med Res Methodol 2015; 15: 32

30 Banzato C, Pereira M, Sartos If A, Silva F, Loureiro Ir J, Barros B. What do Brazilian psychiatrists wart from diagnostic classifications? I Bras Psiquatr 2007; 56 88-93.

31 Nulty D. The adequacy of response rates to online and paper surveys: what can be done? Assess Eval High Educ 2008; 33: 301-14.

32 Duarte G, Osis M, Faúndes A, De Sousa M. Brazilian abortion law: the opinion of judges and prosecutors. Rev Saúde Pública 2010; 44: 406-20.

33 Harzing A. Response rates in irternational mail surveys: results of a 22 country study. Int Bus Rev 1997; 6: 641-65.

34 Samano E, Ribeiro L, Camos A, Lewin F, Filho E, Goldenstein P, et al. Use of complementary and alternative medicine by Brazilian oncologists. Eur I Cancer Care 2005; 14: 143-8.

35 Lucchetti AL, Lucchetti G, Leão FC, Peres MFP, Vallada H. Mental and physical health and spiritual healing: an evaluation of complemertary religious therapies provided by spiritist centers in the city of Säo Paulo, Brazil. Oult Med Psychiatty 2016; 40: 404-21. 
b) Menegatti-Chequini MC, Maraldi EO, Peres MFP, Leão FC, Vallada H. How psychiatrists think about religious and spiritual beliefs in clinical practice: findings from a university hospital in Sao Paulo. São Paulo, Brazil. Braz J Psychiatry 2018; 41(1): 58-65.

Brazilian Journal of Psychiatry. 2019 Jan-Feb;41(1): $58-65$

Brazilian Psychiatric Association

Revista Brasileira de Psiquiatria
CC-BY-NC I doi:10.1590/1516-4446-2017-2447

\title{
ORIGINAL ARTICLE
}

\section{How psychiatrists think about religious and spiritual beliefs in clinical practice: findings from a university hospital in São Paulo, Brazil}

\author{
Maria C. Menegatti-Chequini, ${ }^{1}$ (iD Everton de O. Maraldi, ${ }^{2}$ Mario F.P. Peres, ${ }^{1,3}$ Frederico C. Leão, ${ }^{1}$ \\ Homero Vallada ${ }^{1}$ \\ 'Departamento e Instituto de Psiquiatria (ProSER/IM23), Hospital das Clínicas, Faculdade de Medicina da Universidade de São Paulo \\ (FMUSP), São Paulo, SP, Brazil. ${ }^{2}$ Instituto de Psicologia, Universidade de São Paulo (USP), São Paulo, SP, Brazil. ${ }^{3}$ Departamento de \\ Neurologia, Hospital Albert Einstein, São Paulo, SP, Brazil. (iD https://orcid.org/0000-0002-8958-983X
}

\begin{abstract}
Objective: To examine the relationship between psychiatrists' religious/spiritual beliefs and their attitudes regarding religion and spirituality in clinical practice.

Methods: A cross-sectional survey of religion/spirituality (R/S) in clinical practice was conducted with 121 psychiatrists from the largest academic hospital complex in Brazil.

Results: When asked about their R/S beliefs, participants were more likely to consider themselves as spiritual rather than religious. A total of $64.2 \%$ considered their religious beliefs to influence their clinical practice and $50 \%$ reported that they frequently enquired about their patients' $\mathrm{R} / \mathrm{S}$. The most common barriers to approaching patients' religiosity were: lack of time $(27.4 \%)$, fear of exceeding the role of the doctor $(25 \%)$, and lack of training $(19.1 \%)$. Those who were less religious or spiritual were also less likely to find difficulties in addressing a patient's R/S.

also less likely to find difficulties in addressing a patient's R/S. attitudes concerning their approach to $\mathrm{R} / \mathrm{S}$. The results suggest that medical practice may lead to a religious conflict among devout psychiatrists, making them question their faith. Training might be of importance for handling $\mathrm{R} / \mathrm{S}$ in clinical practice and for raising awareness about potential evaluative biases in the assessment of patients' religiosity.
\end{abstract}

Keywords: Religion; ethics; education, psychiatric; psychotherapy

Introduction

Although a relationship between medicine, religiosity, and spirituality has been observed since antiquity, only in the last few decades has a significant increase in scientific publications addressing such topics been observed. A bibliometric study using the Boolean expression "spiritual* OR religion" "and covering a period of 15 years found that the number of PubMed publications increased steadily between 1999 and 2013 , resulting in a total of 30,532 references. $^{1}$ The evidence obtained so far indicates a positive relationship between religious involvement/spirituality $(R / S)$ and physical health on one side and mental health and R/S on the other, including an increase in coping capacity. ${ }^{2}$

Overall, research in the mental health area indicates that $\mathrm{R} / \mathrm{S}$ is associated with improved well-being, feelings of meaning and peace, ${ }^{3}$ and reductions in suicide rates, depression, anxiety, and substance abuse. ${ }^{4,5}$ Such benefits are not restricted to mild and moderate conditions, but also include patients with severe mental illness. ${ }^{6}$

Correspondence: Maria Cecilia Menegatti-Chequini, Departamento e Instituto de Psiquiatria (UM23/ProSER), Hospital das Cínicas, Faculdade de Medicina da Universidade de São Paulo, Rua Dr. Ovídio Pires de Campos, 785, CEP 05403-010, São Paulo, SP, Brazi. E-mail: mceciliamc@usp.br

Submitted Aug 10 2017, accepted Oct 17 2017, Epub Nov 082018.
Based on these studies, many professional organizations, such as the World Psychiatric Association (WPA), ${ }^{7}$ the Royal College of Psychiatrists (RCP), ${ }^{8}$ the American Psychiatric Association (APA), ${ }^{9}$ the Joint Commission on Accreditation of Healthcare Organizations (JCAHO), ${ }^{10}$ and the Brazilian Psychiatry Association (ABP) ${ }^{11}$ have noted the importance of taking spirituality into consideration and have raised awareness of its implications for clinical practice and medical training.

There is a growing body of research investigating how the patient's R/S is approached in clinical practice. ${ }^{12}$ The evi dence shows that a large majority of physicians consider it important to integrate $\mathrm{R} / \mathrm{S}$ into their practice, but most of them face difficulties in addressing such topics with their patients, due to a lack of time and a lack of appropriate training. . $^{13,14}$

Psychiatry is no different from other areas of medicine in this regard. Even though psychiatrists reported having fewer difficulties and more experience in handling their patients' R/S, these attitudes and perceptions have not always been reflected in their practice, and they face the

How to cite this article: Menegatti-Chequini MC, Maraldi EO, Peres MFP, Leão FC, Vallada $\mathrm{H}$. How psychiatrists think about religious and spiritual beliefs in clinical practice: findings from a university hospital in São Paulo, Brazil. Braz J Psychiatry. 2019;41:58-65. http://dx.doi.org/10.1590/1516-4446-2017-2447 
same barniers as other medical specialists when approaching patients' R/S. ${ }^{15}$ In a recent survey of 484 Brazilian psychiatrists, all members of the ABP, Menegatti-Chequini et al. found that more than half of the participants $(55.5 \%)$ did not enquire frequently about their patients' R/S. The most common reasons for not doing so included being afraid of exceeding the role of the doctor $(30.2 \%)$ and lack of training $(22.3 \%) .{ }^{16}$

The evidence suggests that the religious characteristics and beliefs of physicians (including psychiatrists) are directly related to their attitudes and behaviors regarding $\mathrm{R} / \mathrm{S}$ in clinical practice. ${ }^{13,17-20}$ When psychiatrists consider themselves to be more religious or spiritual, they are also more likely to ask their patients about their $\mathrm{R} / \mathrm{S}$ and to see the integration of R/S into clinical practice as important. ${ }^{16}$ However, more research is needed to clarify the relationship between psychiatrists' attitudes toward R/S, as well as their approach to these issues in clinical practice, including the role of specific religious or spiritual beliefs and religious coping.

The aim of the present study was to investigate the religious and spintual beliefs of Brazilian psychiatrists working at the Instituto de Psiquiatria, Hospital das Clínicas, Faculdade de Medicina, Universidade de São Paulo (IPqHC-FMUSP) to verify whether these beliefs affected their approach to their patients' R/S. The IPq-HC-FMUSP is the largest academic psychiatric hospital in Brazil and a national reference in psychiatry. ${ }^{21}$ In this respect, although not representative of Brazilian psychiatrists, the obtained results reflect the beliefs, attitudes, and behaviors of influential professionals in this area regarding R/S.

The study also aimed to investigate in more detail some aspects of psychiatrists' attitudes toward religion and spirituality that have not been assessed previously, ${ }^{16}$ including: 1) religious and spiritual beliefs, such as God, life after death, and reincarnation; 2) the specific ways in which their perspective on R/S influence clinical practice; 3) the ways in which medical practice affects their own $\mathrm{R} / \mathrm{S}$; and 4) the potential impact of religious coping strategies in their practice as physicians.

\section{Methods}

\section{Study design and sampling}

The study comprised a cross-sectional investigation of 121 psychiatrists working at IPq-HC-FMUSP. Participants were personally approached by one of the authors (MCMC) and invited to collaborate with the study by answering a brief and confidential questionnaire. Data collection occurred between December 2013 and May 2014.

\section{Survey content}

A questionnaire was developed based on the instrument Religion and Spirituality in Medicine: Physicians' Perspectives, by Curlin et al. ${ }^{22}$ to investigate attitudes and behaviors of physicians from different specialties concerning R/S in clinical practice.

The questionnaire was translated into Portuguese and tested in a pilot study with two groups: initially with
30 health professionals (from different specialties) and with 20 psychiatrists in training (residents) at IPq-HC-FMUSP. The questions were considered clear and no additional adaptation was necessary during the testing phase.

The questionnaire consisted of a self-report measure assessing the three principal areas described below.

\section{Sociodemographic and professional characteristics}

This section included data related to age, gender, marital status, psychiatric specialty, degree level, and the number of years of professional experience.

\section{Participants' religious and spiritual characteristics}

The R/S dimension was measured based on two questions, one evaluating the reported level of religiousness ("To what extent do you consider yourself a religious person?") and the other evaluating spirituality ("To what extent do you consider yourself a spiritual person?"). Each question contained four alternatives: 1 = not at all, 2 = slightly, 3 = moderately, and 4 = very. It was decided not to define the terms religiousness or spirituality. Thus, participants were given the opportunity to rely on their own interpretations of these concepts.

Psychiatrists were also questioned about their beliefs in God, life after death, and reincarnation. Their answers to these questions were given based on three alternatives: $2=$ yes, $1=$ undecided, and $0=$ no. These beliefs were chosen because of the marked syncretism of Brazilian religiosity and the widespread influence of Christian and spiritualist ideas in this cultural context. ${ }^{23}$

Religious affiliation was determined based on the following choices: Catholic, Protestant or Evangelical, Spiritist, other religion (including Judaism, Islam, Hinduism, Buddhism, and Mormonism), and none (including agnostic and atheist). Religious affiliations were presented according to the Brazilian context, where Catholics, Evangelicals, and Spiritists constitute the majority of the religious followers. ${ }^{24}$

Coping styles were measured based on two questions extracted from the Spiritual/Religious Coping Scale $(\mathrm{RCOPE})^{25}$ : one evaluating religious coping ("I look to God for strength, support, and guidance.") and the other evaluating individual or non-religious coping ("I try to make sense of the situation and decide what to do without relying on God."). Each question contained four alternatives: 1 = never, 2 = rarely, 3 = occasionally, and 4 = often.

Opinions and behaviors related to religiousness/spirituality

Participants were questioned on the extent to which they agreed with the following statements: "My experience as a physician has made me question my religious and spiritual beliefs"; "I find it challenging to remain faithful to my religion in my work as a physician," and "My religious/ spiritual beliefs influence my clinical practice." Four possible alternatives were given to participants: $1=$ not at all, 2 = slightly, 3 = moderately, and $4=$ strongly.

Regarding the approach to R/S in clinical practice, participants were questioned on the frequency with which they usually enquire about a patient's R/S. The four alternatives included $1=$ never, 2 = rarely, $3=$ occasionally, 


\begin{tabular}{|c|c|c|c|c|c|c|c|}
\hline & & \multicolumn{3}{|c|}{ Religiosity } & \multicolumn{3}{|c|}{ Spirituality } \\
\hline & & Mean (SD) & $r$ & $\mathrm{p}$-value & Mean (SD) & $r$ & p-value \\
\hline Age in years, mean (SD) & $45.6(9.8)$ & - & 0.03 & 0.744 & - & 0.07 & 0.455 \\
\hline Gender, n (\%) & & & & 0.373 & & & 0.962 \\
\hline Female & $32(38.1)$ & $1.84(0.95)$ & & & $2.43(0.94)$ & & \\
\hline Male & $52(61.9)$ & $2.03(0.94)$ & & & $2.42(0.91)$ & & \\
\hline Marital status, n (\%) & & & & 0.459 & & & 0.323 \\
\hline Without a partner & 24 (28.6) & $2.08(0.88)$ & & & $2.58(0.88)$ & & \\
\hline With a partner & $60(71.4)$ & $1.91(0.97)$ & & & $2.36(0.93)$ & & \\
\hline Subspecialty, n (\%) & & & & 0.247 & & & 0.508 \\
\hline Adult & $70(83.3)$ & $1.88(0.90)$ & & & $2.37(0.93)$ & & \\
\hline Child & $18(21.4)$ & $2.33(0.97)$ & & & $2.77(0.73)$ & & \\
\hline Old age & $13(15.5)$ & $1.92(1.18)$ & & & $2.30(1.10)$ & & \\
\hline Forensic & $11(13.1)$ & $2.45(1.28)$ & & & $2.54(0.68)$ & & \\
\hline Other & $8(9.5)$ & $2.12(0.99)$ & & & $2.37(0.91)$ & & \\
\hline Years as a psychiatrist, mean (SD) & $19.8(10.1)$ & $\cdot$ & -0.02 & 0.828 & $\cdot$ & -0.09 & 0.326 \\
\hline Level of instruction, $n(\%)$ & & & & 0.446 & & & 0.433 \\
\hline Residency & $12(14.3)$ & $1.75(1.05)$ & & & $2.16(1.11)$ & & \\
\hline Specialization & $15(17.9)$ & $1.66(0.89)$ & & & $2.20(0.86)$ & & \\
\hline Masters & $13(15.5)$ & $2.23(0.72)$ & & & $2.76(0.82)$ & & \\
\hline Doctorate & $32(38.1)$ & $2.00(0.98)$ & & & $2.50(0.91)$ & & \\
\hline Post-doctorate & $12(14.3)$ & $2.16(1.02)$ & & & $2.41(0.90)$ & & \\
\hline
\end{tabular}

$r=$ Pearson's correlation coefficient; $S D=$ standard deviation.

and 4 = frequently. Additionally, they were asked whether enquiring about the patient's R/S is something the psychiatrist can (or should) do. Their answers to these questions were selected from three alternatives: 2 = yes, $3=$ undecided, and $1=$ no.

To identify the barriers and difficulties most frequently found by psychiatrists in addressing patients' R/S, participants were asked to answer a multiple-choice question including the following alternatives: 1) None, 2) Fear of exceeding the role of the doctor, 3) Lack of training, 4) Lack of time, 5) Not being comfortable with the issue, 6) Irrelevance of the subject for the patient, 7) Fear of offending the patient, 8) Fear of disapproval from peers, 9) It is not the doctor's job, and 10) Do not know why.

\section{Statistical analysis}

SPSS version 17 was used for the data analyses. Chisquare tests were generated to estimate associations between categorical variables. The t-test and ANOVA were employed to evaluate differences between groups. Pearson product-moment coefficients were obtained to investigate correlations between variables. Finally, a stepwise multiple regression analysis was undertaken to identify which of the difficulties faced by the psychiatrists in addressing $\mathrm{R} / \mathrm{S}$ in clinical practice were most important in the decision to enquire (or not) about their patients' R/S.

\section{Ethics}

The study was approved by the local research ethics committee. Participants were informed of their rights to deny participation, to withdraw from the study at any time, and to have their anonymity preserved. They were also informed about the study's objectives and the voluntary nature of their participation.

\section{Results}

Of the 121 psychiatrists employed by IPq-HC-FMUSP, 86 answered the questionnaire $(71 \%)$. Two response forms were eliminated due to incompleteness. The remaining 84 were analyzed.

\section{Sociodemographic characteristics}

Almost two-thirds of the participants were male. Most were married or in a stable relationship. The majority were post-graduates and treated adult patients. None of these demographic variables showed statistically significant associations with our measures of R/S ( $p>0.05)$. Those dedicated to child psychiatry presented higher levels of spirituality (Table 1).

\section{Religious and spiritual beliefs}

With respect to the psychiatrists' levels of R/S, the participants in this sample were slightly more spiritual (mean $[M]=$ 2.43; standard deviation $[S D] \pm 0.92)$ than religious $(M=$ 1.96 ; SD \pm 0.95 ). Only $31 \%$ of the respondents considered themselves to be very or moderately religious, whereas $53.5 \%$ considered themselves to be very or moderately spiritual.

More than half of the psychiatrists $(57.7 \%)$ said they had a religion, of which the majority was Catholic (Table 2). Almost two-thirds of the sample $(59.5 \%)$ stated that they believe in God. Approximately half of the participants (47.6\%) answered no when questioned about their belief in the 


\begin{tabular}{lc}
\hline \multicolumn{2}{l}{ Table 2 Psychiatrists' religious/spiritual characteristics } \\
\hline & $\mathrm{n}(\%)$ \\
\hline Religious affiliation & \\
Catholic & $28(33.7)$ \\
Protestant or Evangelical & $8(9.6)$ \\
Spintist & $5(6.0)$ \\
Other religion & $7(8.4)$ \\
None & $35(42.8)$ \\
Missing value & 1 \\
Do you believe in God or a higher power? & \\
Yes & $50(59.5)$ \\
No & $20(23.8)$ \\
Undecided & $14(16.7)$ \\
Do you believe there is life after death? & \\
Yes & $24(28.6)$ \\
No & $40(47.6)$ \\
Undecided & $20(23.8)$ \\
Do you believe in reincarnation? & \\
Yes & $16(19.0)$ \\
No & $58(69.0)$ \\
Undecided & $10(11.9)$ \\
I try to make sense of the situation and decide & \\
what to do without relying on God & \\
Often & \\
Oocasionally & $39(48.1)$ \\
Rarely & $22(27.2)$ \\
Never & $9(11.1)$ \\
Missing values & $11(13.6)$ \\
I look for God as a source of strength, support, & 3 \\
and guidance. & \\
Often & \\
Oocasionally & \\
Rarely & \\
Never & $18(21.9)$ \\
Missing values & $15(18.3)$ \\
\hline & $16(19.5)$ \\
& $33(40.2)$ \\
& 2 \\
\hline
\end{tabular}

existence of life after death. In addition, more than twothirds $(69 \%)$ answered that they do not believe in reincarnation.

Regarding religious coping, $58.3 \%$ of the respondents look for God as a source of strength, support and guidance, while $83.3 \%$ decide what to do without relying on God. As one might expect, the latter option was chosen significantly more often by non-religious $(\mathrm{M}=3.34 ; \mathrm{SD} \pm$ 1.16) than by religious participants $(M=2.89 ; S D \pm 0.96)$; $t_{(78)}=1.92 ; p=0.049$. In terms of mean values, the psychiatrists in this sample refer to individual or nonreligious coping strategies slightly more often than they look for God's support (Table 2).

\section{Attitudes and behaviors related to the approach to $R / S$ in clinical practice}

\section{Questioning of faith}

A total of $63.1 \%$ of participants stated that their experience as a physician made them question their religious beliefs at least a little, while $39.3 \%$ found some degree of challenge in remaining faithful to their religion in their job as a physician (Table 3). Questioning of faith showed moderate correlations with different religious and spiritual
Table 3 Psychiatrists' attitudes regarding religion/spirituality in clinical practice

\begin{tabular}{lc}
\hline & $\mathrm{n}(\%)$ \\
\hline $\begin{array}{l}\text { My experience as a physician has made me question } \\
\text { my religious beliefs. }\end{array}$ \\
Strongly & $9(11.0)$ \\
Moderately & $22(26.8)$ \\
Slightly & $22(26.8)$ \\
Not at all & $29(35.4)$ \\
Missing values & 2 \\
I find it challenging to remain faithful to my religion in & \\
my work as a physician. & \\
Strongly & \\
Moderately & $4(4.9)$ \\
Slightly & $8(9.7)$ \\
Not at all & $21(25.6)$ \\
Missing values & $49(59.7)$ \\
& 2 \\
My religious beliefs influence my clinical practice. & \\
Strongly & $6(7.1)$ \\
Moderately & $31(36.9)$ \\
Slightly & $17(20.2)$ \\
Not at all & $30(35.7)$
\end{tabular}

How often do you enquire about patients' religious/ spintual issues?

$\begin{array}{lc}\text { Frequently } & 42(50.0) \\ \text { Occasionally } & 27(32.1) \\ \text { Rarely } & 12(14.3) \\ \text { Never } & 3(3.6)\end{array}$

Enquiring about the religion/spirituality of the patient is something the psychiatrist can (or should) do.

\begin{tabular}{lc} 
(or should) do. & \\
Yes & $74(88.1)$ \\
No & $7(8.3)$ \\
Undecided & $3(3.6)$ \\
\hline
\end{tabular}

characteristics (Table 4), indicating that the more religious or spiritual the psychiatrists were, the more their work as physicians made them question their religious and spiritual beliefs.

Influence of beliefs in clinical practice

More than half of the sample $(64.2 \%)$ considered their religious and spiritual beliefs to influence their clinical practice. This variable showed moderate to strong correlations with religiosity, spirituality, religious coping, and belief in God, life after death, and reincarnation (Table 4). As might be expected, the influence of beliefs in clinical practice differed between religious and non-religious affiliations $\left(F_{4,78}=10.42 ; p<0.001\right)$. The least significant difference post-hoc tests indicate that all religious groups scored significantly higher $(p<0.05)$ than atheists and non-religious participants in the influence they attribute to religious and spiritual beliefs in clinical practice.

Psychiatrists who worked with children $\left(t_{[82]}=2.52\right.$; $p=0.013)$ and adults $\left(t_{[82]}=2.03 ; p=0.045\right)$ were more likely to think that their beliefs influence clinical practice.

A total of $88.1 \%$ of psychiatrists consider enquiring about the patient's R/S as something the psychiatrist can or should do. Half of the sample $(50 \%)$ answered that they frequently ask their patients about their religious/spiritual beliefs, while 
$46.4 \%$ enquire occasionally or rarely. None of the sociodemographic or professional characteristics were associated with addressing the patient's R/S. However, belief in reincamation correlated positively with the frequency with which psychiatrists ask about patients' R/S (Table 4).

Barriers to addressing religiosity and spirituality in clinical practice

Almost half of the sample stated that they have no difficulty in addressing the religiosity and spirituality of their patients, and they were more likely to be male than female (Fisher's exact test, $\mathrm{p}=0.041$; adjusted residual $=2.2$ ), as well as less spiritual $\left(M=2.19 ; S D \pm 0.97 ; t_{882}=2.16\right.$; $p=0.034)$ and less religious $\left(M=1.68 ; S D \pm 0.81 ; t_{[82]}=\right.$ $2.55 ; p=0.013$ ).
The most commonly reported barriers to approaching patient R/S in clinical practice were lack of time, fear of exceeding the role of the doctor, and lack of training (see Figure 1 for the other responses).

More male than female psychiatrists considered lack of time to be a relevant barrier (Fisher's exact test, $p=$ 0.023 ; adjusted residual $=2.4$ ). Those who considered fear of exceeding the role of the doctor as a challenge scored significantly higher in religiosity $(\mathrm{M}=2.52 ; \mathrm{SD} \pm$ $\left.1.03 ; t_{[82]}=-3.30 ; p=0.013\right)$ and spirituality $(M=2.29$; $\left.S D \pm 0.96 ; t_{[50.43]}=-3.06 ; p=0.004\right)$.

A stepwise multiple regression analysis was undertaken to identify which of the barriers or difficulties in addressing a patient's $\mathrm{R} / \mathrm{S}$ would best predict the frequency with which they enquire about the patient's $R / S$ (adjusted $R^{2}=0.25$; $\left.F_{3,80}=10.15 ; p<0.001\right)$. The most significant predictors

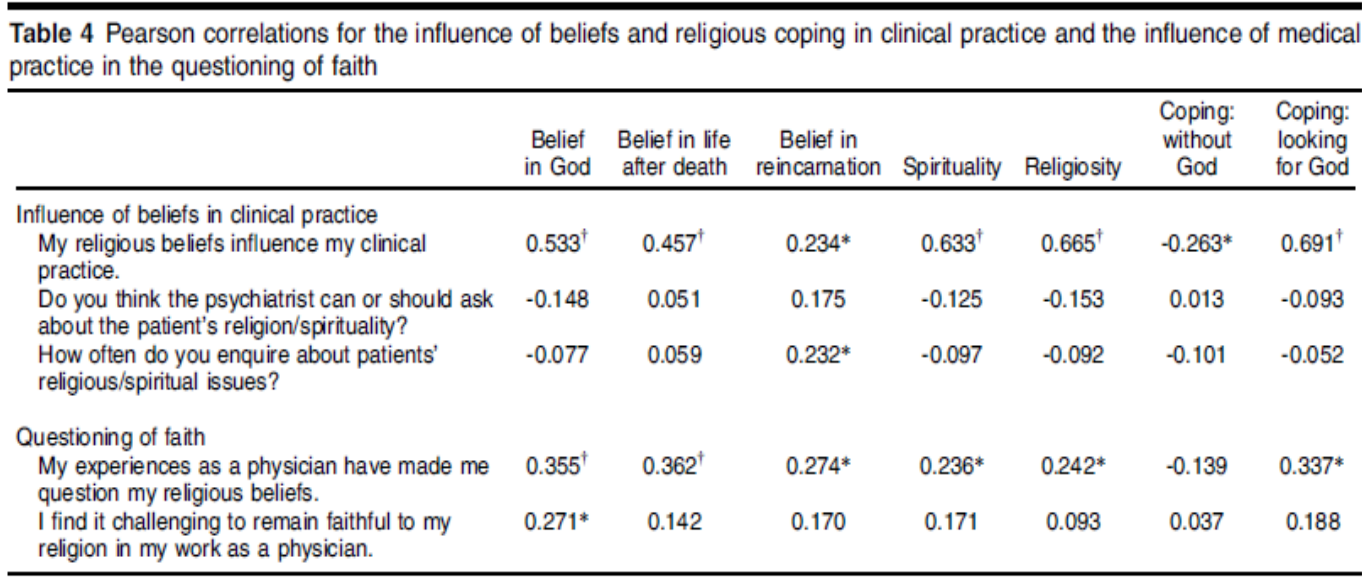

${ }^{*} p<0.05 ;{ }^{\dagger} p<0.001$.

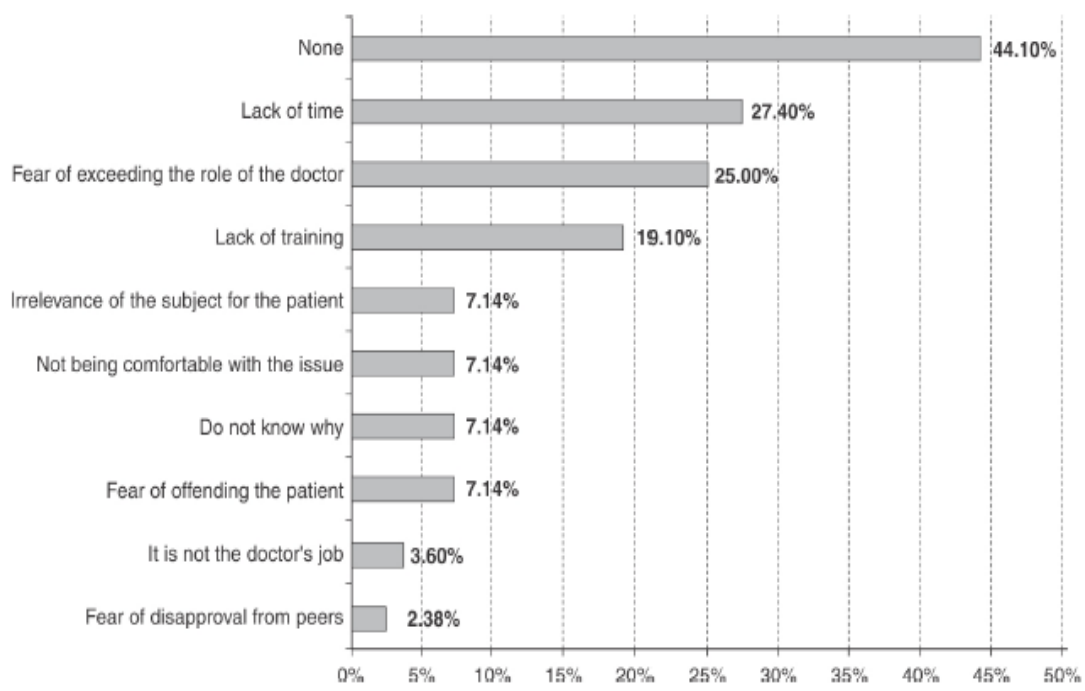

Figure 1 Challenges/barriers to approaching patients' religiosity/spirituality. 
in the final model were: it is not the doctor's job $(\beta=-0.42$; $t=-4.34 ; \mathrm{p}<0.001)$, do not know why $(\beta=-0.30 ; t=-3.12$; $p=0.002)$, and lack of time $(\beta=-0.25 ; t=-2.56 ; p=0.012)$. In terms of whether the psychiatrist should ask about the patient's R/S (adjusted $R^{2}=0.16 ; F_{2,81}=9.04 ; p<0.001$ ), the best predictors were: it is not the doctor's job ( $\beta=-0.40$; $t=-3.88 ; \mathrm{p}<0.001)$ and not being comfortable with the issue $(\beta=0.25 ; t=2.46 ; p=0.016)$.

\section{Discussion}

Differences in psychiatrists' religious and spiritual characteristics are associated with different attitudes concerning the approach to $\mathrm{R} / \mathrm{S}$ in clinical practice. For example, the results showed that religious participants attribute more influence to religious and spiritual beliefs in their clinical practice than those not considered religious. In this regard, those who believe in reincarnation were more likely to ask their patients about R/S issues than those who do not. The study also found that experience as a physician might produce a religious conflict among religious psychiatrists, leading them to question their beliefs, which could affect their approach to their patients' R/S. In this sense, those who reported a fear of exceeding the role of the doctor scored significantly higher in religiosity and spirituality. Accordingly, those who were less religious and less spiritual were less likely to find difficulties in addressing the patient's R/S.

Training might be of importance in handling R/S in clinical practice (whether the psychiatrist is religious or not) and could also raise awareness about potential evaluative biases in the assessment of patients' R/S. Training might also help reduce the discomfort reported by some psychiatrists when they need to approach R/S issues. However, certain challenges may be harder to overcome, such as a lack of time, which will depend on circumstances that are not entirely under the psychiatrist's control.

Although spiritual care may not be considered an exclusive prerogative of healthcare chaplains, making them part of the multi-disciplinary team could also help prevent psychiatrists' fear of exceeding the role of the doctor when addressing patients' R/S. This strategy could be important when providing integral care for the patient.

Psychiatrists' approaches to religious issues appeared to be influenced by gender differences, with males reporting fewer difficulties than females. Although there were no R/S differences between genders, women appeared to give particular relevance to such topics, in a way that is different from male psychiatrists, which should be further investigated.

It was also observed that child psychiatrists scored higher in spirituality and were more likely to think their religious beliefs influenced their clinical practice. Interestingly, Curlin et al. ${ }^{26}$ reported that family physicians and pediatricians are more religious than physicians from other specialties. There is a current scarcity of reports regarding the potential impact of psychiatry subspecialties on the $\mathrm{R} / \mathrm{S}$ of psychiatrists.
Similar to what was observed in previous investigations, ${ }^{15,17}$ the psychiatrists in this sample consider themselves more spiritual than religious. This finding may reflect an understanding of spintuality as a broader category than religion or religiosity. Despite the lack of consensus on R/S concepts, most studies refer to religion as an organized, collective system of beliefs and practices in the search of the sacred or transcendent, while spirituality is understood as a personal form of search or connection with the sacred or transcendent. Spirituality was found in many studies to be related to a sense of well-being, a sense of purpose in life and experiences of life satisfaction without necessarily depending on commitment to a religious community. ${ }^{3,27}$

More than half of the participants reported a religious affiliation, a percentage significantly lower than that of the Brazilian population, of which only $8 \%$ said they had no religion. ${ }^{24}$ The percentage in our sample was also lower than that of Brazilian physicians from other specialties $(94.9 \%)^{28}$ and that of medical students from 12 different schools of medicine $(66.1 \%){ }^{29}$

Compared to medical students, our sample also showed lower percentages for belief in God $(59.5 \%$ vs. $84.2 \%)$, belief in life after death $(28.6 \%$ vs. $66.8 \%)$, and belief in reincarnation ( $19 \%$ vs. $36.9 \%){ }^{29}$ Our data are in accordance with previous reports in which psychiatrists were less likely to believe in God and declare a religious affiliation than the general population ${ }^{16-18,30}$ or physicians from other specialties. ${ }^{31}$ This more secular trait of psychiatrists continues to appear in studies addressing the R/S of health professionals in general. ${ }^{20,32}$ Some authors ${ }^{33,34}$ attribute this finding to the influence of psychological theories, such as Sigmund Freud's ${ }^{35}$ psychoanalysis, which is known to have pathologized religious behavior. According to Curlin et al.,.", the historical tensions between psychiatry and religion influenced many psychiatrists in the past century and continue to be influential today.

In Brazil, the tendency to "pathologize" religious expressions such as trance and possession is also historical. In the second half of the 20th century, these experiences were considered by most Brazilian psychiatrists to be symptoms of mental disorders. ${ }^{36}$ More recenty, a culturally sensitive understanding of these experiences has emerged, and specific diagnostic criteria have been developed to help differentiate pathological from culturally accepted and healthy spiritual manifestations. ${ }^{37}$ Still, mental health professionals do not generally receive adequate training to address the $R / S$ aspects of their patients, ${ }^{38}$ including experiences of possession, which would be of paramount importance for avoiding erroneous diagnoses and iatrogenic symptoms. ${ }^{37,39}$

In conclusion, although half of the psychiatrists in this study often address their patients' R/S, most report difficulties in approaching this topic and almost half report that their beliefs strongly or moderately influence their medical practice. Their religious/spiritual characteristics are associated with their attitudes and behaviors regarding their approach to R/S in clinical practice. Information and training regarding $R / S$ issues might help psychiatrists overcome the barriers to approaching this topic and adequately integrating the R/S aspects of their patients into therapeutic work. 
This investigation has some methodological limitations. First, the range of religious and spiritual beliefs covered in the questionnaire is very limited. Second, the sample was restricted to psychiatrists from only one institution and, despite being one of the most respectable academic organizations in Brazil, the results could not be generalized as a representation of what most Brazilian psychiatrists think. Finally, self-report measures and questionnaires are vulnerable to response bias. Future investigations would benefit from the complementary use of qualitative and in-depth interviews. Additional aspects to be evaluated include psychiatrists' opinions on the relationship between religion and mental health, their knowledge about issues regarding R/S, the most common approaches to patients' R/S, and patients' perceptions of psychiatrists' approach to their religious and spiritual issues.

\section{Acknowledgements}

The study received financial support from the Associação Mantenedora João Evangelista, São Paulo, Brazil. EOM is funded by the Fundação de Amparo à Pesquisa do Estado de São Paulo (FAPESP; grant 2015/05255-2).

We would like to thank all the psychiatrists who took the time to complete the survey, as well the IPq-HC-FMUSP staff, Dr. Edson Shiguemi Hirata, Ms. Katia Ichi, and the secretaries of the outpatient units for their help in the data collection.

\section{Disclosure}

The authors report no conflicts of interest.

\section{References}

1 Lucchetti G, Lucchetti AL. Spirituality, religion, and health: over the last 15 years of field research (1999-2013). Int J Psychiatry Med. 2014; 48:199-215.

2 Moreira-Almeida A, Neto FL, Koenig HG. Religiousness and mental health: a review. Rev Bras Psiquatr. 2006;28:242-50.

3 Peres MF, Kamei HH, Tobo PR, Lucchetti G. Mechanisms behind religiosity and spirituality's effect on mental health, quality of life and well-being. J Relig Health. 2017 Apr 25. doi: 10.1007/s10943-017-0400-6. [Epub ahead of print]

4 Koenig HG, King D, Carson V. Handbook of religion and health. 2nd ed. New York: Oxford University; 2012.

5 Bonelli RM, Koenig HG. Mental disorders, religion and spirituality 1990 to 2010: a systematic evidence-based review. J Relig Health. 2013;52:657-73.

6 Pargament KI, Lomax JW. Understanding and addressing religion among people with mental illness. World Psychiatry. 2013:12:26-32.

7 Moreira-Almeida A, Sharma A, van Rensburg BJ, Verhagen PJ, Cook CC. WPA position statement on spirituality and religion in psychiatry. World Psychiatry. 2016;15:87-8.

8 Royal College of Psychiatrists. Spirituality and psychiatry special interest group [Internet]. 1999 [cited 2017 Oct 26]. www.rcpsych.ac. uk/college/specialinterestgroups/spirituality.aspx

9 American Psychiatric Association (APA), Committee on Religion and Psychiatry. Guidelines regarding possible conflict between psychiatrists' religious commitments and psychiatric practice. Am J Psychiatry. 1990;147:542

10 Joint Commission on Accreditation of Healthcare Organizations (JCAHO). Medical Record - Spiritual Assessment [Internet]. 2017 [cited 2017 Oct 26]. www.jointcommission.org/standards_information jcfagdetails.aspx? StandardsFaqld $=1492 \&$ Programld $=46$

11 Cordeiro Q. Creation of the section on spirituality and mental health at the Brazilian psychiatric association. Psyche Spirit. 2014;1:2-3.
12 Hvidt NC, Korup AK, Curlin FA, Baumann K, Frick E, Sondergaard J, et al. The NERSH international collaboration on values, spirituality and religion in medicine: development of questionnaire, description of data pool, and overview of pool publications. Religions (Basel). 2016;7:107.

13 Curlin FA, Chin MH, Sellergren SA, Roach CJ, Lantos JD. The association of physicians' religious characteristics with their attitudes and self-reported behaviors regarding religion and spirituality in the clinical encounter. Med Care. 2006:44:446-53.

14 Moreira-Almeida A, Koenig HG, Lucchetti G. Clinical implications of spirituality to mental health: review of evidence and practical guidelines. Rev Bras Psiquiatr. 2014;36:176-82.

15 Curlin FA, Lawrence RE, Odell S, Chin MH, Lantos JD, Koenig HG, et al. Religion, spirituality, and medicine: psychiatrists' and other physicians' differing observations, interpretations, and clinical approaches. Am J Psychiatry. 2007;164:1825-31.

16 Menegatti-Chequini MC, Gonçalves JP, Leẫ FC, Peres MF, Vallada $\mathrm{H}$. A preliminary survey on the religious profile of Brazilian psychiatrists and their approach to patients' religiosity in clinical practice. BJPsych Open. 2016;2:346-52.

17 Neeleman J, King MB. Psychiatrists religious attitudes in relation to their clinical-practice - a survey of 231 psychiatrists. Acta Psychiatr Scand. 1993;88:420-4

18 Baetz M, Griffin R, Bowen R, Marcoux G. Spirituality and psychiatry in Canada: psychiatric practice compared with patient expectations. Can J Psychiatry. 2004;49:265-71.

19 Shin JH, Yoon JD, Rasinski KA, Koenig HG, Meador KG, Curlin FA. A spiritual problem? Primary care physicians' and psychiatrists' interpretations of medically unexplained symptoms. J Gen Intern Med. 2013,28:392-8.

20 Yoon JD, Shin JH, Nian AL, Curlin FA. Religion, sense of calling, and the practice of medicine: findings from a national survey of primary care physicians and psychiatrists. South Med J. 2015;108:189-95.

21 Seixas A, Zilberman M. O Instituto de psiquiatria do Hospital das Clinicas - FMUSP. In: Mota A, Marinho M, editores. História da psiquiatria: ciências, prática e tecnologias de uma especialidade médica. São Paulo: Casa de Soluçőes e Editora; 2012. p. 177-90.

22 Curlin FA, Lawrence RE, Chin MH, Lantos JD. Religion, conscience, and controversial clinical practices. N Engl J Med. 2007; 356:593-600.

23 Moreira-Almeida A, Pinsky I, Zaleski M, Laranjeira R. Envolvimento religioso e fatores sociodemográficos: resultados de um levantamento nacional no Brasil. Rev Psiquiatr Clin. 2010;37:12-5.

24 Instituto Brasileiro de Geografia e Estatística (IBGE). Censo Demográfico 2010: características gerais da população, religião e pessoas com deficiência [Internet]. 2010 [cited 2017 Oct 26]. biblioteca.ibge. gov.br/biblioteca-catalogo?view=detalhes\& id $=794$

25 Pargament KI, Koenig HG, Perez LM. The many methods of relgious coping: development and initial validation of the RCOPE. J Clin Psychol 2000:56:519-43.

26 Curlin FA, Lantos JD, Roach CJ, Sellergren SA, Chin MH. Religious characteristics of U.S. physicians: a national survey. J Gen Intern Med. 2005;20:629-34.

27 Goldim J, Salgueiro J, Raymundo M, Matte U, Bôer A. Bioética e espiritualidade. Porto Alegre: EDIPUCRS; 2007.

28 Lucchetti G, Ramakrishnan P, Karimah A, Oliveira GR, Dias A, Rane A, et al. Spirituality, religiosity, and health: a comparison of physicians' attitudes in Brazil, India, and Indonesia. Int J Behav Med. 2016; 23:63-70.

29 Lucchetti G, de Oliveira LR, Koenig HG, Leite JR, Lucchetti AL, SBRAME Collaborators. Medical students, spirituality and religiosityresults from the multicenter study SBRAME. BMC Med Educ. 2013;13:162.

30 Bergin $\mathrm{AE}$, Jensen JP. Religiosity of psychotherapists: a national survey. Psychotherapy (Chic). 1990;27:3-7.

31 Curlin FA, Odell SV, Lawrence RE, Chin MH, Lantos JD, Meador KG, et al. The relationship between psychiatry and religion among US physicians. Psychiatr Serv. 2007;58:1193-8.

32 Robinson KA, Cheng MR, Hansen PD, Gray RJ. Religious and spiritual beliefs of physicians. J Relig Health. 2017;56:205-25.

33 Neeleman J, Persaud R. Why do psychiatrists neglect religion. Br J Med Psychol. 1995;68:169-78.

34 Koenig HG. Research on religion, spirituality, and mental health: a review. Can J Psychiatry. 2009;54:283-91. 
35 Freud $\mathrm{S}$. The future of an illusion, civilization and its discontents. In: The Standard Edition of the Complete Psychological Works of Sigmund Freud (trans \& ed. Strachey). Londres: Hogarth Press; 1953-1974. vol. 21. 36 Almeida AAS, Oda AMGR, Dalgalarrondo P. O olhar dos psiquiatras brasileiros sobre os fenômenos de transe e possessão. Rev Psiquatr Clin. 2007;34:34-41.

37 Moreira-Almeida A, Cardena E. Differential diagnosis between nonpathological psychotic and spintual experienœs and mental disorders: a contribution from Latin American studies to the ICD-11. Rev Bras Psiquiatr. 2011;33:S21-36.

38 Moreira-Almeida A, Lotufo-Neto F. Methodological guidelines to investigate altered states of consciousness anomalous experiences. Int Rev Psychiatry. 2017;29:283-92.

39 Maraldi EO, Krippner S, Barros MC, Cunha A. Dissociation from a cross-cultural perspective: implications of studies in Brazil. J Nerv Ment Dis. 2017;205:558-67. 


\title{
APÊNDICE 2. Cópia do manuscrito aceito para publicação
}

\author{
BMC Psychiatry \\ Patterns of religiosity and spirituality of psychiatrists in Brazil and the implications for \\ clinical practice: A latent profile analysis \\ --Manuscript Draft--
}

\begin{tabular}{|c|c|}
\hline Manuscript Number: & BPSY-D-20-00412 \\
\hline Full Title: & $\begin{array}{l}\text { Patterns of religiosity and spirituality of psychiatrists in Brazil and the implications for } \\
\text { clinical practice: A latent profile analysis }\end{array}$ \\
\hline Article Type: & Research article \\
\hline Section/Category: & I don't know (Editor will decide Section) \\
\hline Funding Information: & Instituto Homero Pinto Vallada (BR) \\
\hline Abstract: & $\begin{array}{l}\text { Background: Although there is consensus, in psychiatry, over the inclusion of religious } \\
\text { and spiritual aspects when evaluating and treating the patient, investigation of these } \\
\text { dimensions is rare. There is evidence as to the relationship between psychiatrists' } \\
\text { religious/spiritual beliefs and their willingness to discuss a patient's religion and } \\
\text { spirituality (R/S). } \\
\text { Aims: To analyze the religious/spiritual profiles of Brazilian psychiatrists and their } \\
\text { influence on attitudes and behaviors in psychiatric practice. } \\
\text { Methodology : } 592 \text { psychiatrists from Brazil answered a questionnaire about R/S in } \\
\text { clinical practice. The latent profile analysis was used to search for differences of } \\
\text { religious/spiritual profiles. The ANOVA and Pearson's chi-square tests were employed } \\
\text { to identify any correlation between clinical opinion and behaviors according to the } \\
\text { different profiles. } \\
\text { Results: Two religious/spiritual profiles were identified (entropy value }>0,96 \text { ): the so } \\
\text { called "less religious" group ( } n=245 \text { ), comprised predominantly by men, professionally } \\
\text { more experienced, with a higher level of academic education (Master or PhD degrees) } \\
\text { and were the ones who least enquired about their patients' R/S; and the "more } \\
\text { religious" psychiatrists (n=347) those who had higher consideration for R/S on health, } \\
\text { and who more often addressed R/S with their patients and therefore usually ascribed } \\
\text { importance to include R/S in their professional training. } \\
\text { Conclusion: The latent profile analysis produced two distinct classes between the } \\
\text { Brazilian psychiatrists according to their R/S views: the more religious professionals, } \\
\text { who investigate the patient's R/S in a more detailed manner, and the less religious, } \\
\text { who tend to disregard this aspect. }\end{array}$ \\
\hline Corresponding Author: & $\begin{array}{l}\text { Maria Cecilia Menegatti-Chequini, Ph.D. student } \\
\text { Universidade de Sao Paulo Faculdade de Medicina } \\
\text { São Paulo, São Paulo BRAZIL }\end{array}$ \\
\hline Corresponding Author E-Mail: & mcmchequini@gmail.com \\
\hline \multicolumn{2}{|l|}{$\begin{array}{l}\text { Corresponding Author Secondary } \\
\text { Information: }\end{array}$} \\
\hline Corresponding Author's Institution: & Universidade de Sao Paulo Faculdade de Medicina \\
\hline \multicolumn{2}{|l|}{$\begin{array}{l}\text { Corresponding Author's Secondary } \\
\text { Institution: }\end{array}$} \\
\hline First Author: & Maria Cecilia Menegatti-Chequini, Ph.D. student \\
\hline \multicolumn{2}{|l|}{ First Author Secondary Information: } \\
\hline \multirow[t]{5}{*}{ Order of Authors: } & Maria Cecilia Menegatti-Chequini, Ph.D. student \\
\hline & Alexandre Andrade Loch, PhD \\
\hline & Frederico Camelo Leão, $\mathrm{PhD}$ \\
\hline & Mario Fernandes Pietro Peres, PhD \\
\hline & Homero Vallada, PhD \\
\hline Order of Authors Secondary Information: & \\
\hline
\end{tabular}

Powered by Editorial Manager $($ and ProduXion Manager $($ from Aries Systems Corporation 


\section{Opposed Reviewers:}

Additional Information:

\section{Question}

Response

Has this manuscript been submitted

No

before to this journal or another journal in

the BMC series? 
Title:

Patterns of religiosity and spirituality of psychiatrists in Brazil and the implications for clinical practice: A latent profile analysis

\author{
Authors: \\ Maria Cecilia Menegatti-Chequini ${ }^{1}$, Alexandre Andrade Loch $^{2,3}$, Frederico Camelo \\ Leão ${ }^{1}$, Mario Fernandes Pietro Peres ${ }^{1,4}$, Homero Vallada ${ }^{1}$

\footnotetext{
${ }^{1}$ Departamento e Instituto de Psiquiatria (LIM-21, LIM-23 and ProSER), Hospital das Clinicas, Faculdade de Medicina, Universidade de São Paulo (HCFMUSP), São Paulo, SP, Brazil.

${ }^{2}$ Laboratorio de Neurociencias (LIM-27), Instituto de Psiquiatria, Hospital das Clinicas, Faculdade de Medicina, Universidade de São Paulo (HCFMSUP), São Paulo, SP, Brazil.

${ }^{3}$ Instituto Nacional de Biomarcadores em Neuropsiquiatria (INBION), Conselho Nacional de Desenvolvimento Cientifico e Tecnologico, Brazil.

${ }^{4}$ Departamento de Neurologia, Hospital Albert Einstein, São Paulo, SP, Brazil
}

Corresponding author: M. C. Menegatti-Chequini, Departamento e Instituto de Psiquiatria (LIM-21, LIM-23 and ProSER), Hospital das Clinicas, Faculdade de Medicina, Universidade de São Paulo (HCFMUSP), Rua Dr. Ovídio Pires de Campos, 785, Zip Code 05403-010, São Paulo, SP, Brazil.

Email: mceciliame@usp.br_D http://orcid.org/0000-0002-8958-983X 


\section{Abstract}

1 Background: Although there is consensus, in psychiatry, over the inclusion of religious

2 and spiritual aspects when evaluating and treating the patient, investigation of these

3 dimensions is rare. There is evidence as to the relationship between psychiatrists'

4 religious/spiritual beliefs and their willingness to discuss a patient's religion and

5 spirituality $(\mathrm{R} / \mathrm{S})$.

6 Aims: To analyze the religious/spiritual profiles of Brazilian psychiatrists and their

7 influence on attitudes and behaviors in psychiatric practice.

8 Methodology: 592 psychiatrists from Brazil answered a questionnaire about $\mathrm{R} / \mathrm{S}$ in

9 clinical practice. The latent profile analysis was used to search for differences of 10 religious/spiritual profiles. The ANOVA and Pearson's chi-square tests were employed

11 to identify any correlation between clinical opinion and behaviors according to the

12 different profiles.

13 Results: Two religious/spiritual profiles were identified (entropy value $>0,96$ ): the so

14 called "less religious" group ( $\mathrm{n}=245)$, comprised predominantly by men, professionally

15 more experienced, with a higher level of academic education (Master or PhD degrees)

16 and were the ones who least enquired about their patients' R/S; and the "more religious"

17 psychiatrists $(\mathrm{n}=347)$ those who had higher consideration for $\mathrm{R} / \mathrm{S}$ on health, and who

18 more often addressed $\mathrm{R} / \mathrm{S}$ with their patients and therefore usually ascribed importance

19 to include $\mathrm{R} / \mathrm{S}$ in their professional training.

20 Conclusion: The latent profile analysis produced two distinct classes between the

21 Brazilian psychiatrists according to their $\mathrm{R} / \mathrm{S}$ views: the more religious professionals,

22 who investigate the patient's $\mathrm{R} / \mathrm{S}$ in a more detailed manner, and the less religious, who

23 tend to disregard this aspect. 
24 Keywords: Psychiatrics, psychiatry, clinical practice, religion, spirituality, latent profile

25 analysis

26

\section{Background}

The importance of addressing religiosity and spirituality $(\mathrm{R} / \mathrm{S})$ in clinical practice 30 has been increasingly acknowledged by medical and educational organisations. The 31 American Psychiatric Association (APA) $)^{2}$, World Psychiatric Association (WPA) 32 Royal College of Psychiatrists (RCP) $)^{4}$, European Psychiatric Association (EPA) ${ }^{5}$ and the 33 Brazilian Association of Psychiatry $(\mathrm{ABP})^{6}$ are just a few of the institutions which have 34 verified the need to consider the spiritual dimension in psychiatry education, research and 35 clinical practice. Indeed, the Accreditation Council for Graduate Medical Education $36(\mathrm{ACGME})^{7}$, which sets out the requirements for the post-graduate medical programs in 37 the USA, stipulated that resident physicians should be capable of demonstrating the skills 38 to deal with the religious and spiritual aspects of patients.

39 This acknowledgment comes as a result of the abundant evidence of the impact of $40 \mathrm{R} / \mathrm{S}$ on physical and mental health ${ }^{8}$. In the last 20 years, a consistent body of research has 41 demonstrated that, although some negative religious/spiritual beliefs may have a harmful 42 effect on health ${ }^{9,10}$, in the majority of cases, religious involvement is associated with 43 positive outcomes in terms of physical health and, principally, mental health ${ }^{11,12}$. Studies 44 have noted that $\mathrm{R} / \mathrm{S}$ is associated with a better quality of life $^{13}$, lower rates of substance 45 abuse $^{14}$, anxiety ${ }^{15,16}$, suicide ${ }^{17,18}$, depression ${ }^{19,20}$ and various other health benefits in 46 general $^{8,21}$ for example it may foster feelings of meaningfulness and peace of mind $^{22}$.

47 The growing awareness about the importance of a new paradigm in healthcare,

48 which views the patient within a comprehensive perspective has resulted in greater 
interest in physician behavior related to $\mathrm{R} / \mathrm{S}$. Researchers from different regions of the world, principally the USA and the UK, have begun to study how these professionals deal with $\mathrm{R} / \mathrm{S}$ in their medical consultations $\mathrm{s}^{23,24}$.

The results of this research showed that, despite the fact the vast majority of physicians, including psychiatrists, agree on the importance of and need to assimilate R/S into clinical work, investigation of the religious/spiritual aspects of patients is rare ${ }^{25,26}$. $\mathrm{R} / \mathrm{S}$ is barely considered by physicians, who prefer to delegate the role of discussing matters of this kind to the chaplains ${ }^{26}$. This mismatch may be the result of difficulties encountered by these professionals in the approach to $\mathrm{R} / \mathrm{S}$ which, generally speaking, relate to lack of time and, mainly, lack of knowledge and training ${ }^{26,27}$.

Moreover, medical practitioners in general, particularly psychiatrists, are less religious than the general population ${ }^{28,29}$ and, according to some studies, this more secular characteristic may lead them to ignore the importance of $\mathrm{R} / \mathrm{S}$ in the clinical setting, thereby undermining the practitioner/patient relationship ${ }^{27,30}$, since patients do feel a need for and expect their practitioners to deal with, religious and spiritual subjects as part of the treatment ${ }^{31}$.

There is substantial evidence as to the relationship between physicians' religious/spiritual beliefs and their willingness to discuss patient $\mathrm{R} / \mathrm{S}^{27,32-34}$. A recent study, analyzing over 6,000 health professionals, stemmed from 11 studies conducted in 9 countries across 6 continents, and demonstrated that the large differences in moral and religious values among the diverse nations and cultures explains the different clinical approaches of health professionals ${ }^{23}$.

In Brazil, we performed two studies with the aim of ascertaining the religious/spiritual profiles of psychiatrists and investigating the field of work of these professionals in terms of the religious/spiritual issues of their patients. The first study ${ }^{35}$ 
was conducted on a sample of psychiatrists from the Brazilian Association of Psychiatry (ABP), representing the population of psychiatrists practicing in Brazil, while the second ${ }^{36}$ was carried out using a sample of psychiatrists working in the Institute of Psychiatry at the University of São Paulo, Faculty of Medicine teaching hospital (IPqHC-FMUSP), reflecting the thoughts and behaviors of the professionals working in one of the most important center for the practice, research and learning of psychiatry in Brazil.

In both studies, the results corroborated previous works ${ }^{37,38}$, noting that the different religious/spiritual characteristics of the psychiatrists were linked to different R/S-related clinical opinions and behaviors. Given these findings, we decided to expand our investigation and analyze both samples jointly from our previous studies in order to identify the different religious/spiritual profiles of Brazilian psychiatrists and investigate how these might impact their attitudes and behaviors, regarding $\mathrm{R} / \mathrm{S}$, in psychiatric practice, using the latent profile analysis (LPA) method. Investigating the possibility of different patterns of behavior in the approach to $\mathrm{R} / \mathrm{S}$ might furnish important tools for tailoring suitable training programs for each of these professional's profiles.

\section{Methods}

This took the form of a quantitative, cross-sectional study, evaluating psychiatrists in Brazil. In the initial phase, 3.120 psychiatrists from the Brazilian Association of Psychiatry (ABP) were selected and invited to complete a questionnaire on $\mathrm{R} / \mathrm{S}$ and psychiatric practice (a more detailed description can be found in Menegatti-Chequini et al. ${ }^{35}$ ). In the second phase, 121 psychiatrists were selected, working at the Institute of Psychiatry at the University of São Paulo, Faculty of Medicine teaching hospital (IPqHC-FMUSP), who were also invited to answer the questionnaire (see detailed description 
99

100

101

102

103

104

105

106

107

108

109

110

111

in Menegatti-Chequini et al. ${ }^{36}$ ). The final number of participants of the present study were 592 psychiatrists.

\section{Measurements}

The questionnaire used in this study was developed based on the instrument "Religion and Spirituality in Medicine: Physicians' Perspectives" developed by Curlin et al. ${ }^{39}$, which evaluates the attitudes and behaviors of physicians concerning $\mathrm{R} / \mathrm{S}$ in clinical practice.

The instrument was adapted for the purposes of this research. It was translated into Portuguese and tested in a pilot study conducted in two phases: initially with 30 health professionals from various specialties and, in the after, with 20 psychiatrists residing at IPq-HC-FMUSP. The questions were considered clear and objective in both steps and no additional adaptation was necessary during the testing phase.

The questionnaire consisted of self-reporting measurements that accessed three main areas:

\section{a) Sociodemographic and professional characteristics}

The data included age, gender, marital status, location, degree level, length of professional experience and specialty within psychiatry.

$$
\text { b) Participants' religious/spiritual characteristics }
$$

The psychiatrists were questioned about their beliefs in a God or superior power, life after death and reincarnation. There were three response options to each of these questions: yes $=2$, undecided $=1$, and no $=0$. These responses were chosen due to the enormous influence of Christian and spiritualist ideals in the sociocultural scenario in Brazil. 
Participants were also polled about their religious affiliations. The answers to this question were divided into five categories: Catholic, Spiritist (including the AfroBrazilian Spiritism), Protestant or Evangelic, Other religions (encompassing Judaism, Islam, Hinduism, Buddhism, Mormon and Others) and None (including Agnosticism and Atheism). The response options were presented in accordance with the Brazilian context in which Catholics, Evangelists and Spiritists account for the majority of religious devotees ${ }^{40}$.

The questionnaire also contained questions relating to the frequency of attendance at churches or temples, the frequency of religious/spiritual practices such as praying, reading religious/spiritual scriptures and spiritual practices, such as meditation and yoga. To all these questions, the response options were: never $=1$, once a year or more $=2$, once a month or more $=3$, once a week or more $=4$ and daily $=5$.

Measurements of religiosity and spirituality were obtained by applying two questions evaluating the degree to which the participants saw themselves as spiritualized or religious. The questions "To what extent do you consider yourself a religious person?" and "To what extent do you consider yourself a spiritual person?" provided four response options: not at all $=1$, slightly $=2$, moderately $=3$ and very $=$ 4. We did not define the terms religiosity and spirituality, thereby allowing the participants to apply their own interpretations of the concepts. However, they were questioned in such a way as to distinguish between their religiosity and their spirituality.

In order to evaluate coping styles in situations of stress, two questions were applied, extracted from the Spiritual/Religious Coping Scale (RCOPE) ${ }^{41}$; one evaluating religious coping: " I look to God for strength, support and guidance", while 
the other evaluated personal or non-religious coping: "I try to make sense of the situation and decide what to do without relying on God". Each question has four response options: often $=4$, occasionally $=2$, rarely $=3$ and never $=1$.

Intrinsic religiosity, which refers to the degree to which individuals put their religious/spiritual beliefs into practice, was measured by means of two statements that were inspired by the scale from Hoge's Intrinsic Religious Motivation Scale ${ }^{42}$, widely used for these ends: "I try hard to carry my religious/spiritual beliefs over into all my other dealings in life. My whole approach to life is based on my religious/spiritual beliefs". The response options were as follows: "I completely disagree" = 1, "I moderately disagree" $=2$, "I moderately agree" $=3$ and "I completely agree" $=4$.

c) Opinions and behaviors related to $R / S$ and the approach to $R / E$ in clinical practice and in professional training.

With regard to the influence $\mathrm{R} / \mathrm{S}$ may have on the actions of the medical practitioner, psychiatrists responded to questions evaluating: whether their own beliefs influenced their clinical work; whether they saw medicine as a calling or a mission; whether experience as a medical professional led them to question their own beliefs and, whether they considered it a challenge to remain faithful to their beliefs working as a medical professional. To all these questions, the response options were as follows: strongly $=4$, moderately $=3$, slightly $=2$ and not at all $=1$.

The participants also responded if they considered it important to include $\mathrm{R} / \mathrm{S}$ into clinical practice, medical training and continuing medical education. The questions had four possible responses: very important $=4$, reasonably important $=3$, a little important $=2$ and not important $=1$.

With respect to opinions on the influence of $\mathrm{R} / \mathrm{S}$ on health, the psychiatrists answered questions about the degree to which they considered R/S might influence 
patients' decisions concerning the indicated treatment and if $\mathrm{R} / \mathrm{S}$ might affect wellbeing and the clinical evolution of their patients. The response options were: frequently $=4$, occasionally $=3$, rarely $=2$ and never $=1$.

As for the approach to $\mathrm{R} / \mathrm{S}$ in clinical assessments, the participants were questioned as to the frequency with which they would gather their patients' $\mathrm{R} / \mathrm{S}$ histories and if they felt that evaluating a patient's $\mathrm{R} / \mathrm{S}$ was something the medical professional should or could do. To the first question, the response options were: frequently $=4$, occasionally $=3$, rarely $=2$ and never $=1$, while for the second question, the responses were no $=1$, yes $=2$ and undecided $=3$.

To identify the barriers and difficulties encountered by the participants in addressing religious/spiritual issues with their patients, they were asked to answer a multiple-choice question with the following alternatives: 1) None, 2) Fear of exceeding the role of a doctor, 3) Lack of training, 4) Lack of time, 5) Not being comfortable with the issue, 6) The religious/spiritual aspect is not relevant for the patient, 7) Fear of offending the patient, 8) Fear that peers may not approve, 9) It is not the doctor's job, 10) Do not know why.

\section{Statistical analysis}

The sample's continuous and categorical data were described. For the LPA, the sample of psychiatrists from the IPq-HC-FMUSP and from the ABP was viewed as a single sample, excluding of course the 11 individuals who were common to both samples. LPA is a statistical method used to identify homogeneous groups or classes using categorical and continuous multivariate data. It is designed to verify whether the data can or cannot be grouped according to similar response patterns. LPA is similar to latent class analysis (LCA). While the former may handle continuous and categorical variables, the 
198

199

latter only deals with dichotomous variables. The analysis is performed by attempting to pigeonhole the data in a specific number of categories and observing which parameters this categorization generates. The optimal solution/categorization will be chosen according to which parameters are generated. The following parameters were employed in this study: a) Akaike information criterion (AIC), where the lowest value indicates the best quality of information supplied by the categories generated, b) sample-size adjusted Bayesian information criterion (BIC), where the lowest value also indicates the best quality of information supplied by the categories generated, c) entropy, a homogeneity measure of the classes generated, ranging from 0 to 1 , in which 1 denotes perfectly homogeneous classes, d) Parametric bootstrapped likelihood ratio test, in which $\mathrm{p}<0.05$ indicates there is no difference between classifying the data into $n$ categories or into $n-1$ categories, and e) the Lo-Mendell-Rubin (LMR) adjusted likelihood ratio test, where $\mathrm{p}<0.05$ indicates that the real solution is statistically different from the solution with $n-1$ classes, indicating that the real solution should be chosen over the solution with $n-1$ classes. There is no perfect solution for the division of data into profiles, so, according to Muthen \& Muthen ${ }^{43}$, the best solution must be presented taking into account the above parameters and clinical judgment.

$$
\text { The analyses were conducted using Mplus Version } 8 \text { for Mac OS. }
$$

\section{Results}

A total of 592 psychiatrists took part in this study. In this sample, the mean age was $47.96(\mathrm{SD}=11.7), 60 \%$ were men and more than two-thirds were married. As far as professional experience is concerned, the data showed that the average length of time working in psychiatry was 20.63 years $(\mathrm{SD}=11.65)$ and, in terms of level of education, 
the majority of the sample had a post-graduate qualifification and had earned a speciality 4 in Psychiatry. As for religious affiliation, $66.5 \%$ of the psychiatrists stated at least one religion, the majority being Catholic.

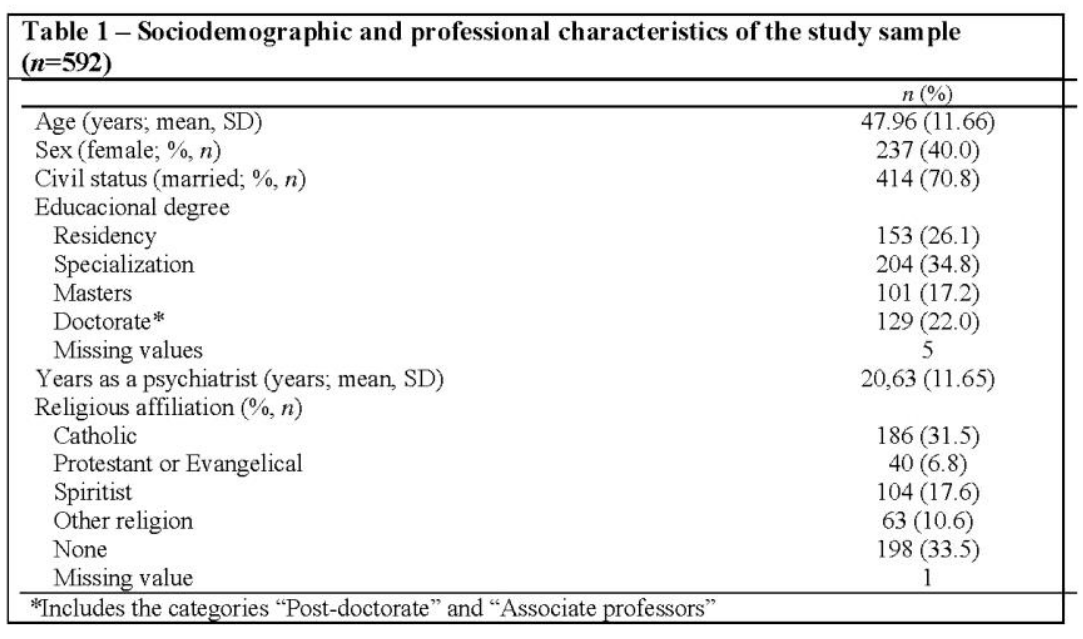

With regard to the participants' opinions and behaviors in respect to $\mathrm{R} / \mathrm{S}$ in health and clinical practice, the results showed that $44.6 \%$ considered that $\mathrm{R} / \mathrm{S}$ frequently interferes with the patient's decision concerning the indicated treatment; the remainder of the respondents were divided between the following responses: occasionally (37.7\%), rarely $(13.6 \%)$ and never $(4.1 \%)$. As for the consideration that $\mathrm{R} / \mathrm{S}$ affects patients' wellbeing, $64.8 \%$ responded frequently, $29.6 \%$ occasionally, $3.8 \%$ rarely and $1.8 \%$ never. To the question evaluating whether they felt it important to include $\mathrm{R} / \mathrm{S}$ in medical training, they answered as follows: $43.2 \%$ very important, $28.9 \%$ reasonably important, $14.9 \%$ a little important and $12.9 \%$ not important. The inclusion of $\mathrm{R} / \mathrm{S}$ in psychiatric training was considered very important by $40.6 \%, 30.1 \%$ responded that it was reasonably important, $16.7 \%$ a little important and $12.6 \%$ not important. The data also showed that 
$46.5 \%$ of psychiatrists frequently broached the religious and spiritual issues of their patients, $33.8 \%$ occasionally, $14.6 \%$ rarely with just $5.1 \%$ saying they never addressed $\mathrm{R} / \mathrm{S}$ in clinical practice.

Table 2 shows the latent profile analysis (LPA) of the psychiatrists' responses to the questionnaire. The results indicated that the best LPA output was with two classes of psychiatrists, as this presented the best entropy value and was the number of classes that had a statistically significant Lo-Mendell-Rubin value.

Table 2 - Latent profile analysis of psychiatrists' answers to the questionnaire on Religion /Spirituality in psychiatric practice

\begin{tabular}{|lllllll|}
\hline & AIC & Adjusted BIC & Entropy & $\begin{array}{l}\text { Parametric } \\
\text { bootstrapped LRT }\end{array}$ & $\mathrm{p}$ & $\begin{array}{l}\text { Lo-Mendell-Rubin } \\
\text { Adjusted LRT Test }\end{array}$ \\
\hline 2 classes & 23291.237 & 23354.096 & $\mathbf{0 . 9 6 7}$ & -13756.570 & 0.0000 & $\mathbf{0 . 0 0 0 0}$ \\
3 classes & 22306.700 & 22393.735 & 0.927 & -11593.618 & 0.0000 & 0.4218 \\
4 classes & 21858.771 & 21969.983 & 0.925 & -11081.349 & 0.0000 & 0.7613 \\
5 classes & 21724.447 & 21859.835 & 0.933 & -10837.386 & 0.0000 & 0.7357 \\
\hline
\end{tabular}

Figure 1 depicts the religious/spiritual characteristics of the psychiatrists and their opinions related to $\mathrm{R} / \mathrm{S}$ in clinical practice, according to the different profiles. Profile 1 we call the "less religious" as, when comparing these individuals to the psychiatrists in the other profile, they were the ones who least frequently attended religious/spiritual places of worship (mean of 1.4 vs. 2.79), who least read religious/spiritual scriptures (mean of 1.5 vs. 3.41 ), who prayed less (mean of 1.56 vs. 4.38 ) and who demonstrated the lowest frequency of spiritual practices, such as meditation and yoga (mean $1.74 \mathrm{vs.}$ 2.74). They also exhibited lower mean values for intrinsic religiosity (1.49 vs. 3.25$)$, spirituality (mean 2.03 vs. 3.37), religiosity (mean 1.34 vs. 2.86) and religious coping (mean 1.41 vs. 3.43). For the sake of consistency, and solely for the question that evaluated non-religious coping, the rates were higher (mean 3.38 vs. 2.38). As for R/Srelated opinions in clinical practice, they were the ones who least considered that their religious/spiritual beliefs influenced their work as medical professionals (mean $1.46 \mathrm{vs.}$ 
2.93), who least believed that medicine was a calling or mission (mean $1.76 \mathrm{vs.} 3.10$ ) and, moreover, who least considered that medicine practice might make them question their own beliefs (mean 1.95 vs. 2.53 )

Figure 1- Psychiatrists' religious/spiritual characteristics according to different religious profiles

Figure 2 shows the religious/spiritual beliefs of the psychiatrists according to the different profiles. We can see that profile 1 also groups individuals with the lowest percentages of believing in God (40.2\% vs. $99.4 \%)$, life after death (13.5\% vs. $87.9 \%)$ and reincarnation $(5.2 \%$ vs. $57.7 \%)$.

As demonstrated in figures 1 and 2, profile 2 groups the most "believers" psychiatrists, ie those who had the highest indexes of religious/spiritual beliefs and practices and was therefore named as "more religious".

Figure 2- Psychiatrists' religious/spiritual beliefs according to different religious profiles

Table 3 describes the conditional likelihood of each response item in the respective profile. Profile 1 consisted of $245(41.5 \%)$ psychiatrists with an average age of 48.54 while profile 2 accommodates the majority of the participants $(n=347,59.6 \%)$ with an average age of 47.54. Comparing individuals in the two profiles, we can see that the profile 1 psychiatrists who had been practicing psychiatry longer (an average of 21.79 years vs. 19.82), was the group which contained more males (66.5\% vs. $55.3 \%)$ and embraced psychiatrists of a higher educational level: $28.0 \%$ had a Doctorate, as a minimum, and some also had postdoctoral degrees or were associate professors, while in profile 2 , the percentage was just $17.7 \%$. 


\begin{tabular}{|c|c|c|c|}
\hline & $\begin{array}{l}\text { Class } 1(\mathrm{n}=245) \\
\text { Less religious }\end{array}$ & $\begin{array}{l}\text { Class } 2(\mathrm{n}=347) \\
\text { More religious }\end{array}$ & $\mathrm{p}$ \\
\hline \multicolumn{4}{|l|}{ Sociodemographics and professional data } \\
\hline Age (years; mean, SD) & $48.54(11.95)$ & $47.54(11.46)$ & $0.313^{2}$ \\
\hline Sex (female; \%,n) & $33.5 \%(82)$ & $44.7 \%(155)$ & $0.006^{1}$ \\
\hline Civil status (married; $\%, \mathrm{n}$ ) & $73.4 \%(177)$ & $68.7 \%(237)$ & $0.473^{1}$ \\
\hline Education (Phd+post-doc; \%,n) & $28.0 \%(68)$ & $17.7 \%(61)$ & $0.001^{1}$ \\
\hline Years as a psychiatrist (years; mean,SD) & $21.79(11.75)$ & $19.82(11.53)$ & $0.044^{2}$ \\
\hline \multicolumn{4}{|l|}{ Religious characteristics } \\
\hline Religious affiliation (none; \%,n) & $69.3 \%(169)$ & $8.4 \%(29)$ & $0.000^{1}$ \\
\hline $\mathrm{R} / \mathrm{S}$ medical formation (mean, SD) & $2.47(1.14)$ & $3.37(0.81)$ & $0.000^{2}$ \\
\hline R/S psychiatrist formation (mean, SD) & $2.39(1.09)$ & $3.36(0.80)$ & $0.000^{2}$ \\
\hline $\mathrm{R} / \mathrm{S}$ affects patient decision (mean,SD) & $3.01(0.87)$ & $3.36(0.78)$ & $0.000^{2}$ \\
\hline $\mathrm{R} / \mathrm{S}$ affects patient's well-being (mean, S D) & $3.29(0.78)$ & $3.75(0.47)$ & $0.000^{2}$ \\
\hline $\mathrm{R} / \mathrm{S}$ approach (mean, SD) & $3.06(0.97)$ & $3.33(0.78)$ & $0.000^{2}$ \\
\hline \multicolumn{4}{|l|}{${ }^{1}$ Chi-square test } \\
\hline \multicolumn{4}{|l|}{${ }^{2}$ ANOVA test } \\
\hline Bold: significant correlations & & & \\
\hline
\end{tabular}

The majority $(69.3 \%)$ of individuals in profile 1 stated they did not observe any religion, unlike profile 2 where $91.6 \%$ of psychiatrists indicated a religious affiliation. With regard to the opinions related to $\mathrm{R} / \mathrm{S}$ and health, the psychiatrists in profile 1 were the ones who least considered that R/S exerted an influence on patients' decisions about the indicated treatment $($ mean $=3.01$ vs. 3.36$)$ and that $R / S$ could affect the patient's health and wellbeing (mean $=3.29$ vs. 3.75 ). The individuals in profile 1 were also those who considered least important the inclusion of $\mathrm{R} / \mathrm{S}$ in medical training (mean $=2.47 \mathrm{vs}$. 3.37 ) or psychiatric training (mean $=2.39$ vs. 3.36 ). As for the $R / S$ approach in clinical practice, we found that the psychiatrists in profile 1 were those who least asked about the religious $/$ spiritual issues of their patients (mean $=3.06$ vs. 3.33 ).

\section{Discussion}

The results from this sample indicated that Brazilian psychiatrists are split into two different religious/spiritual profiles. The "less religious" profile was the smaller 
group, consisting of those psychiatrists with lower indices of belief and frequency of religious/spiritual practices; more men than women belonged to this profile, they were the participants with the highest educational levels, who had been working for longer in the field of psychiatry and who least broached $\mathrm{R} / \mathrm{S}$ in clinical practice. The "more religious" profile consisted of psychiatrists who were more devout and active in religious life; this was the group that most took into account the influence of $\mathrm{R} / \mathrm{S}$ within healthcare and medical treatment, that ascribed greater importance to the inclusion of $\mathrm{R} / \mathrm{S}$ in professional training and which most addressed the $\mathrm{R} / \mathrm{S}$ of patients.

The psychiatrists within the "more religious" profile were designated as such due to their higher indices of religiosity, spirituality, intrinsic religiosity, religious coping, belief in God, life after death and reincarnation and, logically, were the ones who were the most dedicated to religious and spiritual practices, such as attending religious services, praying and reading religious/spiritual scriptures. They were also the ones who most felt their beliefs had an influence on their clinical activity, and that these practices influenced their personal beliefs. These results are similar to those found in a previous study in which a potential reciprocal influence of $\mathrm{R} / \mathrm{S}$ is discussed regarding clinical practice and its influence on the professional's religiosity ${ }^{44}$. They also match the findings of a metaanalysis of ten samples of professionals from seven countries, which showed very strong positive correlation between the professional's degree of religiosity and the perception of the effects it had on his/her work ${ }^{45}$. Another characteristic that defined the "more religious" profile was considering medicine as a calling, this being compatible with data found in other studies in which medical professionals in general and psychiatrists with higher levels of $\mathrm{R} / \mathrm{S}$ have a greater tendency to regard the practice of medicine as a vocation ${ }^{46,47}$. 

The majority of psychiatrists belonging to the "less religious" profile were male, showing, as it does in the literature, that female psychiatrists attribute greater importance to $\mathrm{R} / \mathrm{S}$ in their lives ${ }^{36,48,49}$. In addition to grouping a larger number of men, the "less religious" profile, not surprisingly, also brought together psychiatrists with less religious affiliation, data similar to those found in the Brazilian population in general, in which the male sex leads the "no religion" group, with a proportion of $9.7 \%$ for men against $6.4 \%$ for women ${ }^{40}$. A large number of empirical studies have demonstrated that religiosity in women is greater than in men, this difference having sparked intense investigation since as far back as $1930^{50,51}$. However, although many theories attempt to explain the reasons for this difference, ranging from approaches of a sociological ${ }^{52}$ and psychological $^{53}$ nature to those that substantiate men's greater non-religiosity on physiological grounds ${ }^{54}$, no conclusive empirical studies yet exist capable of justifying any concrete position on the matter. So far, what can be seen is an inchoate consensus in terms of the multifactorial nature of its origins ${ }^{55}$.

The psychiatrists who had worked for a longer time within the field were also more concentrated in the "less religious" profile and, in this regard, we need to pay attention to the possibility that these data represent more of a generational phenomenon than a fact necessarily relating to the length of time within the field, as has already been discussed in one of our studies, in which longer-serving psychiatrists were shown to have less religious affiliation ${ }^{35}$.

In this regard, we must consider that, at the beginning of the twentieth century, some theories, such as those of Sigmund Freud ${ }^{56,57}$, ascribed a neurotic character to religious experiences, guiding much of the theoretical currents in psychiatry and psychology which began to pathologize religious/spiritual beliefs and practices ${ }^{58}$. 
Even in the seventies, mystical manifestations or experiences were still almost exclusively associated with pathological behaviors of the psychotic type, or with a phenomenon of regression or flight, as proclaimed in 1976 by the GAP's (Group for the Advancement of Psychiatry) "Committee on Psychiatry and Religion", in the USA".

Although this negative perception of religious experiences was not based on scientific research or systematic studies, merely derived from clinical observation and, mainly, the personal opinions and beliefs of authors ${ }^{60}$, its persistence heavily influenced the field of study that examines the intersection of science and religion ${ }^{61}$ and ended up sharply reflecting on the development of mental health professionals. The reflection of this influence is probably more conspicuous in professionals that were practicing at the time these ideas predominated.

Moreover, in the beginning, psychiatric approaches were partisan; some theories supported the predominance of biological aspects in the etiology of mental illness, while others pointed to psychological factors as their determining cause. Only recently have more comprehensive models emerged, which incorporate diverse elements in the understanding of mental health ${ }^{62}$. Nowadays, psychiatry aims towards an integral approach and takes into consideration the interaction of biological, psychological, social, and religious/spiritual factors in medical assessments and interventions ${ }^{63}$.

Regarding the influence of $\mathrm{R} / \mathrm{S}$ on the health and treatment of patients, the results found here indicate that the "more religious" participants were those that most believed in this kind of impact. These data are similar to those found in the literature, showing that psychiatrists with a higher index of intrinsic religiosity had a greater perception of the influence of $\mathrm{R} / \mathrm{S}$ on the health of patients and, the more religious they were, the more they tended to regard this influence as positive $e^{27,64}$. Other studies with health professionals from several specialties also signaled this tendency ${ }^{26,65}$. 
The "less religious" psychiatrists were those that least discussed R/S with their patients, underlining the "religiosity gap" phenomenon between doctors and patients, so widespread in the literature ${ }^{30,66}$, in which doctors, by not attaching importance to $\mathrm{R} / \mathrm{S}$ in their own lives, assume that the same is true of their patients and end up disregarding these aspects, already understood to be important for the majority of them ${ }^{31}$.

Several studies have demonstrated the relationship which exists between medical professionals' religious/spiritual beliefs and their tendencies to approach (or not) R/S in clinical care ${ }^{34,37,67}$. Generally, practitioners with greater self-perception of R/S exhibit a greater tendency to investigate patients' $\mathrm{R} / \mathrm{S}^{35,49}$, the same holding true for those that say they indulge more frequently in public and private religious practices ${ }^{27,33}$, unlike the health professionals that do not identify with any religion and do not take part in religious gatherings, who are less inclined to empathize with the $\mathrm{R} / \mathrm{S}$ of patients and/or to recommend them for spiritual counseling ${ }^{68}$.

The analyses performed also show that psychiatrists in the "less religious" profile regard the inclusion of $\mathrm{R} / \mathrm{S}$ in professional training as of little importance, which appears to be consistent for professionals who accord little importance to the influence of $\mathrm{R} / \mathrm{S}$ on health and are less willing to address patients' $\mathrm{R} / \mathrm{S}$, differently from the study of Rensburg et al. ${ }^{69}$, in which all academic psychiatrists agreed that spirituality should be assimilated into clinical assessment and training in psychiatry.

One of the most relevant results of this study is in respect of education. Psychiatrists belonging to the "less religious" profile had the highest levels of education: it was the group with the most $\mathrm{PhDs}$, Post-doctorates and associate professors. This negative relationship between religion and education had already been verified in previous studies $^{70,71}$, but there is no consensus on the matter, as studies exist that counter this idea, showing a positive association between religious beliefs and education ${ }^{72-74}$. 
There is, moreover, evidence that this negative relationship has diminished significantly over recent years ${ }^{75}$, suggesting the plausibility of religion and science being compatible visions of the world ${ }^{74,76}$.

However, our data seem to corroborate the erstwhile theory that education leads to a decline in religion ${ }^{77}$, which might be understood as part of the process of the desacralization or secularization of society, where the fundaments of religion were replaced by belief in science, secular beliefs, generally opposed to religious beliefs ${ }^{78,79}$. Again, we are faced with the possibility of our data representing a generational phenomenon, as obtaining academic titles demands more time in the field and, therefore, more exposure to anti-religious theories which may have influenced the beliefs of these psychiatrists.

Our analyses further reveal that the most educated psychiatrists are also those that least discuss $\mathrm{R} / \mathrm{S}$ with their patients and, in this respect, despite evidence reporting the tendency of the less religious to disregard $\mathrm{R} / \mathrm{S}$ in patient care, these data are something of an oddity as they indicate a negative association between education and addressing R/S in clinical practice.

It is surprising that psychiatrists with higher levels of education, who have supposedly had more contact with scientific evidence and should be advocating in its favor, guide their clinical behavior based on outdated assumptions. Given the countless studies showing the impact of $\mathrm{R} / \mathrm{S}$ on mental health, it might be expected that these more educated professionals would approach these topics without prejudice, regardless of their own religious values. Considering the influence of $\mathrm{R} / \mathrm{S}$ as negative for patients is itself sufficient reason to include it as part of the medical treatment instead of ignoring it ${ }^{80}$. Ascertaining if $\mathrm{R} / \mathrm{S}$ plays any role in the illness and if this influence is positive or negative for the patient's recovery, is fundamental in avoiding diagnostic error ${ }^{81}$. 
It is necessary to understand that psychiatry does not lose its scientific character when investigating the relationship of $\mathrm{R} / \mathrm{S}$ in healthcare, as they are phenomena that can be scientifically investigated ${ }^{82}$.

The latent profile analysis in this study identified polarized patterns in the clinical practice of Brazilian psychiatrists related to their personal beliefs; the ones who were more religious explored $\mathrm{R} / \mathrm{S}$, while the less religious tended to ignore it.

These findings suggest that psychiatrists (both religious and non-religious) must, therefore, undergo training regarding the importance of $\mathrm{R} / \mathrm{S}$ to the causes, diagnoses, and, treatment of mental disorders ${ }^{83}$. Moreover, this training must be able to expand these professionals' awareness of the possible evaluative biases in the assessment of their patients' $\mathrm{R} / \mathrm{S}^{36}$. It must inform them on the relevance of "good psychiatric practice", which observes important limits with regard to the approach to $\mathrm{R} / \mathrm{S}$ and rules out the possibility of any form of proselytization, whether it be on account of religious, political or atheistic beliefs ${ }^{84}$. It is fundamental for psychiatrists to contemplate their own religious values and to respect ethical limits in their work, prioritizing comprehensive care for the patient.

Thus, training programs must be directed towards all psychiatrists, including academic professionals with the highest levels of education, as it is precisely these professionals that will be educating future generations of psychiatrists, in order to avoid the potential perpetuation of neglect when addressing $\mathrm{R} / \mathrm{S}$.

Limitations

The present study does have some methodological limitations, perhaps the most important of which is the fact that it is a cross-sectional study that does not allow for formal inferences regarding causality. Furthermore, data was obtained via self-reports from psychiatrists, a form of measurement that is more susceptible to biases. 

aroused more interest, in both very religious and very non-religious individuals, to participate. In a similar study previously performed by Curlin et al. ${ }^{37}$, the non-religious medical professionals seem to have been more willing to answer the questionnaire.

As there is still no consensus in the literature regarding the concepts of religiosity and spirituality, we allowed the psychiatrists to use their own definitions to answer the questions that drew a distinction between the terms. Thus, interpretation of results and their comparison with other studies must be conducted with caution.

Lastly, future investigations should include the aspects psychiatrists consider positive or negative in the questions that evaluate their perception of the influence of $\mathrm{R} / \mathrm{S}$ on the health and treatment of patients; furthermore, it would be important to find out about their conceptions of $\mathrm{R} / \mathrm{S}$, how they understand and handle the approach to $\mathrm{R} / \mathrm{S}$ and if they have undergone training in the area.

\section{Conclusions}

The results of this study contribute important data to the literature of the area. They show that, if we consider the R/S characteristics of psychiatrists in Brazil, we have basically two distinct types of professionals. Comparing the two groups, we concluded that those psychiatrists who were seen to be less religious/spiritual, have been in psychiatry practice for a longer period of time, are more highly educated and are the ones who tend to lend scant importance to religious/spiritual aspects of their patients. On the other hand, psychiatrists with greater levels of $\mathrm{R} / \mathrm{S}$, although they may have fewer academic qualifications and less experience in the field of psychiatry, are the professionals that attribute greater relevance to the religious/spiritual aspects when assessing and treating their patients. 


\section{List of abbreviations}

R/S: Religiosity and spirituality; APA: American Psychiatric Association; WPA: World Psychiatric Association; RCP: Royal College of Psychiatrists London; EPA: European Psychiatric Association; ABP: Brazilian Association of Psychiatry; ACGME:

Accreditation Council for Graduate Medical Education; IPq-HC-FMUSP: Instituto de Psiquiatria do Hospital das Clinicas da Faculdade de Medicina da Universidade de Sao Paulo; LPA: Latente profile analysis; RCOPE: Spiritual/religious coping scale; AIC: Akaike information criterion; BIC: Bayesian information criterion; LMR: Lo-Mendell-

Rubin; GAP: Group for the advancement of psychiatry.

\section{Ethical approval and consent to participate}

This study was approved by the Research Ethics Committee of the University of São Paulo Medical School. The participants received information regarding the study's objectives and the confidential and voluntary nature of their participation in the research. All psychiatrists had to confirm their agreement to participate in the survey.

\section{Funding}

This study received financial support from IHPV, São Paulo, SP.

\section{Acknowledgements}

We would like to thank Prof. Dr. Wang Yuan Pang for the support and all the psychiatrists who took the time to complete the survey.

Authors' contributions 
502 the data collection and AAL carried out the statistical analysis. MCMC and HV drafted

503 the manuscript and AAL, MFPP and FCL jointly performed a critical review. All of the

504 authors contributed to the completion of the manuscript and approved the final version

505 thereof

\section{Competing interest}

The authors report no conflicts of interest.

\section{Availability of data and materials}

The dataset is available from the corresponding author on reasonable request.

\section{Consent for publication}

Not applicable

\section{References}

518 1. Poole R, Cook CCH, Higgo R. Psychiatrists, spirituality and religion. BJPsych. $5192019 ; 214: 181-2$.

2. American Psychiatric Association - APA. Committee on religion and psychiatry. Guidelines regarding possible conflict between psychiatrists' religious commitments and psychiatric practice. Am J Psychiatry. 1990; 147:542.

3. Verhagen P, Cook C. Proposal for a world psychiatric association consensus or position statement on spirituality and religion in psychiatry. In: Verhagen P. et al., editors. Religion and psychiatry: beyond boundaries. John Wiley \& Sons, Ltd.; 2010. p. 615-32.

4. Royal College of Psychiatrists London - RCP. Recommendations for psychiatrists on spirituality and religion. Position Statement 2011. http://www.repsych.ac.uk/pdf/PS03 2013.pdf (2011). Acessed 15 feb 2020.

5. Campion J, Bhui K, Bhugra D. European Psychiatric Association (EPA) guidance on prevention of mental disorders. Eur Psychiatry. 2012; 27:68-80. 
6. Cordeiro Q. Creation of the section on spirituality and mental health at the brazilian psychiatric association. Psyche and spirit. 2014; 1: 2-3.

7. Accreditation Council for Graduate Medical Education - ACGME. Acgme Program requirements for graduate medical education in Psychiatry. http://www.acgme.org/Portals/0/PFassets/ProgramRequirements/400 psychiatry 201707-01.pdf (2017). Accessed 23 apr 2018.

8. Koenig HG, King D, Carson V. Handbook of religion and health. 2nd ed. New York: Oxford University Press; 2012.

9. Pargament K. The psychology of religion and coping: theory, research, practice. New York: The Guilford Press; 1997.

10. Kovess-Masfety V, Saha S, Lim CCW, et al. Psychotic experiences and religiosity: data from the WHO world mental health surveys. Acta Psychiatr Scand. 2018; 137:306-15.

11. Bonelli R, Koenig HG. Mental disorders, religion and spirituality 1990 to 2010: a systematic evidence-based review. J Relig Health. 2013; 52:657-73.

12. Vitorino LM, Lucchetti G, Leão FC, Vallada H, Peres MFP. The association between spirituality and religiousness and mental health. Sci Rep. 2018; 8:17233.

13. Stroppa A, Colugnati FA, Koenig HG, Moreira-Almeida A. Religiosity, depression, and quality of life bipolar disorder: a two-year prospective study. Rev Bras Psiquiatr. 2018; 40:238-43.

14. Geppert C, Bogenschutz MP, Miller WR. Development of a bibliography on religion, spirituality and addictions. Drug Alcohol Rev. 2009; 26:389-95.

15. Rosmarin DH, Pargament KI, Pirutinsky S, Mahoney A. A randomized controlled evaluation of a spirituality integrated treatment for subclinical anxiety in the jewish community. J Anxiety Disorder. 2010; 24:799-08.

16. Ellison CG, Bradshaw M, Flanelly KJ, Galek KC. Prayer, attachment to God, and symptons of anxiety-related disorders among US adults. Sociol Relig. 2014; 75:208-33.

17. Stack S, Laubepin F. Religiousness as a predictor of suicide: an analysis of 162 european regions. Suicide Life Threat Behav. 2019; 49:371-81.

18. Jacob L, Haro JM, Koyanagi A. The association of religiosity with suicidal ideation and suicide attempts in the United Kingdom. Acta Psychiatr Scand. 2019; 139:164-73.

19. Miller L, Wickramaratne P, Gameroff MJ, Sage M, Tenke CE, Weissman MM. Religiosity and major depression in adults at high risk: a ten-year prospective study. Am J Psychiatry. 2012; 169:89-94. 
20. Miller L, Bansal R, Wickramaratne P, et al. Neuroanatomical correlates of religiosity and spirituality. A study in adults at high and low familial risk for depression. JAMA Psychiatry. 2014; 71:128-35.

21. Gonçalves JP, Lucchetti G, Menezes PR, Vallada H. Religious and spiritual intervention in mental health care: a systematic review and meta-analysis of randomized controlled clinical trials. Psychol Med. 2015; 45:2937-49.

22. Peres MFP, Kamel H, Tobo P, Lucchetti G. Mechanisms behind religiosity and spirituality's effect on mental health, quality of life and well-being. J Relig Health. 2017. doi:10.1007/s10943-017-0400-6.

23. Hvidt NC, Korup AK, Curlin FA, et al. The nersh international collaboration on values, spirituality and religion in medicine: Development of questionnaire, description of data pool, and overview of pool publications. Religions. 2017; doi: $\underline{10.3390 / \text { rel7080107. }}$.

24. Korup AK, Christensen R, Nielsen CT, et al. The international nersh data pool - a methodological description of a data pool of religious and spiritual values of health professionals from six continents. Religions. 2017; doi: $10.3390 /$ rel 8020024.

25. Shafranske E. Religious involvement and professional practices of psychiatrists and other mental health professionals. Psychiatr Ann. 2000; 30:525-32.

26. Best M, Butow P, Olver I. Doctors discussing religion and spirituality: A systematic literature review. Palliative Medicine. 2016; 30:327-37.

27. Lee E, Baumann K. How korean psychiatric staff deal with religious and spiritual issues of patients: what is professional? Religions. 2019; doi:10.3390/rel10100544.

28. Curlin FA, Lantos J, Roach C, Sellergren S, Chin M. Religious characteristics of U.S. physicians. J Gen Intern Med. 2005; 20:629-34.

29. Curlin FA, Lawrence R, Odell S, et al. Religion, spirituality, and medicine: Psychiatrists' and other physicians' differing observations, interpretations, and clinical approaches. Am J Psychiatry. 2007; 164:1825-31.

30. Milner K, Crawford P, Edgley A, Hare-Duke L, Slade M. The experiences of spirituality among adults with mental health difficulties: a qualitative systematic review. Epidemiol Psychiatr Sci. 2019. https://www.cambridge.org/core/services/aopcambridgecore/content/view/ADE2530ED239C4A12DCFA540611BBF74/S204579601 9000234a.pdf/experiences of spirituality among adults with_mental health_difficulti es a qualitative systematic review.pdf. Acessed $16 \mathrm{feb} 2020$.

31. Best M, Butow P, Olver I. Do patients want doctors to talk about spirituality? A systematic literature review. Patient Educ Couns. 2015; 98:1320-8.

32. Al-Yousefi NA. Observations of muslim physicians regarding the influence of religion on health and their clinical approach. J Relig Health. 2012; 51:269-80. 
33. Voltmer E, Buessing A, Koenig HG, Al Zaben F. Religiosity/Spirituality of german doctors in private practice and likelihood of addressing $\mathrm{R} / \mathrm{S}$ issues with patients. J Relig Health. 2014; 53:1741-52.

34. Franzen AB. Influence of physicians' beliefs on propensity to include religion/spirituality in patient interactions. J Relig Health. 2018; 57:1581-97.

35. Menegatti-Chequini MC, Gonçalves JPB, Leão FC, Peres MFP, Vallada H. A preliminary survey on the religious profile of brazilian psychiatrists and their approach to patients' religiosity in clinical practice. BJPsych Open. 2016; 2:346-52.

36. Menegatti-Chequini MC, Maraldi EO, Peres MFP, Leão FC, Vallada H. How psychiatrists think about religious and spiritual beliefs in clinical practice: findings from a university hospital in São Paulo, Brazil. Braz J Psychiatry. 2018; 41:58-65.

37. Curlin FA, Chin M, Sellergren S, Roach C, Lantos J. The association of physicians' religious characteristics with their attitudes and self-reported behaviors regarding religion and spirituality in the clinical encounter. Med Care. 2006; 44:446-53.

38. Lawrence RE, Rasinski KA, Yoon JD, Curlin FA. Religion and anxiety treatments in primary care patients. Anxiety Stress Coping. 2013; 26:526-38.

39. Curlin FA, Lawrence R, Chin M, Lantos J. Religion, conscience, and controversial clinical practices. N Engl J Med. 2007; 356:593-600.

40. Instituto Brasileiro de Geografia e Estatistica - IBGE. Censo Demografico 2010 Caracteristicas gerais da populacao, religiao e pessoas com deficiencia. [2010 Population Census - General characteristics of population, religion and persons with disabilities]. https://biblioteca.ibge.gov.br/visualizacao/periodicos/94/ed 2010 religiao deficiencia.p df (2010). Acessed 16 feb 2020

41. Pargament K, Koenig HG, Perez L. The many methods of relgious coping: development and initial validation of the RCOPE. J Clin Psychol. 2000; 56:519-43.

42. Hoge DR. A validated intrinsic religious orientation and prejudice. J Sci Study Relig. 1972; 11:369-76.

43. Muthen B, Muthen LK. Integrating person-centered and variable-centered analyses. Growth mixture modeling with latent trajectory classes. Alcohol Clin Exp Res. $2000 ; 24: 882-91$.

44. Ramakrishnan P, Karimah A, Kuntaman K, et al. Religious/spiritual characteristics of indian and indonesian physicians and their acceptance of spirituality in health care: a cross-cultural comparison. J Relig Health. 2015; 54:649-63.

45. Korup AK, Sondergaard J, Lucchetti G, et al. Religious values of pshysicians affect their clinical practice. A meta-analysis of individual participant data from 7 countries. Medicine (Baltimore). 2019; doi: 10.1097/MD.0000000000017265. Acessed 16 feb 2020. 
46. Curlin F, Dugdale L, Lantos J, in M. Do religious physicians disproportionately care for the underserved? Ann Fam Med. 2007; 5:353-60.

47. Yoon J, Shin J, Nian A, Curlin F. Religion, sense of calling, and the practice of medicine: findings from a national survey of primary care physicians and psychiatrists. South Med J. 2015; 108:189-95.

48. Neeleman J, King M. Psychiatrists religious attitudes in relation to their clinicalpractice - a survey of 231 psychiatrists. Acta Psychiatr Scand. 1993; 88:420-4.

49. Baetz M, Griffin R, Bowen R, Marcoux G. Spirituality and psychiatry in Canada: psychiatric practice compared with patient expectations. Can J Psychiatry. 2004; 49:26571.

50. Gallup Jr., GH. Why are women more religious? 2002. http://news.gallup.com/poll/7432/why-women-more-religious.aspx. Accessed 21 may 2018).

51. Beit-Hallahmi B. Psychological perspectives on religion and religiosity. New York: Routledge; 2015.

52. Francis LJ, Penny G. Gender differences in religion. In: Saroglou V, editor. Religion, personality, and social behavior. New York: Psychology Press; 2014. p. 31337.

53. Francis LJ. The psychology of gender differences in religion: a review of empirical research. Religion. 1997; 27:81-96.

54. Stark R. Physiology and faith: addressing the 'universal' gender difference in religious commitment. J Sci Study Relig. 2002; 41:495-507.

55. Sullins DP. Gender and religion: deconstructing universality, constructing complexity. AJS. 2006; 112:838-80.

56. Freud S. The future of an illusion, civilization and its discontents. 1974 ed. London: Hogarth Press; 1927.

57. Freud S. Moses and monotheism. 1964 ed. London: Hogarth Press; 1939.

58. Neeleman J, Persaud R. Why do psychiatrists neglect religion. Br J Med Psychol. $1995 ; 68: 169-78$.

59. Group for the Advancement of Psychiatry - GAP. Committee on Psychiatry and Religion. Mysticism: spiritual quest or psychic disorder? New York: Brunner-Routledge; 1976.

60. Koenig HG. Religion, spirituality and psychiatry: a new era in mental health care. Rev Psiquiatr Clin. 2007; 34:5-7. 
61. Ellis A. Psychotherapy and atheistic values: a response to A. E. Bergins's "Psychotherapy and religious values". J Consult Clin Psychol. 1980; 48:635-9.

62. Loch AA. Estereótipos e crenças relacionados à esquizofrenia: um levantamento comparativo entre profíssionais de saúde mental e a população geral do Brasil [Stereotypes and beliefs related to schizophrenia: A comparative study between mental health professionals and the general population of Brazil]. São Paulo: Universidade de Sao Paulo; 2013.

63. Hefti R. Integrating spiritual issues into therapy. In: Huguelet P, Koenig HG, editors. Religion and Spirituality in Psychiatry. New York: Cambridge University Press; 2009. p. 244-67.

64. Lee E, Baumann K. German psychiatrists' observation and interpretation of religiosity/spirituality. Evid Based Complement Alternat Med. 2013; 2013:1-8.

65. Curlin F, Sellergren S, Lantos J, Chin M. Physicians' observations and interpretations of the influence of religion and spirituality on health. Arch Intern Med. 2007; 167:649-54.

66. Crosby JW, Bossley N. The religiosity gap: preferences for seeking help from religious advisors. Ment Health Relig Cult. 2012; 15:141-59.

67. Randwijk CB, Opsahl T, Hvidt EA, et al. Characteristics of religious and spiritual beliefs of danish physicians: And likelihood of addressing religious and spiritual issues with patients. J Relig Health. 2019; 58:333-42.

68. Welgemoed M, Staden C. Does religious identification of south african psychiatrists matter in their approach to religious matters in clinical practice? S Afr J Psychiatr. 2014; 20:140-5.

69. Rensburg JABR, Poggenpoel M, Myburgh CPH, Szabo CP. Experience and views of academic psychiatrists on the role of spirituality in south african specialist psychiatry. Rev Psiquiatr Clin. 2012; 39:122-9.

70. Deaton AS. Aging, religion, and health. In: Wise DA, editor. Explorations in the economics of aging. Chicago:University of Chicago Press, 2011. p. 237-62.

71. Hungerman DM. The effect of education on religion: Evidence from compulsory schooling laws. J Econ Behav Organ. 2014; 104:52-63.

72. Lee JJ. Religion and college attendance: change among students. Rev High Ed. $2002 ; 25: 369-84$.

73. Uecker JE, Regnerus MD, Vaaler ML. Losing my religion: The social forces of religious decline in early adulthood. Soc Forces. 2007; 85:1667-92.

74. Curcio CSS, Moreira-Almeida A. Who does believe in life after death? Brazilian data form clinical and non-clinical samples. J Relig Health. 2019; 58:1217-34. 
75. Schwadel P. Birth cohort changes in the association between college education and religious non-affiliation. Soc Forces. 2014; 93:719-46.

76. Baker DP. The great antagonism that never was: unexpected affinities between religion and education in post-secular society. Theory Soc. 2019; 48:39-65.

77. Baker JO, Smith BG. The nones: social characteristics of the religiously unaffiliated. Soc Forces. 2009; 87:1251-63.

78. Chaves M. Secularization as declining religious authority. Soc Forces. 1994; 72:749-74.

79. Glaeser EL, Sacerdote BI. Education and religion. J Hum Cap. 2008; 2:188-215.

80. Huguelet P, Koenig HG. Religion and Spirituality in Psychiatry. Cambridge, UK: Cambridge University Press; 2009.

81. Moreira-Almeida A, Cardena E. Differential diagnosis between non-pathological psychotic and spiritual experiences and mental disorders: a contribution from latin american studies to the ICD-11. Rev Bras Psiquiatr. 2011; 33:21-36.

82. Pajevic I. Secular and postsecular psychiatry. Psychiatr Danub. 2012; 24:262-6.

83. Cox J, Verhagen PJ. Spirituality, religion and psychopathology: towards an integrative psychiatry. Int J Pers Cent Med. 2011; 1:146-8.

84. Cook $\mathrm{CCH}$. Religion and spirituality in clinical practice. BJPsych Advances. $2015 ; 21: 42-50$. 
Figure 1

Click here to download Figure FIGURE 1 .docx $\underline{\underline{\underline{ }}}$

Figure 1

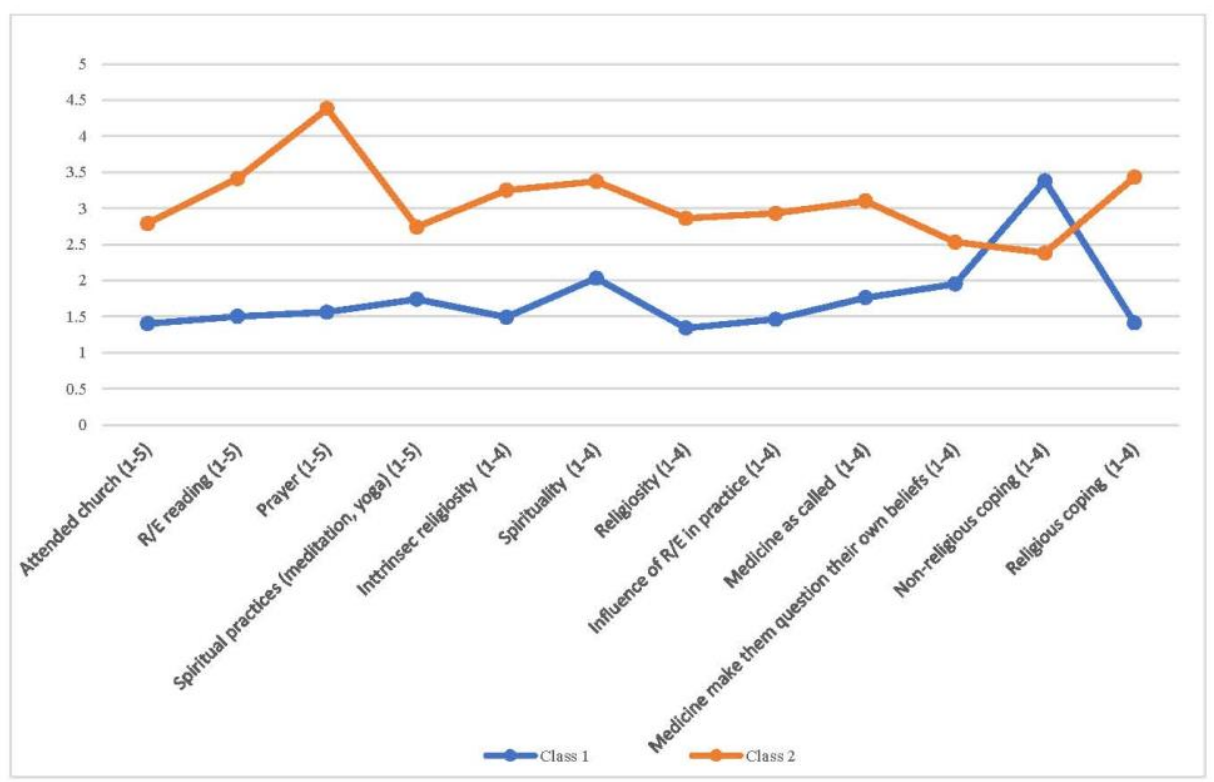


Figure 2

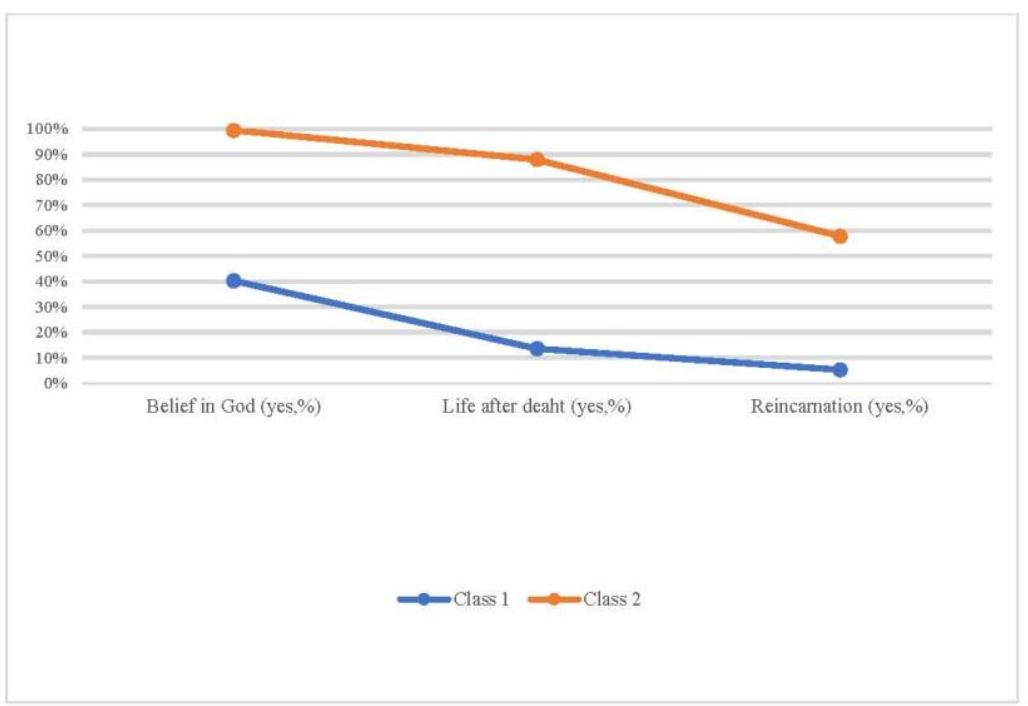




\section{APÊNDICE 3. Produção acadêmica desenvolvida durante o doutorado}

\section{Artigos publicados}

Menegatti-Chequini M. C., Gonçalves J. P. B., Leão F. C., Peres M.F.P., Vallada H. A preliminary survey on the religious profile of brazilian psychiatrists and their approach to patients' religiosity in clínical practice. BJPsych Open. 2016; 2:34652.

Menegatti-Chequini M.C., Maraldi E. O., Peres M. F. P., Leão F. C., Vallada H. How psychiatrists think about religious and spiritual beliefs in clínical practice: findings from a university hospital in São Paulo, Brazil. Braz J Psychiatry. 2018; 41:5865.

\section{Manuscrito aceito para publicação}

Menegatti-Chequini M. C., Loch A. A., Leão F. C., Peres M. F. P., Vallada H. Patterns of religiosity and spirituality of psychiatrists in Brazil and the implications for clínical practice: A latent profile analysis. Submetido.

\section{Apresentação de trabalhos}

Menegatti-Chequini, \& Vallada $H$. A religiosidade e a espiritualidade no enfrentamento de doenças graves. (Palestra) $18^{\circ}$ Congresso Brasileiro de Medicina Psicossomática - Humanização e Integração na Saúde. São Paulo, SP, 2016.

Menegatti-Chequini, M. C.; Maraldi, E. O.; Leao, F. C.; Peres, M. F. P.; Vallada, H. O perfil religioso dos psiquiatras do Instituto de Psiquiatria do Hospital das Clínicas da Faculdade de Medicina da Universidade de São Paulo e sua relação com 
a prática clínica. (Pôster). $2^{\circ}$ Simpósio Internacional Mente-Cérebro. Juiz de Fora, MG, 2017.

Menegatti-Chequini M.C. \& Vallada H. A questão mente-cérebro entre psiquiatras brasileiros. (Relator na mesa redonda 26) XXXV CBP Congresso Brasileiro de Psiquiatria. São Paulo, SP, 2017.

Menegatti-Chequini, M. C. \& Vallada H. Espiritualidade, religiosidade e saúde. (Palestra). Centro Universitário São Camilo. São Paulo, SP, 2018.

\section{Participação em eventos}

$18^{\circ}$ Congresso Brasileiro de Medicina Psicossomática. São Paulo, SP, 2016.

XXXIV Congresso Brasileiro de Psiquiatria. São Paulo, SP, 2016.

2 Simpósio Internacional Mente-Cérebro. Juiz de Fora, MG, 2017.

XXXV CBP Congresso Brasileiro de Psiquiatria. São Paulo, SP, 2017.

\section{Entrevista}

TV NUPES: Menegatti-Chequini, M. C. \& Vallada H. O perfil religioso dos psiquiatras brasileiros e a sua relação com a prática clínica. $2^{\circ}$ Simpósio Internacional Mente-Cérebro. Juiz de Fora, MG, 2017. 